\title{
Report of the
}

\section{1st NATIONAL CONFERENCE ON}

WEIGHTS AND MEASURES 1956

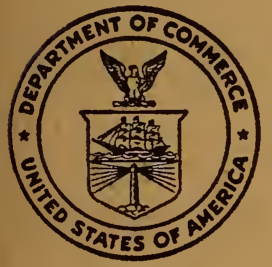

U. S. DEPARTMENT OF COMMERCE

NATIONAL BUREAU OF STANDARDS

MISCELLANEOUS PUBLICATION 219 


\section{SELECTED WEIGHTS AND MEASURES PUBLICATIONS OF THE NATIONAL BUREAU OF STANDARDS}

NBS HANDBOOK 37 Testing of Weighing Equipment ..... \$1.25

NBS HANDBOOK 44-2d Edition-1955 Specifications, Tolerances, and Regulations for Commercial Weighing and Measuring Devices :

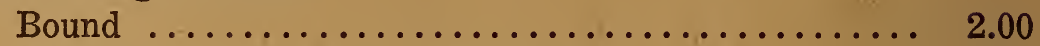

Loose Leaf (does not include binder) $\ldots \ldots \ldots \ldots \ldots \ldots \quad 1.00$

NBS HANDBOOK 45 Testing of Measuring Equipment .... 1.50

NBS CIRCULAR 501 Federal and State Weights and Measures Laws ............................. 6.50

NBS CIRCULAR 540 Weights and Measures Case Reference Book ..................................

NBS CIRCULAR 570 Units and Systems of Weights and Measures-Their Origin, Development, and Present Status ..

NBS CIRCULAR 572 Calibration of Line Standards of Length and Measuring Tapes at the National Bureau of Standards

AVAILABLE REPORTS OF THE

NATIONAL CONFERENCE ON WEIGHTS AND MEASURES

1947 Miscellaneous Publication 189 . $40 \phi$

1950 Miscellaneous Publication 199 .. $50 \varnothing$

1951 Miscellaneous Publication $202 \ldots 50 \varnothing$

1952 Miscellaneous Publication 206 . . $40 \phi$

1953 Miscellaneous Publication 209 .. $40 \varnothing$

1954 Miscellaneous Publication 212 .. $50 \phi$

1955 Miscellaneous Publication 216 . $70 \phi$

Index to the Reports of the National Conference on Weights and Measures from the First to the Thirty-sixth, 1905 to 1951, Miscellaneous Publication 203 ... 20ф

ORDER ALL PUBLICATIONS, WITH REMITTANCE, FROM THE SUPERINTENDENT OF DOCUMENTS, GOVERNMENT PRINTING OFFICE, WASHINGTON 25, D. C. 



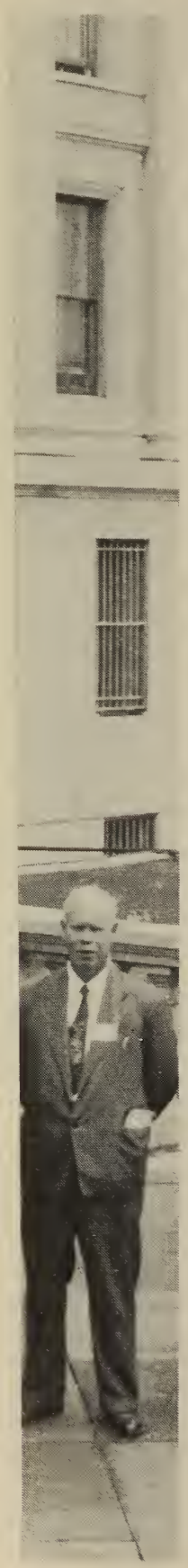




\section{Report of the}

\section{1st National Conference on}

\section{Weights and Measures 1956}

Attended by Representatives from Various States

Sponsored by the National Bureau of Standards

Washington, D. C., May 21, 22, 23, 24, 25, 1956

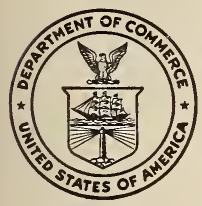

United States Department of Commerce - Sinclair Weeks, Secretary

National Bureau of Standards $-A . V$. Astin, Director

National Bureau of Standards Miscellaneous Publication 219

Issued February 25, 1957 


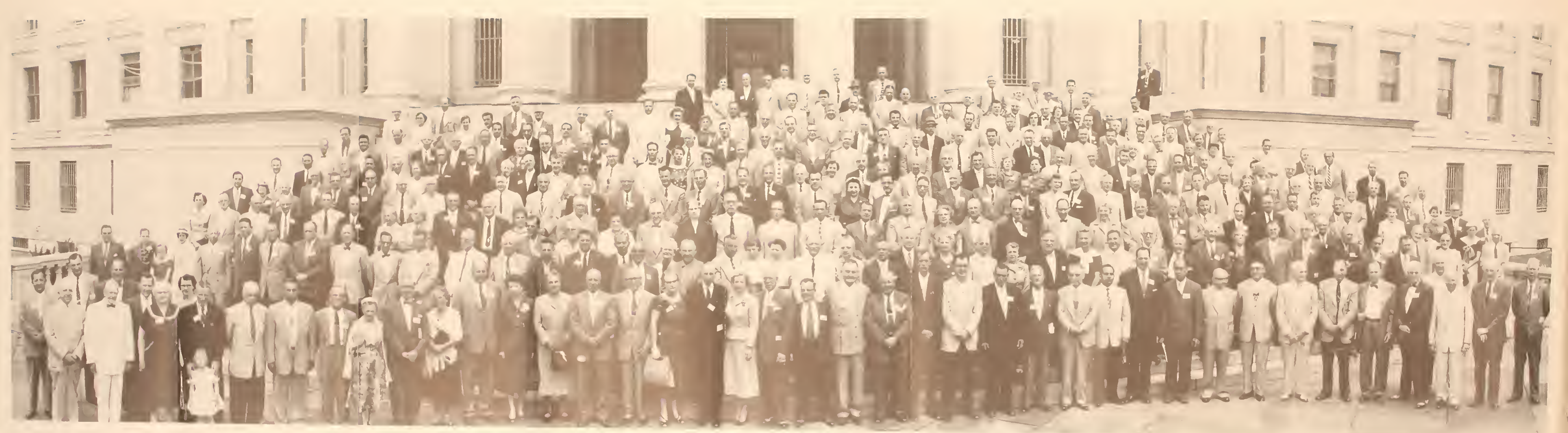





\section{CONTENTS}

Officers and Committees

Committee Meetings

Persons Attending Conference

FIRST SESSION-MORNING OF TUESDAY, MAY 22, 1956

Address, by Hon. Sinclair Weeks, Secretary of Commerce

Report of the President, by A. V. Astin, Director, National Bureau of Standards

Address, by Miss Genevieve Blatt, Secretary of Internal Affairs, State of Pennsylvania

Appointment of Committees

Presentation of Honor Awards

Roll Call of States

SECOND SESSION-AFTERNOON OF TUESDAY, MAY 22, 1956

Roll Call of States (continued)

Report from National Scale Men's Association, by O. H. Watson, President, NSMA, and Manager, Chicago Division, Exact Weight Scale Company, Chicago, Illinois

Discussion of Foregoing Paper

The Weights and Measures Advisory Committee, by J. P. McBride, Chairman, Director of Standards, State of Massachusetts

Report of the Special Committee of Vice Presidents of the Conference, Presented by C. A. Lyon, Chairman

Obtaining Evidence and Preparing a Case for Court, by G. F. Taylor, Chief Assistant Prosecuting Attorney, Pontiac, Michigan

Discussion of Foregoing Paper

Report of the Outgoing Executive Committee, Presented by W. A. Kerlin

Quantity Requirements under Federal Alcohol and Tobacco Tax Regulations:

Distilled Spirits, Beer, Wine, and Alcohol, by H. A. Serr, Assistant Director, Alcohol and Tobacco Tax Division, Internal Revenue Service, U. S. Department of Treasury

Tobacco, by N. T. Morsell, Chief, Tobacco Branch, Alcohol and Tobacco Tax Division, Internal Revenue Service, U. S. Department of Treasury

THIRD SESSION-MORNING OF WEDNESDAY, MAY 23, 1956

"Testing Mass Standards by Substitution" (The new National Bureau of Standards training film)

Petrochemicals-Their Composition, Handling, and Quantity Control, by J. H. McClintock, Oil Loss Prevention Division, Esso Standard Oil Company, Elizabeth, New Jersey

Report Forms for the Weights and Measures Official, by H. F. Wollin, National Bureau of Standards

An Automatic Prepackaging Scale, by K. C. Allen, Director, Special Research Division, Hobart Manufacturing Company, Dayton, Ohio Discussion of Foregoing Paper

FOURTH SESSION-AFTERNOON OF WEDNESDAY, MAY 23, 1956

Symposium on Prepackaged Commodities:

Statistics in Quantity Control of Packages, by E. P. Lee, General Foods Corporation, White Plains, New York

Quantity of Lubricating Oil in Sealed Cans, by J. W. D. Harvey, State Oil Laboratory, State of Georgia

Progress Report on Packaging of Flour, by J. T. Lynch, International Milling Company, representing Millers' National Federation, Washington, D. C. 
Legibility of Quantity Declaration, by K. L. Milstead, Federal Food and Drug Administration

Accuracy Requirements for Quantity Declaration, by J. C. Pearson, Federal Food and Drug Administration

Prepackaged Produce, by B. E. Dobell, Manager, Legal Department, Safeway Stores, Inc., Oakland, California

Quantity Statements on Packing House Products, by J. R. Scott, U. S. Department of Agriculture

Prepackaging of Meat in Meat Packing Plants, by Herbert Rumsey, Jr., Executive Vice President and Manager, Tobin Packing Company, Inc., Rochester, New York, representing National Independent Meat Packers Association

FIFTH SESSION-MORNING OF THURSDAY, MAY 24, 1956

Report of the Committee on Education, Presented by H. E. Crawford, Chairman

Food Packages-When the Responsibility of the State, by L. E. Stern, Deputy Attorney General, Department of Law and Public Safety, State of New Jersey

State-City Weights and Measures Cooperation in Wisconsin, by C. L. Jackson, Chief, Division of Economic Practices, Department of Agriculture, State of Wisconsin

Why Weights and Measures Training Schools?, by T. C. Harris, Jr., Supervisor, Weights and Measures Section, Division of Markets, Department of Agriculture, State of Virginia

Quantity Statements on Rolls of Wallpaper, by H. J. McDade, County Sealer of Weights and Measures, San Diego County, California

SIXTH SESSION-AFTERNOON OF THURSDAY, MAY 24, 1956

Report of the Committee on Trading by Weight, Presented by G. L. Johnson, Chairman

Trade Practice in the Meat Packing Industry, by L. D. Sinclair, Chief, Packers and Stockyards Branch, Livestock Division, A. M. S., U. S. Department of Agriculture

Discussion of Foregoing Paper

Packaged Food Standardization, by T. E. Sullivan, Director, Food and Drug Division, State Board of Health, State of Indiana

Discussion of Foregoing Paper

Report of the Committee on Nominations, Presented by F. M. Greene, Chairman, and election of Officers

127

133

134

Report of the Committee on Laws and Regulations, Presented by G. H. Leithauser, Chairman, and Discussion Thereon

BREAKFAST MEETING OF THE INCOMING EXECUTIVE COMMITTEE OF THE CONFERENCE, FRIDAY, MAY 25, 1956

SEVENTH SESSION-MORNING OF FRIDAY, MAY 25, 1956

National Bureau of Standards Railway Track Scale Activities, by H. L. Badger, National Bureau of Standards (Presented by C. H. Oakley, National Bureau of Standards)

The Current Situation in Highway Axle-Load Weighing, by C. L. Richard, Consultant, Truck-Trailer Manufacturers Association, Los Angeles, California

Discussion of Foregoing Paper

Report of the Committee on Specifications and Tolerances, Presented by R. E. Meek, Chairman, and Discussion Thereon

Tribute to Stanley Q. Bennett

Report of the Committee on Resolutions, Presented by C. M. Fuller, Chairman

Report of the Treasurer 


\section{OFFICERS AND COMMITTEES}

\section{OFFICERS}

(As elected by the Fortieth National Conference to serve during the Forty-first National Conference)

President: A. V. Astin, Director, National Bureau of Standards.

Vice Presidents:

G. L. Johnson, Director, Division of Weights and Measures, Department of Agriculture, State of Kentucky.

W. A. KerLIN, Alameda County Sealer of Weights and Measures, Oakland, California.

C. A. Lyon, Director, Division of Markets and Standards, Department of Agriculture, State of New Hampshire.

J. E. MAHONEY, Superintendent of Weights and Measures, Department of Markets, State of Maryland.

M. A. NELson, Chief, Bureau of Foods and Standards, Department of Agriculture, State of Michigan.

W. K. TRIPPLE, Chief, Bureau of Weights and Measures, Norfolk, Virginia. Secretary: W. S. BusseY, Chief, Office of Weights and Measures, National Bureau of Standards.

Treasurer: .G. F. Austin, Jr., Deputy Sealer of Weights and Measures, Detroit, Michigan.

Chaplain: R. W. Searles, Deputy Sealer of Weights and Measures, Medina County, Ohio.

Sergeant at Arms: JoSEPH SHAW, Assistant Superintendent of Weights and Measures, Passaic, New Jersey.

(As elected by the Forty-first National Conference for the ensuing year)

President: A. V. Astin, Director, National Bureau of Standards.

Vice Presidents:

J. C. GolL, Chief Inspector, Weights and Measures Department, Public Service Commission, State of North Dakota.

J. E. MAHONEY, Superintendent of Weights and Measures, Department of Markets, State of Maryland.

A. J. MAYER, Director, Division of Weights and Measures, Department of Agriculture and Immigration, State of Louisiana.

M. A. Nelson, Chief, Bureau of Foods and Standards, Department of Agriculture, State of Michigan.

R. K. Slough, Sealer of Weights and Measures, Akron, Ohio.

C. J. WILLS, JR., Sealer of Weights and Measures, Portland, Maine.

Secretary: W. S. BusseY, Chief, Office of Weights and Measures, National Bureau of Standards.

Treasurer: G. F. Austin, Jr., Deputy Sealer of Weights and Measures, Detroit, Michigan.

Chaplain: R. W. Searles, Deputy Sealer of Weights and Measures, Medina County, Ohio.

Sergeant at Arms: F. J. DeLANEY, Inspector of Weights and Measures, Food and Drug Commission, State of Connecticut.

\section{EXECUTIVE COMMITTEE}

(As elected by the Forty-first National Conference)

A. V. Astin

J. C. GOLL

J. E. MAHONEY

A. J. MAYER

M. A. NELSON

R. K. Slough

C. J. WILLS, JR.

W. S. BUSSEY

G. F. AUSTIN, JR.

R. W. SEARLES

F. J. DELANEY

Ex officio 
NALls BerRyman, of Florida.

J. E. BowEN, of Newton, Massachusetts.

S. H. Christie, JR., of New Jersey.

A. H. DitTrich, of New Hampshire.

J. T. KENNEDY, of District of Columbia.

N. KIRSCHBAUM, of Wisconsin.

I. M. LEVY, of Chicago, Illinois.

E. F. Moran, of Providence, Rhode Island.

J. J. Powers, of Philadelphia County, Pennsylvania.

G. A. Pullman, of Genesee County, New York.

E. L. RANDALL, of Nevada.

C. H. STENDER, of South Carolina.

J. F. TRue, of Kansas.

ToM WEBB, of Nashville, Tennessee.

F. G. Yarbrough, of Dallas, Texas.

\section{STANDING COMMITTEES}

(As constituted at the conclusion of the Forty-first National Conference, the personnel and organization of each of the standing committees of the Conference are as reported below. As reported, the membership of each committee reflects the appointments made by the President of the Conference, changes that have occurred from expiration of term or other cause, and the elections by the several committees of chairmen for the ensuing year. The remaining term of office for each committee member, in years, is shown by the figure in parentheses following each entry. Mr. W. S. Bussey, National Bureau of Standards, by his election to the office of Secretary of the Conference is a nonvoting member of and secretary to each of the standing committees. As recommended by the Executive Committee of the 40 th $\mathrm{Na}$ tional Conference, the Committee on Trading by Weight was dissolved at the close of the Forty-first Conference and its duties absorbed by the Committee on Laws and Regulations.)

\section{COMMITTEE ON SPECIFICATIONS AND TOLERANCES*}

R. E. MEEK, of Indiana, Chairman.

H. E. HowARD, of Miami, Florida.

J. E. BRENTON, of California. (3)

M. W. Jensen, National Bureau of Standards.

D. M. Turnbull, of Seattle, Washington.

\section{COMMITTEE ON LAWS AND REGULATIONS*}

G. H. Leithauser, of Baltimore, Maryland, Chairman.

M. A. Nelson, of Michigan. (1)

E. C. Westwood, of Salt Lake City, Utah.

NALLS BERRYMAN, of Florida.

F. M. GREENE, of Connecticut.

J. A. BoYLe, of Maine. (3)

J. T. KENNEDY, of the District of Columbia.

G. L. Johnson, of Kentucky. (5)

\section{COMMITTEE ON EDUCATION*}

T. C. HARRIS, JR., of Virginia, Chairman.

W. A. BAERWoLF, of Pontiac, Michigan.

C. A. Lyon, of New Hampshire.

J. E. MAHONEY, of Maryland.

I. M. LEVY, of Chicago, Illinois.

\footnotetext{
*W. S. Bussey, Secretary of the Conference, is ex officio a nonvoting member of and Secre-
} tary to the Committee. 


\section{COMMITTEES ACTING ONLY DURING THE FORTY-FIRST NATIONAL CONFERENCE}

Committee on Resolutions: C. M. Fuller, of Los Angeles County, California, Chairman; LeONARD DeRIEnzo of Englewood, New Jersey, A. H. DitTrich of New Hampshire, J. J. Leonard of New York, G. S. MCINTYRE of Michigan, J. J. Powers of Philadelphia County, Pennsylvania, C. H. STENDER of South Carolina.

Committee on Nominations: F. M. Greene, of Connecticut, Chairman; E. R. Fisher of Rhode Island, ERLiNg HANSEN of Minnesota, J. T. KENNEDY of the District of Columbia, I. M. LEVy of Chicago, Illinois, J. P. LEONARD of Paterson, New Jersey, RoBerT Williams of Nassau County, New York.

Ladies' Committee: Mrs. W. S. Bussey, Mrs. J. M. Dietz, MrS. M. W. Jensen, Mrs. R. E. Meek, Mrs. R. D. ThOmpson, Mrs. H. F. Wollin.

\section{IN CHARGE OF REGISTRATIONS}

Mrs. R. E. Taylor, Mrs. F. C. Bell, Mrs. K. M. Schwarz, Miss B. S. Gilliam.

\section{OFFICIAL REPORTER}

Mrs. F. T. ACHENBACH.

\section{PRESS RELEASES}

J. F. HARDESTY, JR.

\section{Committee Meetings, Monday, May 21, 1956}

Monday was set aside for meetings, both open and executive, of the Conference committees. Announcements to this effect were carried in all invitations, all pre-Conference publicity, and in the tentative and printed programs.

Many delegates took full advantage of the committee meetings, which were very well attended and informative to all.

The Conference committees that met on Monday, May 21, were the Executive Committee, Committee on Laws and Regulations, Committee on Specifications and Tolerances, Committee on Trading by Weight, and Committee on Education. 



\title{
REPORT OF THE FORTY-FIRST NATIONAL CONFERENCE ON WEIGHTS AND MEASURES ${ }^{1}$
}

\section{FIRST SESSION-MORNING OF TUESDAY, MAY 22, 1956}

\author{
(A. V. Astin, President, and C. A. Lyon, Vice President, Presiding)
}

The invocation and the memorial service for departed members were delivered by the Conference Chaplain, Rev. R. W. Searles, Deputy County Sealer of Weights and Measures, Medina County, Ohio.

\section{ADDRESS, BY HON. SINCLAIR WEEKS, SECRETARY OF GOMMERCE}

Gentlemen of the Conference, I want to extend to you my very warm greetings on this, your 41st meeting. Your gathering here has become something of a tradition-a most useful and important tradition, one which has a direct bearing on the health of the American economy.

It is not my intention at this time to go into any detail about the productive and commercial state of our Nation. Suffice it so say that I find, for the most part, that the condition of the American economy is good. It is dynamic. It is growing.

Part of the reason for our present economic health lies in the fact that the American people have confidence in our economic system. Confidence or good will, as you all well know, is a critical, although sometimes intangible, element of the American mind. I want, at this time, to give recognition to the work of this Conference and to the services performed by each and everyone of you in helping to breed this confidence.

Commerce is a fancy word. It means simply the exchange of goods, by barter, by providing services, or by purchase. But whatever the exchange, there must be an understanding or an agreement between members participating in the exchange. We all know this, though sometimes it is forgotten in the everyday activities of the American people. A pound must have the same meaning for all. The same applies to the various units in hundreds of areas.

Now who sets the units? Who sees that they have some consistency? Who enforces the units?

I like to think of it as a wonderful cooperative enterprise between the Federal Government and the State Government. This principle of cooperation has been recognized by the Department of Commerce since the institution of these conferences. The principle has worked out indeed well. I think that its success demonstrates amply that such shared. responsibility should be expanded in many other areas of mutual concern between Federal and local Government.

The principle was fully appreciated by former President Herbert Hoover, when he was still a Secretary of Commerce. I believe it was President Hoover who gave this Conference its strongest support. It is my intention to follow his excellent example. It was

\footnotetext{
1 With the exception of formal papers and committee reports, the record of this 41 st National Conference on Weights and Measures has been rearranged, consolidated, and condensed wherever necessary to reduce it to essentials for future reference.
} 
President Hoover who clearly enunciated this idea of mutual effort toward a common "weights and measures" goal. He said:

You have yourselves been the expression of that cooperation in your Conferences in Washington and have yourselves spread this gospel of cooperation between your own agencies and business fabric of your own States. The cooperation on your part will enable you to make your office a greater power for the common good in your community; it will enable you to render greater service under the statutes enacted; and it will enable you to raise to their highest usefulness the technical knowledge and the skill which you have in your chosen field .... Y You are part of the machinery by which we are all trying to make progress through cooperation.

I fully endorse these sentiments. It seems to me that it is only by this means that we can best effect the good interests of the American people. Certainly, it is such means that most efficiently insure the confidence of the American people in our commercial and economic practices.

Later on, you will receive reports by various members of the National Bureau of Standards. These will be technical in nature, but may I steal some of their thunder by telling you some of the things which I learned about the business of weights and measures through my interest in the Bureau?

I have learned first that standards are not always easy to come by. It is an intricate technical activity. The whole chain of measurement must be consistent and as refined as modern science can make it. More than that, I have learned that standards have a romance to them. There is truly a fascinating history in man's effort to create better and more precise measures. And still more than that, I have learned the sharp meaning of standards to our economy. It is the truest of true statements when I say that all of you people engaged in weights and measures activities help to provide the bases for our healthy frame of mind (economically speaking) and our higher standard of living.

It has pleased me to learn that the National Bureau of Standards shares with me a respect for the principle of cooperation. I know how sincerely they are working to keep it effective. The people at the Bureau try to give the best technical standards advice and services to the members of the Conference. But, at the same time, they recognize that you are the people who can make best use of their advice and services and that you are the people who can carry the meaning of standards to the people, to business, and to industry.

We, at the Department and at the Bureau, are pleased with the success of these Conferences and with the work you are doing. I believe that there is no field where so much constructive work can be accomplished in this direction of national efficiency of the whole of American economy, from production to distribution, than in the field of standards. Thus it is warming to note that the membership of this Conference has grown from that day in 1905 when only 11 delegates were in attendance, representing eight States and the District, to more than 500 delegates, representing about 40 States, the District, and Puerto Rico.

To all of you, my heartiest wishes for a good and productive series of sessions. 


\section{REPORT OF THE PRESIDENT}

\section{By A. V. Astin, Director, National Bureau of Standards}

I should like to report to you at this time some of the activities of the National Bureau of Standards during the past year, especially those activities which have a bearing upon the work of this Conference.

I might begin by telling you of the general clarification of our program objectives during the past 3 years. You all know, of course, that in 1953 the Secretary of Commerce appointed a committee under the chairmanship of Dr. Mervin Kelly of the Bell Telephone Laboratory to survey and to consider the functions of the National Bureau of Standards. I reported to the 39th Conference on the findings and recommendations of that committee. Since then, we have been working toward the implementation of those recommendations.

First, we have sought to increase the emphasis on our basic programs and thereby to achieve greater technical balance. We have done this in two ways: (1) by applying greater selectivity in the projects that we accept from other agencies of the Government, and (2) by seeking more effective means for shifting our resources into programs that are directly related to our primary mission. Our effort to achieve such a balance has met with some success, although progress in this direction is still slow.

Second, we have attempted to develop a direct means for understanding and meeting the needs of science and technology. Toward this end, and with the help of various professional organizations, we have appointed 12 technical advisory committees. One of these is the Weights and Measures Advisory Committee, whose members come from this Conference. These committees serve us in two principal ways. On the one hand, they assist us in looking over our programs and in making recommendations toward increasing their effectiveness. On the other hand, they take to their professional organizations an understanding of the needs, progress, achievements, and limitations of the National Bureau of Standards. Thus, these committees set up a two-way communication, which is most valuable to us and, I hope, useful to the technical groups they represent.

Now I should like to comment briefly on some of the projects we are hoping to activate so as to strengthen our basic programs. I might say at the outset of this listing that we are seeking to strengthen all of our technical programs and that this listing is considered only as a beginning to what we deem necessary to the board responsibilities of the Bureau.

In the field of electronics, we are hoping to establish a coordinated electronics research and information service. We hope, in the long run, to provide scientists in this field with informatoin on such items as standard circuits, tube fabrication, and transistor parameters. In the field of metrology, we hope to be able to undertake greater refinements in our length and gage standards. In the field of heat and power, we want to increase our efforts toward the development of more accurate temperature scales. In atomic and radiation physics, we hope to increase substantially our research 
on the development of much needed data and standards. In the field of chemistry, we want to increase the number of spectrographic standard samples and to raise the level of basic organic chemical research. In organic and fibrous materials, we hope to embark on a number of new studies on polymers and to establish new polymer standards. In metallurgy, we are increasing our studies of the fundamental processes that cause corrosion of metals. Incidentally, we have a new Division Chief to administer this program. Upon the retirement of Dr. J. G. Thompson, Dr. James I. Hoffman, formerly Assistant Chief of the Chemistry Division, was appointed as his successor.

In the field of mineral products, we hope to raise the level of basic research, especially in those studies which apply to the behavior of materials at very high temperatures. In the field of mechanics, we hope to establish studies in the field of rheology-the flow of matter-in order to bring our viscosity standards up to date. We are also undertaking a new project to redetermine the value of the acceleration of gravity. In building technology, we hope to undertake a basic study of accident prevention by investigating the hazards of materials, structures, and equipment. In the field of radio, we are seeking to develop much needed standards for various segments of the radio spectrum. In the area of weights and measures, we hope to undertake a survey of the present conditions of State standards as a basis for estimating the requirements for modernizing these standards. This is in response to a request of the 40th National Conference on Weights and Measures.

This short review, I believe, indicates the direction in which the National Bureau of Standards is going. Most of the projects that I have mentioned are part of an expanded program for next year, which is now under consideration by the Congress.

I should like next to turn to developments of the past year that have a direct application to weights and measures administration, and thus are of immediate interest to you. These may be listed briefly as follows:

The completion of our second motion pictured entitled "Testing Mass Standards by Substitution." You will see this film Wednesday morning.

The publication and distribution of the completely revised, "Specifications, tolerances, and regulations for commercial weighing and measuring devices." This publication is identified as NBS Handbook 44-Second Edition-1955.

A comprehensive survey and resulting series of recommendations on weights and measures administration in the Commonwealth of Puerto Rico.

We have given special attention to performance requirements for metering systems for liquefied petroleum gas. The Specifications and Tolerances Committee met in Washington with us during March and has listed in its tentative report a proposed code for these devices. We are now having constructed a piece of special equipment for testing LP-gas meters. Our intention is to determine the essential components for such testing equipment and to develop testing procedures. 
Calibration and, where indicated, reconditioning of State standards have been accomplished in our laboratories for several of the States. We again urge all States to submit their reference standards to us at least as often as once each ten years, as is required by the laws of most States.

Both railway track scale testing units have been operating on a full time basis. You will hear more of that program later during this meeting.

The Weights and Measures Advisory Committee of the Conference, previously mentioned, met in Washington and has submitted its report. It is with deep and sincere regret that I announce the death on March 5, 1956, of Mr. Burns H. Dreese, Vice President of the Hobart Manufacturing Company. Mr. Dreese served with distinction on the Weights and Measures Advisory Committee since it was established about 2 years ago.

There have occurred three changes among the heads of State weights and measures agencies. In Pennsylvania, Mr. H. M. Turrell has taken office as Director, Bureau of Standard Weights and Measures. Two members of the Conference of long standing have retired: Mr. J. Roy Jones, Commissioner of Agriculture of South Carolina, and Mr. Joseph G. Rogers, Superintendent, Division of Weights and Measures of New Jersey. These two men have served the Conference faithfully and well, and we wish them the best of everything in their retirement or in any ventures they may undertake. Mr. William L. Harrelson has been appointed as South Carolina Commissioner of Agriculture. Mr. Samuel H. Christie, Jr., is serving as Acting Superintendent in New Jersey.

This summary has of necessity been brief. We hope that the delegates will take advantage of their visit to Washington to bring their technical problems to the individuals of the Bureau competent in special fields.

I would direct your attention especially to the Wednesday sessions of the Conference. These two sessions are scheduled for the Auditorium of the East Building on the grounds of the National Bureau of Standards. I shall look forward to welcoming you to the Bureau at that time.

\section{ADDRESS, BY MISS GENEVIEVE BLATT, SECRETARY OF INTERNAL AFFAIRS, STATE OF PENNSYLVANIA}

It seems to me a very great honor, both for me as an individual and for my State of Pennsylvania, that you have afforded me this opportunity to meet with you and discuss. with you some of the problems that we all share in our effort to enforce standard weights and measures throughout this great country of ours.

We all recognize the important part that the National Conference has played for many years in weights and measures administration, and it is my fervent hope that, during my term of office, my State may attain something of the same sort of success. While it is true that my work in connection with weights and measures enforcement consumes only part of my time, the Department of Internal Affairs having many other unrelated but equally important administrative responsibilities, still I look upon this particular 
work as one of my most vital obligations to the people of Pennsylvana, and one which I, as a government official, as a lawyer, and as a would-be student of better government want to fulfill to the very best of my ability.

When I took office I had an opportunity which many of you might envy, but which filled me with considerable apprehension. By force of circumstances, it was necessary for me to reorganize our Bureau of Standard Weights and Measures completely. The Director and the Assistant Director had both resigned before I took office, and many of the field inspectors had done the same. While the opportunity to select my own appointees and to install my own program was desirable in many respects, it gave me some cause for alarm because I was very anxious that the enforcement of standard weights and measures in the state should not be adversely affected in the slightest degree. I think it is a tribute to our new Director and Assistant Director, both of whom are attending this Conference, that we have already made as much progress as we have, and I feel sure that the things they will learn here, and the suggestions they will get from all of you, will help them to do an even better job. And certainly I could not let this occasion go by without thanking the dedicated men in the National Bureau of Standards for the tremendous assistance they have given us. Without their help and encouragement, indeed without their actual tutoring, I am sure we could not have met our heavy responsibilities.

One of the very first acts of the new Director was to have Pennsylvania's State standards calibrated and verified at the National Bureau of Standards here in Washington. We had discovered, to my consternation, that no such checking had been done for many years, and we were indeed grateful to National Bureau men for their prompt help in this connection.

Another of the things we have done in Pennsylvania-indeed one of the things we absolutely had to do because we were recruiting a new force-was to conduct weights and measures training schools. I notice that your program includes a discussion period regarding these schools, and I would certainly like to give them my unqualified endorsement. We have held three of them in Pennsylvania during the past year, and I consider them not only the best means of bringing our inspectors up to date, but also of obtaining a much desired uniformity in inspection methods and in enforcement procedures.

The first of these training schools was held last August for quick orientation of the new office and field staff of the reorganized Bureau. That school emphasized an explanation of weights and measures laws and regulations, instruction in the theory and practice of weights and measures supervision, and discussion of the duties and responsibilities of the Bureau under existing law.

In November a second training school was held at Pennsylvania State University. State inspectors attended three days of instruction, with lectures and laboratory demonstrations, to insure that uniform methods and procedures would be employed in approving calibration of milk tanks. 
Our third training school was held for two days in March in order that our inspectors might be fully informed of new rules and regulations which we promulgated on April 2, 1956. In another effort to attain uniformity, Pennsylvania at that time adopted these new rules and regulations for weights and measures inspection, based on the National Bureau of Standards Handbook 44, second edition. In addition to the new rules and regulations, the curriculum of this training school also included scale design, scale testing, coal violations, legal aspects of the weights and measures program, and the farm milk tank program.

We have found these training schools very useful. They have been effective because we have had the cooperation of the best experts in the field in conducting them. Mr. W. S. Bussey, Mr. M. W. Jensen, and Mr. Harold Wollin of the Office of Weights and Measures, were most generous in sharing their time and talents in helping make our training program a success, and the former chief, Mr. Ralph W. Smith, was a tower of strength and helpfulness upon whom we leaned heavily for guidance.

We are also indebted to many officials in our neighboring States as well. Preparatory to the revision of our regulations, and to promote as much uniformity as possible, our Director or Assistant Director attended conferences in Ohio and New York regarding farm milk tanks, in Maryland and Massachusetts regarding remote-control gasoline pumps, and in New Jersey regarding Babcock test milk bottles. Everywhere they were given the utmost cooperation, and we were very grateful for it.

There are several specific weights and measures problems with which we have been coping, and I would like to take a moment to tell you what we have been doing about them.

Because such a large percentage of Pennsylvania's farms are dairy farms, the farm milk tank has been a weights and measures problem of considerable size in our State. Because our inspectors were required to approve the calibration of the milk tanks; and so many tanks were being installed, a practice developed by which our inspectors were doing the actual calibrating themselves. The result was that an undue portion of the time of many of our inspectors was being monopolized in witnessing these calibrations.

Effective at the beginning of this month, we adopted a new policy. The manufacturer now is required to calibrate the farm milk tank when it is installed. The inspector can recheck the calibration later, enabling him to work that assignment into his schedule along with other duties. The new policy promotes a more efficient performance of all the inspector's duties.

Pennsylvania is one of the leading coal-producing States, and we have tightened up enforcement of the State's Solid Fuel Law. Much coal is hauled by truck direct from the mine to the consumer. To aid the consumer in getting the correct weight, we have a system of weighmasters' certificates, but an investigation revealed that the law was not followed closely, either deliberately or through misunderstanding, with the result that the purchasers of the coal 
sometimes did not receive full value for their money. We have prosecuted some coal trucker-drivers, who were fined. We have warned other trucker-drivers and a number of weighmasters, and our inspectors have been making the rounds of truckers and weighmasters to explain the law and to warn that infractions will mean fines and license suspensions.

There are two other problems in which the solutions we have reached may interest you.

You know how frequently these days a person buys a part of a carcass of meat, has it frozen and processed, and delivered to him in numerous small packages for storage and later use. We have obtained an opinion from the Attorney General of Pennsylvania which provides that if the whole or a part of a carcass of meat is processed by a food freezer bank firm, the buyer is entitled to have the net weight of the meat contained in each package plainly and conspicuously marked on the outside of the wrapper.

Barbecued chickens have become very popular in Pennsylvania, as I suppose they have in your States, too. Many were offered for sale at a fixed price per chicken, with no statement of weight. The Attorney General has advised us that under our Pennsylvania Commodity Law, such chickens should be sold at a stated price per pound, and any proportion of the pound should be sold at the stated price in direct proportion to the price per pound.

There, briefly, is what Pennsylvania's new weights and measures program has been accomplishing in the past twelve monthsin reorganization and training, in efforts toward uniformity in inspection and enforcement, and in meeting specific problems.

It may surprise some of you to be receiving such a report from a woman, for I have been told that, in all of these United States, I am the only woman who heads a Department which includes a weights and measures enforcement agency.

Why this should be, I cannot say and do not particularly care, but because I am a. woman, I want to leave with you what may be a new viewpoint regarding our efforts to educate the public concerning the provisions of weights and measures laws, and the nature of your job in enforcing those regulations. I have passed these thoughts on to our inspectors in Pennsylvania and because they have told me they have found them helpful, I wish to sketch them here in the hope that they may be of help to some of you, too.

Professional purchasing agents may know all of the details applying to the materials they buy, but women do the vast majority of the buying for the home and I believe many of them know very little concerning the laws affecting their purchases.

For instance, I doubt that many women know the extent to which food must be sold by weight or count. For that matter, I also doubt that some of our sellers know. If you walk past the stalls at a farmer's market, or stop at some roadside stand along the open road, you will find farm products sold by the box, or the carrier, or the basket, when they should be sold by the weight or the count. I do not believe the farmers who sell that way know that they violate the law; and I feel sure that if they knew what the law provides they would gladly conform. 
The more educational work you and your inspectors can do, the less trouble you will have in getting complete compliance with the law, so I suggest that you and your staff use whatever means is at your command to enlighten the public-especially the women shoppers-regarding your activities and why certain practices are illegal. Tell the newspapers. Get on a question and answer program on the radio. Take actual samples with you to a television studio to show the audience what is legal, and what is illegal and why. Talk to service ciubs and ask the men to tell their wives. Reach the farmer's through the weekly newspapers, the farm columns of daily newspapers, and through the Grange and other farm organizations. If there is a farm program on your local radio station, the man who runs it will be glad to have you or one of your inspectors appear on the program and tell the provisions of the commodities act pertaining to farm products. You also can discuss the coldwall holding tanks for milk, if they have become one of the problems in your State.

But especially, tell your story to the women. Make speeches to women's clubs and civic clubs. Appear before Parent-Teacher groups. If the local radio or television station has a women's program, with menus and household hints and features of that kind, offer to supply shopping hints to tell the housewives what to look for when they go to the corner grocery or the supermarket. Tell your story to the Home Economics classes in high schools-start the girls right and they'll know how to be wise shoppers by the time they start marketing for themselves.

I'd like to repeat-tell your story to the women. They do more buying than anyone else. They are the largest group directly affected by the results you are trying to achieve. Educate them regarding what the law provides for their protection, and they will be alert to see that they get honest weight for their dollar.

There never will be enough weights and measures inspectors to keep constant check on all scales and measuring devices in the United States, but educate the women shoppers regarding their rights and before long you will have countless women as unofficial assistants in your State or city, all trying to achieve the same result you are.

It has been a pleasure to be here with you this morning, and I thank you for your courtesy in inviting me. I am looking forward to working with the National Conference and all of you from the various states, and I hope you will enjoy our association as much as I know that I will. 


\section{APPOINTMENT OF COMMITTEES}

The President made the following committee appointments :

COMMITTEE TO SERVE DURING THE 41 st NATIONAL CONFERENCE

Committee on Nominations: F. M. Greene, Connecticut, Chairman; E. R. Fisher, Rhode Island; Erling Hansen, Minnesota; J. T. Kennedy, District of Columbia; I. M. Levy, Chicago, Ill.; J. P. Leonard, Paterson, N. J.; Robert Williams, Nassau County, N. Y. Committee on Resolutions: C. M. Fuller, Los Angeles, Calif., Chairman; Leonard DeRienzo, Englewood, N. J.; A. H. Dittrich, New Hampshire; J. J. Leonard, New York; G. S. McIntyre, Michigan; J. J. Powers, Philadelphia County, Pa.; C. H. Stender, South Carolina.

\section{STANDING COMMITTEES}

Committee on Education: T. C. Harris, Jr., Virginia, 5-year term.

Committee on Laws and Regulations: G. L. Johnson, Kentucky, 5 -year term.

Committee on Specifications and Tolerances: D. M. Turnbull, Seattle, Wash., 5-year term.

\section{PRESENTATION OF HONOR AWARDS}

DR. AsTiN: At this point in our proceedings we reach a new item for a program of the National Conference-the Presentation of Honor Awards. You will recall that a plan for public recognition of commendable records of attendance at Conference meetings was approved by the Conference last year. I am happy to be able to inaugurate at this time a series of ceremonies honoring those who have been present at many meetings of this organization. Surely, a good attendance record is significant, and the physical evidence of official commendation for such a record, in the form of an engraved "Honor Award", is something to be prized by each person who earns one, and to be displayed proudly as a mask of accomplishment in his profession or business.

To refresh your memories regarding the plan for these awards, let me say that four attendance categories are being recognized, that is, attendance at $10,15,20$, and 25 or more, meetings. When one has been present at 10 meetings, he becomes eligible to receive, at the succeeding meeting, a 10-year certificate, which will be decorated with a green wafer impressed with the Conference seal. Similarly, after attending 15, 20, and 25 meetings, he will become eligible to receive appropriate certificates decorated respectively, with red, blue, and gold wafers. Each certificate will be engrossed with the name of the recipient, and Secretary of the Conference.

It is planned to present these awards each year on the opening day of the meeting. If a person is not in attendance and thus cannot personally accept his award, the certificate will be mailed to him after adjournment of the meeting.

In this first year of awards, each certificate has been prepared to show the exact number of prior meetings attended, according to the Conference records. For example, an individual who has to his credit attendance at 13 prior meetings will receive a certificate with a green seal and with 13 as the number of meetings attended. After this year all certificates will be for $10,15,20$, or 25 meetings. 
The number of prior meetings attended are shown in parentheses following each name.

25-year Certificates

T. A. Seraphin (29), R. W. Smith (29), C. A. Lindsay (28).

20-year Certificates

J. S. Burke (24), E. Kent Lawrence (24), J. G. Rogers (24), G. F. Austin, Jr. (22), C. M. Fuller (22), G. A. Howe (22), J. G. Hugel, Sr. (22), L. V. Judson (22), M. D. Ribble (22), G. L. Berry (20), C. G. Crockett (20), G. S. Smith (20), Wilmer Souder (20).

15-year Certificates

H. S. Bean (18), R. M. Bodenweiser (18), C. L. Richard (18), E. C. Smith (18), C. D. Baucom (17), H. E. Crawford (17), G. H. Leithauser (17), J. P. McBride (17), J. H. Meek (17), S. Q. Bennett (16), J. A. Boyle (16), E. E. Powell (16), J. W. Saybolt (16), Robert Williams (16), H. W. Bearce (15), W. S. Bussey (15), R. E. Gould (15), J. C. Kenney (15), D. W. Kingsley (15), J. A. Logan (15), R. E. Meek (15), C. C. Morgan (15), A. T. Pienkowsky (15), Mrs. Edith G. Saybolt (15), C. P. Smith (15).

10-year Certificates

R. S. Ackerman (14), C. P. Griffith (14), J. C. Miller (14), G. Denny Moore (14), A. O. Oslund (14), A. T. Smith (14), F. G. Williams (14), W. A. Jones (13), E. A. Powell (13), H. H. Russell (13), A. C. Samenfink (13), E. M. Schiemer (13), Nalls Berryman (12), Lyman J. Briggs (12), V. D. Campbell (12), Leonard DeRienzo (12), J. M. Dietz (12), E, R. Eyler (12), E. R. Fisher (12), F. W. Gast (12), L. L. Kennedy (12), J. D. Laird (12), J. P. Leonard (12), Alfred Lirio (12), C. J. McCaffrey (12), A. E. McKeever (12), D. R. Miller (12), William Miller (12), W. H. Sieger (12), F. J. Black (11), J. F. Blickley (11), S. H. Christie, Jr. (11), William Kirk, Jr. (11), I. L. Miller (11), R. L. Slater (11), L. E. Witt (11), C. A. Baker (10), L. G. Close (10), W. M. Harks (10), H. E. Howard (10), J. J. Levitt (10), W. E. Louthan (10), W. F. Masinda (10), R. A Parham (10), W. P. Reed (10), S. C. Rowe (10), S. H. Seighman (10), Mrs. Ida Seraphin (10), Louis Snow (10), R. D. Thompson (10), G. W. Warner (10), S. H. Wilson (10), F. C. Yarbrough (10).

\section{ROLL CALL OF STATES}

The Secretary called the roll of States. Delegates and their ladies were introduced individually. (Roll call continued at afternoon session.)

(The Conference was recessed until 2 p.m.) 
(G. L. Johnson, Vice President, Presiding)

\section{ROLL CALL OF STATES (Continued)}

The Secretary completed the roll call of States. Delegates from 40 States, the District of Columbia, the Philippine Islands, and Puerto Rico responded.

(Written reports from many States and Associations were supplied to the Secretary in advance of the Conference. These were duplicated and distributed.)

\section{REPORT FROM NATIONAL SCALE MEN'S ASSOCIATION}

By O. H. Watson, President, N.S.M.A., and Manager, Chicago Division, Exact Weight Scale Company, Chicago, Illinois

The National Scale Men's Association in its Annual Conference in March, at Chicago, elected me as president for a term of one year. In that office I follow in the footsteps of a long line of illustrious gentlemen who have filled the office with credit to them and the Association. It gives one a sober feeling of responsibility. Incidentally, as of April 13, 1956, the name National Scale Men's Association has become practically a misnomer. On April 13 was established the Ontario Division at Toronto, Canada, with thirty charter members, giving us our first out-of-states division.

It is unnecessary for me to restate the objects of the N. S. M. A. That has been done before by qualified men, and those statements are a matter of record. However, it may be appropriate to restate one of our general purposes: "To serve the best interests of the public by promoting (1) more accurate weighing services, (2) improved controls over weighing, and (3) better understanding by that public of the weighing of commodities."

It has been proposed that in my remarks I should deal directly with a topic which is encompassed by that first category, "more accurate weighing services." I have been asked to say a few words in a few minutes about what the National Scale Men's Association is doing toward the training of a more adequate number of competent scale mechanics. I do not think that question is meant to be interpreted in the sense, "Do we have an active, functioning training program complete with school and instructors?" We do not have, and everybody knows it. Under our present organization, we cannot execute such a program. I do think the question is meant without a location, without adequate finances, without a paid staff, to be interpreted, "In what ways and how successfully are the activities of the N. S. M. A. pointed toward the education of scale mechanics?"

In this question what kind of scale men are we talking about? Scale servicemen working for individual industries? I don't think so. For that class of serviceman the several scale manufacturing companies offer excellent opportunities for schooling and experience in scales of their manufacture. The employing company usually is glad to take advantage of that opportunity. If we are not talking about him, then we must be talking about the professional scale mechanics who offer their services anywhere. This group runs the gamut all the way from the men who work in the employ of scale manufacturing companies to the single mechanic who is self 
employed. The men in the former group usually become quite proficient if they last. Their opportunities for broad experience are great. In the latter group, usually called the independents, are often found some excellent mechanics, but sometimes, on the other hand, there are found certain inadequate, poorly informed, and inexperienced men.

The manufacturer does not feel any compulsion to educate the independent serviceman. He usually regards that man as a competitor. The N. S. M. A. however is as much interested in the independent serviceman as in any other, and it does offer him something.

To enable him to meet the problems and perplexities of his craft, what does the scale mechanic need? Two important needs are (1) printed basic instructive material, (2) opportunity to work or practice under conditions where he will encounter actual problems and have to solve them. The N. S. M. A. has not yet met fully either of these needs. But it is doing, I think, within its limitations, the next best thing. It is offering the scale man, at its annual conference, a program of addresses and discussions which bear directly on a wide variety of practices in scales and weighing. It comes as close as possible within its limitations to meeting the second need, when in divisional meetings it gives the mechanic opportunity to meet all kinds of scale men who are willing to talk about scales and share with him much of their hard-won knowledge.

The annual conference of the National Scale Men's Association presents an extensively diversified program. Its proceedings and all discussions are published complete in the Scale Journal, its official organ. Aside from that, the Association operates in divisions. A typical division holds meetings every other month, five or six a year.

The divisions are encouraged to organize meetings at which the program is educational and at which a scale mechanic, either novice or skilled, may add to his fund of knowledge of his craft. Some divisions have gone even farther and have attempted a series of meetings actually simulating a school. Starting with rudimentary scale problems and descriptions, they have worked toward more complicated subjects. The success of these schools has not been outstanding. The men who need it most stay away from the meetings. I have seen this happen so often that I have come to expect it. I have been forced to the conclusion that you can offer a man enlightenment, but you cannot make him try to assimilate it.

What are the reasons that these things are so?

In the first place, you are shooting at a very diversified group. At a typical division meeting will be men including every group from scale plant owner to the beginner in shop practice, from the city, county, or State official to the highly skilled scale engineer or designer. Consequently, you cannot interest everybody to the utmost all the time. I can take any young scale mechanic and interest him intensely by expounding a scale principle that is within the grasp of his knowledge, but I cannot hold the attention of a skilled expert by working out a simple problem in compound leverage. Secondly, there is not in evidence a huge desire by many to become well grounded and completely educated scale men. Most are satisfied with only a narrow segment. In the third place, there seems to be a feeling that there should be some royal road to education. I don't think there is such a road. 
I have been led to the conclusion that a complete printed text is what is most needed, some handbook into which a mechanic can dip for information when he needs it and which will serve as a supply from which he can draw knowledge as fast as he can assimilate it. Such a text has long been a dream of scale men. The N. S. M. A. would willingly produce it if it could find the ways and means.

With our most recent increase in membership we probably have now about 600 members. We should have several times that many. At least half of the sealers and enforcement men of the country should be members instead of the scant fifty that are.

The Association has on paper a plan to sell memberships to industrial companies, offering the argument that their prosperity is tied to their scales and that investment in improved technology in scales and weighing will pay off. If we do succeed in selling this program to industry, we believe that we can organize on a permanent basis and work toward accomplishments of some of the things which are now only dreams.

We need more numbers, because even in numbers alone there is strength. But the Association is growing, and it has a more alert and forward-looking attitude than at any time during the twenty years I have been a member. I think it will be around for a long time.

\section{DISCUSSION ON FOREGOING PAPER}

Mr. BAUCOM: Mr. Watson, please give me your association's definition of "scale mechanic." What are the qualifications?

Mr. WATSON: The National Scale Men's Association has never officially gone on record in an attempt to qualify any type of scale man, although we are sometimes asked to do that. We might be able to undertake such an activity if we were to become more thoroughly organized. My personal definition of a scale mechanic is any man who works with his hands repairing or servicing scales or in any way administering to their utilization.

MR. BAUCOM: Recently a man applied to us for a license as a scale mechanic. He was in the employ of a scale company. He had only a fifth-grade education, had never visited a scale factory, was unfamiliar with accepted scale terminology, and worked by "trial and error." Was he a "mechanic"? Should we attempt to say how much a man must know before he is qualified to be licensed?

Mr. WATSON: We, as an association, may eventually be able to help you, but not now. The man you described makes my definition fall flat, for undoubtedly he is not a mechanic.

\section{THE WEIGHTS AND MEASURES ADVISORY COMMITTEE}

\section{By J. P. McBride, Chairman, Director of Standards, State of} Massachusetts

This is the second report to the National Conference on Weights and Measures of the Weights and Measures Advisory Committee. The terms of two members of the original committee, W. M. Harks, Vice President, Bowser, Inc., and A. V. Hokanson, President, National Association of Retail Grocers, expired in May 1955, and the committee wishes to express to these gentlemen its sincere appreciation for their services. The new members of the committee 
are C. J. McCaffrey, Vice President, Ralph N. Brodie Company, Inc., and Seth T. Shaw, Vice President, Safeway Stores, Inc., and, while we have lost two good members, we have also gained two equally energetic and able committeemen.

The committee held its first meeting of the year during the period of the National Conference in May, at which time we consulted with Dr. Astin and elected John P. McBride as chairman. On December 14 and 15, 1955, the committee held a meeting at the National Bureau of Standards, where Bureau facilities and staff members were made readily available to the committee for the purpose of its meeting and thorough discussion was had with Dr. Astin and Bureau staff members. We are happy to be able to report that progress has been made on several committee recommendations submitted to the Director last year. Bureau staff members have cooperated with the Office of Weights and Measures and industry on the liquefied-petroleum-gas program, and it now appears that there will be submitted to the Conference a plan of operation on this commodity. The committee was impressed last year with the sound film "A True Standard," and has recommended a continuance of this type of educational program. It is our information that a second film is completed and will be shown before this conference.

While the committee is ambitious and the Bureau is receptive, there are, of course, limitations in the way of availability of necessary funds for the several contemplated projects, and, although the Bureau general appropriations for this current fiscal year was increased over the previous year, there is still need of additional funds. The committee has come to the realization that the National Bureau of Standards is an ever expanding governmental agency with a wide scope of coverage in the field of science and technology and plays a very important part in our national life, both from the standpoint of economy and security.

The Director of the National Bureau of Standards is traditionally the President of this Conference, and each year the Conference opens with an address by the President in which are outlined some of the highlights of Bureau activities during the preceding year. This, at best, gives a sketchy idea of Bureau work. The committee has been favored with the opportunity of close observation of some of these activities, and we, as a people, can very well be proud of this agency of our National Government. Two members of our committee attended a viewing of Scientific Exhibits and a Demonstration on the Science of Measurement during the Bureau Guest Week in January of this year.

Weights and measures is one of the early National Bureau of Standards projects in the maintenance and custody of standards of length, mass, and volume, but the Bureau's expanding field lies in the science of physical measurement. We in weights and measures therefore have a vital stake in the Bureau and have great need of its services in this rapidly advancing technological world. One of the difficulties confronting Bureau operations is necessary funds to meet the demands from commerce, industry, and governmental sources. We are in hearty accord with the Bureau budgetary requests for the coming fiscal year.

The committee has submitted to Dr. Astin, Director of the Bureau, certain recommendations which we believe will strengthen 
the Bureau program in its services to weights and measures. We have included in these recommendations a research project to study the static weighing of axle loads, a research project on the commercial measurement of liquid fertilizers, and a continuance of the educational work by the Office of Weights and Measures in its training program of weights and measures officials.

The committee feels honored to have served in this highly interesting work and wishes to take this opportunity to thank Dr. Astin, Director of the Bureau, W. S. Bussey and M. W. Jensen of the Office of Weights and Measures, and other members of the Bureau staff for their cooperation with the committee in its work.

\section{REPORT OF THE SPECIAL COMMITTEE OF VICE PRESIDENTS}

OF THE CONFERENCE, PRESENTED BY C. A. LYON, CHAIRMAN

The vice presidents of the National Conference have again met and organized as a special committee, under authority of a resolution of the 39th National Conference, to propose to this body, for its nomination, the names of persons to fill vacancies on the Weights and Measures Advisory Committee to the Director, National Bureau of Standards. There are two vacancies to be filled, occurring by reason of the expiration of the term of Mr. C. M. Fuller, Sealer of Weights and Measures of Los Angeles County, Calif., and by reason of the death of $\mathrm{Mr}$. B. H. Dreese, Vice President of the Hobart Manufacturing Co., Troy, Ohio, whose term would also have expired this year.

We are of the opinion that the vacancies this year should be filled by persons representing like interests to those of the persons whom they will succeed on the Advisory Committee, that is to say, by a weights and measures officer and by a representative of a manufacturer of commercial weighing devices. The hold-over members of the Advisory Committee are Mr. J. P. McBride, Director of Standards of Massachusetts, and Mr. H. J. Kennedy, Vice President, Continental Oil Co., each of whom has 1 more year to serve, and Mr. C. J. McCaffrey, Vice President, Ralph N. Brodie Co., and Mr. Seth Shaw, Vice President, Safeway Stores, Inc., each of whom has 2 more years to serve. The new appointments will be for 3-year terms.

The Committee of Vice Presidents has canvassed the field of industry and proposes, for nomination by the Conference as the representative from the ranks of manufacturers of commercial weighing devices, a man who for many years has demonstrated a sincere interest in weights and measures administration, Mr. W. A. Scheurer, Vice President, Exact Weight Scale Co., Columbus, Ohio.

With respect to its proposal for nomination of the weights and measures officer to succeed Mr. Fuller, the Committee has reached a decision that it wishes to explain to the Conference. Mr. Fuller, in the Committee's opinion, is an official of recognized competence who has brought to the fulfillment of every assignment given him by the National Conference an unusual degree of ability and enthusiasm. We have taken cognizance of the fact that Mr. Fuller's term of service on the Advisory Committee has been only two years, instead of the normal full term of three years. We feel that we would be performing a disservice to the National Conference and to the Director of the National Bureau of Standards were we now to make a proposal that would deprive the Advisory Committee of 
the contributions to its deliberations and recommendations that Mr. Fuller is in a position to make during the next few years.

Accordingly, with no desire to establish any precedent with respect to future replacement on the Advisory Committee, but acting in the light of those special conditions prevailing at this time and with a desire to advance to the greatest degree the opportunities for constructive action, the Committee proposes, as a representative of weights and measures officials on the Advisory Committee, that the Conference nominate Mr. Charles M. Fuller, Sealer of Weights and Measures of Los Angeles County, Calif., to succeed himself.

You will understand that both of the nominations under consideration at this time are for 3-year terms.

(The report of the Special Committee of Vice Presidents was adopted by the Conference.)

\section{OBTAINING EVIDENCE AND PREPARING A CASE REPORT FOR COURT}

By G. F. TAYlor, Chief Assistant Prosecuting Attorney, Pontiac, Michigan

When we have realized that approximately 50 percent of all our earnings are spent for commodities necessary to our existence that are either weighed or measured, we then begin to realize the great responsibility which rests upon weights and measures inspectors to protect the public from great loss, either through deliberate and willful intent or through ignorance, mechanical failure, or carelessness. It has been estimated that the average family will lose approximately $\$ 50$ yearly through either intentional or unintentional acts of the seller that results in short weight or short measure.

In the past, practically all violations under the weights and measures laws have been prosecuted either under city ordinances or under State statutes which have been created to regulate and control and to guarantee to the public that the purchaser will receive just weight. It is my opinion that, if the inspector is empowered through proper legislation to penalize the deliberate willful cheat under regular criminal law rather than under city ordinance, this method would gain more publicity and tend to more ranidly discourage this type merchant.

Permit me to digress for just a moment to explain the difference between the terms malum prohibitum and malum in se. Malum in se means an act or case involving illegality from the very nature of the transaction, upon principles of natural, moral, and public law. It is under this particular section of the law that I recommend that the deliberate cheat be prosecuted, rather than under "malum prohibitum," which means a thing which is wrong because it is prohibited, even though it may have been committed with good motives or with no element of intent to violate the law. To make the words malum prohibitum more easily understood, the following example is used. If a merchant displays a package of food whereon it is printed that it contains eight ounces, and in fact at the time it was packed it did contain eight ounces, but through shrinkage, inadvertence of an employee, or without making allowance for said shrinkage, the package when sold or offered for sale contained less than the labeled weight, the owner is in violation of the law 
and is guilty, even though he had no such intention. In malum in se, the intent is self evident before the merchandise ever reaches this particular package.

When short weight merchandise is found and prosecution is contemplated, immediately place the article under seizure. Insist that the owner, manager, or others in control are present through the entire transaction. That is, suppose you find a quantity of short-weight merchandise, place the package or parcel on the scale, but first test the scale to make sure that the one to be used in testing the alleged short weight merchandise is accurate. Then continue to weight the articles, marking each package plainly as to the shortage of weight.

It is a good idea to carry with you a camera with flashbulb attachment. Place the short weight article on the scale and take a picture of both the package and the reading on the scale. If possible, place the printed label of the package toward the camera, so that the printed weight will be exposed, as well as the reading on the scale. This, you will find in some instances, will be highly valuable in trial, especially if the package contains a commodity where there would be great doubt in the jury's mind as to whether or not such a commodity would retain its weight from the date of the alleged infraction to the date of trial, such as ice cream or popcorn. By the prosecutor laying the proper foundation, this photograph could be admitted in evidence.

It is good practice, where it is necessary to leave merchandise with the owner or manager after it has been seized and sealed, to place it in a position where the owner has suggested that it will be safe, and to take a picture of the seized sealed merchandise. The reason for doing this is that, where you are dealing with large supermarkets, there may be change in personnel, and in some instances you will find that the seized merchandise has either disappeared or been opened, contrary to the law, without any criminal intent on the part of the manager. The photograph will show that you have done your job expertly, and it will further indicate the quantity of merchandise seized. This photograph and the one previously suggested will make reasonably sure the successful prosecution of a case.

Be sure and take full and complete notes, either at the time of the seizure or violation or as soon thereafter as you find it possible. Your notes should cover any pertinent conversation between the inspector and the owner, especially so if there is an admission on his part that the merchandise is short weight, that the scale is incorrect, that it has been moved and no request made for rechecking it, or whatever other statement is made that will assist in the proofs at the time of trial. Your notes should further contain the names of persons present, the location of the merchandise, the date and time of the seizure or violation, the condition of the weather, which in many instances is important, and all other information which you believe will help refresh your memory at the time of trial, which sometimes takes place months after the offense has occurred, especially where there is an appeal.

You will be surprised how confident you will be when you take the stand, knowing that you can answer questions without saying, as has happened, "I think so" or "I believe so, you know this happened months ago." Here, you can pull out your notebook, and, 
through the proper foundation being laid by the prosecutor by asking the inspector whether or not those notes were made on that particular day, the court will permit the witness to completely refresh his memory on any point which might not be clear.

With the normal change of prosecutors, you may have an entirely different prosecutor when the case comes to trial than the one when the offense occurred. Your notes again, and the information to the new prosecutor as to what the witnesses will testify, will aid in the conviction. This is especially true in large cities, where the assistant prosecutors are so busy trying many cases that they do not have the opportunity or time for complete and proper preparation.

In most cases, the inspector will know more about the laws under which he operates than the prosecutor. In Oakland County, where Pontiac is the county seat, for example, we have a population of over 500,000 people. We are the second largest county in the State of Michigan, and adjoin Detroit. Our office carries eleven assistant prosecutors. Violations of weights and measures laws total less than 4 percent of our criminal work. One reason may be that in our county we have many incorporated areas where the prosecution for violations under the weights and measures law is handled exclusively by the city attorneys under the city ordinance. It is suggested that, where an inspector knows in advance that the prosecutor does not have a complete working knowledge of the law under which the inspector works, an early conference and an understanding between the prosecutor or his assistant would be advisable.

Exhibits must be properly marked, so that it will not be necessary for two or three persons to testify with respect to them. In some instances, a jury will lose interest in a case because of repetitious and unnecessary testimony. Not only does such testimony add to the cost of the trial, but it also causes a delay in the proceedings. With proper identification marks on packages, extensive identification testimony can be entirely avoided.

Some incorporated cities have created special weights and measures ordinances which have stipulated penalties. Pontiac, Michigan, for instance, has such an ordinance, one section of which works in the following manner. Should a complaint of short weight be received by the inspector, arrangement is made for a citizen to be sent to the particular store and he or she is instructed to purchase three separate kinds of merchandise at three different prices. The inspector or someone else in the store waits until the parcels are wrapped and marked or paid for. The inspector then steps up and takes charge of each parcel for rechecking, first checking the scales to make sure they are correct, and, if it is found that there is short weight on each package, these are prosecuted as three separate and distinct offenses. The statute provids a minimum fine of $\$ 25.00$ for each offense.

Where it is found that three or four scales in an establishment are within tolerance but on the outer edge, is is suggested that a citation be given to the properietor or manager, so that, if there are later violations from this same establishment, these citations may be used as cross examining material to show that these warnings have been given. This, in many instances, tends to take the sting out of the impression that someone is being persecuted rather than prosecuted. This same method should be used where 
you find a violation and believe a warning only should be given, such warning informing the merchant that recurrence will result in prosecution. When the merchant takes the stand at trial and is asked by the prosecutor whether or not he received a warning on a certain prior date relative to the same type of violation, both the judge and the jury will be impressed with the considerate and efficient manner with which your work is being performed.

When you have noticed that a new establishment has come into being, you should work carefully with the city or county clerk to make sure the new merchant has been given a copy of the laws, rules, and regulations regarding this particular subject matter. Some time should be spent with this merchant in apprising him of the laws and his duties and assisting him and instructing him as to what his responsibilities are. This is an exceptionally good method of creating good public relations between your department and the businessman.

Never assume the Dr. Jekyll-Mr. Hyde attitude. Proper attitude toward both prosecutor and counsel is important. Do not show any favoritism one way or the other. Many times cases have been lost by a witness being biased or showing prejudice. In other words, never assume a prosecution complex.

While testifying, you should provide a cushion between question and answer. Always make sure you understand the question in every detail before you attempt to answer. By taking your time between questions and answers, you give the prosecutor an opportunity to make an objection. If an answer is given and it is later stricken, the jury has had the full import, and merely striking is useless. The period between question and answer should not be too long or the jury will take a skeptical view as to the weight they will give your testimony. Improper questions may be asked, and again, if a witness answers before an objection is raised, great damage may result.

Never be lulled into a state of semihypnosis. Many defense attorneys will attempt to be overly considerate of a witness and, in doing so, will lead that witness into what will sometimes be a wrong answer to a material question. At all times be at ease on the witness stand; at the same time be alert, never completely relaxed.

There is no case important enough to an officer to justify anything but the truth. There is no place in law enforcement for any man who is not thoroughly honest with himself, his department, and others. One may undo by a false statement all the respect a department has commanded through the years. Perjury is the willful assertion as to a matter material to the issue in a judicial proceeding, known to the witness to be false.

You should never volunteer information when a mere yes or no answer will suffice.

Public relations amounts to doing a good efficient job in a courteous manner and then letting the public know about that job.

People form their opinion of the entire weights and measures department from their contacts with you. You must remember that you are no longer a private citizen.

An important phase of your public relations is your conduct during court appearances. If there is any doubt in your mind as to the questions that will be asked you by the prosecuting attorney at 
the time of a trial, ask him for a pretrial interview to go through the various questions. As stated previously, there is no substitute for preparedness. In addition, it makes a tremendous impression with the jury if your answers to the questions asked are brief and to the point, and without any unnecessary hesitation; except, as stated elsewhere, on cross examination you should permit time for the prosecutor to enter an objection, if necessary.

It is good practice to remain outside the courtroom until called by the prosecutor, as many jurors will give your testimony more weight if you have not had the opportunity to hear the testimony of other witnesses. It is best to ask your prosecutor whether or not he wishes you to remain in or out of the courtroom. Cases have been lost by public officers who have had a tendency to appear to throw their weight around; this should never be done either in the field or in the courtroom.

During a trial, the defense counsel in many instances will ask a weights and measures inspector what his qualifications are. It is always good to have in mind what courses you have pursued, the books you have read, with the titles and the authors, an outline of your practical experience, and an explanation, to the best of your ability, of the term and meaning of tolerances.

Cross examination is, in fact, a substitute for the torture endured in medieval times by civilians. Cross examination is the greatest legal means ever invented for the discovery of the truth. Wendell Phillips said, "You can do anything with a bayonet but sit on it." To cross examine or not to cross examine, by the prosecutor, can be determined only by the amount of information which you, as officers, have compiled. Prior arrests and convictions are very important, and an officer should do everything he can to procure this information for the prosecutor.

The investigation of complaints on suspected short weight or measure is one of the most important responsibilities in our weights and measures law. Many complaints of varied nature are received annually from persons who suspect they have received less than the quantity which was represented and for which they paid. These complaints are investigated thoroughly to determine if there was cause for complaint and if evidence can be secured to prove the person has been shorted. If the results of your investigation show the complaint is valid, corrective measures must be taken.

In some instances, the short weight or measure is obviously unintentional, as previously stated, and an adjustment is made by the seller to the purchaser. When it is obvious that the shortage is a result of a deliberate intent to defraud, in most cases the evidence is secured and presented to the prosecutor of the county, and criminal proceedings are instituted against the violator without delay.

\section{SUMMARY OF PREPARATION FOR TRIAL}

The main points that the officer witness should remember for trial preparation are as follows:

1. He should speak clearly and distinctly, but in a normal tone of voice.

2. He should speak so that his testimony is heard by all persons within the court. 
3. He should avoid the use of technical terms and police slang, but, where their use is necessary, follow them with an explanation so that they are understood.

4. He should avoid the use of profanity unless used in repeating words spoken by others and so indicated.

5 . He should pay strict attention to counsel while questions are being asked, listening carefully.

6 . He should be certain that he has heard and clearly understands the question.

7. He should develop the habit of hesitating briefly between completion of the question and his answer.

8. He should answer questions briefly and concisely, using "Yes" and "No" when possible.

9 . He should never volunteer information not specifically requested by counsel.

10. He should never avoid a question, but answer all questions to which he knows the answer.

11. He should never fabricate an answer, nor depend on his conclusions. If he does not know the answer, he should say so.

12. He should never hesitate to correct an honest mistake in his testimony.

13. He should avoid prosecution complex.

14. He should show equal respect to counsel for both sides and never show animosity.

15. When answering a question, the answer should be directed to either the judge or jury, as the case may be.

16. When demonstrating or illustrating, he should be certain that all interested persons can see him.

17. When indicating or adding information to a scale chart, he should place himself in a position so as not to block the view of interested persons.

18. He should show utmost respect for the court, the jury, and counsel, being polite and courteous at all times.

19. He should never become familiar with counsel or the magistrate at any time while on the stand.

20 . He should be fair and impartial in all of his testimony, showing no bias, prejudice, or partiality.

\section{Discussion on FOREgoing PAPER}

MR. WRENN : Who should be charged in the case of a corporation?

MR. TAYLOR: If the violation is of the malum prohibitum type, innocently committed through carelessness or inadvertence, always charge the corporation. If the manager is not directly connected with the violation, why give him an arrest record? Moreover, the name of the corporation will be publicized much quicker than will the name of an individual. If the manager is at fault, charge both him and the corporation; it is the duty of the corporation to see to it that its employees obey the law.

Mr. DIETZ: Should an inspector have another person with him when making test purchases?

MR. TAYLOR: When collecting evidence for a possible prosecution, by all means have a witness with you. 


\section{REPORT OF THE OUTGOING EXECUTIVE COMMITTEE, \\ PRESENTED BY W. A. KERLIN}

The Executive Committee report this year will be rather a brief one. There were several items which were considered by the committee, and we submit these as suggestions to the incoming Executive Committee.

Considerable study was made concerning the dates of the Conference and the securing of accommodations. It is suggested that the incoming Executive Committee consider the last week in May and the first two weeks of June as possible Conference dates. It is felt that this would give the Secretary and his staff a better opportunity to secure the best accommodations available. It is also suggested that Conference arrangements be made as far as three years in advance.

It is also recommended that the Sheraton Park be considered for the 1957 Conference for the first week in June.

As required by the report of the 1955 Executive Committee, this committee made a review of the functioning of the standing committees and reports that it is apparent that they are functioning properly.

The 1956 committee also recommends that the new Executive Committee make a review and study of the voting procedures of the Conference.

This committee also wishes to remind the Conference of the resolution passed by the 1955 National Conference on Weights and Measures requesting that guest rooms be closed during Conference sessions.

(The report of the outgoing Executive Committee was adopted by the Conference.)

\section{QUANTITY REQUIREMENTS UNDER FEDERAL ALCOHOL AND TOBACCO TAX REGULATIONS}

DISTILLED SPIRITS, BEER, WINE, AND ALCOHOL

By H. A. SERR, Assistant Director, Alcohol and Tobacco Tax Division, Internal Revenue Service, U. S. Department of Treasury

Regulations administered by the Internal Revenue Service which relate to liquors are concerned with quantities in the individual package. Quantities are important in achieving compliance with, first, the taxing statutes involved and, secondly, the Federal Alcohol Administration Act. This latter Act is a law designed to prevent certain undesirable trade practices and also to give certain protection to consumer's. In general, under these statutes, our aim is to see that the proper amount is placed in packages, first, so there will be no loss in taxing revenue and, secondly, so that there will be no misbranding or mislabeling of the product.

\section{Distilled Spirits}

In packaging distilled spirits, quantities may vary, first, as to proof, and, secondly, as to volume. Regulations prescribe the size of bottles which may be used, the fill of the bottle, and its labeling and stamping. 
Bottles containing distilled spirits are required to have a strip stamp, so placed over the mouth of the bottle that it will be broken when the bottle is opened. The strip stamps are not tax stamps, but are indicative that the tax on the liquor has been paid. The stamps are issued in various denominations, and the correct denomination must be used for each bottle. Bottles which are usually referred to as miniatures-that is having a capacity of less than $1 / 2$ pint-all use strip stamps marked with the phrase "less than 1/, pint."

Bottles prescribed for distilled spirits are as follows: for all distilled spirits, whether domestically manufactured, domestically bottled, or imported, one gallon, 1/2 gallon, 1 quart, 4/5 quart, 1 pint, $1 / 2$ pint, $1 / 8$ pint, and 1/10 pint. Scotch and Irish whiskey and Scotch and Irish type whiskies, and brandy and rum may also use a $4 / 5$ pint bottle. In addition to the foregoing, a 1/16 pint bottle is authorized for brandy, whether domestically manufactured, domestically bottled, or imported. There are no standards of fill for distilled spirits, such as cordials and liqueurs, cocktails, high balls, gin fizzes, bitters, and other specialties, which means that these products may be packaged in any size bottle.

We recognize that there may be variations due to lack of uniformity of the bottles, but this may not vary more than 2 percent from the amount stated to be contained therein. Furthermore, we expect substantially as many bottles to be overfilled as are underfilled in each lot. We expect the bottles to be filled as nearly as possible to conform to the amount stated on the stamp and on the label. For all bottles, other than miniatures, the headspace may not be more than 8 percent of the total capacity of the bottle after closure.

Tolerances in fill are stated in our regulations (27 CFR 5.73), as follows:

The following tolerances shall be allowed:

(1) Discrepancies due exclusively to errors in measuring which occur in filling conducted in compliance with good commercial practice.

(2) Discrepancies due exclusively to differences in the capacity of bottles, resulting solely from unavoidable difficulties in manufacturing such bottles so as to be of uniform capacity: Provided, That no greater tolerance shall be allowed in case of bottles which, because of their design, cannot be made of approximately uniform capacity than is allowed in case of bottles which can be manufactured so as to be of approximately uniform capacity.

(3) Discrepancies in measure due exclusively to differences in atmospheric conditions in various places and which unavoidably result from the ordinary and customary exposure of alcoholic beverages in bottles to evaporation. The reasonableness of discrepancies under this paragraph shall be determined on the facts in each case.

During the process of bottling, Internal Revenue Officers are required from time to time to test and examine the bottled spirits to determine whether the bottle is properly labeled, whether the bottled spirits agree in proof with the data on the label, stamp, or bottle. The usual test as to the quantity is made by weighing a given number of bottles before and after filling and determining the average net content per bottle. With regard to proof, the bottler is required to set the proof in the bottling tank to the exact tenth of proof called for on the label. Because of evaporation and losses during process of filtering and bottling, the Government Officer is permitted to accept a drop in proof of not to exceed $3 / 10$ th of a degree of proof (26 CFR 225.990, 230.243, and 235.773). 
Except for spirits bottled in bond, the excise tax of $\$ 10.50$ per tax gallon is paid on all distilled spirits before bottling takes place. This furnishes a substantial incentive to the bottler to stretch his taxpaid goods as far as possible by shading the proof, or shading the fill, to his advantage. Any such underfilling or underproofing, however, works to the disadvantage of the Government taxwise. These divergent interests probably assure a more proper fill of bottled distilled spirits than most other packaged goods.

\section{Beer}

Our regulations do not provide standards of fill for beer. Any size container may be used for the packaging of malt beverages if properly marked to show the actual net contents. However, we do insist on the proper labeling of all bottles or cans, and expect that the net contents will be accurately stated. Internal Revenue Officers are not stationed at breweries to check on the fill of containers, so in this respect our controls differ from those on distilled spirits. We do have meters in the breweries, and these, together with the brewery records, enable our inspector's to determine the over-all disposition of the beer.

Because of our tax interest on beer removed from breweries, we have always insisted that the fill of bottles and cans should conform to acceptable bottling standards. We are presently amending our regulations (26 CFR Part 245) so that they will read as follows with reference to fill of containers.

The statement of net contents shall indicate exactly the volume of beer within the bottle except for such variations in measuring as may occur in filling conducted in compliance with good commercial practice.

This is a general rule, and does not state precise tolerances. However, we normally have Internal Revenue Inspectors visit breweries at least once a month, and the proper fill of bottles and cans is a matter of regular inquiry.

Beer is also packaged in kegs or barrels, and fractional barrels. A barrel contains 31 gallons. Authorized fractional barrels are halves, thirds, quarters, sixths, and eighths. Tax is paid according to the barrel size, and any excess filling subjects the keg to tax according to the next larger size. Where the excess quantity of beer in any such container does not exceed the standard volume by 2 percent, the tax is computed at the rated barrel size.

\section{Wine}

Standards of fill are prescribed for domestic wines and for foreign wines bottled in this country. Fifteen bottle sizes are prescribed, ranging from 2 ounces to 4.9 gallons (27 CFR 4.71). Wine containers must be so made and filled as to have a headspace not in excess of 6 percent of their total capacity after closure if the net contents of the container is $2 / 5$ pint, or more, and a headspace not in excess of 10 percent of such capacity in the case of all other containers. The net contents of the bottle must be shown either on the label or in the bottle. Bottlers are permitted some tolerance in recognition of normal commercial bottling practices, as well as variations in the size of bottles, but no allowances are made for consistent over or underfilling. The regulations (26 CFR 240.578) 
require that "bottles must be filled as nearly as possible to conform to the amount shown on the label or blown in the bottle to be contained therein, but in no event may the amount of wine contained in any bottle due to lack of uniformity of the bottle vary more than 2 percent from the amount stated to be contained therein; and, further, in such case there shall be substantially as many bottles overfilled as there are bottles underfilled for each lot of wine bottled."

Internal Revenue Officers make only occasional visits to wine bottling premises. Such visits probably do not average more than once or twice a year. Prior to 1955, many wine bottling establishments received no supervision from Internal Revenue Officers. Changes made in the 1954 Internal Revenue Code extended our authority to premises bottling taxpaid wines and has resulted in a more uniform administrative control over wines which are entering the American market.

Alcohol

Ethyl alcohol, either undenatured or denatured, may be packaged in various approved containers, such as drums, barrels, steel containers having a capacity of not more than 10 wine gallons made of not less than 24-gage steel, small packages containing exactly $1,2,5$, or 10 wine gallons, and in bottles. It may also be packaged in railroad tank cars, tank trucks, and even in tank ships and barges. In packaging alcohol in glass containers of one gallon or less, a strip stamp is affixed over the mouth of each bottle. Strip stamps, however, do not show denominations for the bottle size. Such bottling is conducted under the supervision of an Internal Revenue Officer, and the same labeling and filling provisions apply as were described above for distilled spirits.

Small packages containing exactly $1,2,5$, or 10 wine gallons require weighing with scales that read to pounds and ounces so that weights may be calculated in pounds and hundredths of a pound.

The fill of larger containers is determined by weighing. The scales must weigh accurately, and the beams on the scale must be graduated according to the size of the scale. For example, $1 / 2$ pound graduations are required for scales having a capacity not to exceed 2,000 pounds. Beams of scales must be graduated to enable readings to be made to the nearest pound for scales having a capacity over 2,000 pounds but not exceeding 6,000 pounds; to the nearest two pounds for scales having the capacity of 6,000 pounds but not exceeding 20,000 pounds; to the nearest five pounds for scales having a capacity of 20,000 pounds but not exceeding 50,000 pounds; and to the nearest ten pounds for scales having a capacity of over 50,000 pounds. Most Ethyl alcohol is moved in large quantities and weighed in tank scales. Provision is made for the frequent testing of all scales, and all removals from the alcohol plant and the bonded warehouses are made following a gage made by the proprietor which is verified by a Government Officer. Gaging of alcohol also involves the accurate setting and reading of proof. Tolerances in proofing and taking weights are not provided, since it is expected that every reasonable accuracy permitted by the gaging and weighing instruments will be utilized. 
By N. T. Morsell, Chief, Tobacco Branch, Alcohol and Tobacco Tax Division, Internal Revenue Service, U. S. Department of Treasury

Several years ago I appeared on the program of your Conference to outline certain Federal internal revenue requirements in regard to manufactured smoking tobacco, as the result of a request by one of your members that manufacturers of tobacco be required to show a net weight marking on each of their packages of smoking tobacco. At that time the Conference decided to postpone further action on this matter after I had explained that, under the Federal internal revenue laws and regulations, manufacturers of tobacco were required for Federal tax purposes to affix to each package of manufactured tobacco suitable internal revenue stamps of the proper kind and denominations which would indicate the net weight contents of the packages on which Federal tax was paid.

At each of your subsequent Conferences, I have appeared before the appropriate committee, headed in each instance by the very capable and efficient Mr. M. A. Nelson, Chief, Division of Foods and Standards for the State of Michigan. On each of my appearances before the committee headed by Mr. Nelson, I reviewed the matter of net weight or content markings on packages of tobacco products for Federal tax purposes, and pointed out that the situation is the same as indicated by me when I appeared at your general meeting several years ago.

It is noted from the program of this particular Conference that I am expected to make a statement on "Quantity Requirements under Federal Alcohol and Tobacco Tax Regulations" as they relate to tobacco. It is quite obvious from the subject which has been assigned to me that you are interested in the Federal requirements with respect to the packaging of chewing and smoking tobacco. cigars and cigarettes, and the labeling and marking of the packages of such products, particularly as to the quantity or $n \in t$ weight contents of the packages.

Under present Federal internal revenue laws, the Internal Revenue Code of 1954, which became effective on January 1, 1955, and the Federal Regulations, which have been issued to implement the Code, manufacturers of tobacco products are permitted to put up in a package any number of cigars, or cigarettes, or any quantity of manufactured chewing or smoking tobacco as desired by them. However, the manufacturers are required to securely affix to each such package one or more Federal internal revenue tax stamps of the proper class and denominations to cover fully the tax due on the net weight or numeral contents of the package. In addition, for protection of the Federal revenue, a manufacturer is required to show on each package of tobacco products his name and the address of his factory, or the number of the Federal permit which he must secure to operate his factory. The manufacturer is also required to place on the package a mark or warning against the reuse of the Federal tax stamps thereon and a statement that the law requires such stamps to be destroyed when the package is emptied. In the case of large cigars, weighing more than three pounds per 
thousand, the manufacturer is also required to affix to each package of such cigars a class designation which shall include the appropriate class letter of the tax bracket into which the cigars fall and a statement of the intended retail price of the cigars contained in the package. This class designation is required, since the Federal law imposes seven different rates of tax on large cigars, which are denominated from Class A through $\mathrm{G}$, with the rate of tax to be paid to be based on the intended retail price of a single cigar in its principal market. In the case of cigars and cigarettes, the manufacturer is further required to show the number of such product in each package, which may be indicated by an appropriate numeral or spelled out.

A manufacturer of tobacco products is not only required to give bond to and qualify with the Internal Revenue Service, but he is required to receive a Federal permit to cover the operation of his tobacco products factory. The manufacturer is also required to keep records and to furnish reports monthly of the entire operations of his factory. These records and reports include an accurate and complete accounting for all tobacco materials received into and removed from the factory, also of products manufactured and removed for taxable and tax-exempt purposes, and the values of United States internal revenue tax stamps of each kind and class purchased and used. Such records and reports must also show the quantities of the different tobacco products, both stamped and unstamped, also a breakdown of tax stamps by class and value, held in the factory at the beginning and close of each month. A manufacturer is further required to furnish an inventory annually, and at the time of commencing or closing a factory, of the quantities of all tobacco materials, manufactured tobacco products, and the values of Federal tax stamps held in the factory on the dates of such inventories.

Tobacco materials received, which are not accounted for as removed, destroyed, or on hand, are charged against the factory as used in the manufacture of taxable tobacco products. Such materials must be accounted for by the manufacturer by way of tobacco products manufactured, which products must be correctly and accurately reported by the manufacturer in his records and monthly reports. After the product is reported manufactured, it must thereafter be accurately accounted for by way of removal for taxable and tax-exempt purposes or as on hand by way of inventory. In accounting for removals of tobacco products, the manufacturer must place in a package at the time of tax payment, by the affixture of Federal tax stamps, the quantity of manufactured tobacco, or number of cigars or cigarettes, as indicated by the denominations of the tax stamps, because he can take credit only for the quantity of such product on which tax is paid. If he put more product in the package than that covered by the tax stamps affixed thereto, the manufacturer would come up with a shortage in manufactured product, which would render him not only liable to tax thereon, but would make him subject to penalty and prosecution for violation of the law. On the other hand, it is conceivable that, after a manufacturer has prepared a package of smoking or chewing 
tobacco and affixed the proper tax stamps to the package to show the net weight contents of the package and to denote payment of tax on such contents, a very small loss from such weight is apt to occur by the time the package reaches the consumer, due to shrinkage or drying of the tobacco, since tobacco is subject to normal shrinkage.

I trust I have made it clear by my comments that all packages of tobacco products must bear evidence as to the contents of the packages, either by weight or number, for internal revenue tax purposes. This arrangement, accordingly, affords protection to purchasers or consumers of such products.

I would now like to discuss briefly the prospects for the continuance or abandoning of Federal tax stamps on packages of tobacco products, since much has been said and has appeared in print to the effect that the use of Federal tobacco products tax stamps may be discontinued. The Treasury Department recently authorized, at the urgent request of a number of cigar manufacturers, a daily tax return system for the payment of the Federal taxes on cigars on an optional basis. The Tobacco Tax Branch of the Internal Revenue Service, of which I am the Chief, is now engaged in drafting the necessary regulations to carry this optional daily return system for cigar taxes into effect. We are concentrating on this project in an all-out effort to have this return system become effective by July 1, 1956, if possible, since this is the date which the Treasury Department and the Forand Subcommittee of the House Ways and Means Committee, which recently concluded its hearings on excise tax technical and administrative problems, indicated such return system would become effective. I would like to emphasize the word "optional" in connection with this return system, because manufacturers of cigars will be permitted the option of changing over to the daily return system or staying on the present stamp tax system for the payment of cigar taxes. Therefore, when this return system becomes effective, cigars may be removed from factories and appear on domestic markets with and without Federal tax stamps. However, a recent survey by our office of cigar manufacturers indicates that such manufacturers who account volume-wise and taxwise for more than 75 percent of all cigars produced domestically will change over to the daily return system for the payment of tax on their cigars. Accordingly, after the return system becomes effective, it is likely that more than 75 percent of all cigars will appear in domestic markets without the customary Federal internal revenue tax stamps. It is my opinion that, in order to meet competition, it will not be long before all cigar manufacturers convert to the return system. However, I want to assure you that, in the drafting of the necessary regulations to carry the optional daily return system for cigars into effect, we plan to continue the present requirement that all packages of cigars must bear a numeral or statement indicating the number of cigars in each package.

There has been no concerted appeal to the Treasury Department by other segments of the tobacco industry for a daily return system 
for the payment of their Federal tobacco products taxes comparable to that now authorized for the cigar industry. It is not believed that the Treasury Department is likely to authorize such a return system for segments of the industry, other than cigar manufacturers, unless there is unanimity on the part of the other segments of the industry for a daily tax return system. However, the Forand Subcommittee, to which I previously referred, issued its report on April 20, 1956, to the House Ways and Means Committee. In this report, the subcommittee recommended that provision should be made in the case of tobacco taxes to shift from the present stamp system for collecting these taxes to a semimonthly return system for the period August 1, 1957, to July 30, 1958, and the filing of return and payment of tax on the 18th of each month on taxable tobacco products removed for the first fifteen days of the month and for the filing of return and payment of tax on the third day of each month on taxable tobacco products removed during the period of the 16th to the end of the preceding month. The subcommittee also recommended that, beginning August 1, 1958, and for subsequent years, a monthly return system for the payment of such taxes should be adopted with a return to be filed and tax to be paid on the 15th day of each month on taxable tobacco products removed during the preceding month. I want to emphasize that the statements just made with respect to a return system for all tobacco products taxes represents the recommendations of the Forand Subcommittee, and I am sure that you are aware that the determination as to whether these recommendations will be adopted rests with the Congress. I would like to state, however, that, regardless of the manner in which the taxes on tobacco products may be paid, I believe it is essential for the protection of the Federal internal revenue and for consumers that packages of tobacco products bear some mark or numeral indicating the net weight or number of tobacco products contained in such packages. 


\section{THIRD SESSION-MORNING OF WEDNESDAY, MAY 23, 1956}

\section{(A. V. Astin, President, and W. A. Kerlin, Vice President, Presiding)}

\section{"TESTING MASS STANDARDS BY SUBSTITUTION"}

(This item consisted of the showing of a motion picture, in color and with sound, produced under the direction of the Office of Weights and Measures of the National Bureau of Standards. This is a training film, in color and with sound, designed to demonstrate procedures for testing standards of mass by the method of substitution weighing. Although primarily directed to the weights and measures officer, to teach him how to "maintain the integrity of the tools of his profession," the film will be found useful in science classes and among laboratory personnel for its exposition of a simple procedure for determining quickly, and with a reasonably high degree of precision, the value of a standard by comparing its mass with that of another standard of known value. In addition to this "error testing," there is also demonstrated the procedure for "tolerance testing," a still more simple method for use when it is desired to know merely that the error of a standard is within certain prescribed limits.

A simple form for recording and computing results in error testing, and another form for use in tolerance testing, are illustrated and explained. The several steps involved in each method are described, and are then demonstrated by means of successive entries of data on the appropriate form. In carrying through the instruction, use is made of both live scenes and animation, the latter being employed to show, step by step, the entry of data on the forms.)

\section{PETROCHEMICALS-THEIR COMPOSITION, HANDLING, AND QUANTITY CONTROL}

\section{By J. H. McClintock, Oil Loss Prevention Division, Esso Stand- ard Oil Company, Elizabeth, New Jersey}

The subject of "Petrochemicals," which I have been asked to discuss, covers a broad field. It encompasses all of the management, engineering, technical and operational functions of a major industry, and is improving our standard of living, saving our time, and making life more enjoyable through hundreds of synthetic products we encounter every day.

A definition of petrochemicals which would be acceptable to all of those engaged in the industry is nonexistent. Therefore, I feel that it will be more productive and interesting to you to establish a definition in your minds through example rather than by words.

Your interest in the petrochemical industry is understandable. The industry is new-a little less than 40 years of age-and most of its tremendous growth has occurred since 1940. This newness instills curiosity and desire for understanding. I hope that today's discussion will serve to answer some of the questions in your minds.

As you know, petroleum and natural gas are, for the most part, made up of hydrocarbons. Since 1859, when oil was first produced in commercial quantities, the principal uses of these hydrocarbons have been for the production of energy and for lubrication. Today, these same petroleum hydrocarbons make another important contribution to our American industrial life. They serve as raw materials for the organic chemical industry.

In 1920 , practically all of the organic chemicals in the United States were obtained from sources other than the petroleum industry. Coal, through the coke and manufactured gas industries. provided products such as benzene and toluene, which we call aromatics. Molasses, grains, fruits, and vegetables gave us alcohol, 
ether, and related chemicals. At that time, two organizations, one a chemical company and the other an oil company, recognized that the petroleum refining operations produce hydrocarbons which are convertible into organic chemicals. Thus the first petrochemicals, isopropyl alcohol and ethylene glycol, were made. You probably recognize these petrochemicals as the alcohol and permanent types of antifreeze used in the cooling system of your automobile. The two companies who first started the petrochemical business were Esso Standard Oil Co. and Union Carbide \& Carbon Co. Today, 187 chemical companies, oil companies, and joint companies are active in this business.

When the Japanese attacked Pearl Harbor in 1941, it was evident that conventional peacetime sources of chemicals and munitions would not be able to supply the requirements for the conflict that was to ensue. For example, sufficient TNT could not be produced from the toluene supplied by the coal-tar industry alone. To meet this need, the oil industry constructed facilities to synthesize toluene by hydroforming petroleum fractions, using a process developed by my company. Ultimately, 75 percent of the toluene needed for military purposes was produced from petroleum. Great quantities of ammonia were also required for the production of the nitric acid needed to convert toluene to TNT and for the manufacture of smokeless powder and other explosives. Natural gas produced by the oil companies proved to be an important raw material in the manufacture of ammonia.

Another example of the contribution of the petrochemical industry to our security is in the development and production of synthetic rubber. As you know, the Japanese conquered and controlled the natural-rubber producing areas in Southeast Asia early in World War II, with the result that the source of raw material for our rubber industry was reduced considerably below the requirements for the military alone. This is where the research and development work of the oil, chemical, and rubber companies paid off. Synthetic rubber made up the difference, and then some, in our requirements for rubber products. The synthetic rubber business is still expanding rapidly.

We at Esso Standard take considerable pride in the part that we have played in the development and continued expansion of this phase of the industry. We were the first oil company to operate a synthetic rubber producing plant. This plant later produced the first commercial quantities of Buna-S for tires, and it also provided much of the data from which subsequent Government GRS plants were designed. Its normal production was an oil-resistant rubber known as Buna-N, which was critically needed by the Air Force during the war. In addition, Esso Research \& Engineering Co., our research and engineering affiliate, developed the process most widely used to produce butadiene. Butadiene is, as you know, the principal raw material for synthetic rubber. And finally, there is butyl rubber, also invented by the Esso Research \& Engineering Co., and subsequently produced in the United States for the Government by our own personnel. Butyl, because of special physical properties, has found many applications. For example, over 100 parts in certain models of today's modern car utilize "Enjay" butyl 
rubber in some form. "Enjay Butyl" is identified by this trademark because of its being marketed by Esso's affiliate, the Enjay Co. Examples are battery drain tubes, radiator drain tubes, headlight lens gaskets, radiator hose, heater hose, body insulators, window and windshield seals, and spark plug covers.

Besides the synthetic rubber and explosives industries, there are many other important sectors of our economy that are served by the petrochemical industry. One of the most important of these is agriculture. Rising population, a leveling-off in the available crop land acreage, a decline in soil fertility, and a decline in farm labor population have necessitated the development of means to produce more from available land at a cheaper unit cost. One of the avenues to accomplish this has been through the use of more and better fertilizers. Ammonia, produced from either natural gas or hydrogen made during certain operations in oil refineries, is a major raw material in the production of these fertilizers. The importance of this to our Nation's national economy is evident when we realize that, on the average, $\$ 1.00$ spent for fertilizer produces crops worth $\$ 3.75$ more than would otherwise have been produced.

Petrochemicals are important in the synthetic fiber industry. Nylon, Dacron, and Orlon, and a host of other miracle fabrics are made, either in whole or in part, from petrochemical raw materials. Nylon, for example, is synthesized from butadiene and cyclohexane, both of which can be found in refinery streams. Similarly, Dacron and Orlon are manufactured from organic chemicals produced from refinery hydrocarbons or natural gas. These new synethetic fibers have physical properties that make them useful for many applications.

Plastics are another group of products which are physically related to the synethetic rubbers and synthetic fibers. Plastics are one of the largest consumers of petrochemicals. The phenolic plastics, which are synthesized from phenol and formaldehyde, both of which are produced from petroleum and natural gas, have their largest use in molding structural materials. They are also used for laminates, adhesives, and protective coatings. The vinyl resins, produced either from ethylene or acetylene, are used for raincoats, draperies, upholstery, garden hoses, and electrical insulation. Today, we even find plastics substituting for metals in such uses as pipe. Polyester resins, in combination with glass fibers, are used in the production of small boat hulls, and the fabrication of automobile bodies of plastics is also under way. Chrysler alone is said to be using 26 tons of reinforced plastic per day.

Research in the field of petrochemistry has resulted in the development of many products which are important to the motoring public. For example, consider the synthesis of lubricating oil additives. Early in the research effort, technicians discovered that, when a small percentage of synthetic oil was added to a naturally produced lube oil, the result was a product that flowed at low temperatures. Another chemical made from oil was found to have the property of making the viscosity of lubricating oil more uniform under a wide range of temperature conditions. Other chemicals have been developed, which, when added to lubricants, improved performance under extreme pressure conditions, provided pro- 
tection against corrosion of bearings, and improved crank-case cleanliness. These are only a few examples of the contribution of petrochemicals to the comfort and enjoyment of the motoring public. This research is continuing today on an even broader basis.

The discussion up to this point has, I hope, given you an insight into the technological developments that have contributed to the growth of the petrochemical industry during the past 40 years. For"tunately, the petrochemical industry has during this period had available to it the knowhow, experience, and time-tested methods of the century-old petroleum industry for measuring bulk quantities. Since petrochemicals and the raw materials for the production of petrochemicals are produced and handled much in the same manner as products from an oil refinery, the techniques of measurement developed over the years by the oil industry, in cooperation with the weights and measures officials, scientific societies, and other trade and governmental associations, have provided proved procedures that assure fair measure to all parties in the purchase and sale of these important commodities. For example, in a petrochemical plant, liquids are pumped through pipelines and stored in tanks. much in the same manner as home-heating oil is handled in an oil refinery. This has permitted the petrochemical industry to adopt, without major modification, the measurement methods established for petroleum products by the American Society for Testing Materials. The work of the ASTM on calibration of tanks and other containers has also been adopted generally in the measurement of petrochemicals in bulk. I do not plan to discuss these techniques in detaiI, as I am sure the Conference is familiar with the ASTM publication in these fields and has, in fact, been represented or consulted in many of the Society's deliberations.

The measurement of packaged petrochemicals has also benefited through the developments of the petroleum industry on package filling. Here, regular and frequent checks on package weights and the associated controls on package filling assure fair measure of quantities on this small, but important, segment of the total production.

Handling petrochemicals in tank cars and tank trucks also poses no new problems to those who have been shipping and measuring petroleum products for years. Here, too, the time-tested methods of measurement of the petroleum industry have been shown to produce accurate and dependable results. The use of displacement meters, when designed, installed, and calibrated in accordance with good engineering standards, are as reliable for petrochemicals as they have been proven to be on petroleum products. Care must be taken, however, to tailor each meter installation for the petrochemical being measured. For example, special materials are needed in meters to handle anhydrous ammonia, whereas pressure control facilities are required to minimize vaporization which can occur with certain volatile petrochemicals. The tank car or tank truck can be accurately calibrated and measured in accordance with standard procedures established by societies such as the ASTM and acceptable to all parties concerned. 
Scales that are used to measure petrochemicals are subjected to regular and frequent inspection by the weights and measures authorities, and are subject to all of the safeguards established by such authorities for such operations.

Despite differences in chemical composition of the end products, it is evident that a great similarity exists between the measurement of petrochemicals and petroleum. The experience of the petroleum industry for the last century has served the petrochemical industry well in its efforts to measure quantities accurately. I can visualize that in time the petrochemical industry will make its contributions to the evolving science of quantity measurement.

We can, however, foresee no measurement problems for petrochemicals that cannot be solved through the free exchange of experience and knowhow, utilizing the experience of those technical societies and organizations, which, over the years, have helped the petroleum and allied industries assure fair measure on the purchase and sale of petroleum products.

\section{REPORT FORMS FOR THE WEIGHTS AND MEASURES OFFICIAL}

By H. F. Wollin, National Bureau of Standards

All weights and measures field inspectors are faced with the necessity of reporting their work, both to the owners of establishments inspected and to the office from which they operate. Likewise, certain reports of equipment and activities must be kept by the office staff.

The Model Law adopted by this Conference and most State laws require that adequate records be maintained; however, only infrequently if at all do these statutes prescribe the details of such record systems.

Historically, the head of a weights and measures department has designed such report forms as seemed to him to be required. Although certain types of forms have been available from suppliers of weights and measures equipment, there has grown an almost complete diversity of types, sizes, and formats of reporting systems. This diversity obviously is in conflict with the constant aim of most officials-in fact, one of the basic reasons for the existence of this Conference-uniformity. It has always been the stated objective of the Conference to achieve nationwide uniformity in the statutes, specifications, tolerances, regulations, and testing procedures for weighing and measuring equipment. The standardization of reporting systems is desirable and perhaps can be realized through the establishment of "model" types and designs of report forms. Although no system would be completely suitable for every jurisdiction, it is believed that, with certain basic patterns, a very real semblance of uniformity is possible.

With that in mind, there has been developed by the Office of Weights and Measures, National Bureau of Standards, a series of fifteen basic forms that are offered here, with necessary explanation, for the consideration of the delegates and of all other weights and measures officials. 
Before entering into a discussion regarding the details of the report forms that are illustrated, certain general observations would seem appropriate.

A good report form must serve several purposes. First, it should provide a record in detail of the work of the inspector. Second, it should give an owner or operator clear information as to compliance or noncompliance of his equipment and the official action taken as a result of the test. Third, it should serve as a guide to the serviceman in the repair of rejected equipment. Fourth, it should furnish the office with the recorded history of individual devices and establishments and with necessary data from which may be derived statistics, news releases, annual reports, and the like. Fifth, it should be susceptible of filing as the official record.

A report form should be of simple design, yet not so simple as to sacrifice important information for the sake of simplicity. The size is determined by the number of entries required, the space that is needed for each entry, convenience of handling, and suitability for filing purposes.

Obviously, every report form should have a printed heading, giving the name of the jurisdiction and the department under the authority of which it is to be used. The heading of a form should provide also for the entry of any special data required by the individual filing system. The order of the various items in the heading will be such as to facilitate both the execution and the ultimate filing of the report. Provision must be made for entering the name of the person making the report and the date the report is prepared. On field reports it is necessary to have space for entering the name, address, and business of the establishment visited, and in most instances the signature of the owner or operator acknowledging receipt of the report. It is suggested that each form of a department be given a number, and that this number be printed in the lower left corner of the form along with the date the form was initiated or last revised and the number printed (Form 67, $10 / 2 / 56,2 \mathrm{M})$.

In order to reduce the number of field forms and to simplify the task of the inspector, a single field report form should be so designed as to make its use acceptable for as many as practicable of the devices normally encountered, and yet be informative with respect to any single device. Nonetheless, there are several important classes of commercial equipment for which test reports are properly informative only if these include details of test results, as for example vehicle and livestock scales, meters, and farm milk tanks; thus special and separate report forms are required for these. Such forms should be carefully drawn up to make them informative and readily understandable, and to facilitate the entry of data by the inspector. A special report form, designed for use only in connection with one class of equipment, may properly make use of numerous printed captions, and should be large enough to provide adequate space for all data to be handwritten.

Usually it will be found advisable to have the field report forms made up in books or pads, so that multiple copies can be made conveniently and accurately. At least two copies of every report 
should be prepared-one for delivery to the owner of the equipment, the other for official record. Sometimes it may be useful to have a third copy to be retained by the inspector. To differentiate among the several copies, differently colored sheets should be considered.

There should be provided on each field report form a scheme for indicating the action taken by an inspector as a result of his test of a device. For this purpose the four terms "Approved," "Adjusted," "Rejected," and "Condemned" are recommended as being most meaningful. For example, "Approved" has a single universal meaning, whereas the word "Sealed," currently in use in many jurisdictions, may have several meanings. The term "Rejected" is recommended in lieu of "Condemned for Repairs" and should apply to equipment that cannot be approved but is considered susceptible of repair. "Condemned," on the other hand, should indicate an action that is taken with relation to equipment that, by its design or condition, is considered not to be susceptible of repair; such action may be accompanied by confiscation or destruction.

Field test reports should always provide space for the inspector to enter (1) remarks or appropriate information for the entry of which space is not provided elsewhere, and (2) instructions comprising official orders issued by the inspector.

A sample of each of the fifteen recommended forms follows. There will be found on the reverse of each form an explanation of the intended use of that form, together with such other information as is deemed pertinent. (It is not intended that this explanatory material be reproduced on forms printed by a jurisdiction.)

There are, of course, other report forms not included here that may be required in a weights and measures office. Some of these may be identified as a daily summary report, proposed weekly itinerary, monthly, quarterly, and annual reports, and the like. Such forms are usually of such special character that it is considered impracticable at this time to recommend "models," and thus no recommendations are here included.

It is suggested that adequacy and uniformity of reporting systems are worthwhile aims of State and local weights and measures officials and that the benefits of such uniformity are sufficient to warrant definite consideration. One obvious benefit would be that of leading the field inspector toward correct testing procedures by planning the report form accordingly. The forms included in this series are so designed as to accommodate data developed during tests conducted as recommended in National Bureau of Standards Handbook 37, "Testing of Weighing Equipment," and Handbook 45, "Testing of Measuring Equipment." Another advantage of a uniform reporting system within a State is that this facilitates accurate comparison of work results.

Samples of the forms may be obtained upon request to the Office of Weights and Measures, National Bureau of Standards. These may be altered or supplemented to fit the local situation prior to submission for printing by State or local departments. 


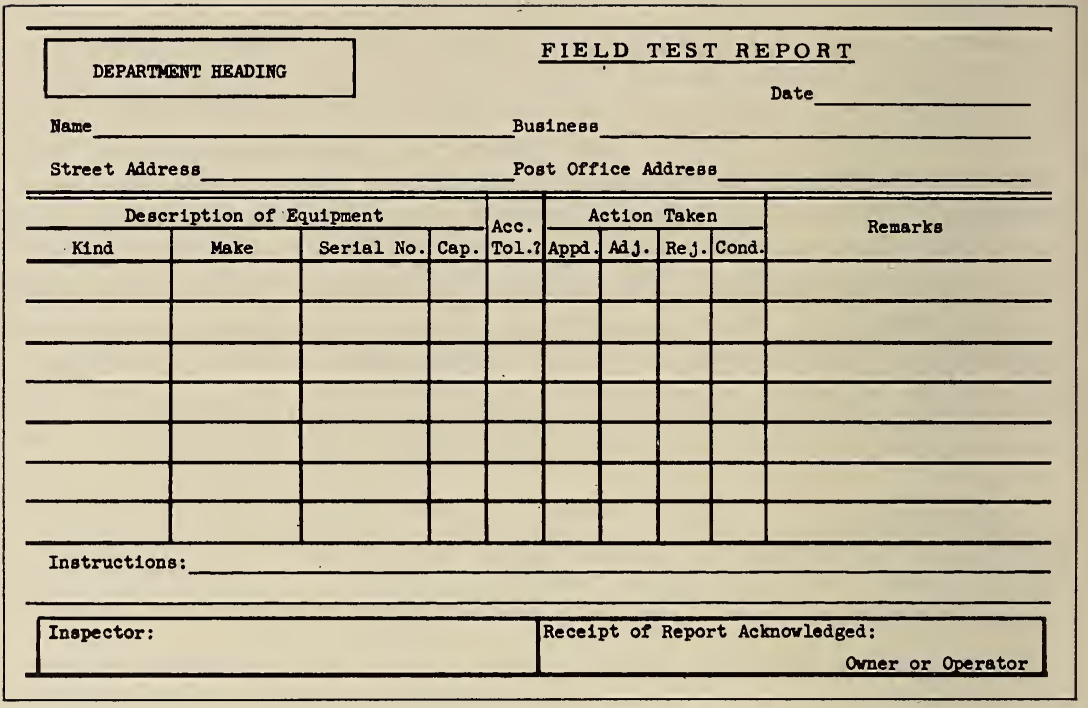

\section{FIGURE 1. Field test report.}

(Suggested size of form $8^{\prime \prime} \times 5^{\prime \prime}$.) This form may be used to report the inspection and test of all weighing and measuring equipment except those types that require the use of special report forms. Devices reported on this form include all scales other than those reported on the special form for vehicle and livestock scales; liquid-measuring devices, including retail gasoline dispensers, but excluding large meter installations ; weights ; liquid measures ; linear measures ; linearmeasuring devices; and the like. Space is provided at the top of the form for the usual entry of general information such as name, type of business, address, and date. Columnar space is found for complete and proper identification of the devices tested. Under the column titled acceptance tolerance ("Acc. Tol.?"), a check mark will indicate that acceptance tolerances were applied. The absence of a check mark will indicate that maintenance tolerances were applied. The action taken by the inspector as a result of the inspection and test is indicated by a check mark in the appropriate column under "Action Taken." The remarks column may be used to show the error of a device if such error is in excess of the applicable tolerance, or to note noncompliance with specification or regulation requirements. Official instructions should be entered in the space provided at the bottom of the form. 


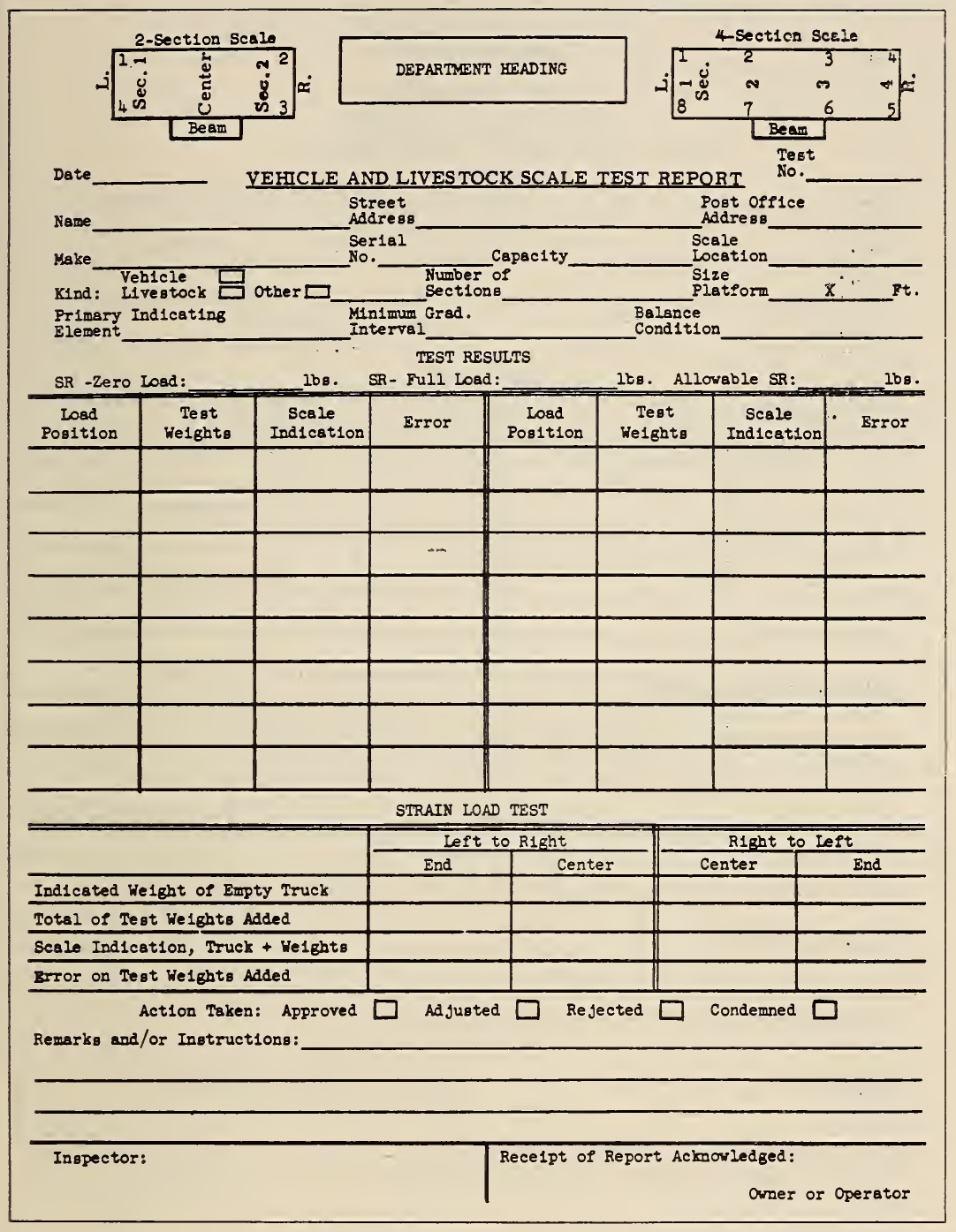

\section{FIGURE 2. Vehicle and livestock scale test report.}

(Suggested size of form $8^{\prime \prime} \times 10^{1 / 2 "}$.) This form is specially designed for use in reporting tests of large scales such as vehicle scales and livestock scales. The heading provides for a rather detailed description of both the establishment and the scale. Space is provided for the entry of SR values determined at zero and full load, and the load positions, values of test weights, scale indications, and errors for sixteen test loads. Simple coded identification of load position is made possible through the diagrams at the top of the form. Columnar tabulations of the results of strain load testing with the direction of the truck, "Left to Right," and "Right to Left," so identified, also is provided. The usual action taken, remarks, and signature spaces are found at the bottom of the form. 


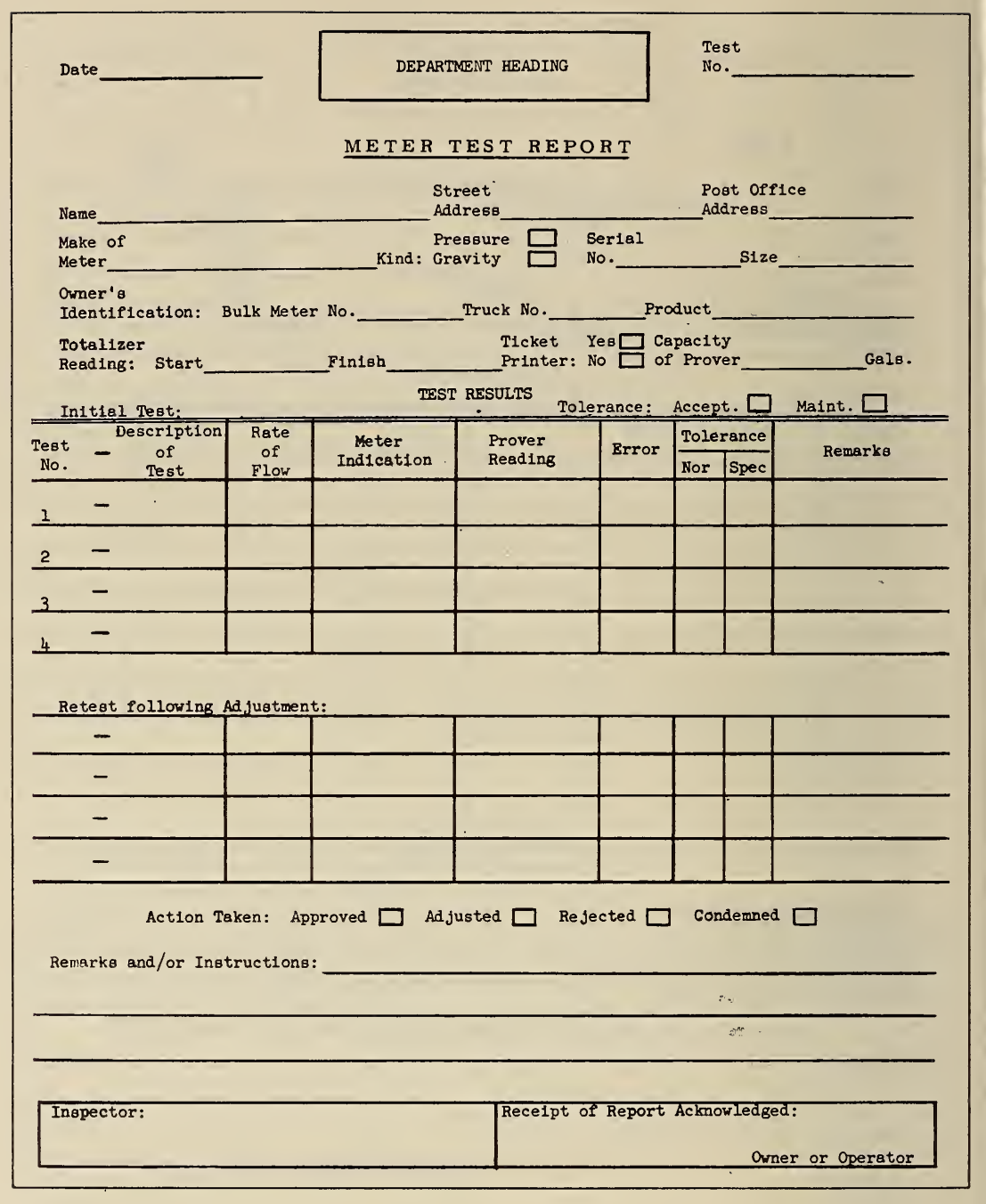

\section{FIGURE 3. Meter test report.}

(Suggested size of form $8^{\prime \prime} \times 10^{1 / 2 "} 2^{\prime \prime}$ ) The design of this special form is such as to make it adaptable to the reporting of tests of vehicle-tank meters, loading-rack meters, and other large meter installations. The heading provides space for the entry of the usual and specially significant identification information. Columnar space is provided for a description of and data developed during four individual drafts-full flow, repeat full flow, slow, and air-eliminator-on the initial test, and a like number of drafts on a retest following adjustment. A check mark in the appropriate box at the bottom of the heading will show whether acceptance or maintenance tolerance was applicable, and another under the column titled "Tolerance-normal (Nor.) and special (Spec.)" will indicate, according to the particular test, which of these was applied. 


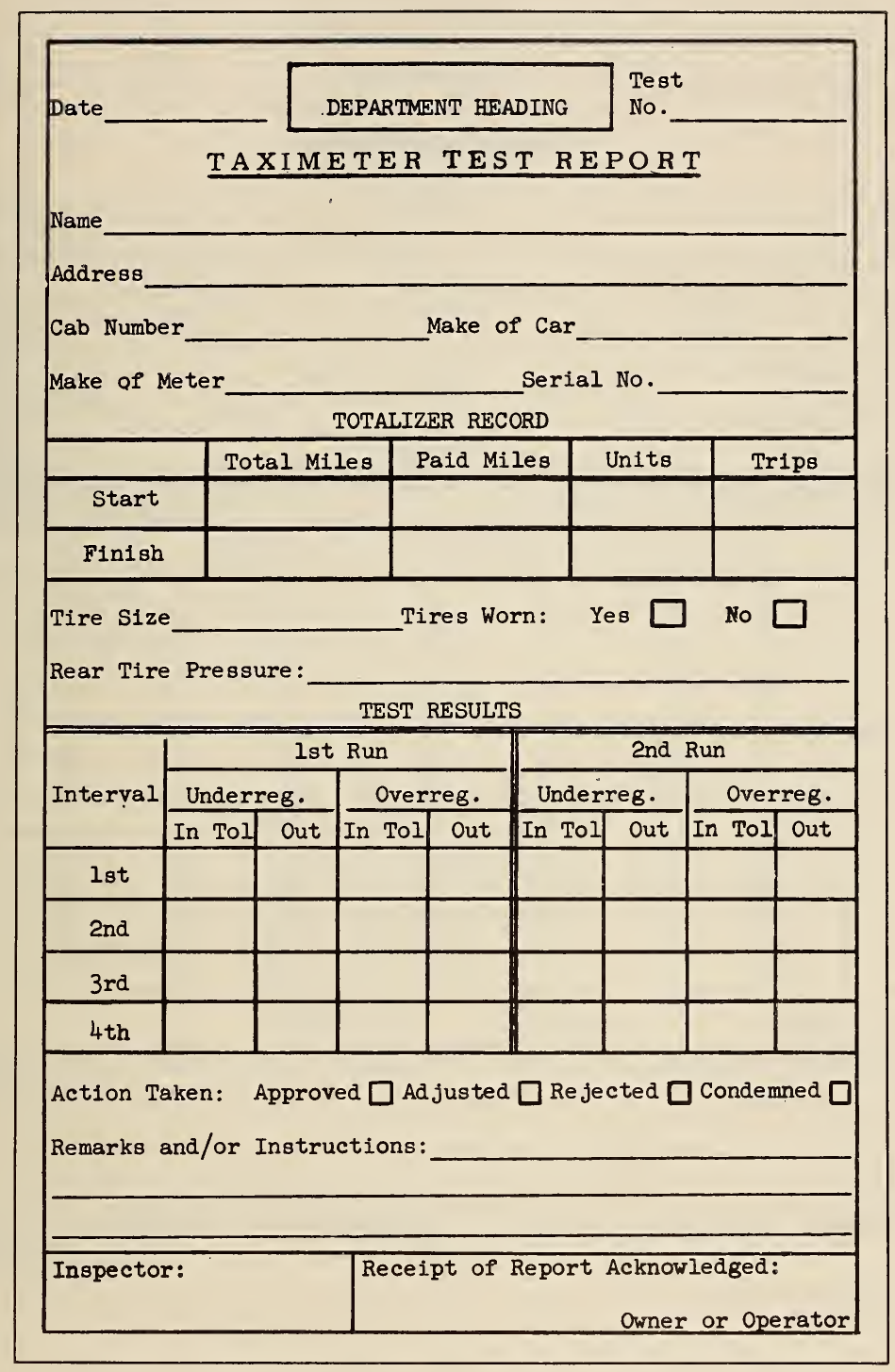

FiguRE 4. Taximeter test report.

(Suggested size of form $5^{\prime \prime} \times 8^{\prime \prime}$.) This is a special form designed for the reporting of road tests of taximeters. No provision is made to record the test of a taximeter time mechanism, as this test is not necessary in those many jurisdictions where charges for time are not allowed. Spaces are provided at the top of the form for entry of identification of the owner, the automobile, and the meter. Since taxicab drivers may be charged on the basis of totalizer indications, provision is made for recording such, both at the start and finish of the test. Tire data that are significant in the test, such as size, pressure, and condition of wear, are entered in spaces provided in the center of the form. The actual test results are recorded as "Underregistration" or "Overregistration" for each of four intervals, and within each a check mark will indicate whether the meter performed within or out of tolerance. The actual linear error is not deemed significant with respect to road tests of taximeters. The action taken as a results of the test is shown by a check mark in the appropriate box near the bottom of the form. Space is provided at the bottom for remarks, official instructions, and signatures. 


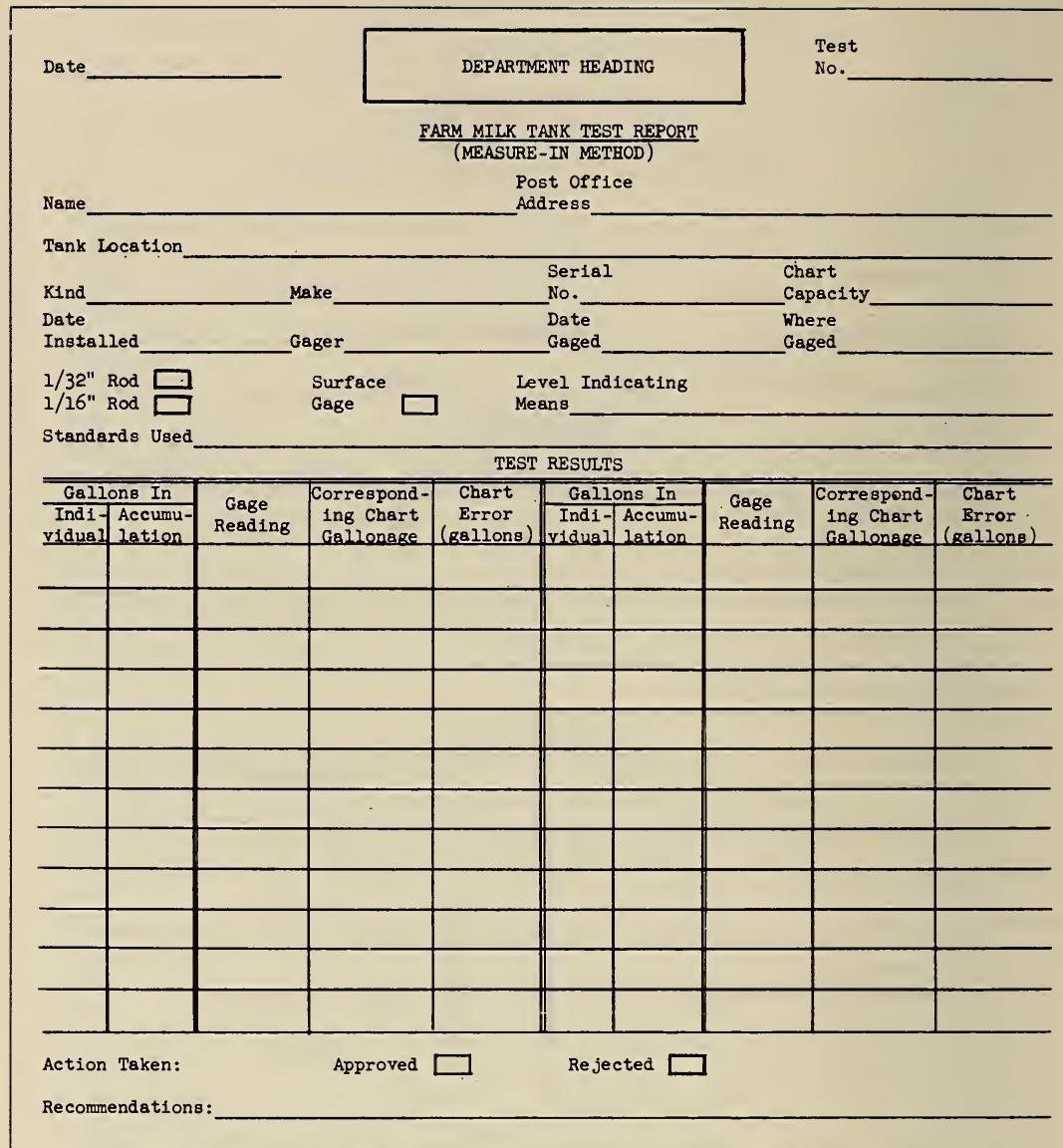

Inspector: Recelpt of Report Acknowledged:

Owner or Operator

Figure 5. Farm milk tank test report (measure-in method).

(Suggested size of form $8^{\prime \prime} \times 10^{1 / 2 "}$.) This special form is designed to report a test based on the testing procedure recommended by the National Bureau of Standards and identified as the "measure-in" method. The usual heading gives space for date, name and address of tank owner, and pertinent tank identification information. Columns are provided for the entry of 24 test drafts of measured liquid (water). In the first column, "Gallons In," are entered the amounts of the individual drafts. These are accumulated in the second column. In the third column are entered the gage readings for each gallon accumulation taken during the test. These then may be compared individually with the gage readings for the indicated gallons as shown on the gallonage chart, which readings are entered in column four. The fifth column provides space for the errors, or differences between test readings and chart readings. Space for action taken, recommendations, and signatures is found at the bottom of the form. 


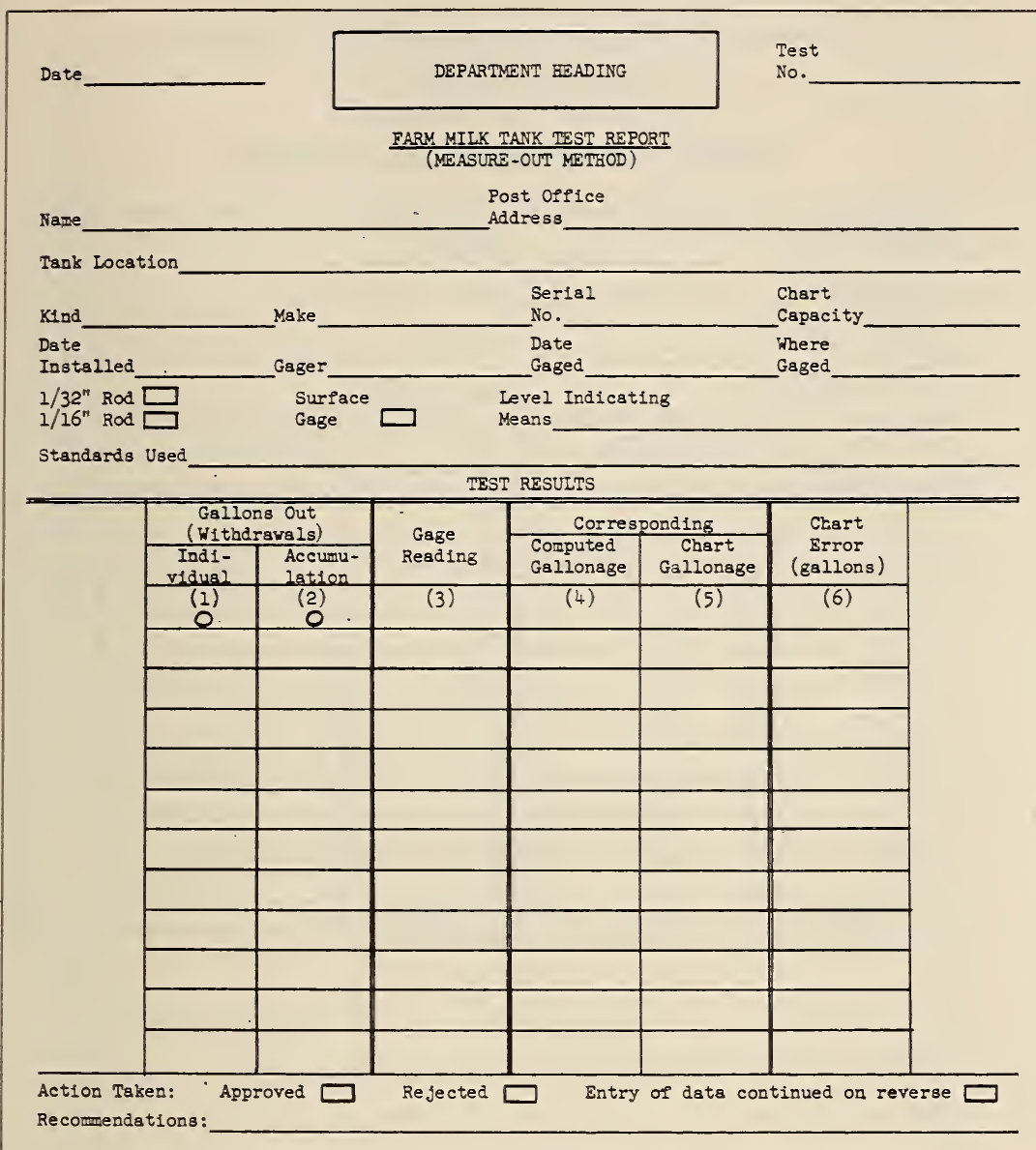

Inspector:

Receipt of Report Acknowledged:

Owner or Operator

\section{FiguRE 6. Farm milk tank test report (measure-out method).}

(Suggested size of form $8^{\prime \prime} \times 101 / 2 "$.) This special form is designed to report a test of a farm milk tank by the "measure-out" method. The usual heading gives space for date, name and address of tank owner, and pertinent tank identification information. In executing the form, the following procedure is suggested: Enter on first line column (3) the gage reading taken with tank full. Enter in column (1) the individual drafts withdrawn from the tank under test. Accumulate these drafts in column (2). Enter in column (3) the gage readings taken following each withdrawal. Transfer final figure in column (2) to first line of column (4). (This figure represents the total volume of water withdrawn from tank.) Subtract figure on second line in column (1) from figure on first line in column (4), enter result on second line in column (4). Continue this process (second figure, column (4), minus third figure, column (1), etc.) to compute figures in column (4). Last entry will be zero. Enter in column (5) gallonage figures obtained from gallonage chart corresponding to gage readings in column (3), and, by comparing the figures in columns (4) and (5), compute errors and enter these in column (6). This form should be printed on both sides, with the columns for "Test Results" contained on the reverse. If entry of data of a test is continued on the reverse, a check mark should be placed in the appropriate square at the extreme right, just below the columns, on the face of the form. Space for action taken, recommendations, and signatures is found at the bottom on the face of the form. 


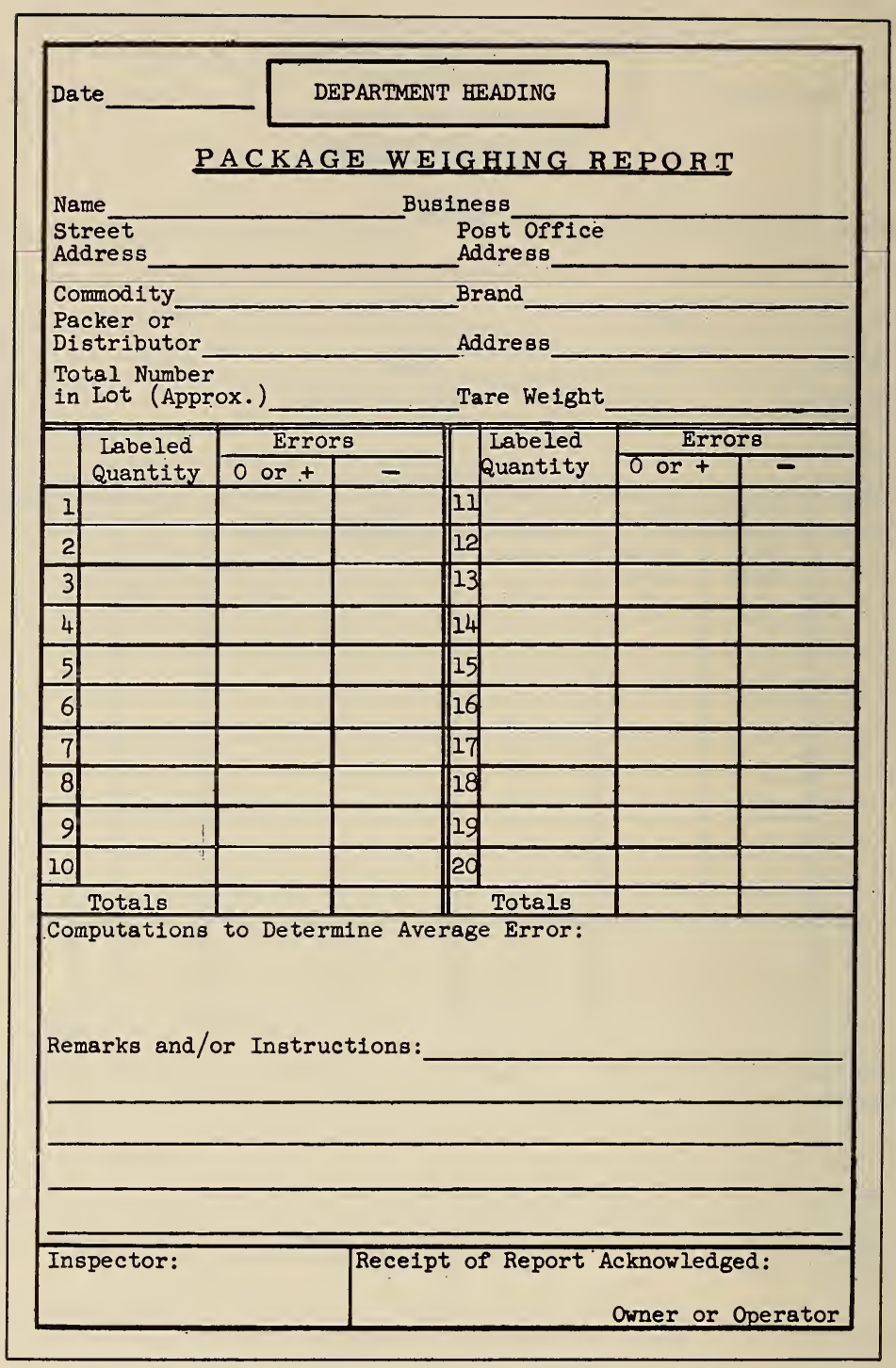

FIGURE 7. Package weighing report.

(Suggested size of form $5^{\prime \prime} \times 8^{\prime \prime}$.) The package weighing report is based on enforcement under the Model State Regulation for Package Marking Requirements as adopted by the National Conference on Weights and Measures. Under the quantity requirements of this regulation, there are two significant items of information that should be determined and recorded-(1) the average error of the packages in a single lot or delivery, and (2) "unreasonable" shortages or overages in individual packages. This form is designed for reporting individual errors in packages, and thus a separate form should be used for each commodity comprising a single lot or shipment. Following the heading, wherein is provided space for identification of establishment and commodity and figures representing an estimated number of packages in the lot and the tare weight, there are columns for entering the labeled quantity and the error (zero or plus in one column, minus in another) for each individual package. The error columns may include in the heading the fraction of the ounce that the scale is being read to, such as " $1 / 16$ ounce," so as to make possible the entry of whole numbers rather than fractions. Space will be found directly beneath the columns for computing the average error. At the bottom of the form, space is provided for remarks and official instructions, as well as the recuired signatures. 


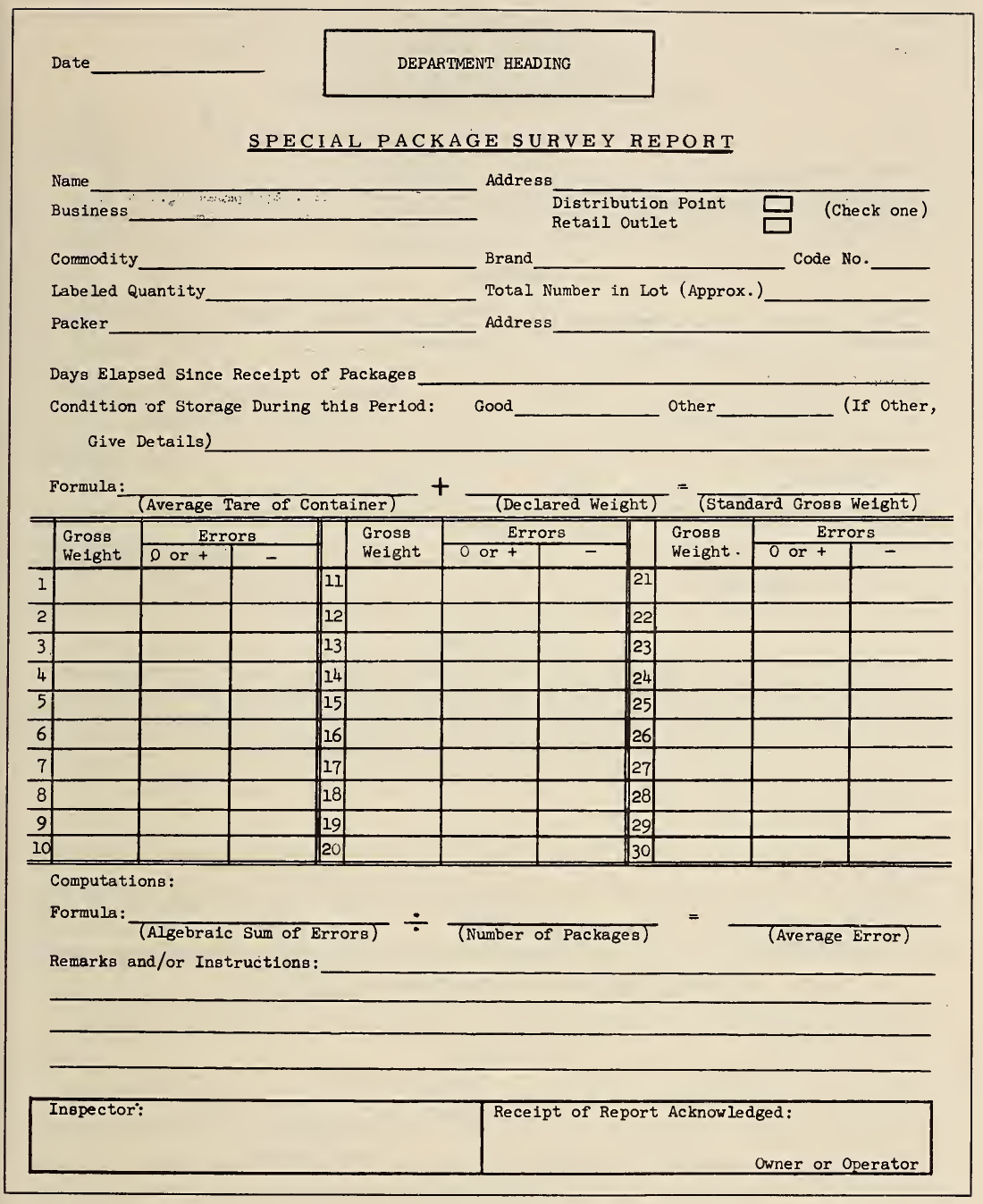

FiguRE 8. Special package survey report.

(Suggested size of form $8^{\prime \prime} \times 1012^{\prime \prime}$.) This form is designed to give extensive information on a single packaged commodity under conditions of a general survey. Spaces at the top of the form are, as indicated, for specific information on the commodity under survey and the establishment where the particular weighing is being accomplished. The formula just above the columns is for the purpose of computing a "standard gross weight," based on the average tare weight and the declared weight. The actual gross weight of individual items is entered in the first of the columns. The actual gross is compared with the "standard gross," and the error thus derived is entered in the appropriate error column. The "average error" is computed below the columns with the formula provided. At the bottom of the form are spaces for remarks, official instructions, and signatures. 


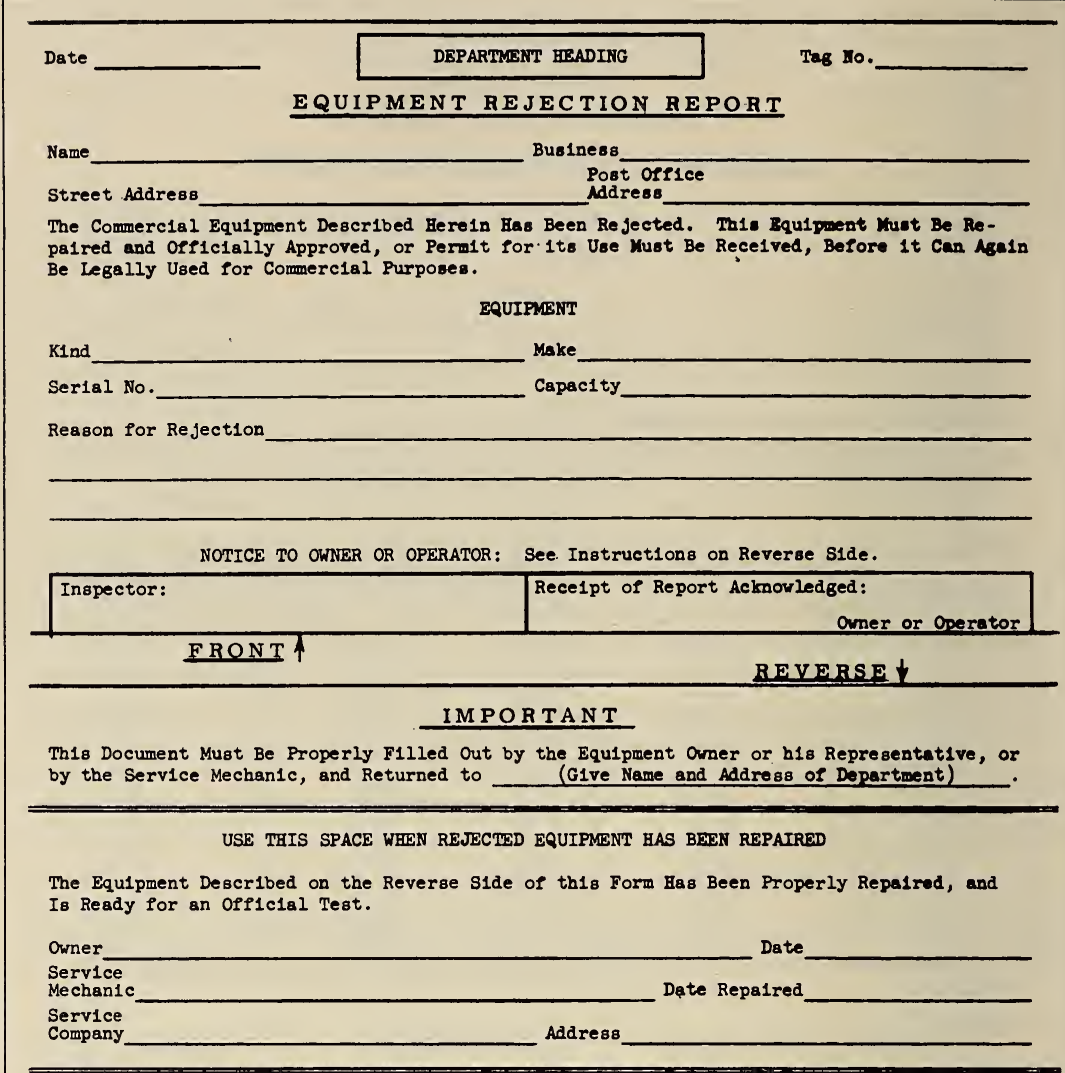

USE THIS SPACE WHEN REJECTED EQUIPMENT IS DISCARDED

The Equipment Described on the Reverse S1de of this Form Has Been D1scarded and Replaced by the Following:

Kind ___ Make

Ser1al No.

Capac1ty

owner

Date Purchssed

\section{FIGURE 9. Equipment rejection report.}

(Suggested size of form $8^{\prime \prime} \times 5^{\prime \prime}$.) The equipment rejection report may be used to report to the owner of rejected equipment the reason for such rejection. Having signed to show receipt of this report, the owner has acknowledged that the device described on the report cannot be used legally for commercial purposes until it has been repaired and officially approved. When the equipment has been repaired or replaced, the reverse of the form must be filled out by the proper authority and returned to the office before an official test can be made or before a temporary use permit for such equipment can be issued. 


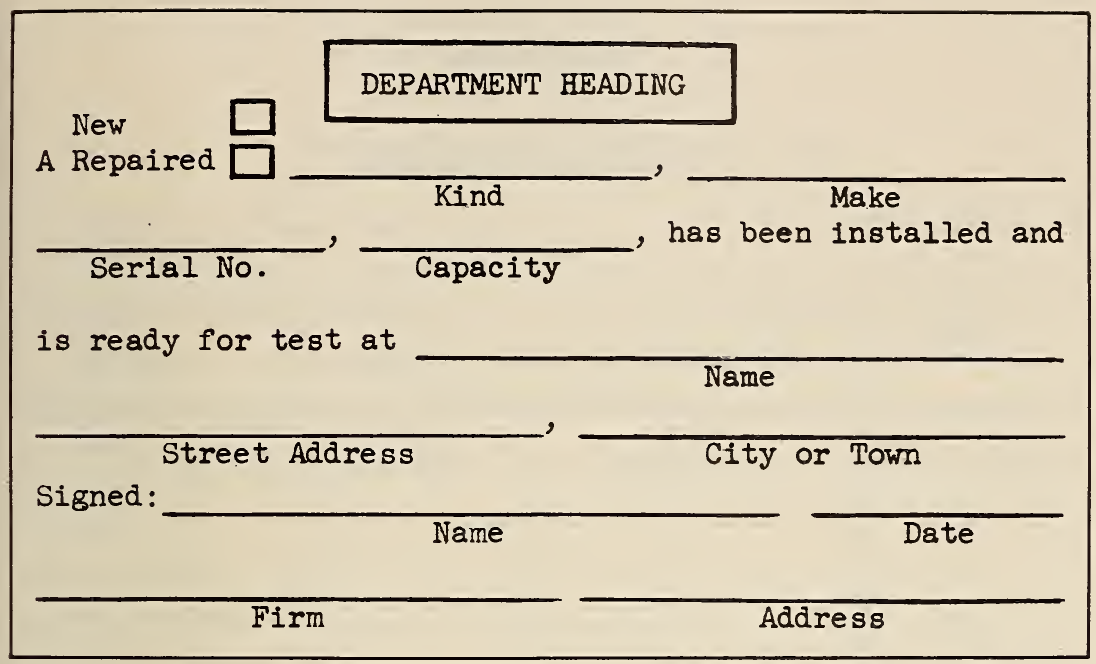

\section{Figure 10. Equipment notification form.}

This form is so designed that it may be printed as a post card. The cards should be preaddressed to the weights and measures office. It is suggested that the cards be distributed to weighing and measuring equipment sales and service personnel, who will fill out and mail a card each time a new device is installed or an existing device undergoes major reconditioning or overhaul.

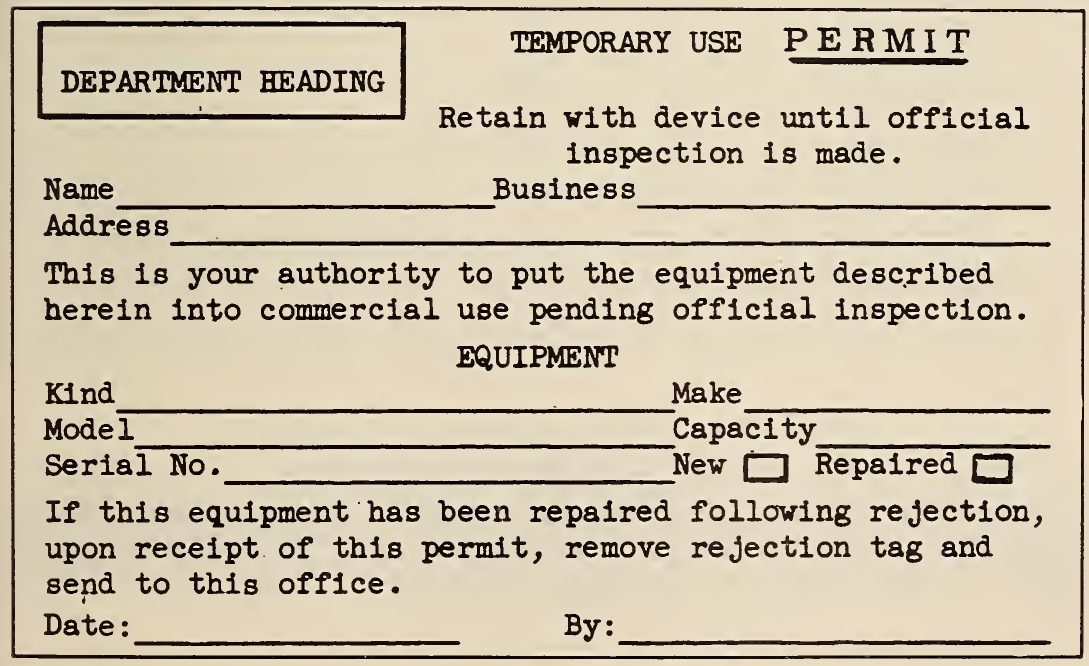

\section{FIGURE 11. Temporary use permit.}

This form may be used by the office to authorize an establishment to put equipment into commercial use pending official inspection and test. Space is provided for proper identification of the establishment and a complete description of the equipment involved. The design of this form is such that it may conveniently be printed as a post card. It is recommended that the temporary use permit be included in a reporting system using the equipment notification form and the equipment rejection report, and be used when either of the latter two forms are received from the equipment owner or agent. 


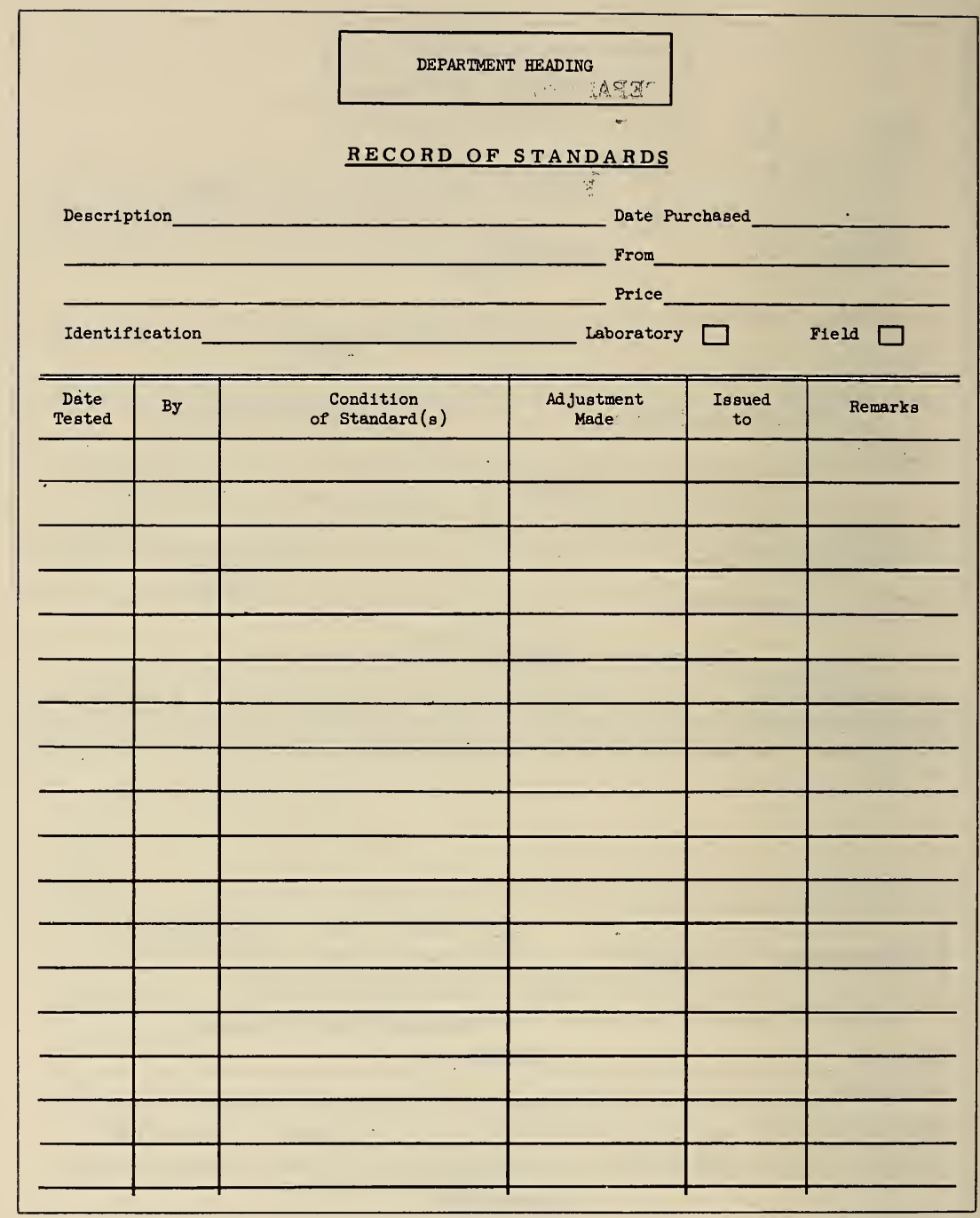

\section{Figure 12. Record of Standards.}

(Suggested size of form $8^{\prime \prime} \times 101 / 2^{\prime \prime}$ ) It is suggested that a weights and measures office have as a permanent record the history of all of its field and office standards. This form may be used so that a detailed record may be kept of each standard or set of standards. A separate form should be prepared each time a new item of equipment is purchased. Entries on the form should be made each time the equipment is tested or examined. 


\section{INSPECTOR'S EQUIPMENT INVENTORY}

Inspector

Date

Prepared by

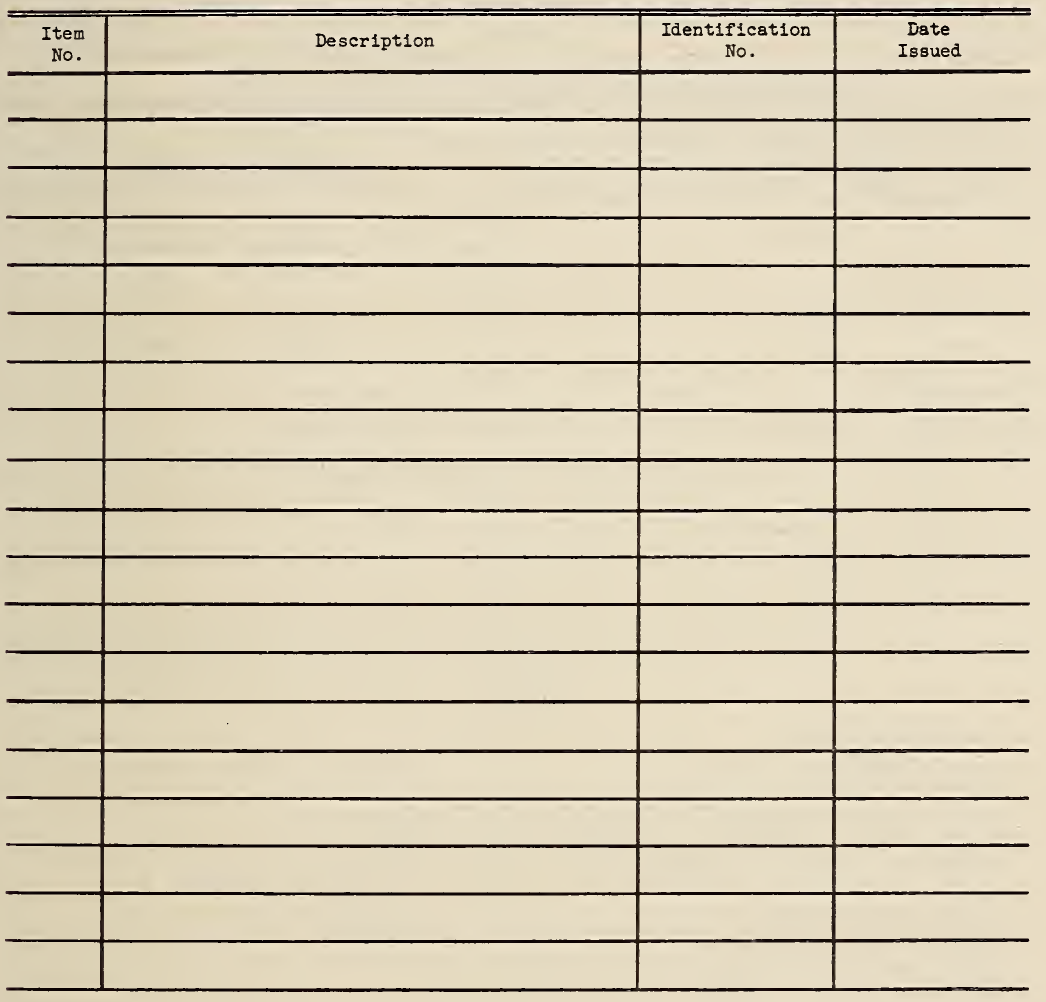

FIGURE 13. Inspector's equipment inventory.

(Suggested size of form $8^{\prime \prime} \times 101 / 2^{\prime \prime}$.) It is considered important that both an inspector and the office from which he operates have a detailed record of the equipment assigned to him.

This form is designed to facilitate such a record. Appropriate entries should be made on the form for each item that has been assigned to an inspector. A set of weights (31 pounds total) may be listed merely as one (1) set Class C test weights, 2 lb to $1 / 16 \mathrm{oz}$. 


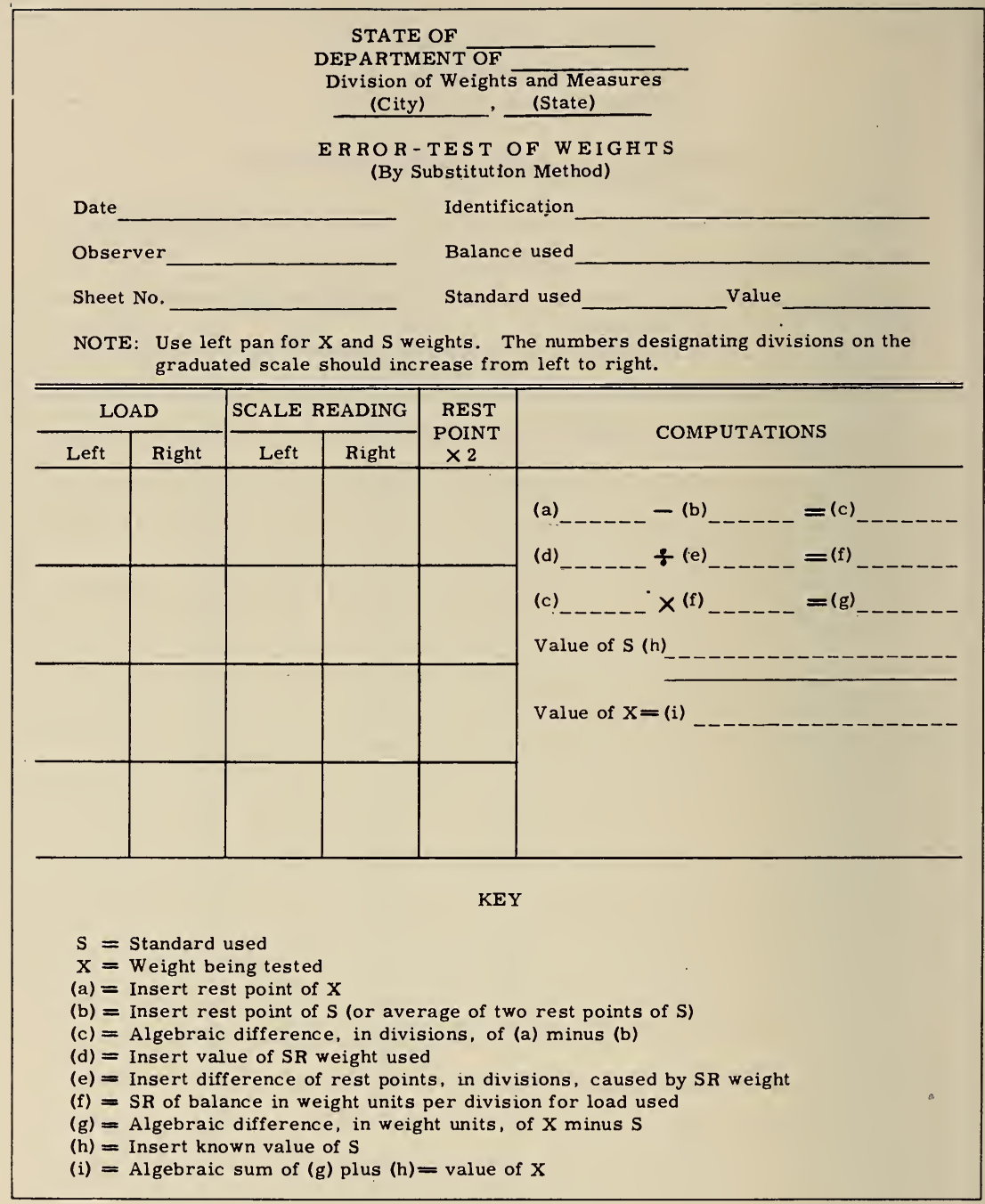

\section{FIgURE 14. Error-test of weights.}

(Suggested size of form $8^{\prime \prime} \times 10^{1 / 2 "}$ ") This form may be used to record the "error-test" of weights, which test is applied when it is desirable to determine the precise error of the weight. In order that each step in the computation can be easily followed, this form has been devised with keyed-in explanations and instructions. The National Bureau of Standards has developed two films, "Testing Mass Standards by Substitution" and "A True Standard." These films describe in detail the purpose and intended use of this form. 
STATE OF

DEPARTMENT OF

Division of Weights and Measures

(City)

(State)

TOLERANCE-TEST OF WEIGHTS

(By Substitution Method)

Date

Identification

Observer

Sheet No.

Standard(s) Used

NOTE: Use left pan for standards and weights being tested.

\begin{tabular}{|c|c|c|c|c|c|c|c|c|c|}
\hline \multicolumn{2}{|c|}{ Load } & \multicolumn{2}{|c|}{$\begin{array}{r}\text { Apparent } \\
\text { Rest Point }\end{array}$} & \multirow[t]{2}{*}{ Action } & \multicolumn{2}{|c|}{ Load } & \multicolumn{2}{|c|}{$\begin{array}{l}\text { Apparent } \\
\text { Rest Point } \\
\end{array}$} & \multirow[t]{2}{*}{ Action } \\
\hline Left & Right & Left & Right & & Left & Right & Left & Right & \\
\hline & & & & & & & & & \\
\hline & & & & & & & & & \\
\hline & & & & & & & & & \\
\hline & & & & & & & & & \\
\hline & & & & & & & & & \\
\hline & & & & & & & & & \\
\hline & & & & & & & & & \\
\hline & & & & & & & & & \\
\hline & & & & & & & & & \\
\hline & & & & & & & & & \\
\hline & & & & & & & & & \\
\hline & & & & & & & & & \\
\hline & & & & & & & & & \\
\hline & & & & & & & & & \\
\hline & & & & & & & & & \\
\hline & & & & & & & & & \\
\hline & & & & & & & & & \\
\hline
\end{tabular}

Remarks

Figure 10. Tolerance-test of weights.

(Suggested size of form $8^{\prime \prime} \times 10^{1 / 2}$ ".) This form may be used by office or laboratory personnel to record the "tolerance-test" of weights by the substitution method of weighing. This test is made to determine merely whether a weight is within tolerance requirements. The National Bureau of Standards film, "Testing Mass Standards by Substitution," explains fully the purpose and use of this form. 
By K. C. Allen, Director, Special Research Division, Hobart Manufacturing Company, Dayton, Ohio

It is my intention to tell you about a product of the Hobart Manufacturing Co. that was developed to fill a need long felt by the industry and by the members of the National Conference on Weights and Measures. It is a fully automatic weighing, computing, printing, and label issuing system for the labeling of randomweight prepackaged products, and is the result of 22 years of research and development by Hobart and many previous years of similar work by the Dayton Scale Division of I.B.M., which division was acquired by Hobart just 22 years ago this month.

This system, designated as the model 2000, consists of three separate units - a scale, a computer, and a labeler. These units are mechanically separate, connected to each other by flexible electrical cables equipped with plug-in connectors, and are completely interchangeable. Because of this three-unit construction, the system is exceedingly flexible, so that it can be installed in the manner preferred by the user. By this, I mean, it can be set up for a right-toleft operation, a left-to-right operation, or, if space is very limited, the computer can be placed in a remote location.

The scale itself is quite similar in its weighing system to our present Project-O and cylinder types. We use the same Iso-Elastic springs, the same lever system, and actually have the same base and platter dimensions, the only dimensional difference being in the height. We thus are using a familiar well-tested weighing system, and by keeping the same base dimensions the system can be adapted to the space occupied by the scale in many existing installations.

The main difference between this scale and our previous ones is that we have installed what is technically known as a servomechanism, which can best be described as a unit similar in operation to power steering. Just as in power steering, where a light touch on the steering wheel causes a power unit to take over and do the work, the weight on the scale platter causes a motor to take over and do the work of moving the weight indicating dials and setting the electric weight read-out switches. Because of this use of a servo motor in the scale, the weighing system is relieved of the friction of driving any indicating devices. A weight placed on the platter has only to operate the lever system and cause it to move electric contacts.

This scale is equipped with the standard zero-balance and tareadjustment devices and provides dials to indicate the weight on the platter. In normal operation, these dials are used only for checking the balance condition and for making the tare adjustments, but are also available for use of the sealers in checking the scale. The capacity of the scale to be precise is 24.99 pounds, which offers a weight range for even the larger hams and turkeys.

The scale weighs and expresses its result in terms of pounds and hundredths of a pound, and in its operation delivers to the computer the weight information to the nearest hundredth of a pound, splitting at the half-hundredth. In this system the computed value is the result of the weight to the nearest hundredth of a pound multiplied directly by the price per pound, then expressed to the nearest penny. This permits the merchant, the customer, and the 
weights and measures official to verify the computations without having to first convert the ounces and fraction and "round off" that result.

Signs will be provided to be placed in the display area which show a sample label and inform the customer that the weight indication is in pounds and hundredths. Since the customers already understand our monetary system, this statement clearly conveys the new method of showing weight. The signs also give an example of the ease of verifying the computation of the label.

For the purpose of either testing the new scales with ounce weights or checking decimally marked packages on pound and ounce scales, conversion tables are available.

The computer is an electromechanical type of our own design. We selected this type rather than the electronic computers because of its low power requirements, its low heat dissipation, and its instant readiness for duty. This computer uses relays identical to those used in many automatic-dial telephone exchanges. As you know, such exchanges have been used for many years, and their components have been brought to a very high degree of perfection and reliability. This computer multiplies exactly as you do with a pencil and paper, using simple arithmetic. There are no approximations, and the machine precisely chooses the nearest cent to produce a mathematically correct result. As stated previously, any label can be readily checked by simple arithmetic.

The labeler prints the entire label, including the store name, the net weight, the price per pound, the total value of the package, the name of the commodity, the U. S. Grade if desired, and a two-letter code that can be used to indicate date, operator, or other data. The labeler employs a well-proved National Cash Register printing mechanism and commodity printing inserts, with which many of you are familiar.

The price-per-pound setting knobs are located on the labeler unit so as to facilitate the mechanical setting of the type for printing the price-per-pound on the label. These knobs simultaneously operate an electrical multiplication table which is connected through the cables to the computer.

Present units are designed for use in the prepackaging of meat, poultry, and cheese, and have a price-per-pound range of 0 to $\$ 1.99$, with no omissions, making a total of 199 prices plus the zero. These prices are set on three knobs, one for the dollar, one for the dimes, and one for the pennies.

Attached to the labeling machine, we have provided ejectors for automatically issuing the label. One is a heat-seal type, which receives the label face down on a thermostatically controlled hot plate, which activates the heat-sensitive adhesive. The label is held in place by a small retractable guard, and the operator has inerely to remove the package from the scale, apply the package to the ejector, and thus in one simple operation the label is attached to the package. The machine is so constructed that another label will not issue until the previous one has been removed. For those who prefer to wrap the labels inside the package, we have an alternate ejector that turns the label over and delivers it face up on the commodity to be wrapped. This unit also holds the label until the operator releases it through a trigger mechanism conveniently operated by the package, and is also interlocked to prevent the 
issuance of another label before the previous one has been removed.

Commodity printing inserts in a suitable rack are provided for printing the names of the various commodities on the labels.

The operation of the machine is very simple. To start weighing a new lot of products, the operator releases a commodity insert lock and removes the previous commodity printing insert. The correct commodity printing insert is selected from the rack and placed in the machine. The price-per-pound of the new commodity is then set on the knobs and the tare weight is offset by means of the tare knob and the weight dials on the scale.

With these three setup operations completed, weighing is started by placing the package on the platter. At this time, the green light on the scale, which has been on, will go out and remain out until the scale has come to balance and remained in balance for about $1 / 4$ second. When, and only when, this true balance has been obtained, the computer will read the scale, the green light will come on again, and the package can be removed and replaced with a second package. The scale then starts weighing the second package while the computer and printer are operating to produce the label for the first package. This label then issues and is held by the ejector until the operator is ready for it. Until such time as the label is removed, the computer is prevented from starting on its next operation. If during this time the scale has come to a true balance, the green light will remain unlit, but, when the previous label is removed, the light will light and the package can again be replaced, and the third weighing and second computation will be started. Thus, the weighing takes place as the operator is handling the previous package with no effort on the part of the operator except to watch for the green light and handle the packages accordingly. If the package is removed before the green light comes on, there is no operation of the computer and thus no label is produced. The package can then be reweighed in the usual manner.

This sequence of automatic operation will take place for all packages in excess of about $1 / 4$. pound, which is below the low limit for most prepackaged articles. The scale does not automatically print below this figure, as we do not wish to issue labels when the scale is in balance at zero or when the scale is being adjusted for tare. If it is desired to weigh packages below $1 / 4$. pound, this can be done by pressing the "start" button after the scale has come to balance. However, the "start" button will not be effective unless the scale is in balance.

For use in labeling a number of predetermined standard-weight packages, a repeat switch is provided. For example, the operator may have a number of 1-pound packages of bacon that have been weighed and guaranteed by the packer. To handle such commodities, the operator selects the correct commodity printing insert, sets the correct price-per-pound, and places a sample package on the scale. Since he does not know the correct tare but does know the correct net weight, he will then adjust the tare knob so that the scale dial indicates exactly one pound, for example. After this indication has been established, he can press the "start" button and get a correct label for this package. The repeat switch may now be operated and "repeat" labels will be issued as fast as they are removed from the ejector. 
From the discussion so far, it will be seen that we have reduced the operator's work to handling the packages across the scale and labeler, and at the same time have provided that the label is printed only when the scale is in balance. In addition to these safeguards, we have provided others.

A. The printing operation will be prevented and an error signal on the labeler will light if:

1. The "start" button is pressed with the scale in balance at a position back of or below zero.

2. A weight is placed on the scale in excess of its capacity of 24.99 pounds

3. The price-setting knobs are moved during the computation.

4. The price-setting knobs have been moved since the last computation and an attempt is made to obtain "repeat" labels.

B. A "change-price" light is also provided on the labeler, and this and the "Error" light will both come on and the printing operation will be prevented if:

1. The price-setting knobs are not properly set, but instead are in-between the correct settings.

2. If the price-setting knobs are not operated after the commodity printing inserts have been changed.

C. When the error light comes on, any further operation is prevented until the error condition is corrected and a reset button is pressed.

D. A third red signal light on the labeler is provided to warn that the paper supply is running low and that a new roll should be inserted.

From the above you can see that we have used sound tested principles and applied many safeguards in the design of this fully automatic-weighing, computing, printing, and label-issuing system.

I know these characteristics are of prime interest to you weights and measures officials.

To the buyer of prepackaged foods this equipment offers a clearly printed, easily verified label, produced by an automatic system.

We sincerely believe this unit to be a major step toward our common goal of the greatest possible accuracy in all commercial transactions. I am sure you will agree when you observe its operation in your various jurisdictions.

\section{DISCUSSION ON FOREgoING PAPER}

Mr. Slough: Assume a package bearing a label showing 1.38 pounds at 79 cents per pound, total price $\$ 1.09$. In your experience, how often will the checkout clerk charge $\$ 1.38$ for that package?

Mr. Allen: Since about February we have had test installations in Dayton, now totalling roughly 100 . To the best of my knowledge such a misreading as you mention has not happened, although it is possible. Misreading is also possible, of course, when the conditions are reversed and the value in terms of pounds is smaller than the selling price in terms of dollars. On our label the total price is shown in larger type than is used for weight or unit price and is boldly spotlighted across the top of the label.

Mr. NICOL: Are the several units separately interchangeable, and is their operation affected by changes in line voltage?

Mr. AlLEN: The units are 100-percent interchangeable. Operation is affected only by large voltage changes. The units will not operate at all if voltage drops far enough; the scale might not come to balance, relays might fail to function, or the register might not operate, resulting in no ticket being issued. I think the register 
requires a little more voltage than do the other units, so it would probably be the first to stop operating in case of a severe voltage drop, but the system is quite insensitive to normal voltage variations. In our tests at the factory, we have no difficulty with voltages varying through a range of 20 to 25 percent.

QUESTION: What testing procedure is recommended?

MR. ALLEN : What is of importance is what appears on the labels; if the values are within tolerance, I would say the system is performing satisfactorily. Using a conversion table giving decimal equivalents, which we supply, ounce and fractional-ounce weights can be used for testing. If at a given test load you want to get a second label, you can press the start button and cause a repeat operation, or if the scale mechanism is caused to oscillate through a considerable range it "thinks" another package has been applied and another ticket will be issued.

Mr. F. G. YARBROUGH : Can the computed money value be read without a label being printed?

Mr. Allen: No. Weight values can be read directly, but computed values can be obtained only by causing a label to be printed.

Mr. WATSON: What about a possible extension of unit prices above $\$ 1.99$ per pound?

Mr. AlLEN : If necessary, we can extend the unit-price range to any desired limit. Our present computer, however, prints only three digits, so $\$ 9.99$ is the greatest total money value that it will print.

Mr. LEvy: Have any tests been made to learn if the consumer understands the decimal-pound indications that replace the conventional indications in terms of pounds and ounces?

Mr. Allen: We have not undertaken anything that could be called a "test." Store managers are almost unanimous in reporting that their experience with the new machine has been wonderful. A very few customers ask for an explanation of the system and seem pleased when they understand it; we have yet to hear of a customer who did not like it.

(The Secretary read to the meeting a letter addressed to the Conference by Mr. J. Roy Jones. Upon motion of Mr. Baucom, the Conference authorized the Secretary to express to Mr. Jones its appreciation of his message.) 


\section{FOURTH SESSION-AFTERNOON OF WEDNESDAY, MAY 23, 1956}

\section{(C. A. Lyon, Vice President, Presiding)}

\section{SYMPOSIUM ON PACKAGED COMMODITIES}

RALPH Magoffin, Director, Bureau of Inspection, South Carolina Department of Agriculture, served as Moderator during the symposium.)

MR. MAGOFFIN : It has been most interesting to read in several newsletters of the great interest which this afternoon's discussion has already aroused, even while in its planning stage. This advance interest points up the importance of prepackaged commodities in the work of the weights and measures official-and it further indicates that the official wants to discuss and to reach decisions on the ever-increasing number of problems which he meets in that work.

A study of the published records of previous National Conferences shows the tremendous development of the prepackaged commodity and the perplexing questions which have been faced. We all know of the great technical advances and new developments which come upon us year by year, always multiplying and compounding, and no sooner has one problem been met than two more appear.

Here, today, we expect to consider some of these problems-not merely to listen to a published paper-but rather to enter into the subject realizing that the problems are not those of the weights and measures official alone, but belong to many agencies.

This afternoon's symposium presents to you eight speakers who will bring you some thought-provoking remarks with the principal object of bringing you into the discussion. The particular value of a symposium is in its open forum approach to each phase of the general topic. It fails in its purpose if there is no discussion. You may wish to consider the afternoon as a workshop in prepackaging problems - the real value of the day's accomplishment can best be weighed by your participation in the questions which will follow each presentation. We expect all of you to bring out various viewpoints, and by questions directed to the scheduled speakers, to clear up any areas of doubt which may exist.

STATISTICS IN QUANTITY CONTROL OF PACKAgES

By E. P. LEE, General Foods Corporation, White Plains, New York

Statistical methods are procedures for making better use of data as a basis for decisions. Decisions made with the assistance of statistical methods are, generally speaking, more often correct than otherwise, because the person making the decision is in a better position to know the degree of confidence he may have in his information.

A decision made without data is a guess. Frequently, the basis for decision is not written down, and yet experience or feeling guides us in the form of a hunch or educated guess. If our experience has been broad or our hunch is fortunate, the decision turns out satisfactorily. Some businesses are run that way-or at least they start out that way.

Generally, these businesses are the so-called one man shows where a particularly sensitive individual has apparently succeeded in stringing together enough correct decisions to offset his wrong 
ones. Actually, it is more likely that this unusual person is mentally weighing the information and data he has available. So long as he does not have to make important decisions on questions that are beyond his experience, he does pretty well. In this way, the engineer can make good "guesses" on engineering problems, the banker in finance, the foreman in production, or the diplomat in affairs of state.

Each of these people pool their experience and available information in making their guesses. If the experience is good and the information clear, the decisions are good. The problems arise when experience is lacking or information is difficult to interpret. Statistical methods are a means of evaluating experience and of interpreting numerical data so that decisions can be made with a predictable probability of being correct.

I do not know of anyone who likes to admit that his decisions were a:guess. We all want and recognize the need for better information. We are all aware of the difficulty of knowing every possible bit of information about our problem. When we feel relatively sure of our information, we drop the word guess and call our decision an estimate. An estimate is much more respectable for it implies that we have used logic and reason. The man who makes a guess savs in effect, "It looked good to me. I had a feeling it was right." The man who makes an estimate can point to a list of information and explain how each item affected his decision. When this list:is long or the estimate is supported by overwhelming evidence, we call it a fact. There is no clear-cut line between a guess, an estimate, and a fact. These three degrees of precision shade from one to another according to the degree of evidence we have that they are sufficiently true or accurate to be useful as a basis for decisions that will guide our future action.

Decisions about quantity are subject to these same degrees of uncertainty. The factory operator or the inspector who weighs one package and then decides that the filleir needs adjustment or that the lot of merchandise should be marked "off sale" may be right or he may be wrong. The one package weight and the degree it differs from the standard is part of the decision. The experience of the operator or the inspector is a second part of the decision. The question facing both persons is, "Do I have enough evidence to be sure? Is this decision based on a guess, an estimate, or a fact? If this is a guess, how many more packages should I test in order to have sufficient evidence to call it an estimate or a fact?" Statistical methods can help answer these questions if we can divide our information in such a way as to arrive at an answer to four additional questions:

1. How much variation in weight is there among the packages?

2. How many packages were tested?

3. How sure do we want to be before we call our guess an estimate or a fact?

4. How much difference is there between the standard and the average of the packages tested?

In attempting to answer question number one, we find that, without prior knowledge or experience, the measurement of one package is not enough. At least two measurements are needed before we have any evidence regarding the degree of variation within the lot. If we have two or more measurements, we can then calculate the root-mean square and get a value that will represent the 
variation. Fortunately, mathematics has shown that we can skip over this more complicated arithmetic and use the difference between the heaviest and lightest package in our sample. This difference is called the range of the sample, and when the range is multiplied by a factor to correct it for the size of the sample, we can get the same estimate of variation.

The number of packages tested is easily determined by making an actual count of them.

The third question is a bit more difficult to answer because it is usually decided as a matter of policy. The answer to the question "how sure do we want to be before we call our decision an estimate or a fact" usually takes the form of a statement such as: "I will accept as factual evidence of a difference, any difference between the standard and the average of the sample that is so large that it could have occurred only once in 100 times by chance alone."

It is general practice to take odds of 1 in 20 to 1 in 100 as evidence of a significantly good estimate. Odds less than 1 in 20, i.e. 1 in 10 , are considered to be getting too close to guessing to be useful.

The fourth question, the difference between the standard and the average of the sample, is determined by adding all the sample weights and dividing by the number of samples. This average value is then subtracted from the standard to obtain the difference.

So that we may see how these four values may be put to. use in arriving at decisions, let us examine the possible procedure of a manufacturer; and following that we can look at the way in which an inspector might use these four values.

In considering the problems of the manufacturer, we may, for the sake of example and at some risk of oversimplification, assume that the manufacturer has purchased and put into operation a new filling machine that runs at 100 packages per minute. He has employed one operator to run the machine, and, as part of her duties, the operator is asked to check package weights and adjust the machine. The operator has only two hands, so she checks the packages as often as possible and adjusts the machine according to what she finds. The packages that are not checked by the operator go on to the store with those that have been checked and the assumption is made that the unchecked packages are no better or no worse than those that were. Thus, the manufacturer or his plant manager says, in effect, "I cannot get perfect weights even if I were to 100 percent hand-weigh or check-weigh these packages. Neither will the customer pay the cost for that additional operation, so I will check a few of these packages, adjust the machine according to some plan, and take a risk on the rest."

The degree of risk this procedure involves will depend upon the average weight the manufacturer decides to put in the package and the degree of variation between the packages. Because the manufacturer is more concerned with the future production than with the past production, he must find a way of predicting the future variation and average in order to make his decisions and lay down rules for guiding the operator in her adjustment of the machine. To do this, he takes advantage of his past experience. Before he purchases the machine he will have drawn on his experience with his product under other circumstances, he will have compared the variation among his competitors' products, and he 
will have drawn on the experience of his equipment supplier and obtain from him assurances that his equipment will meet accepted standards of good packing practice. Because he wants to be sure, he will take steps to actually test the machine to determine if the equipment suppliers' assurances have been complied with.

To do this he will (1) get the equipment supplier service-man or his own best mechanic to adjust the machine so that it performs as near perfectly as possible, and (2) run the machine under carefully regulated conditions and determine the machine capability. To do this, he will take a series of small samples and compute the average for each sample and the difference between the heaviest and lightest package, which will give him the range for the sample. His sample sizes may vary from two to as high as ten packages. General practice indicates that five packages is probably the most efficient size to take. Each group of samples is taken consecutively as they issue from the filler. Each individual package is carefully weighed. The scales used in this weighing should have a sensitivity of not less than one-tenth the anticipated variation.

After 30 to 50 of these small sample groups have been taken and tested (a total of 100 to 300 individual packages), he will calculate the average for all groups combined and average all the ranges to obtain a grand average and an average range for all the test packages.

Package fill variation can then be estimated using the appropriate factor from table 1 . The average range divided by this factor will give the index of variation. Three times this index of variation will give him an estimate of the variation to be expected from his operation if it is maintained under perfect control. Using these values, he can construct a chart such as figure 16 , where he plots the average of all his samples at $B$ and points off three times the variation index below to locate point $A$ and three times the variation factor above $B$ to locate point $\mathbf{C}$. Other tables are readily available from which he can plot the curve between these points for any number of packages.

TABLE 1. Factors for estimating variation $(\sigma)$

\begin{tabular}{|c|c|}
\hline $\begin{array}{l}\text { Packages } \\
\text { in each } \\
\text { small sample }\end{array}$ & $\begin{array}{l}\text { Factor } \\
(\mathrm{d} 2)\end{array}$ \\
\hline $\begin{array}{r}2 \\
4 \\
5 \\
10\end{array}$ & $\begin{array}{l}1.128 \\
2.056 \\
2.326 \\
3.078\end{array}$ \\
\hline \multicolumn{2}{|c|}{ Variation estimate $\sigma=\frac{\text { Average range }}{\text { Factor } \mathrm{d} 2}$} \\
\hline \multicolumn{2}{|c|}{$\begin{aligned} \text { Between average } \pm 1.0 \sigma & =68.0 \% \\
\pm 1.5 \sigma & =87.0 \% \\
\pm 2.0 \sigma & =95.0 \% \\
\pm 3.0 \sigma & =99.7 \%\end{aligned}$} \\
\hline
\end{tabular}

Use of table 1 assumes that the weights are normally distributed symmetrically about the average. In my experience it is rare to find weights that are not essentially normally distributed. When the distribution is not normal, it will be found skewed in the direction of an abnormal number of underweights. This condition results when the forces tending to cause underweight have a greater 


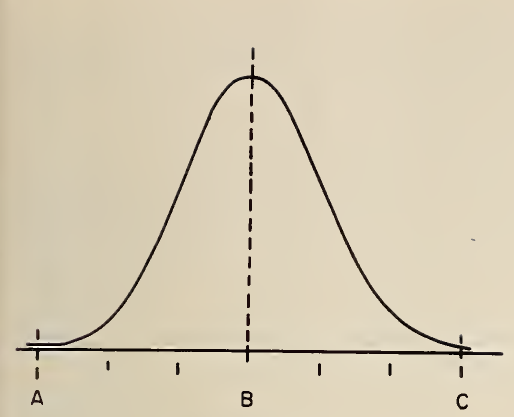

FIGURE 16.

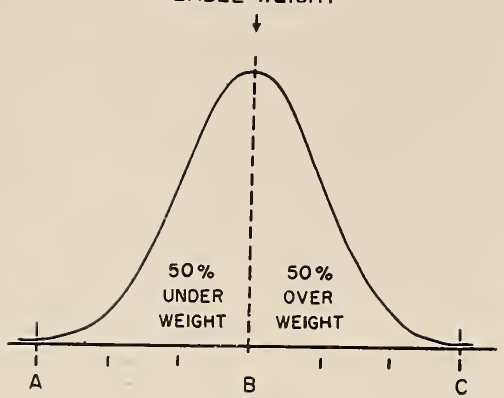

FIGURE 17.

Figure 18.

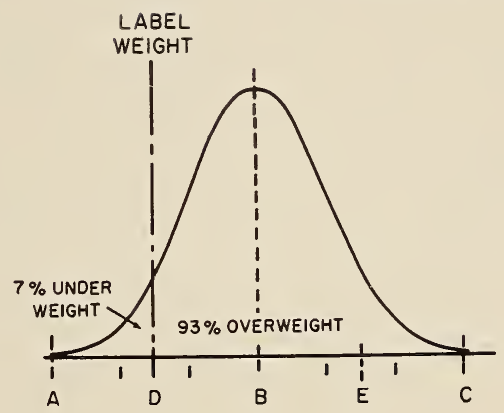

opportunity to come into play than do the forces which cause overweight. For example: when the hopper of a volume filler is not kept full, the measuring pocket may run only partially full. In this case, there is considerable opportunity for underweight with little or no opportunity for corresponding overweight. This condition is not often a serious problem and is easily corrected.

From this curve, he can say "if only the variations due to normal causes occur, then 99.7 percent of all weights will fall between $\mathrm{A}$ and $\mathrm{C}$ on the bottom line. In addition, the distribution of individual packages between $\mathrm{A}$ and $\mathrm{C}$ will range themselves in a pattern matching that of the curve." If the difference between the values $\mathrm{A}$ and $\mathrm{C}$ comply with the standards of good manufacturing practices, he can then proceed to the next step. If this value is larger than can be tolerated and will not meet the standards of good manufacturing practices, he must either change his machine or the method of handling his product in order to achieve better results. This variation will represent the best that he can attain with the particular machine, product, and process that he has set up.

Assuming that the process meets the standards of good manufacturing practice, his next decision is to decide where the average (B) (high point of the curve) should be with relation to the label weight of his package. From this curve, he can predict that when label weight is the same value as $\mathrm{B}$, then 50 percent of the weights will be over label weight and 50 percent will be under label weight (fig. 17). Also, he can in the same way estimate that if he moves the average higher so that label weight is at $\mathrm{D}$, half way between $A$ and $B$ (fig. 18) that 93 percent of the packages will be over 
label weight and 7 percent will be below label weight. Such a procedure would reduce the degree of underweight likely to occur as well as the number of packages. At the same time, such a decision will increase the average amount of product per package by an amount equal to the difference between $\mathrm{D}$ and $\mathrm{B}$.

The final decision may be to place the average anywhere between $\mathrm{A}$ and $\mathrm{B}$, depending upon the degree of control actually achieved and the cost of the excess product. There are some unofficial ways of assisting in this decision; however, space does not permit discussing them here. Basically, this is a policy decision the manufacturer must make in the light of special legal requirements, trade practices, and the economics of the particular situation.

Once the average weight has been decided upon, the problem then becomes one of how to tell what the actual average is during the filling operation. This must be done during the filling operation, for the risk of loss would be too great if the manufacturer waited until the end of the day or week and then found that a majority of the packages were either underweight or much heavier than expected. The process of keeping a more or less continuous check on the average frequently takes the form of a series of small samples and the plotting of the average for each sample (fig. 19). As indicated previously, the samples usually consist of four or five packages but may go as high as ten. One of the important reasons for taking the small samples is that they give a better estimate of the true average than one package alone. Yet they can be selected conveniently and weighed quickly. Samples of 50 or 100 packages would give a more accurate estimate of the true average, but the results would be delayed due to the time required for their weighing and averaging. In general, several small samples or groups are better than one large sample group for control purposes.

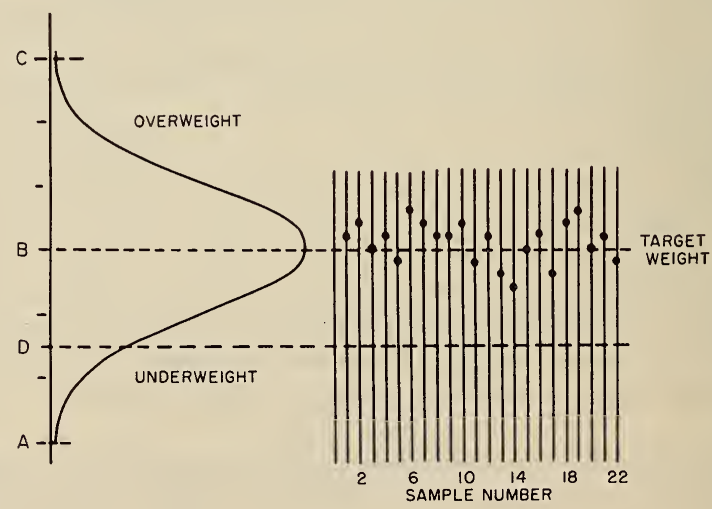

Figure 19. Average weight of sample packages. 
The series of averages plotted on the chart are a series of estimates of the true average. They are estimates bcause no one could be absolutely sure what the true average was unless every package were tested. Also, it is known that the average of a sample group of four packages will vary just as the individual packages did though the variation will not be so great. It can be demonstrated that the variation of the individual packages divided by the square root of the number of packages averaged together, for example the variation of the average of four packages, is one-half (square root of four) the variation of the individual packages.

Using this reasoning, the packer can establish rules for judging whether the estimate made on the basis of a small sample average shows only an expected normal chance variation or deviates more than normal and thus indicates that the filler should be adjusted. These rules take the form of two guide lines on a chart (fig. 20). The lines are located above and below the average decided upon in the previous stages. The distance above the average is half way between $\mathrm{C}$ and $\mathrm{B}$ if the sample size is four. The corresponding distance below $\mathrm{B}$ is at $\mathrm{D}$, half way between $\mathrm{B}$ and $\mathrm{A}$. The larger the sample size, the closer these guide lines will get to line B, the average decided upon. As long as the average for a single sample falls between these lines, or control limits, the operator can be reasonably sure that the true average has not changed and that, therefore, no adjustment needs to be made to the filling machine. If all the sample averages from a series of tests fall within control limits, the operator and the manufacturer can feel sure that operations are progressing normally; and they can predict that, so long as they continue to operate in the same way, future production will have the same average and the same degree of variation.

If, on the other' hand, one of the sample averages falls outside of the control limit, then an immediate adjustment is made, because this is considered to be proof that the true average is no longer at $\mathrm{B}$ but has moved either up or down for some reason. The chart in

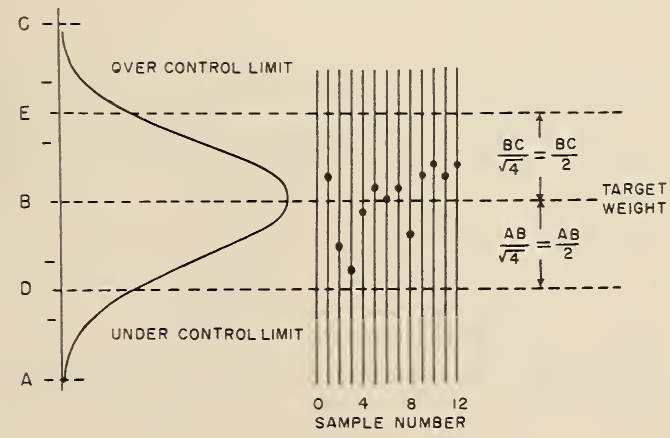

Figure 20. Control of limit line's. 
figure 21 has been made up to show how this operates. There are, of course, many reasons why an average may fall outside of the guide lines or control limits. I have indicated two of them on figure 21 in order to avoid giving you the impression that nothing of this sort ever happens. Each product and set of equipment has its own particular reasons. It is not always possible to determine the cause for an average falling outside of the control limits. However, when the cause can be found along with a means for removing it, or reducing its effect, then control will be improved.

As a final check, the manufacturer will periodically analyze his control records or take samples from the finished goods in his own warehouse to determine what the actual results of the control procedures have been (see fig. 22). The curve he makes from this

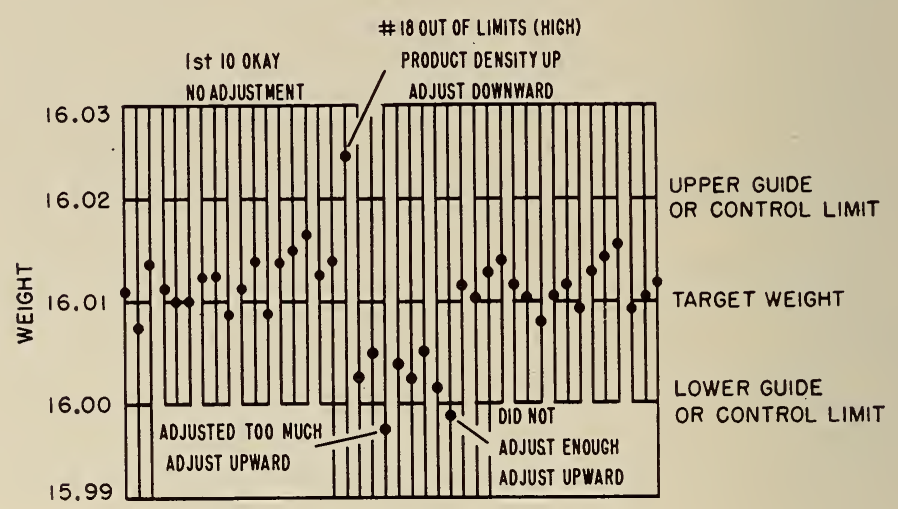

Figure 21. Control chart.

Sample size $=4$.

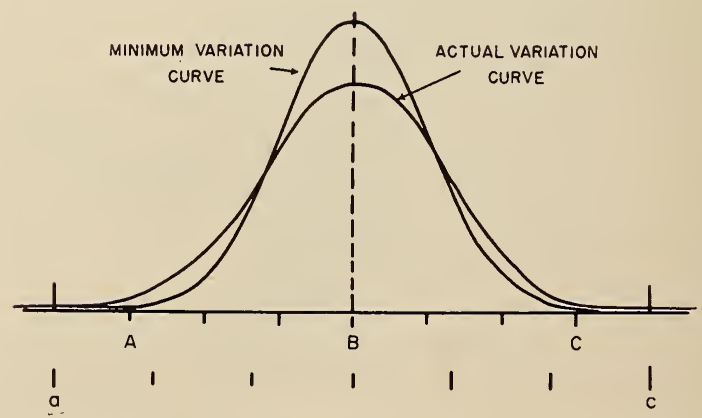

FIGURE 22.

A C curve, $\sigma=1.00$

a c curve, $\sigma=1.25$ 
inspection information usually shows points a and $c$ slightly farther apart than on the original curve (AC) that he made in establishing his target values. If the two curves have an almost identical shape and position, the manufacturer can be confident that the controls are working and that all major causes of variation have been eliminated. If he finds that the shape is the same but that it has moved either up or down the scale, he will then seek the cause by examining the scales and weights that he is using in his control procedures. If the second curve is flatter and more spread out than the original curve, he knows that an improvement is still theoretically possible and that, pending actual improvement, he should go back and consider revising his decision with regard to where the average should be maintained in relation to label weight. $\mathrm{He}$ will also check the distance between $a$ and $c$ on this actual performance curve and compare it with the standards for good packing practice.

It should be noted here that, because the ability to predict on the basis of this control limit assumes that the degree of variation remains constant, the manufacturer also maintains a watchful eye on the variation within each sample group. He does this by computing the range for each sample that he tests and plotting that on a similar chart. This chart is slightly different in that it has only an upper control limit.

In considering the possible application of statistical methods to the problems of the weights and measures inspector, we are confronted with a peculiar absence of generally accepted procedures. I am impressed by the thought that this may be a fertile field for you to discuss with the mathematics department of your State Universities. In the meantime, I would like to offer some of my personal thoughts on how you might proceed. Two important problems of the inspector would appear to revolve around two questions :

1. What size sample should I take?

2. Is the average of the lot I am inspecting below label weight?

Before attempting to comment on the questions, it is perhaps worthwhile to take a moment to discuss the question of sampling. A representative sample is essential to any predictions that may be made with regard to the average or to the general variation and character of the lot. In general, it is safe to say that only packages that have come from the same shipment or delivery should be included within a single sample. A warehouse that contains some old stock representing two different shipments by a manufacturer should have the two different lots sampled separately. Each brand and size of package should be sampled separately. Each lot of material should be sampled in such a way that every package has an equal chance of being selected. It is far better to select one package from each of 50 cases than it would be to check all the packages in each of three or four cases. This procedure is necessary in order to get a true picture of the condition of the lot and to avoid selecting only those packages which are on top of the pile or which may have been produced at a given moment in time. 
In doing your sampling, it will be far more efficient to make exact determinations of the package fill for each package tested rather than to merely classify it as over or under label weight. For a given degree of accuracy, it will require fewer tests if you make an actual determination of the fill. While on the subject of sampling, it should be recognized that no procedure based upon sampling can assure acceptance of only the good lots. Any sampling plan will permit occasionally the approval of a lot which is relatively poor and at the same time may result in rejection of a lot which is actually relatively good. The element of chance cannot be avoided in the drawing of a sample from a lot; consequently, the quality of the items in the sample may occasionally differ considerably from the true value of the lot.

Normally, the burden of proof is on the inspector if he questions the quality of the lot, and he must, therefore, reach some decision, as did the manufacturer, as to how sure he wants to be before he calls his estimate based on a sample a fact. Here again, it is customary to take the attitude that he should be 95 percent sure before making a definite statement. In some serious cases or where the question is particularly important, he may want to increase this assurance to 97.5 or 99 percent. These percentages correspond with chances of one in twenty, one in forty, and one in one-hundred. We will see later on that the level of assurance that you place on this value will have an important effect in the number of samples it is necessary to examine.

The number of samples it is necessary to check is intimately connected with the decision as to whether the lot meets label requirements or not. For this reason, I would like to discuss them together.

An eight-step procedure is suggested as follows. These steps will appear somewhat complicated; however, I believe that with a little experience you will find it will work out quite easily.

Step 1. Select at random 15 packages and weigh each carefully. Record these weights in the order the samples were taken.

Step 2. Divide 15 weights into 3 groups of 5 . For each group, subtract the smallest from the largest and record the difference as the range. Add the three ranges together and divide by three to get an estimate of the average range.

Step 3. Enter table 2 to estimate the total number of samples required. Table 2 is divided up into three parts. Each of the three parts covers a different confidence level. It will be necessary for the inspector or his superior to designate which part of the table is to be used in a particular situation. In the left hand column, locate the value of $R$ corresponding to the average $R$ computed from the three groups. If the exact value is not found in the table, use the next larger value.

Step 4. Move horizontally across the page to the right until you come to the column headed by the value of " $e$ " that you wish to use. "e" is the tolerance that you have decided to use in making your decision. The values of " $\mathrm{e}$ " are the same as those for $R$; i.e. if $R$ is in pounds, " $e$ " is also read in pounds. If $\mathrm{R}$ is in fluid ounces, "e" is also in fluid ounces. In selecting the value of "e" you will be saying, if the average weight of the sample is not short more than the value of "e", I will approve the lot. In the same way, you can say that if 
the average of the lot is short more than the amount "e", I will reject the lot. Under the selected value of "e", you will find the number of samples which should be tested in order to reach your decision.

(Note:-Table 2 is an approximation and will tend to overestimate the larger samples.)

Step 5. Proceed with your selection of samples and testing until the required number have been checked.

Step 6. After the entire sample has been weighed, or at least 50 packages, recheck the value of $R$ as in step 2. If the value of $R$ computed from the larger number of weighings is the same as you had estimated in step 2, your sampling has been completed. If the value of $R$ is found to be smaller than that originally estimated, more samples have been taken than necessary. This may be checked by referring again to table 2 . In the same way, if the value of $R$ on the recheck is larger than that originally estimated, you will have to re-enter table 2 and find out how many more samples it will be necessary to take.

Step \%. All the packages weighed in this sampling procedure should be totaled and their average fill computed.

Step 8. If the actual average of the sample plus the allowance " $\mathrm{e}$ " is equal to or in excess of label weight, the lot can be considered to meet requirements (table 3).

TABLE 2. Estimate of total sample size

\begin{tabular}{|c|c|c|c|c|c|c|c|c|}
\hline \multirow{3}{*}{$\mathrm{R}^{1}$} & \multicolumn{8}{|c|}{ A. $95 \%$ confidence } \\
\hline & \multicolumn{8}{|c|}{ Sample error, e } \\
\hline & 0.2 & 0.4 & 0.6 & 0.8 & 1.0 & 1.2 & 1.4 & 2.0 \\
\hline $\begin{array}{l}1.0 \\
1.5 \\
2.0 \\
2.5 \\
3.0\end{array}$ & $\begin{array}{r}31 \\
57 \\
89 \\
127\end{array}$ & $\begin{array}{l}22 \\
32\end{array}$ & & & & & & \\
\hline $\begin{array}{l}3.5 \\
4.0 \\
4.5 \\
5.0 \\
5.5\end{array}$ & $\begin{array}{l}194 \\
226 \\
288 \\
353 \\
426\end{array}$ & $\begin{array}{r}43 \\
57 \\
71 \\
87 \\
106\end{array}$ & $\begin{array}{l}19 \\
25 \\
32 \\
40 \\
47\end{array}$ & $\begin{array}{l}17 \\
22 \\
26\end{array}$ & 17 & & & \\
\hline $\begin{array}{l}6.0 \\
6.5 \\
7.0 \\
7.5 \\
8.0\end{array}$ & $\begin{array}{l}509 \\
595 \\
693 \\
793 \\
904\end{array}$ & $\begin{array}{l}127 \\
148 \\
173 \\
198 \\
226\end{array}$ & $\begin{array}{r}57 \\
67 \\
77 \\
88 \\
101\end{array}$ & $\begin{array}{l}32 \\
37 \\
43 \\
49 \\
57\end{array}$ & $\begin{array}{l}20 \\
24 \\
28 \\
32 \\
36\end{array}$ & $\begin{array}{l}17 \\
19 \\
22 \\
25\end{array}$ & $\begin{array}{l}16 \\
18\end{array}$ & \\
\hline $\begin{array}{r}8.5 \\
9.0 \\
9.5 \\
10.0 \\
10.5\end{array}$ & 1,019 & $\begin{array}{l}255 \\
286 \\
318 \\
354 \\
389\end{array}$ & $\begin{array}{l}113 \\
127 \\
142 \\
158 \\
173\end{array}$ & $\begin{array}{l}64 \\
71 \\
80 \\
88 \\
97\end{array}$ & $\begin{array}{l}41 \\
46 \\
51 \\
57 \\
62\end{array}$ & $\begin{array}{l}28 \\
32 \\
35 \\
40 \\
43\end{array}$ & $\begin{array}{l}21 \\
24 \\
26 \\
29 \\
32\end{array}$ & 15 \\
\hline $\begin{array}{l}11.0 \\
11.5 \\
12.0 \\
12.5 \\
13.0\end{array}$ & & $\begin{array}{l}428 \\
467 \\
509 \\
552 \\
597\end{array}$ & $\begin{array}{l}190 \\
207 \\
226 \\
245 \\
266\end{array}$ & $\begin{array}{l}107 \\
116 \\
127 \\
138 \\
149\end{array}$ & $\begin{array}{l}69 \\
75 \\
81 \\
88 \\
96\end{array}$ & $\begin{array}{l}48 \\
52 \\
57 \\
61 \\
67\end{array}$ & $\begin{array}{l}35 \\
38 \\
42 \\
45 \\
49\end{array}$ & $\begin{array}{l}17 \\
19 \\
20 \\
22 \\
24\end{array}$ \\
\hline $\begin{array}{l}13.5 \\
14.0 \\
14.5 \\
15.0 \\
16.0\end{array}$ & & $\begin{array}{l}644 \\
693 \\
742 \\
796 \\
906\end{array}$ & $\begin{array}{l}285 \\
307 \\
330 \\
353 \\
402\end{array}$ & $\begin{array}{l}161 \\
173 \\
185 \\
199 \\
226\end{array}$ & $\begin{array}{l}103 \\
111 \\
119 \\
127 \\
144\end{array}$ & $\begin{array}{r}71 \\
77 \\
83 \\
88 \\
101\end{array}$ & $\begin{array}{l}53 \\
57 \\
60 \\
65 \\
74\end{array}$ & $\begin{array}{l}26 \\
28 \\
30 \\
32 \\
36\end{array}$ \\
\hline
\end{tabular}


TABLE 2. Estimate of total sample size-Continued

\begin{tabular}{|c|c|c|c|c|c|c|c|c|}
\hline \multirow{2}{*}{$\mathrm{R}^{1}$} & \multicolumn{8}{|c|}{ Sample error, e } \\
\hline & 0.2 & 0.4 & 0.6 & 0.8 & 1.0 & 1.2 & 1.4 & 2.0 \\
\hline $\begin{array}{l}1.0 \\
1.5 \\
2.0 \\
2.5 \\
3.0\end{array}$ & $\begin{array}{r}21 \\
47 \\
85 \\
135 \\
192\end{array}$ & $\begin{array}{l}22 \\
34 \\
48\end{array}$ & 21 & & & & & \\
\hline $\begin{array}{l}3.5 \\
4.0 \\
4.5 \\
5.0 \\
\mathbf{5 . 5}\end{array}$ & $\begin{array}{l}285 \\
342 \\
434 \\
534 \\
643\end{array}$ & $\begin{array}{r}65 \\
85 \\
108 \\
133 \\
161\end{array}$ & $\begin{array}{l}29 \\
38 \\
48 \\
59 \\
71\end{array}$ & $\begin{array}{l}16 \\
21 \\
27 \\
33 \\
40\end{array}$ & $\begin{array}{l}17 \\
21 \\
25\end{array}$ & 18 & & \\
\hline $\begin{array}{l}6.0 \\
6.5 \\
7.0 \\
7.5 \\
8.0\end{array}$ & $\begin{array}{r}769 \\
898 \\
1,046\end{array}$ & $\begin{array}{l}192 \\
225 \\
262 \\
299 \\
342\end{array}$ & $\begin{array}{r}85 \\
100 \\
116 \\
133 \\
152\end{array}$ & $\begin{array}{l}48 \\
56 \\
65 \\
75 \\
85\end{array}$ & $\begin{array}{l}31 \\
36 \\
47 \\
48 \\
55\end{array}$ & $\begin{array}{l}21 \\
25 \\
29 \\
33 \\
38\end{array}$ & $\begin{array}{l}18 \\
21 \\
24 \\
28\end{array}$ & \\
\hline $\begin{array}{r}8.5 \\
9.0 \\
9.5 \\
10.0 \\
10.5\end{array}$ & & $\begin{array}{l}385 \\
433 \\
481 \\
534 \\
587\end{array}$ & $\begin{array}{l}171 \\
192 \\
214 \\
237 \\
261\end{array}$ & $\begin{array}{r}96 \\
108 \\
120 \\
133 \\
147\end{array}$ & $\begin{array}{l}61 \\
69 \\
77 \\
85 \\
94\end{array}$ & $\begin{array}{l}43 \\
48 \\
53 \\
59 \\
65\end{array}$ & $\begin{array}{l}31 \\
35 \\
39 \\
44 \\
48\end{array}$ & $\begin{array}{l}17 \\
19 \\
21 \\
23\end{array}$ \\
\hline $\begin{array}{l}11.0 \\
11.5 \\
12.0 \\
12.5 \\
13.0\end{array}$ & & $\begin{array}{l}646 \\
704 \\
769 \\
833 \\
902\end{array}$ & $\begin{array}{l}287 \\
313 \\
342 \\
370 \\
401\end{array}$ & $\begin{array}{l}161 \\
176 \\
192 \\
208 \\
226\end{array}$ & $\begin{array}{l}103 \\
113 \\
123 \\
133 \\
144\end{array}$ & $\begin{array}{r}72 \\
78 \\
85 \\
92 \\
100\end{array}$ & $\begin{array}{l}53 \\
57 \\
63 \\
68 \\
74\end{array}$ & $\begin{array}{l}26 \\
28 \\
31 \\
23 \\
36\end{array}$ \\
\hline $\begin{array}{l}13.5 \\
14.0 \\
14.5 \\
15.0 \\
16.0\end{array}$ & & 971 & $\begin{array}{l}432 \\
465 \\
498 \\
534 \\
607\end{array}$ & $\begin{array}{l}243 \\
262 \\
280 \\
300 \\
342\end{array}$ & $\begin{array}{l}155 \\
167 \\
179 \\
192 \\
219\end{array}$ & $\begin{array}{l}108 \\
116 \\
124 \\
133 \\
152\end{array}$ & $\begin{array}{r}79 \\
85 \\
91 \\
98 \\
111\end{array}$ & $\begin{array}{l}39 \\
42 \\
45 \\
48 \\
55\end{array}$ \\
\hline
\end{tabular}

C. $99 \%$ confidence

\begin{tabular}{|c|c|c|c|c|c|c|c|c|}
\hline $\begin{array}{l}1.0 \\
1.5 \\
2.0 \\
2.5 \\
3.0\end{array}$ & $\begin{array}{r}33 \\
72 \\
130 \\
204 \\
291\end{array}$ & $\begin{array}{l}17 \\
32 \\
51 \\
73\end{array}$ & $\begin{array}{l}22 \\
32\end{array}$ & 18 & & & & \\
\hline $\begin{array}{l}3.5 \\
4.0 \\
4.5 \\
5.0 \\
\mathbf{5 . 5}\end{array}$ & $\begin{array}{l}446 \\
519 \\
661 \\
810 \\
977\end{array}$ & $\begin{array}{r}99 \\
130 \\
164 \\
199 \\
244\end{array}$ & $\begin{array}{r}43 \\
57 \\
73 \\
91 \\
108\end{array}$ & $\begin{array}{l}25 \\
32 \\
40 \\
51 \\
60\end{array}$ & $\begin{array}{l}20 \\
27 \\
32 \\
38\end{array}$ & 22 & & \\
\hline $\begin{array}{l}6.0 \\
6.5 \\
7.0 \\
7.5 \\
8.0\end{array}$ & 1,169 & $\begin{array}{l}291 \\
340 \\
396 \\
455 \\
519\end{array}$ & $\begin{array}{l}131 \\
153 \\
177 \\
202 \\
231\end{array}$ & $\begin{array}{r}73 \\
86 \\
99 \\
113 \\
131\end{array}$ & $\begin{array}{l}46 \\
54 \\
64 \\
73 \\
83\end{array}$ & $\begin{array}{l}32 \\
38 \\
45 \\
51 \\
57\end{array}$ & $\begin{array}{l}22 \\
27 \\
32 \\
36 \\
41\end{array}$ & $\begin{array}{l}18 \\
20\end{array}$ \\
\hline $\begin{array}{r}8.5 \\
9.0 \\
9.5 \\
10.0 \\
10.5\end{array}$ & & $\begin{array}{l}584 \\
657 \\
731 \\
812 \\
892\end{array}$ & $\begin{array}{l}259 \\
291 \\
325 \\
361 \\
396\end{array}$ & $\begin{array}{l}146 \\
164 \\
183 \\
202 \\
223\end{array}$ & $\begin{array}{r}94 \\
105 \\
116 \\
130 \\
143\end{array}$ & $\begin{array}{l}65 \\
73 \\
81 \\
91 \\
99\end{array}$ & $\begin{array}{l}48 \\
54 \\
59 \\
67 \\
73\end{array}$ & $\begin{array}{l}22 \\
27 \\
29 \\
32 \\
35\end{array}$ \\
\hline $\begin{array}{l}11.0 \\
11.5 \\
12.0 \\
12.5 \\
13.0\end{array}$ & & $\begin{array}{r}982 \\
1,071\end{array}$ & $\begin{array}{l}436 \\
476 \\
519 \\
561 \\
609\end{array}$ & $\begin{array}{l}245 \\
267 \\
291 \\
317 \\
342\end{array}$ & $\begin{array}{l}158 \\
172 \\
186 \\
202 \\
220\end{array}$ & $\begin{array}{l}110 \\
119 \\
131 \\
140 \\
153\end{array}$ & $\begin{array}{r}80 \\
88 \\
95 \\
103 \\
111\end{array}$ & $\begin{array}{l}40 \\
43 \\
46 \\
51 \\
54\end{array}$ \\
\hline $\begin{array}{l}13.5 \\
14.0 \\
14.5 \\
15.0 \\
16.0\end{array}$ & & & $\begin{array}{l}654 \\
705 \\
756 \\
810 \\
922\end{array}$ & $\begin{array}{l}369 \\
398 \\
425 \\
457 \\
519\end{array}$ & $\begin{array}{l}236 \\
255 \\
272 \\
291 \\
331\end{array}$ & $\begin{array}{l}159 \\
177 \\
189 \\
202 \\
231\end{array}$ & $\begin{array}{l}121 \\
131 \\
139 \\
150 \\
169\end{array}$ & $\begin{array}{l}59 \\
64 \\
68 \\
73 \\
83\end{array}$ \\
\hline
\end{tabular}

1 Average range, 3 groups of 5 samples. 
TABLE 3. Sample inspection record

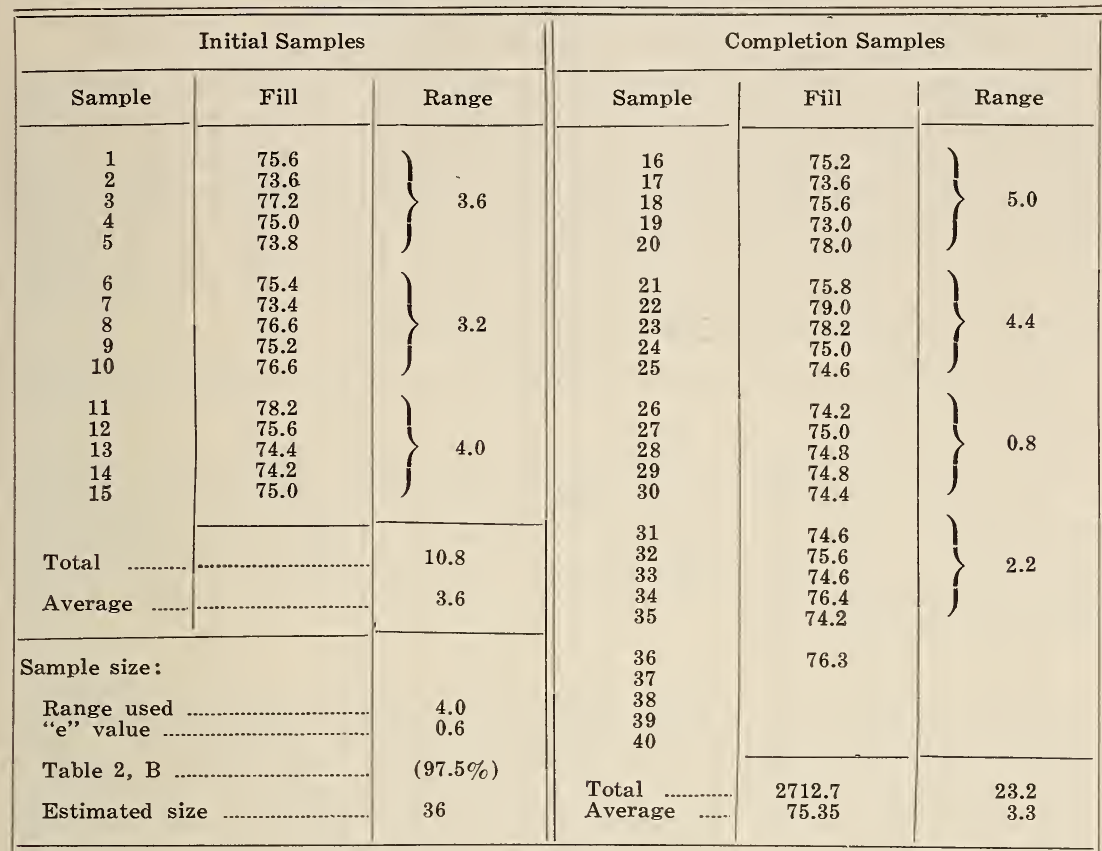

$75.35+0.6=75.95=$ Critical value.

Note-Final average range for 7 groups indicates table value of 3.5 could have been used and sample of 27 would have been enough.

Conclusion. These then are some ways of taking the guess work out of our judgments with statistical methods. All risk of error cannot be removed; however, we should make use of all the tools at our disposal first to understand how large the risks are and then to reduce them as much as practical.

If you are interested in pursuing the subject, I would suggest you send for the American Standards Association publications Z1. 1-1941, Z1. 2-1941, and Z1. 3-1943, and the American Society for Testing Materials "Manual on Quality Control of Materials."

Your local library will have some reference books. If you need assistance, check with your state or city university. These schools have given thousands of men from industry their start with short courses of one or two weeks. I am sure they would be glad to assist you.

Mr. BowEN : Can you explain what would be wrong with taking, say, a straight 10 - or 20 -percent sample?

MR. LEE: The use of a straight 10- or 20-percent sample certainly has the advantage of simplicity. The disadvantages are that, when dealing with small lots, 10 percent does not provide enough references. On the other hand, when dealing with large lots it will frequently involve taking more samples than necessary to get the sample that you want. In straight percentage selection you will find that, as you go from packages in a small lot to packages in a large lot, you will actually be applying an enforcement that will be severe in some cases and less severe in other cases. 
Mr. F. G. YARBROUGH : If a manufacturer can get all the information he needs from checking a sample of four or five, how do you explain the much bigger samples called for by your table?

Mr. LEE: I think the answer to this lies in the fact that the manufacturer actually has long experience with his product. The problem of the manufacturer is primarily one of keeping tabs on a process that he knows something about and is relatively stable. The inspector does not have that advantage. He does not know when he walks up to a pile of merchandise what its history is. He does not have the advantage of this previous data, and he must acquire additional information by taking a larger sample.

Mr. Соттом: Does not the sample size have to change with the size of the lot?

MR. LEE: I think if I were to give a single straight answer to that I would say, "No." You get your information from the number of packages that you weigh, and it does not make much difference whether they are selected from a lot of 1,000 or 10,000 . Your accuracy depends on the number that you take and not on the size of the lot particularly.

There may be problems, however, in taking a representative sample in a large lot. A representative sample is certainly essential to any prediction that you are going to make, and in that regard I would suggest that you try and isolate the lots that you are going to inspect by not mixing up shipments that have arrived several weeks apart. Sample the old stock and the new stock, but keep separate data on each. Sample each brand and size separately. The primary thing to remember in selecting these packages is that you should do it in such a way that every package has an equal chance of being selected. I would prefer you to take one package from each of 50 cases than to take most of them from one case. The object is to get as near a true picture of the lot as possible and to avoid taking just the top of the pile or just those packages that were produced at one moment in time.

Mr. Соттом: Would not a large error in particular packages upset that system?

Mr. LEE: Yes, you may hit one package that is exceptionally heavy or exceptionally light. It spreads the range out and calls for a larger number of samples. Unless you then increase the size of your sample substantially, you put the manufacturer who is doing the most accurate job of control and has the smallest range into the most critical position. The manufacturer who does a poor job of control and has a wide variation forces you to large sample sizes in order to tell for sure what he is doing. I would suggest that, in conjunction with any sampling of this sort, some procedure be set up to collect information with regard to these average ranges for different commodities and different manufacturers within a commodity group, because this average range will be a good estimate of what is good packing practice. The chap who has a range 2.1 times the average range of his industry can be suspected of not observing good manufacturing practices. I do not think it has ever been tried, but it is a possibility, and you can get your data from just such a thing as this. 
By J. W. D. Harvey, State Oil Laboratory, State of Georgia

The purpose of this presentation is to briefly outline the problems involved in checking the quantity of lubricating oil in sealed cans and to encourage, if possible, the development of a method whereby a larger number of containers may be checked in the field at the user's source. Incidentally, the same situation exists with other commodities such as hydraulic brake fluid, additive materials, and the like.

Probably the most common method in use at present to determine the quantity contained in sealed cans is based on a weight routine. A large number of cans are weighed on a simple equal-arm scale to determine the constancy of fill. The heaviest and lightest cans are removed from the lot and emptied, actually measuring the quantity of each separately. From this information and the weights of the well-cleaned empty cans, it is possible to calculate the quaritity in each container.

There are several objections to this method, and in my opinion they are substantial enough to warrant further consideration. One of the objections to the method arises from the determination of the tare weight, which is based on the weight of only two cans. A second objection is that the contents cannot be repackaged and usually will constitute a loss to the station operator, which, in the instance of high priced oils and some other commodities, may be fairly large. A further objection to this method is the fact that oils are packaged on a quantity basis rather than on a net weight declaration, and are canned according to their SAE viscosity, which is independent of actual specific gravity. A brief glance at the specifications and actual analysis records will serve to illustrate this point. The following table has been prepared to show the possible range in weights of 1 quart of oil.

TABLE 4.

\begin{tabular}{|c|c|c|c|}
\hline $\mathrm{SAE}$ viscosity & API gravity & $\mathrm{lb} / \mathrm{gal}$ & Range/qt \\
\hline 40 & $\begin{array}{l}21 \text { to } 29 \\
\quad 26 \text { average }\end{array}$ & $\begin{array}{l}7.727 \text { to } 7.341 \\
7.481 \text { average }\end{array}$ & $1.54 \mathrm{oz}$ \\
\hline 30 & $\begin{array}{l}20 \text { to } 29 \\
\quad 27 \text { average }\end{array}$ & $\begin{array}{l}7.778 \text { to } 7.341 \\
7.434 \text { average }\end{array}$ & $1.75 \mathrm{oz}$ \\
\hline 20 & $\begin{array}{l}23 \text { to } 32 \\
\quad 28 \text { average }\end{array}$ & $\begin{array}{l}7.627 \text { to } 7.206 \\
7.387 \text { average }\end{array}$ & $1.68 \mathrm{oz}$ \\
\hline
\end{tabular}

In table 4, the API gravity was obtained from actual analysis records, the weight per gallon from standard tables, and the possible variation in weight of 1 quart of oil of a given viscosity calculated. It is, of course, realized that with a given brand the range indicated will not be obtained with cans from the same lot, but, since various lots are usually found in the same location, it is probable that, to obtain the desired accuracy, the above method of testing must be carried out on a case-lot basis and a separate check made on each brand of oil of each viscosity. Thus, the number of cans that must be opened, drained, and actually measured multiplies rapidly, with an attendant increase in loss to the dealer, as well as loss of time by the inspector. 
Thus far, we have discussed the present method and its deficiencies. At this point an alternative solution to the problem should be offered. Several possible answers have suggested themselves, but they have not as yet been investigated.

One of these is the use of X-rays or radioactive sources for locating the meniscus. With such a method the can could be placed on a base and the level of oil determined from a micrometer screw, the diameter of the can measured, and the quantity calculated or obtained from a prepared set of tables. The most obvious difficulty here arises from the fact that the diameter of the can is exceptionally large in comparison with the volume and necessitates extremely accurate oil level heights being measured. According to Handbook 44-2d Edition, the tolerance for 1-quart lubricating-oil bottles is 1.8 cubic inches. This would correspond on a typical oil can to a height difference of 0.15 inch. The measurement of the diameter of the container is less critical. For example, an error of .02 inch in measuring the diameter would result in an error of only 0.0015 cubic inch in volume.

While this method has been only outlined as a suggestion, it is hoped that it will encourage further thought on the matter, and that a method will evolve that will allow the checking of a larger number of samples than is now permissible.

The Georgia State Legislature has recently enacted statutes providing for analysis and quantity checking of hydraulic-brake fluid. This is basically an extension of the same problem.

\section{PROGRESS REPORT ON PACKAGING OF FLOUR}

By J. T. LyNCH, International Milling Co., representing Millers' National Federation, Washington, $D$. C.

On behalf of the members of the Millers' National Federation, I wish to express appreciation for this opportunity to report to you on the industry's activities in the past year relative to packageflour-weights and packing procedures.

This warm and friendly gesture on your part has been very heartening to our industry. It assures us of the continuation of a favorable and friendly climate in which to resolve our mutual problems. I want you to be assured that much has been done relative to the solution of these problems. A number of people have been working on it, and I will shortly report to you to this end, in detail.

Review. This attitude has characterized our relationships since 1953 , when our industry was first invited to discuss with you the subject of flour-package weights.

At that time, an executive of the Federation presented a paper to your 38th National Conference and outlined four major points for consideration as a possible solution to our common over-all problem. These recommendations appear on page 32 of the proceedings of that Conference and in the text of this report, so I will not repeat them now.

Subsequently, the Conference took action to appoint a Special Flour Committee to study these recommendations.

This committee initiated certain studies during the first year but made only an interim report to your 39 th Conference, which is reported beginning on page 58 of the proceedings. Early in 1955, the weights and measures members of the Special Flour Committee 
conducted a survey to determine the range of variations from stated weight which might occur in retail stores. Later the milling industry members, through the Millers' National Federation, surveyed packing and weighing methods, equipment, and controls. A final report was made to your 1955 National Conference. The recommendations appear on pages 87 to 93 of the report of that Conference.

Milling Industry Action. In May 1955, the Board of Directors of the Millers' National Federation adopted the following resolution, the full text of which appears on page 91 of the 1955 Conference Report.

1. To promptly inform the members of the industry of the developments reported by the milling members of the Special Flour Committee and of any recommendations made or actions taken by your 1955 Weights and Measures Conference.

2. To recommend that renewed and continued effort be made by all mills to constantly improve weighing and packing procedures and equipment to the end that weight variations in flour packages would be held to the lowest possible minimum and uniform accuracy of package weights be thus attained.

As a consequence of the Board's resolution, and subsequent discussion of it in full convention, the Federation went to work "full steam ahead" on the flour-package-weight problem.

Program of Information and Education. The Federation has no authority to control and does not attempt to control the practices and policies of its members in matters relating to the manufacture, packaging, sale, or pricing of their respective products. Rather, it is concerned with matters that affect the industry as a whole. In tune with this general responsibility it attempts to keep its members informed of developments of importance to the industry.

Thus, it became immediately apparent that the Federation could do its best job by stressing the seriousness of the packing and weighing problem to the industry, and by making use of all of its facilities to inform and educate the member mills.

Pertinent activities seem to fall naturally into two main areas:

1. Determination of actual packaging and weighing conditions currently existing and, at a later date, of improvements resulting from our program for action.

2. An informational and educational program consisting of a school, convention, and other speeches, articles in trade publications and other publicity, to apprise the mills of the weight situation, what they are required to do, and how to do it.

Let us quickly take a look at each of these areas.

Schools and Conventions. First an all day school was conducted at St. Louis on November 30, 1955 by the Millers' National Federation. It was called the "Flour Weights Conference" and 62 millers attended.

The program consisted of four principal subjects each fully presented and followed by a question and answer period, and concluded with an open forum. The four subjects were:

1. Reviews of the following:

a. Federal and State regulations as they apply to flour.

b. Flour-package-weights conditions existing in the industry.

2. Procedures for investigating and handling short weight complaints.

3. How to set up a practical weight control program which would result in getting an adequate over-all job done in any mill anywhere.

4. Exposition of available packing, weighing, and check weighing equipment. 
After the school, bound sets of the papers presented there were distributed to member mills. Thirty-two of the participating companies also circulated them to key operating personnel of their 90 mills.

Subsequently, another school in abbreviated form was run at the Convention of the National Soft Wheat Millers' Association in Louisville on January 13, 1956. Key executives of 50 mills attended this school. A third school was conducted at the Association of Operating Millers' Convention in Dallas, May 9. Eight hundred fifty millers attended this school.

Other School Activities. There also was participation in many other internal and external educational activities. For example, representatives of three of the largest milling companies attended the American Management Association's Weight Clinic at New York in July, 1955. As I recall, your Mr. John P. McBride was a featured speaker at this clinic.

Likewise, representatives of several mills attended the Missouri Weights and Measures Workshop in Jefferson City.

In addition, a number of companies have held special schools for their operating, packing and weighing personnel. For example, one company has covered the subject intensively at all of its annual operating division meetings and reviewed it several times at the weekly department head meetings, both at division headquarters and at each of its mills. Casual conversations with other mill personnel indicate many have followed similar internal programs.

Speeches. Addresses have been made before such groups as the Flour Mill and Grain Accountants Association, a seminar for milling students at Kansas State College, the Pacific Coast District of the Cereal Chemists, the Northwest District Convention of the Association of Operative Millers, and other similar industry groups.

Articles and Publicity. The trade press cooperated in providing both advance publicity and thorough news and editorial coverage of the weight problem and the schools. The "Hook-Up," a news bulletin of the Millers' National Federation, made repeated comments on the problem, the need for the school, and the program as planned. Subsequently, it reported on the major points covered at the school. At least seven key articles appeared in addition to many brief items.

The American Miller and Processer ran five key articles dealing at length with flour-weight control. The titles of these articles are listed in this report for your convenience:

Flour-Packing Weights.

Scale Errors Can Be Costly for Millers.

Flour-Package-Weight Control.

Package-Weight-Control Problems Outlined.

Louisville Listening Post For Soft Wheat Millers.

The Northwestern Miller and the Southwestern Miller, key news journals of our industry, likewise gave substantial coverage to the problem, the schools, and the subject matter. At least five key articles in each publication covered the subject at length. Probably every mill in the country subscribes to one or the other of these publications and many take both. Thus, very excellent dissemination of pertinent material was obtained. 
Progress on Package Weights Control. In view of these many and diversified informational and educational activities it is quite evident that we have made substantial progress.

It is not practical to attempt to list all the various primary and secondary results of these informational and educational efforts. However, here are a few of the more significant advances:

1. Thirty-two companies circulated copies of the papers presented at the various schools, to key personnel at their 98 mills.

2. Check weighing schools were conducted by 34 companies for their mill personnel.

3. Twenty-eight companies issued "other" informational bulletins on package-weight-control practices and related subjects.

4. Twenty-seven companies changed methods of weight checking and 16 changed methods of recording data.

5. Thirty-three companies stepped up their sampling programs and 19 assigned additional personnel to do weight checking.

6. Statistical quality control was introduced by 7 companies for checking packing weights.

At the time these data were compiled, new equipment had been delivered or was on order by many companies. For example:

Types of equipment

Number of companies

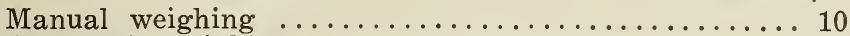

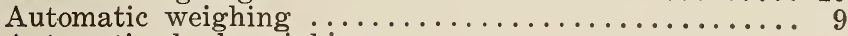

Automatic check weighing $\ldots \ldots \ldots \ldots \ldots \ldots \ldots \ldots$

Manual check weighing ...................... 10

As previously indicated, this list of advances is not all inclusive. It does indicate, however, that many opportunities for improvements were revealed and constructive action promptly taken.

Next Step. The Millers' National Federation pledges a continuation of its educational and informational activities. For example, it will publicize to all its members our discussions here today.

Also, the members of the milling industry who have served on, or in close relationship to, the Special Flour Committee will continue to consult and advise with other mills. For example, one member recently has assisted three mills with specific information on the installation and use of statistical quality control programs for flour-package-weights. Another has assisted several mills in installing procedures for investigating and handling reported instances of short weights.

Many other members of the industry have helped via talks at various industry meetings or by correspondence with various mills. We are confident that all of these executives and many others will continue to work on this problem.

Generally, our industry will be doing all it can to further tighten and improve its packing and weighing controls. Thus, we hope to insure that all packages leaving the mill are at full net weight and in properly sealed packages and containers.

How You Can Help. You can help us move our program along in three principal ways:

1. By concentrating weight checking at mills, warehouses, and other primary storage and distribution points.

2. By advising us quickly and fully of any suspected short weights encountered. You will aid us greatly if you will tell us brand. names, package size, code, where and when picked up, the weight noted, the moisture content, and the present location of the packages and their disposition.

3. By withholding any publicity until the mill affected can investigate and promptly report back to you. Thus, you will have all the facts in hand on which to base any action you may elect. 
Our industry acknowledges gratefully the cooperation you have extended us. We ask that you continue extending it along the lines just outlined.

Conclusion. In concluding, let me say again that the milling industry greatly appreciates this opportunity to report to you on our progress in the area of flour-weight-control.

Let me reiterate, that we intend to broaden and continue our activities.

Both you weights and measures officials, and we millers are dealing with a product possessed-like the weather-of irritating propensities. The hygroscopic nature of flour and of the atmosphere in which we live has caused much grief to all of us.

Mark Twain once quipped "Everybody complains about the weather but nobody does anything about it."

Gentlemen, we cannot change the nature of flour any more than you can change the weather, but, believe me, our industry is doing something about the flour-weight problem.

Mr. MORTON: When you pick up a 4-pound bag of flour that weighs 4 ounces short, what can you think?

MR. LYNCH : I think there must be something wrong with it. Tell us about it right away. We mean it sincerely. Millers seem to fall in three categories. Those who honestly try, but moisture trips them up. The second group is the miller who has variations, but such variations are unavoidable in good practice. There is a third group, and I hope they are in the minority, who may have underpacked deliberately. These should be given the penalty prescribed by law.

MR. BECK: We have found that sifting is quite a problem. In the majority of the cases we attributed the shortage to sifting where the bag is folded rather than to loss of moisture. Would it be practical to package flour in some other kind of container?

MR. LYNCH: That is a good point and one that we had in mind when I mentioned insuring all packages to be full net weight when they leave the miller. The problem of sifting is one which seems to apply to bags folded over at the top. We have several experiments going and we hope to find a solution.

Mr. Dimase: How much loss of moisture do you expect in a 2-pound bag of flour?

Mr. LYNCH : I will ask Mr. Oudal to answer that.

MR. OUDAL: Moisture can vary in any size package. It depends on the length of time stored, humidity, etc. Recently, we have had instances where flour has been returned or at least checked in outlets where the moisture content in the heated storage season, January, February, and March, was down as low as 8 to 9 percent. That is about the extreme. I would hazard a guess that, on an average, in most flour samples, after they have been out on retail shelves during seasons of the year when they are exposed to some evaporation loss, and that is the majority of the seasons, the average moisture content would be around 10 or 12 percent. That would represent a loss in the neighborhood of 2 percent. Customarily most flour at the time of milling and packaging is around 13.5 or 14 percent moisture. Let us say you have a loss of 2 percent. In a 5-pound bag a 2-percent evaporation loss would be a little over one ounce and a half. In a 10-pound bag it would be something over three ounces. 
QUESTION : I am wondering if the millers could use a uniform code on their packaging so when the inspectors pick up a package they would have an idea of when this flour was packed.

Mr. OUDAL: That has not occurred to me frankly, but I would be happy to carry it back to the Federation. You would suggest some system such as a letter of the alphabet, to indicate the month the flour was packed? That is, so you could know whether it was 1 month old or 7 months old.

MR. LYNCH: Unless Mr. Joyce or Mr. Oudal has something to add, I will take it as my responsibility to report that suggestion back to the Federation and see whether there is some practical way to solve that.

MR. TRAVIS: I would like to say from a retail point of view it would be extremely desirable in controlling rotation in stores.

MR. BAUCOM : Is the effect of evaporation in direct proportion to the area exposed?

MR. OUDAL: The shrinkage or evaporation is dependent on the conditions to which the flour is exposed. At 50 to 65-percent humidity it does not change much. If exposed to relative humidities lower than that, which prevail a great deal of the time, there will be some loss. The lower the humidity, and of course the longer the exposure, the greater the rate of loss. The rate of the exaporation loss is directly proportional to the area exposed, but eventually, if exposed long enough, either a 2- or 5- or 10-pound bag would come to the same moisture content.

Mr. BAUCOM: From a practical viewpoint, atmospheric exposure should have the same effect upon each and every bag exposed. We find an irregular variation in the field. I do not think we can charge all of the shortage to the weather conditions or storage conditions.

MR. LYNCH: In view of the improvements we have reported to you, I think that may not happen in the future.

\section{LEGIBILITY OF QUANTITY DECLARATION}

By K. L. Milstead, Federal Food and Drug Administration

I am happy to be here to observe the functioning of this organization, since I have always been greatly impressed with the enthusiasm and zeal with which weights and measures officials carry on their work. I have often thought that, if all public officials discharged their responsibilities with the same devotion, the people would indeed receive a "full measure" of return for the money invested to operate their Government. Perhaps the answer lies in the fact that you enforce laws and regulations that are as old as recorded history, for you will recall the laws of Moses contain this edict: "Thou shalt not have in thy bags divers weights, a great and small; thou shalt not have in thy house divers measures, a great and a small; but thou shalt have a perfect and just weight, a perfect and just measure shalt thou have."

It has always been the concern of the State that its citizens not be cheated. Your laws and regulations are based on this fundamental philosophy, as is the quantity of contents requirements in the Federal Food, Drug, and Cosmetic Act. All of you are familiar with the requirement of the Federal law that the label of foods, drugs, devices, and cosmetics in package form bear an accurate statement of the quantity of contents in terms of weight, measure, or numerical count. 
Perhaps you are not so familiar with another provision that is concerned with how the net weight or net volume statement appears on the label. This provision reads: "A food (or drug, or cosmetic, or device) shall be deemed to be misbranded if any word, statement, or other information required by or under authority of this Act to appear on the label or labeling is not prominently placed thereon with such conspicuousness (as compared with other words, statements, designs, or devices in the labeling) and in such terms as to render it likely to be read and understood by the ordinary individual under customary conditions of purchase and use."

This requirement is closely related to other requirements of the Act which state that the labeling of foods, drugs, devices, and cosmetics shall not be false or misleading in any particular. If the quantity of contents statement appears inconspicuously or in such a manner as not to be understood, it is likely that the consumer will be deceived. There is one interesting reported case based on this theory which I will discuss later.

In an effort to give you a little more background on the requirements of the Act covering the conspicuousness of required labeling statements, I have reviewed the legislative history of the law, but have failed to find any discussion of these requirements. It can be assumed therefore that there was no disagreement by the Members of Congress over these requirements and that it was taken for granted that whatever is required to appear on the label of a food, drug, device, or cosmetic will appear thereon in such a manner that it can be easily located and readily understood by the ordinary purchaser.

The general rules covering the prominence and conspicuousness of the quantity of contents statements are set forth in six paragraphs of a regulation. This regulation constitutes an excellent guide to compliance.

Neither the law nor the regulations specifically dictates how or where the quantity of contents statement must be placed on the label. The regulation points out the conditions under which the statement may lack that prominence and conspicuousness reauired by the law. These conditions are:

1. Failure to appear on the part or panel which is displayed under customary conditions of purchase. We believe the principal display panel or panels are usually the place where it should appear.

2. Failure to appear on all display panels when there are more than one. An example is a package bearing similar opposite display labels. The net contents statement should be on them both.

3. Failure of the package to bear a label of sufficient size for the prominent placing of the net contents statement. This means simply that the label should be large enough to carry the statement prominently. If a small label is used, a larger proportion of it may be required for the net contents statement than would be the case with a larger label.

4. The use of label space for words or design not required by the law. The net contents statement is required and should not be subordinated to other information not required.

5 . Use of label space to give greater conspicuousness to other information, design, or devices. We have no objection to the use of pictures or designs on labels, but a prominent place must be left for the net contents statement and other information required by the law.

6. Use of small type, insufficient background contrast, obscuring designs or vignettes, or crowding with other written, printed, or graphic matter. Bull'seying of brand name, trademark design, or other features is consistent with good packaging design to the extent that it does not interfere with the right and the ability of the consumer readily to see and read mandatory label information under conditions of purchase. 
Now these are the broad guiding principles under which we evaluate the prominence and conspicuousness of the net contents statement on labels. These principles are based on the fundamental concept that the people have a right to know how much they are buying when they purchase a package of a food, drug, device, or cosmetic, and they should not be required to search the label for this information.

While we have issued a considerable number of advisory statements on the application of these principles to specific types of packages, there have been few interpretative court decisions. Manufacturers in general have done a commendable job in designing their labels to comply with the spirit of the regulation. Unfortunately, there are still packages that do not comply with these regulations; however, we have not had the resources to institute many legal actions in the field. As our resources are increased, we hope it will be possible for us to proceed against the more flagrant violators.

I have been able to locate only two reported cases in which the Government charged that the net contents statement and other required information failed to appear prominently and conspicuously. A brief discussion of these two cases may be of interest.

The first was a seizure of Life Savers in which the Government charged that the quantity of contents statement and other information required by the Act to appear on the label did not appear conspicuously, since the required information was printed in such small type and on such a background as to be practically invisible. The claimant denied the charges and stated that it had been forced by shortage of materials due to the war to use lettering which was less conspicuous than its regular labels, but which was nevertheless the best it could do under the circumstances. This case did not go to trial, but the claimant consented to a decree because the label had been abandoned and the court found the goods to be misbranded. (See Food Notice of Judgment No. 14769).

The other action involved the product "Quenchies." Among other charges, it was alleged that the product was misbranded because the common or usual name of each ingredient contained in the article did not appear prominently on the label. This case went to trial and the court found that the Government failed to prove all the charges except the one regarding the conspicuousness of the ingredient statement. To this the court said:

But the label amounts to misbranding. If saccharin is to be used it should be so stated in sufficient size type so that it may be read as easily as other parts of the label. Here the printed word "saccharin" is so small that one is unable to read it without the aid of a magnifying glass. Section 403 (f) of the Act requires labeling in such terms as to render it likely to be read and understood by the ordinary individual under customary conditions of purchase and use. (See Food Notice of Judgment No. 18851.)

As mentioned earlier, there is one reported case where the charge was made that the manner in which the quantity of contents declaration appeared on the label was false and misleading. (See Food Notice of Judgment No. 19643.)

This case involved a seizure of frozen strawberries. The Government charged that the product was misbranded because the label statement "This one pound package serves four" was false and misleading as applied to a package containing less than one pound. 
There was also a charge that the package was deceptive. The front label of this frozen food package bore the marking "Net Weight $14 \mathrm{oz}$." The label on the side of the package bore the statement, "This one pound package serves four." In granting the Government's motion for summary judgment, the court said:

It seems plain to me that the label is ambiguous and liable to mislead a purchaser. A jury could not find otherwise on the evidence, viz., the labeled package itself. If a purchaser read only the front of the label, he would not be misled. If he read only the side of the label, he would certainly be misled. If he read both, he could only be confused. That to me means that the label may mislead or deceive a purchaser and is false and misleading within the language of Section 403 (a).

While these decisions support the fundamental philosophy of the law and regulation that whatever is required to appear on the label must appear in such a manner that it can be easily read and understood by the ordinary consumer, it should be borne in mind that it is a question of fact in each case as to whether or not the law is satisfied. I wish there were a formula by which we could determine whether the quantity of contents statement appears conspicuously on labels. When in doubt about a particular label we sometimes try it out on a number of disinterested individuals to obtain their reaction to it. A general agreement of a panel either for or against the conspicuousness of the wording is very helpful in arriving at an estimate as to what the ordinary consumer would think about it. In more controversial areas it may be necessary to support the opinion of the regulatory official with evidence obtained by public opinion research or public opinion surveys. This type of evidence is being used more and more in court proceedings where the nature of consumer reaction is all-important. We have used opinion survey techniques in several types of court cases where it was necessary to ascertain the reaction of the public to a certain set of facts. We have not yet used the technique to support action on violations involving conspicuousness of label statements, but we are almost sure to do so if there is any question about how the ordinary consumer would feel about a particular label. While we think that opinion research is the only method available to obtain reliable knowledge regarding the opinion of the public on a certain question, let me caution you that this work must be carried out by experts who are qualified by training and experience to conduct consumer opinion surveys. Otherwise, the results will not be admissible in court. This technique offers great possibilities for obtaining reliable information as to public opinion on questions where there may be a difference of opinion, and the Food and Drug Administration plans to utilize opinion research methods to guide us in controversial fields. You may also find the technique helpful to you.

In the short time available, it has been necessary to restrict my discussion on the requirements of the law on the legibility of the quantity of contents statement to general comments. We are always glad to comment on specific problems or labels, and we invite all of you to write us at any time about any question on which you would like our views. We are anxious to assist in every way we can to bring about full compliance with the spirit and letter of the law without legal action.

In closing, I would like to say that we in the Food and Drug Administration are proud of our relations with weights and meas- 
ures officials throughout the United States. As I stated earlier, we regret that we have not had the resources to do as much work on net weight as we would like to, but, as our appropriations increase, we hope that it will be possible to devote more attention to this type of violation.

You are doing an excellent job, and the legitimate industry and the American public are indebted to you for protecting them from fraud and from being cheated. With the continuously rising costs of consumer goods, your work assumes ever-increasing importance.

Mr. AUSTIN : Dr. Milstead, I would like to ask who conducts your opinion surveys.

Dr. Milstead: We have utilized several different universities. The U. S. Department of Agriculture has facilities we have used. Also there is the Bureau of Social Science Research of American University here in Washington that does a lot of work in that field. A large number of universities are developing facilities for opinion surveys in the Psychology Departments. We are utilizing those also.

Mr. R. E. MEEK: Is it necessary for the quantity of contents statement to appear on the container, or may it appear on a label or tag that is clipped or otherwise attached to the container?

DR. MILSTEAD: We think that a label or tag permanently or securely attached is satisfactory. It must be readily available to the consumer, and in such terms that he can read and understand it.

Mr. J. G. RoGERS : Dr. Milstead, the regulations at one time had a minimum size of print. Does that still maintain?

DR. MILSTEAD: There is nothing in the regulations now, except that the statement of quantity must appear conspicuous so that it can be read with ease.

MR. BECK: Is the statement blown in the bottle sufficient as a quantity of contents statement?

DR. MilsteAD : This comes back to the question of whether it is conspicuous and can be read. Generally we have frowned on the "blown in the bottle" type of label. It usually does not meet the requirements.

QUESTION: Are qualifying statements such as "average weight when packed" acceptable?

Dr. Milstead: The Food, Drug and Cosmetic Law requires that the package bear a full weight when introduced in interstate commerce. If the purpose of "when packed" is an effort to avoid jurisdiction under the law, it would not. The law requires the package to have full weight when shipped. That statement would have no effect or meaning.

Mr. Rowe: The Model State Law on Weights and Measures also rules that out.

Mr. William Miller: Let us take an instance of a package weighing 12 ounces. It is marked .75 pound. Would you approve that?

Mr. Rowe: We have as yet no indication of consumer reaction on such a declaration. There does not seem to be any objection, but whether or not anybody would be misled we do not know. If it is misleading, it may be in conflict with the Federal Food and Drug Law. The regulations provide for declarations in decimal fractions of pounds and ounces so long as no more than two figures to the right of the decimal point are given. 
Mr. R. E. MEEK: What would be your view with regard to the use of plus or minus signs on packages of commodities labeled 13 ounces minus?

DR. MILSTEAD: The law requires an accurate statement of the contents. Any statement plus or minus something would really have no meaning.

\section{ACCURACY REQUIRMENTS FOR QUANTITY DECLARATION}

By J. C. Pearson, Federal Food and Drug Administration

The Food and Drug Administration, of the Department of Health, Education, and Welfare, is responsible for the enforcement of five Federal statutes. Only one of these-the Federal Food, Drug, and Cosmetic Act-requires a declaration of net contents. However, any article subject to either of the other acts must comply with the net content requirements of the Food, Drug, and Cosmetic Act if it is also subject to that Act.

The Food, Drug, and Cosmetic Act includes a prohibition against the introduction or delivery for introduction into interstate commerce of any food, drug, device, or cosmetic that is misbranded. The Act states that any article of such products, if in package form, shall be deemed to be misbranded unless it bears a label containing an accurate statement of the quantity of contents in terms of weight, measure, or numerical count; provided that reasonable variations shall be permitted, and exemptions as to small packages shall be established by regulations prescribed by the Secretary. These regulations have the force and effect of law.

Regulations promulgated for foods, drugs, devices, and cosmetics vary only in minor respects. They are set forth in reprints of the Act, which are obtainable from the Food and Drug Administration, or in quantity from the U. S. Government Printing Office. However, they are too lengthy to be quoted in full here.

The regulations with respect to foods provide, in part, that the statement of the quantity of contents shall reveal the quantity of food in the package, exclusive of wrappers and other material packed with such food. The net contents statement shall be expressed in terms of weight, measure, numerical count, or a combination of numerical count and weight or measure, which are generally used by consumers to express quantity of such food and which give accurate information as to the quantity thereof. But if no general consumer usage in expressing accurate information as to the quantity of such food exists, the statement shall be in terms of liquid measure if the food is liquid, or in terms of weight if the food is solid, semisolid, viscous, or a mixture of solid and liquid; except that such statement may be in terms of dry measure if the food is a fresh fruit, fresh vegetable, or other dry commodity.

A statement of weight shall be in terms of the avoirdupois pound and ounce. A statement of liquid measure shall be in terms of the United States gallon of 231 cubic inches, and quart, pint, and fluid ounce subdivisions thereof, and, except in the case of frozen food which is so consumed, shall express the volume at $68^{\circ} \mathrm{F}$. A statement of dry measure shall be in terms of the United States bushel and peck, dry quart, and dry pint subdivisions thereof; or in terms of the United States standard barrel and its subdivisions of third, half, and three-quarters barrel. 
Unless an unqualified statement of numerical count gives accurate information as to quantity of food in the package, it shall be supplemented by such statement of weight, measure, or size of the individual units of the food as will give such information.

The statement shall express the minimum quantity, or the average quantity, of the contents of the packages. If the statement is not so qualified as to show definitely that the quantity expressed is the minimum quantity, the statement shall be considered to express the average quantity.

Where the statement expresses the minimum quantity, no variation below the stated minimum shall be permitted except variations below the stated weight or measure caused by ordinary and customary exposure, after the food is introduced into interstate commerce, to conditions which normally occur in good distribution practice and which unavoidably result in decreased weight or measure. Variations above the stated minimum shall not be unreasonably large.

Where the statement does not express the minimum quantity, variations from the stated weight or measure shall be permitted when caused by ordinary and customary exposure, after the food is introduced into interstate commerce, to conditions which normally occur in good distribution practice and which unavoidably result in change of weight or measure. Variations from the stated weight, measure, or numerical count shall be permitted when caused by unavoidable deviations in weighing, measuring, or counting individual packages which occur in good packing practice, but these variations shall not be permitted to such extent that the average of the quantity in the packages comprising a shipment or other delivery of the food is below the quantity stated, and no unreasonable shortage in any package shall be permitted, even though overages in other packages in the same shipment or delivery compensate for such shortage. The extent of variations from the stated quantity of contents permissible in the case of each shipment or other delivery shall be determined by the facts in such case.

Let us consider the requirement of an accurate label statement of the quantity of contents with reasonable variations. This phrase, "with reasonable variations," has been widely discussed by industry and government, and has been the subject of court interpretation. The permitted variations in the regulations are of two general types:

(1) Deviations from the stated weight or measure caused by ordinary and customary exposure, after introduction of the food into interstate commerce, and

(2) variations in weight, measure, or count caused by unavoidable deviations in weighing, measuring, or counting conducted in accordance with good commercial practice.

The first type deals with packages which are not airtight. We are concerned here with moisture losses which we call normal shrinkage. Under the second type, where there is the customary declaration of contents, as mentioned earlier, the average packages comprising a specific shipment must not fall below the declared amount at the time of shipment, and no unreasonable shortage in any package is permitted even if compensated by overage in other packages. Where the minimum quantity is expressed, there is no allowance below the declared minimum. 
The problem of normal shrinkage has probably caused more difficulty and misunderstanding than any other factor. You will recall that recently the President of the National Conference on Weights and Measures, at the suggestion of the flour industry, appointed a committee to study the shrinkage of flour in order to obtain data regarding that problem.

Under the Federal Act it is mandatory that the product be full weight when offered for shipment in interstate commerce, regardless of when it was packed or how long it was held before shipment. Therefore, such words as "When packed" used in conjunction with the net contents statement have no significance so far as the Federal law is concerned. It is the responsibility of the shipper to see that the article is packed so as to be properly labeled when it comes within the jurisdiction of the Act.

After the shipment enters interstate commerce, allowances for normal shrinkage are made by the Food and Drug Administration. Recognition is given to the fact that the packer has little or no control of the conditions to which the product may be subjected once it is shipped in interstate commerce. The exact amount to allow in any case depends upon a number of factors, such as the type and size of package, the temperature and humidity of the atmosphere to which the article is subjected, the length of time in storage, and the type of product. These variables make it impossible to specify allowances for general application which would be fair and equitable to all concerned. Nevertheless, the Food and Drug Administration has accumulated shrinkage data for many years, and any Federal, State, or local food and drug official is welcome to look over the file of this material at any of our field offices. We are constantly adding data to this material. It is not in a form suitable for distribution. These data represent different products comprising a portion of regular commercial shipments where careful check was made of all factors which cause a loss of moisture content with resultant loss in weight of the product. They often afford a reliable basis for arriving at an allowance appropriate to a given set of circumstances.

The regulations state that the extent of variations from the stated quantity of contents shall be determined by the facts in each case. Manufacturers sometimes express the opinion that specific tolerance figures should be established for each product. It is my understanding that a few States have done some work along these lines. In interpreting the Federal law, the Food and Drug Administration has always regarded the proviso for "reasonable variations" as being of a general rather than of a specific nature. Here again we feel that what is good manufacturing practice must be the controlling factor in any given case.

Many years ago, in the Shreveport Grain and Elevator Company case (287 N. J. 77), and again recently in U. S. v. Badger Fruit and Extract Company (E. D. Wisc. No. 228 Crim. U.), the constitutionality of the net weight amendment was attacked on the grounds that it was vague and indefinite and did not meet the requirements of the Sixth Amendment that a defendant be informed of the nature and cause of the accusation. In both cases the constitutionality of the quantity of contents provision and regulations was upheld by the courts. In the latter case, the court frequently 
referred to the former U. S. Supreme Court opinion and in conclusion stated,

The Court believes that the regulations in question establish adequate standards permitting reasonable variations in fulfillment of the purposes and provisions of the Act.

In another case of U. S. v. The Merchants Biscuit Co: (D. C. Code (1924) the court stated,

There can be no doubt as to what the producer, or manufacturer, must do under that provision and it is not made uncertain because a "reasonable variation" shall be permitted. That does not mean that persons subject to the act do not have to be accurate in their representations, and they do not have to ascertain and affix the weight, measure, or numerical count at the time they put up the package, etc. It does mean that if, due to causes over which they have no control, an unavoidable variation occurs after the goods leave their possession, then the law is not violated if the variation is a reasonable one.

That part of the section which is attacked, therefore, imports common sense or the rule of reason into the Act, and does not require the impossible. But for this provision we might be compelled to hold it unconstitutional ... as imposing an intolerable burden, or impossible requirement.

I am aware that many State and local laws are not identical in all respects with the Federal law. It is my understanding that in 1953 this Conference adopted a Model State Law on Weights and Measures, which appears to be substantially the same as the Federal requirements. It would seem to me that it would be in the interest of all concerned to have uniformity in these statutes.

MR. ROBERT WILLIAMS: When a shipping package contains a number of individual packages, must those packages be labeled individually? Must the shipping packages bear the weight content also?

Mr. PEARSON: If the individual retail packages in a shipping carton are properly labeled, we do not think that it is necessary that the shipping carton also contain the mandatory labeling. It would, however, be helpful to the retailer to know that, for instance, there are 24 one-pound packages in a carton.

QUEsTion: Mr. Pearson, does your office ever make available for distribution the data which you have established as reasonable variations on certain commodities?

Mr. Pearson: We are continually adding information to that data. I do not know whether, or when, we will ever think that it is in a form that would be suitable for distribution. I know a great deal of it requires explanation as to just what the data mean. It would be a rather voluminous report.

Mr. JACKSON : I wonder, Mr. Pearson, if you would care to comment on the question of the use of the numerical count, in other words, statements in numerical count versus the other forms of quantity statement? We have problems in our State on the use of numerical count in cases where other expressions probably are more descriptive. What are your limitations or your definition of when you will accept numerical count as an accurate statement?

Mr. Pearson: It is my understanding that it depends upon the consumer usage. You might say "a dozen eggs," and I believe that would be sufficient for a net content statement. On the other hand, we have considered the possibility of whether or not " 6 tomatoes" is fully informative. We doubt that it is. 
Mr. RowE: I might say that generally speaking we think of a count declaration as one to be supplemented by a net-weight declaration. If you can look inside a package and see 4 tomatoes, we do not object to a count statement. Ordinarily we do like to have a net-weight statement supplementing a numerical count statement.

Mr. BAUCOM: Am I correct in my conclusion that the Federal Food and Drug Act deals with interstate commerce only? If I ship to a warehouse in a city and from that point it is delivered to the retail outlet, is the last transaction interstate or intrastate commerce?

Mr. Pearson : I will not take time to go into all the exceptions of the law, but there are exceptions under which we deal with certain products in intrastate commerce. To give you one example, it is a violation of the law to give a false guarantee with respect to a product, and the product itself does not necessarily have to move interstate. If a shipment of flour originates in one State and goes to a warehouse in another State, that is an interstate shipment. Moving from a warehouse to a point in that same State would not be an interstate shipment. If you have in mind whether or not the flour if adulterated or misbranded would be subject to seizure, I would say that it would be. It is subject to seizure any time after it is shipped interstate.

MR. BAUCOM : In general, we say that every man must absorb his own shrinkage. If they ship it to a warehouse and it is stored so long as to lose weight for any cause, and then moves out into the retail outlet, we contend that the warehouse is responsible, that it was intrastate commerce, and the State law has jurisdiction.

MR. PEARSON: Your State law I presume would give you jurisdiction. I know of nothing in the Federal Act that takes away the State's jurisdiction.

DR. MiLSTEAD : To sum up, the flour is still subject to the Federal law. It is a question then of who is responsible for the violation. Obviously, if the package was legal when it was shipped in interstate commerce to the warehouse, the original shipper could not be held under the criminal provisions. Once that flour crosses the State line, it is subject to the jurisdiction of the Act continuously, up to the time it is ultimately consumed. Somebody else may be responsible for a violation if he does something to that flour that results in its being adulterated or misbranded. The flour is not only subject to seizure, but one who causes it to be adulterated or misbranded may be subject to the criminal penalties of the law for doing something that resulted in the flour being misbranded. There is no requirement that the flour be shipped again in order for the Act to remain in effect.

\section{PREPACKAGED PRODUCE}

By B. E. DoBelL, Manager, Legal Department, Safeway Stores, Inc., Oakland, California

The subject "Prepackaged Produce" is listed for me on the program. I shall dispose of that almost unlimited subject by commenting that prepackaging of all produce is believed to be generally desirable. I shall limit the scope of this discussion and present an industry problem in unitizing produce. In this presentation the 
term "unitizing," as distinguished from the popular concept of "prepackaging," means putting an item in the simplest form that can be pricemarked. The item may be an unwrapped individual unit-for example, an avocado-or it may be normally bulk produce, such as green beans packaged in a transparent container.

The problem is this. The marking of unitized produce items with only the selling prices, determined according to weight, is not a uniformly approved method of sale. However, the cost of complying with present labeling requirements is excessive in relation to the value of the units.

For identification, I have labeled this problem "Operation Pricemark." I would like to preface my presentation with these explanatory remarks:

1. My assignment is to submit the problem; we do not have the answer.

2. The objective of pricemarking is to improve service to customers. Dominant factors are quality protection, convenience, and faster checkout.

3. We recognize that your basic concern is economic protection of the customer.

4. In "Operation Pricemark," pricing by weight is considered to be generally more equitable than pricing by count, and to offer the best comparison of competitive prices.

[At this point Mr. Dobell showed and explained a number of slides. These slides, with captions, are presented as figs. 23 to 31.$]$

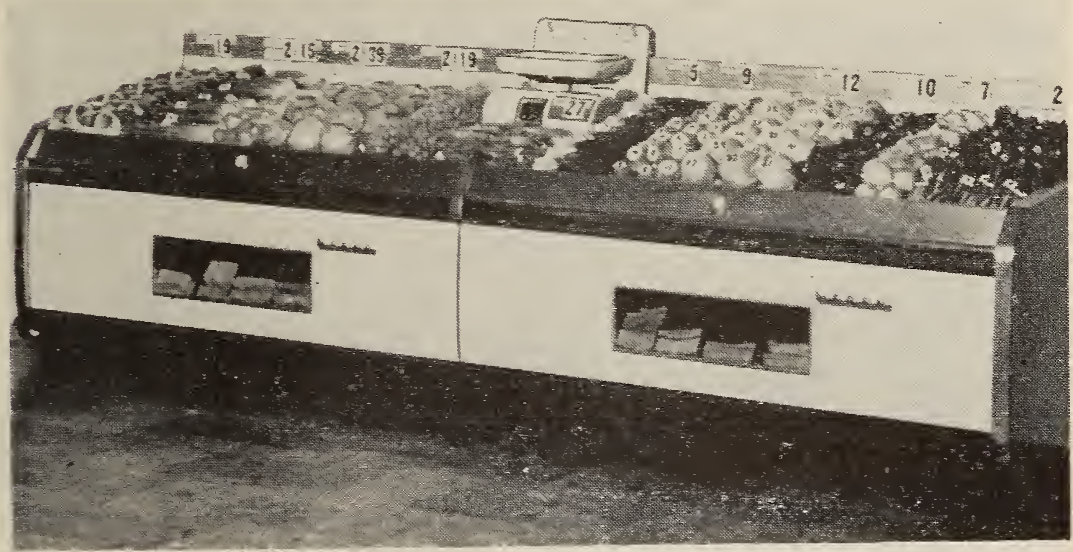

Figure 23. Produce display with scale.

Figure 23 simply illustrates how a display of unitized produce might be set up. You will note these features to protect the customer: (1) Selling prices marked on the produce items as unitized; $(2)$ a price tag above each item; and (3) a convenient scale on which net weights and prices may be readily checked. 

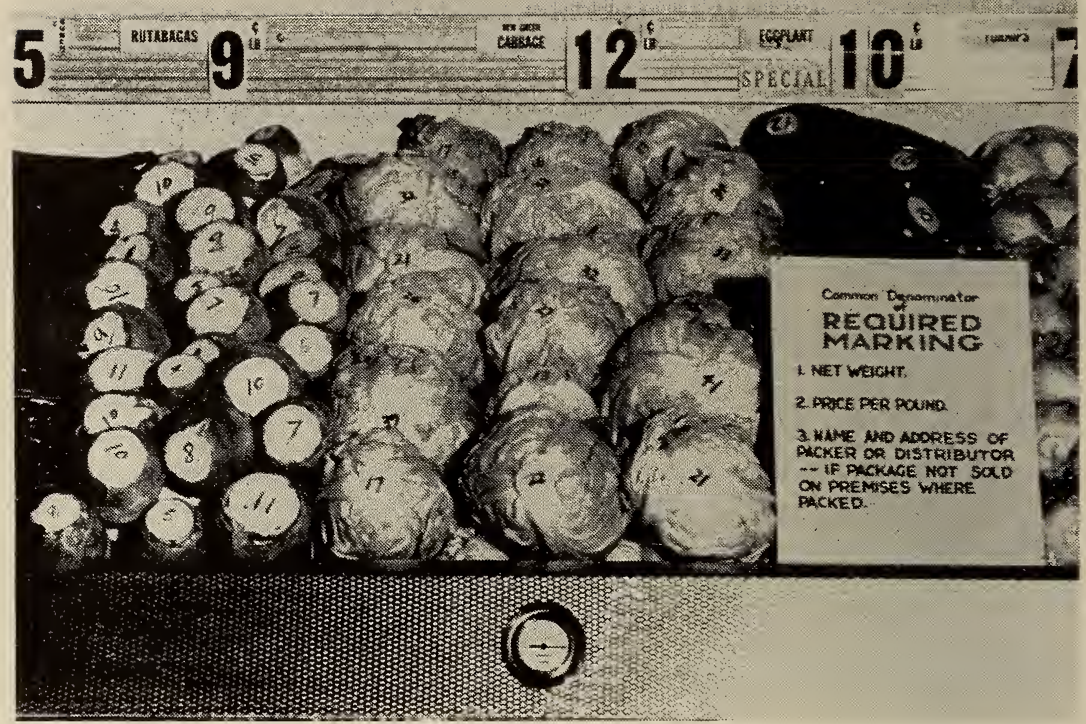

FIGURE 24. Egg plant, cabbage, rutabaga-unwrapped, preweighed, price-marked.

The display shown in figure 24 illustrates the feasibility of marking total price directly on certain items. However, in some areas if an item, although unwrapped and unbanded, is marked with a selling price, it is considered to be in package form and must bear additional markings. The display card in this picture lists the markings which we have designated as making up a "common denominator" of labeling required for uniform marking in the areas of this company's operations.

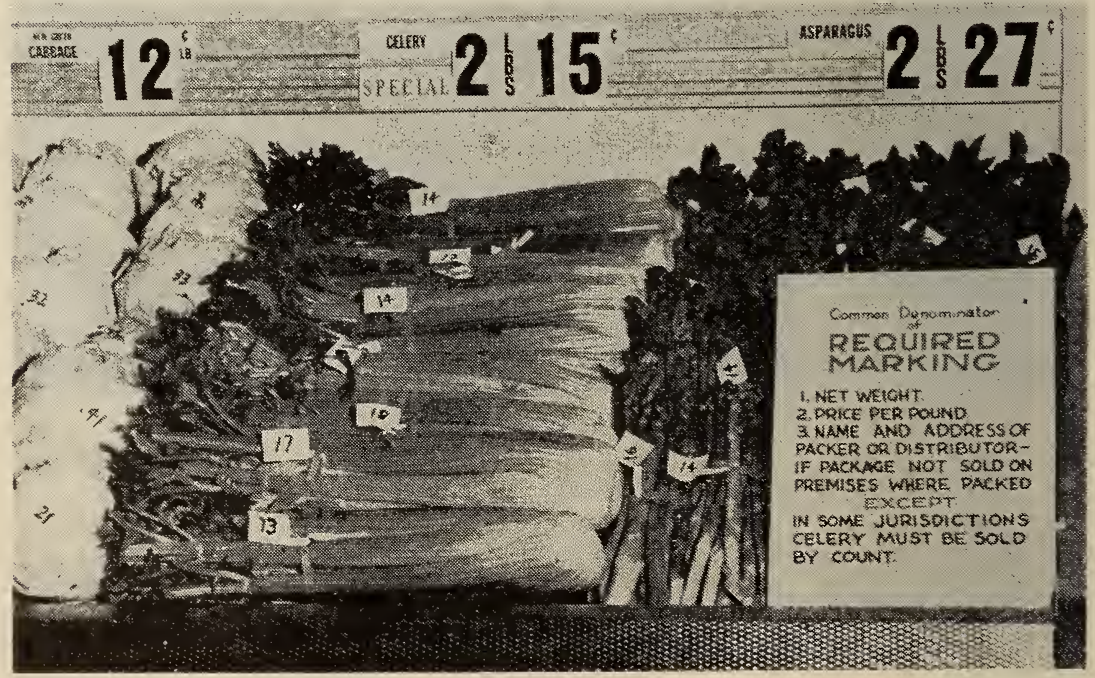

Figure 25. Celery, asparagus-banded, preweighed, price-marked.

This illustrates price-marking on a stalk of celery which has been banded for protective purposes, and on a bunch of asparagus spears. In each case the price has been determined by weight. The result again is that in some jurisdictions each unit is considered to be in "package form" and required to bear additional markings. A further complication is that in some jurisdictions celery must be sold by count, in which event the treatment shown in the display is not permissible. 

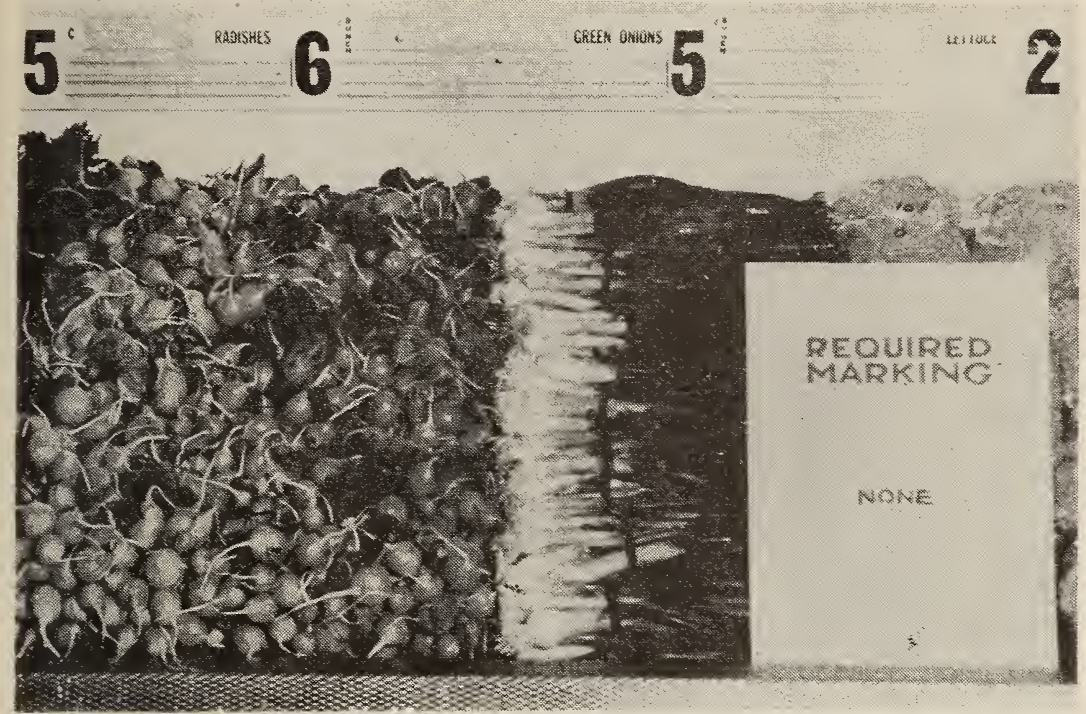

FIGURE 26. Bunches of green onions and radishes-standard bunches, uniformly priced.

This illustration is for comparative purposes. The items are standard bunches of green onions and radishes, either of which may be sold by the bunch if one price is applicable to all bunches in the display, regardless of size or weight.

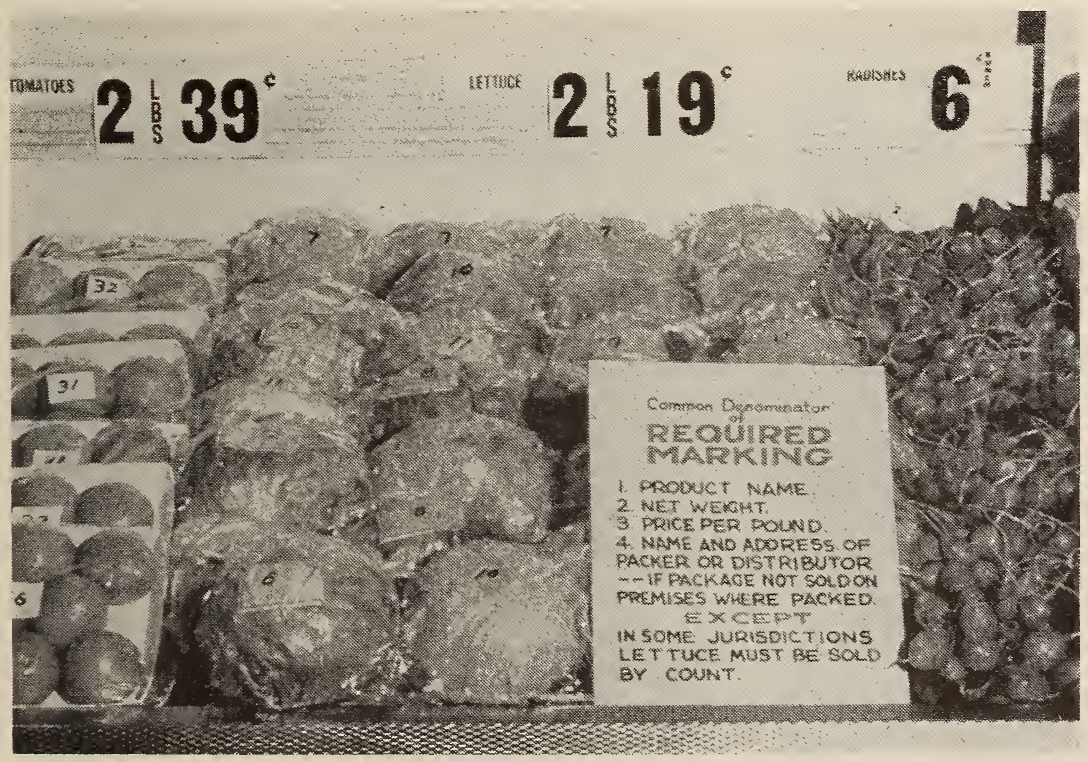

FIGURE 27. Lettuce in transparent bag-prepackaged in transparent bag, preweighed, price-marked.

This display illustrates prepackaging of head lettuce in transparent bags. Material costs for such prepackaging may be offset by savings, through prevention of waste. However, if the retailer must comply with the labeling requirements shown on the card in the picture, the labor costs make this method uneconomical. In further explanation of required marking, I should mention that the "common denominator" takes into consideration not only weights and measures laws and regulations, but also requirements under food laws administered by Federal and State agencies. 


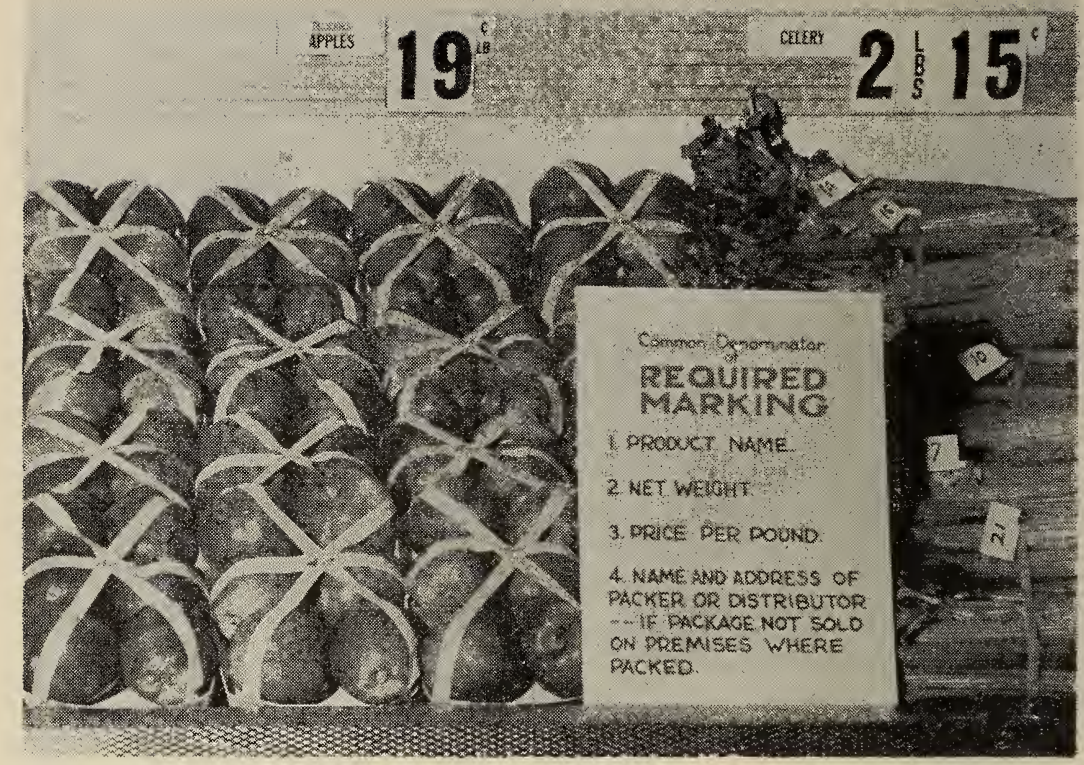

Figure 28. Apples-banded in tray, preweighed, price-martied.

A variant in prepackaging is illustrated here. Items such as apples lend themselves to unitizing for convenient handling and for protection. Banding in a tray leaves each item visible, yet this is considered a closed container and in some jurisdictions full labeling is required.

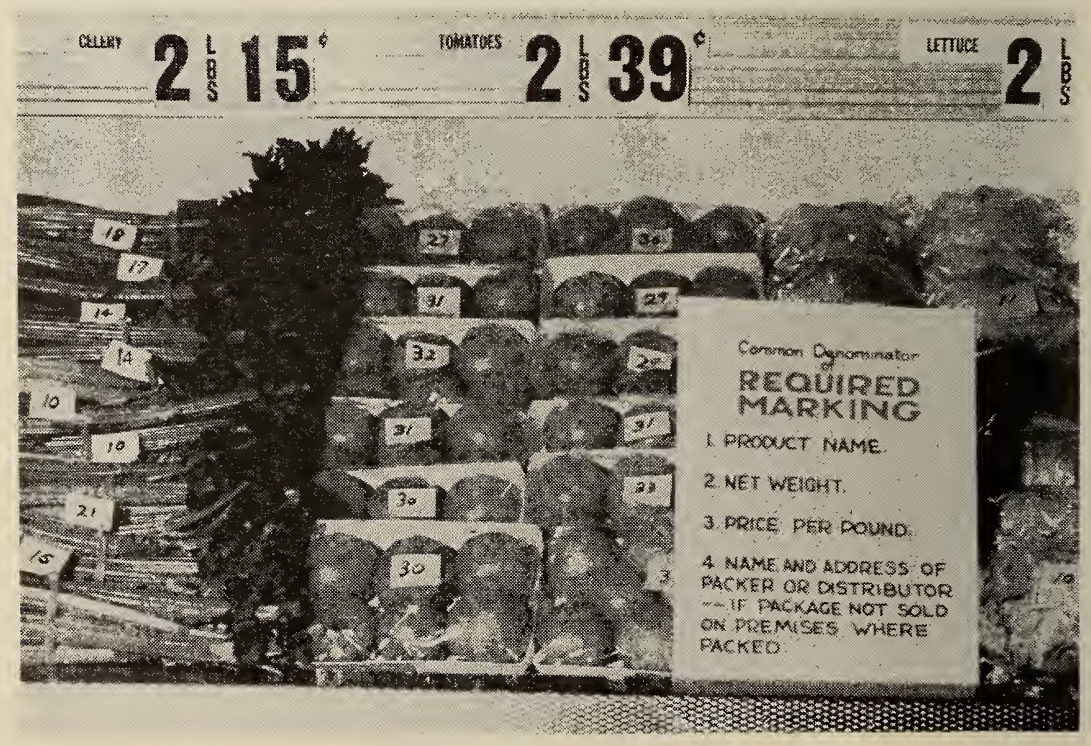

FIgURE 29. Tomatoes-prepackaged in tray with transparent film overwrap, preweighed, price-marked.

Tomatoes present their individual problems in packaging. Because of perishable qualities and variations in size, packaging of tomatoes in trays with transparent overwraps has some advantages. However, here again the use of a closed container, although transparent, and the marking of a total price result in requirements for additional expensive labeling. 


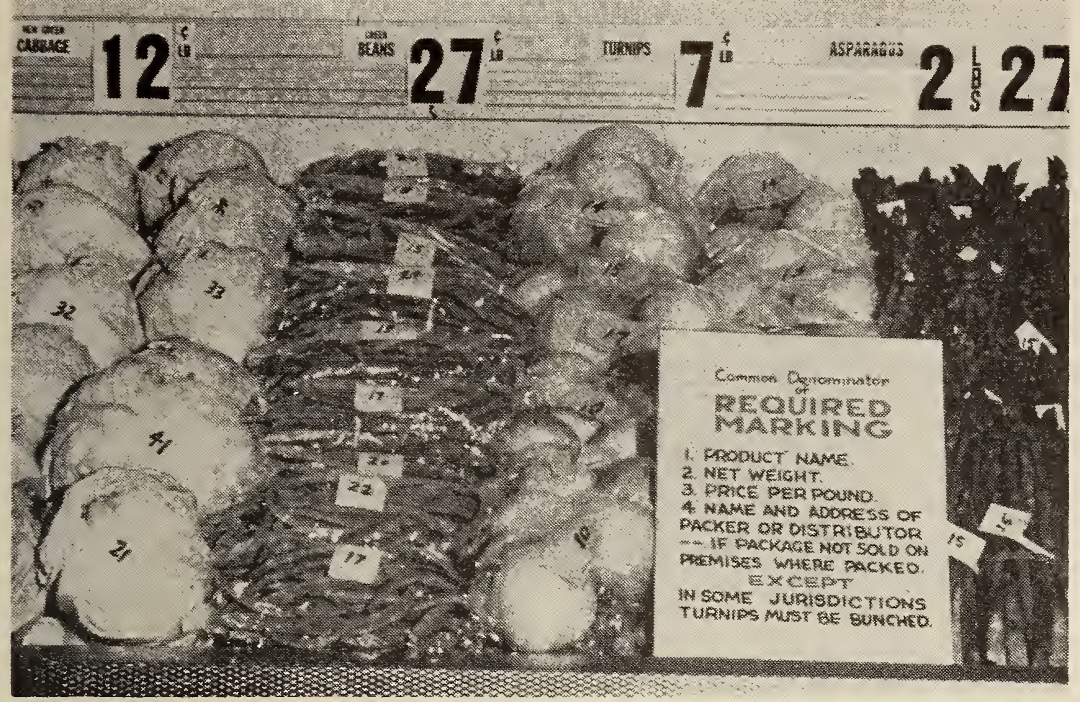

FIGURE 30. Green beans and turnips_prepackaged in transparent bags, preweighed, price-marked.

This display illustrates full packaging and price-marking of two types of bulk items-green beans and turnips. Information provided me is that these are particularly good illustrations of items for which full packaging under proper handling conditions contributes substantially to quality control. However, the labor cost of price-marking becomes prohibitive when full labeling is required. A further complication in price-marking is that in some jurisdictions turnips must be sold by the bunch, even though tests have shown that leaving the tops on depletes the vegetable.

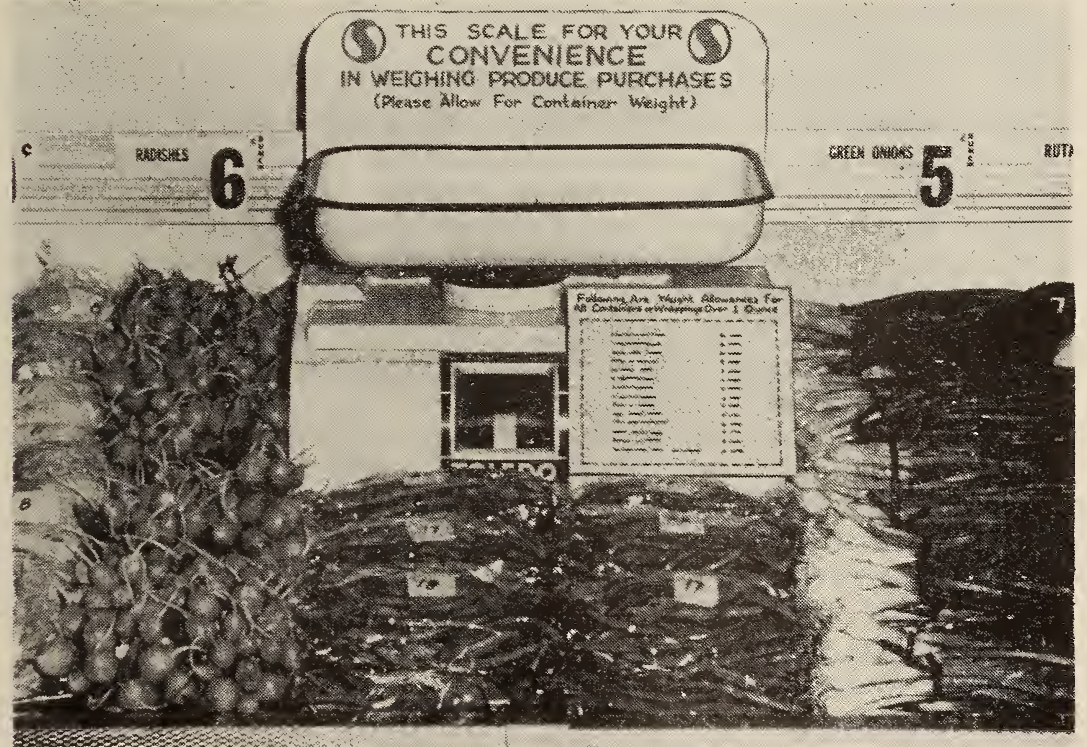

Figure 31. Scale and tare sheet.

Figure 31 presents an answer to a question we anticipate being asked, namely, "How can a customer check the net weight of these items in relation to the total price marked on them?" Figure 23 shows a full display with a scale conveniently located. Figure 31 illustrates the use of a chart listing the tare for each type of prepackaged unit. It is not submitted as the complete answer, but simply as one method of handling the particular problem. 


\section{SUMMATION}

We have presented "Operation Pricemark" in the light of the common interest you and retailers have in satisfying the customer -although more specifically your interest is a concern for protecting the customer, while the retailer's interest is a necessity for pleasing the customer.

The retailer also must find practical ways of meeting your requirements. However, the labor costs in fully labeling unitized produce are so high in relation to the value of the product that they make this method of sale impractical. In that regard the situation is substantially different from pricemarking meat, which has higher unit values. Labeling which is reasonably necessary for protecting customers is proper and expected, but unnecessary burdensome requirements must be removed if pricemarking is to be feasible.

The objective in presenting "Operation Pricemark" has been to illustrate the problem.

\section{QUANTITy STATEMENTS ON PACKING house PRODUCTS}

\section{By J. R. Scotт, U. S. Department of Agriculture}

It is a real pleasure for me to participate with representatives of industry, members of the Conference, and officials of the Food and Drug Administration in this symposium on prepackaged commodities. I am sure that through our discussions we will all gain a better understanding of the problems which are of mutual interest and we will be better equipped to discharge our responsibility of providing the American purchaser with truthfully labeled products.

In order to properly lay the groundwork for my subject, I think it would be desirable to briefly review our meat inspection program.

This year, the Federal Meat Inspection service is celebrating its Golden Anniversary. The Meat Inspection Act of June 30, 1906, marked the beginning of the Federal Meat Inspection Program as we know it today. This act extended Federal inspection of meat by making inspection mandatory for meat entering into interstate commerce. If any of the product of an establishment is to move interstate, the inspection will, of course, cover the entire production of the establishment. The Federal Meat Inspection Act contemplates continuous on-the-job inspection, which includes sanitation of the establishment, inspection of the live animals prior to slaughter, inspection of the carcasses and internal organs at the time of slaughter, inspection of the product as it is being processed in the establishment, supervision over the disposal of the condemned material, and marking and labeling of the meat and meat food products.

Today, Federal Meat Inspectors are servicing approximately 1200 establishments located in 468 different cities. During this fiscal year, over one hundred million meat animals were slaughtered under Federal Meat Inspection. Consumers now take for granted that the meat products which they purchase are derived from healthy animals, prepared in a cleanly manner, and that the label is accurate and truthful. 
With this introduction I think we are ready to consider the labeling of meat and meat food products. The Federal Meat Inspection Regulations require official approval of labeling material before it is used. This requirement for prior approval conforms to the policy of the Meat Inspection Act, action to prevent violations. In 1955 some 36,000 new labels were approved for use. In the same year, approval was denied 2,265 labels because they did not comply with the labeling requirements. When any U.S. inspected and passed meat food product is placed in a container or covering constituting an immediate or true container, such container or covering is required to carry a label showing the true name of product, an ingredients statement when the product is fabricated from two or more ingredients, the name and place of business of the manufacturer or person for whom the product is prepared, an accurate statement of quantity of contents, and the inspection legend with the identifying establishment number.

Our regulations pertaining to the statement of quantity of contents are similar to those of the Food and Drug Administration. They read as follows:

The statement of quantity of contents shall represent in terms of avoirdupois weight or liquid measure the quantity of product in the package (exclusive of materials packed with it) except as provided for in subparagraph 17.7. When no general consumer usage to the contrary exists, the statement shall be in terms of liquid measure if the product is liquid, or in terms of weight if the product is solid, semi-solid, viscous, or a mixture of solid and liquid. Unless the statement is so qualified as to show that it expresses the minimum quantity, it shall be taken to express the actual quantity. When the statement expresses the minimum quantity, no variation below the stated minimum shall be permitted, and variations above the stated minimum shall be no greater than is consistent with filling the container to the stated minimum in accordance with good commercial practice. When the statement expresses actual quantity, variations incident to packaging in accordance with good commercial practice shall be allowed, but the average shall not be less than the quantity stated; provided that packages of product having a capacity of less than $1 / 2$ ounce avoirdupois or less than $1 / 2$ ounce fluid shall not be required to be labeled with the statement of quantity of contents.

When any product is enclosed in a container along with a packing substance such as brine, vinegar, or agar jelly, a declaration of the packing substance shall be printed prominently on the label in connection with the name of the product, as for example, "Frankfurters Packed in Brine," "Lamb Tongues Packed in Brine," or "Beef Tongue Packed in Agar Jelly," as the case may be. The statement of the quantity of contents shall represent the weight of the drained product when removed from the container to the exclusion of the packing substance. The packing substance shall not be used in such a manner as will result in the container being so filled as to be misleading.

\section{The following instructions appear in our Inspectors Manual:}

The statement of net weight or measure shall be expressed in the largest applicable unit. Therefore, one pound is used instead of 16 ounces, and one pound four ounces, in lieu of 20 ounces. However, small packages of sliced bacon may be shown as containing $1 / 2$ pound or 8 ounces; packages of sliced dried beef may be labeled $1 / 4$ pound or 4 ounces.

A statement of the gross and tare weights in lieu of the net weight on such containers as tierces, barrels, drums, boxes, crates, and large size fiberboard containers is acceptable.

It has not been required by this branch that meat and meat food products in casings be marked with a statement of quantity of contents; however, no objection is offered to providing on the casings facilities for applying the weight, such as an opaque area preceded by the words "Net Weight." The presence of such facilities should not be construed to mean that the weight must be shown before the product leaves the establishment; however, if the 
casings are marked with the statement of quantity of contents, the inspector should check to determine whether such statements are accurate.

Systematic control should be maintained at all times to check the quantity of contents. It is not practical to state definitely how many units per hour or per carton should be weighed or measured, owing to many variable factors. Inspectors, however, must assume the responsibility of this labeling to the fullest extent, making such tests as are necessary. Keep in mind that time, temperature, altitude, storage and packing practices are some of the variable factors that must be considered. Deceptive filling of containers must not be permitted, even though a correct statement of quantity of contents is shown.

In the case of canned products, the average net weight of the cans checked should equal at least the stated net weight. There should be as many cans that are overweight as are underweight. The underweight should equal the maximum tolerance of not more than $20 \%$ of the total cans. The following underweight tolerances are allowable for canned comminuted products and for liquid and partly liquid products in which the liquid is included in the net weight: for a 6 -pound can, $3 / 4$ of 1 ounce-for a 4 -pound can, $1 / 2$ of 1 ounce -for a 2-pound can, $3 / 8$ of 1 ounce-for a 1-pound can, 5/16 of 1 ounce-for a 12 -ounce can, $1 / 4$ of 1 ounce-for an 8-ounce can, $3 / 16$ of 1 ounce-for a 6 ounce can or less, $1 / 8$ of an ounce. The overweight tolerances for canned comminuted products and for liquid and partly liquid products in which the liquid is included in the net weight are as follows: for a 6-pound can, $2 \frac{1}{2}$ ouncesfor a 4 -pound can, 2 ounces-for a 2 -pound can, 11/2 ounces-for a 1 -pound can, 1 ounce-for a 12 -ounce can, $3 / 4$ of 1 ounce-for an 8 -ounce can, $1 / 2$ of 1 ounce-for a 6 -ounce can or less, $3 / 8$ of 1 ounce. The overweight should not result in an overstuffed appearance of the cans. The following net weight tolerances are applicable to canned frankfurters packed in brine in consumer size units: The overweight should not exceed the weight of one whole link. The average net weight should equal the stated net weight. No underweight should exceed $4 \%$ of the stated net weight. The average net weight for the large institutional size cans should equal the stated net weight. The overweight should not exceed $4 \%$ of the stated net weight and the underweight should not exceed $2 \%$ of the stated net weight.

As outlined in our instructions to inspectors which I have just read, animal and artificial casing used to enclose meat or meat food products are not required to bear a statement of quantity of contents.

Our inspectors in the plants weigh a sufficient number of packages on the day of shipment from the plant to determine that the labeling bears an accurate statement of quantity of contents. When our inspector finds a product that does not bear an accurate statement of quantity of contents, he retains the lot until it has been reweighed and remarked with the correct net weight statement. This rarely happens unless the product has been in storage for some time. With the advent of impervious films for the packaging of meat, we are having less and less net weight problems at the plant level.

Our jurisdiction does not extend beyond the confines of the official establishment. Therefore, inaccuracy of the statement of the quantity of contents, due to shrinkage between the time the product leaves the official establishment and the time it is offered for sale, is a problem which would come under the jurisdiction of either the Food and Drug Administration or by the local or State weights and measures officials, whoever had jurisdiction. 
By Herbert Rumsey, Jr., Executive Vice President and Manager, Tobin Packing Company, Inc., Rochester, New York, representing National Independent Meat Packers Association.

On behalf of the National Independent Meat Packers Association, I thank this Conference for extending to us an invitation to participate in your discussion of a subject in which both of our associations have a growing and very important interest, namely, "Prepackaging of Meat in Meat Packing Plants."

If one were to fully explore and debate the multitude of controversial problems involved with this subject, it most certainly would be very time-consuming and involve the viewpoint of specialists from many fields of science. For the purpose of my presentation, it will be necessary to abbreviate and touch only on certain of the most important factors involved.

I accordingly suggest that our discussion center around the following topics, which, out of necessity, I present in outline form.

I. Various types of transparent films available and their special characteristics.

(a) Classifications by degree of air or gas transmission.

1. High gas air transmission films comprised of certain types of Cellophane and certain types of Pliofilms and are desirable primarily for fresh red-meat packaging.

2. Low air gas transmission would comprise of Saran, Crv-O-Vac, most types of Pliofilm, certain types of Cellophane, Mylar, and Polyethylene. These films are desirable primarily for processed or fresh frozen meats.

(b) Classification by heat shrinkability or nonheat shrinkability.

1. Heat shrinkable films are primarily Saran, Cry-OVac, Mylar, Oriented Pliofilm, and Polyethylene. The special advantage of these films is the minimizing of air within the packaging due to the ability of the film to shrink on being heat treated so that the film wrapper is in very tight-fitting relation to the product packaged.

2. Nonheat shrinkable films would be all types of Cellophane, stabilized Polyethylene, and Pliofilm. Desirable usage of these items for packaging product where tight-fitting relation of the film may be injurious to the product being packaged and where presence of air is not particularly undesirable.

II. Color bleaching resulting from exposure of product to the rays of fluorescent lighting as provided for in dealer display cases. This problem can cause shopworn appearance of product within five to six hours of exposure, and to date no positive solution has been forthcoming. However, problem can be minimized to an extent by resorting to the following:

(a) Use of tinted film.

(b) Use of gas and/or vacuum packages on limited number of products.

(c) Application of light filters adjacent to fluorescent lamp bulb.

III. Weighing problem resulting from product shrinkage variables in cases where a predetermined weight package is the objective.

(a) Packer purchases livestock based on weights at time of sale and has to absorb tissue shrink in transit which will vary from 3 to 9 percent, depending on circumstances.

1. As a result, packer does not know actual carcass cost until livestock has been dressed and chilled. 
(b) Dressed carcasses and fresh meat cuts resulting are subject to further shrinkage variables depending on the following:

1. Time held in storage fresh or frozen.

2. Refrigeration temperature held at and degree of air circulation present.

3. Variable in shrinkage based on chemical composition of meat tissue itself has bearing on ultimate shrinkage as natural moisture contact can vary as much as 11 percent.

(c) Processing shrinkage variables constitute one of the packers most serious problems as in many instances this step is the final one in preparation of many consumer prepackaged items. This problem centers largely around the following obstacles.

1. Variable in natural chemical composition of meat tissue, particularly fat and moisture.

2. Variables in smoking and cooking yields.

3. Variables resulting from time finished product is held in refrigerated storage.

4. Variable in density of comminuted meat emulsion of sausage variety based on inability to maintain constant pressure within the container in which the emulsified meats are cooked or smoked.

5. Variables in size dimensions where predetermined number of units are required to be an eventual predetermined finished weight. Illustration-ten pieces of frankfurts to be processed so as to weigh 16 ounces when packaged.

Because of our limited time, I have touched on only three of the important problems involving the prepackaging of meat products. However, I would like to point out that, if a thorough review of this subject were possible, further consideration should be given to the following items :

1. Means of combating perishability.

2. Consumer packaging preferences.

3. The effect of prepackaging on consumer brand preferences.

4. The exceptionally small margin of profit that the packer has to operate on in an effort to satisfy the demand for prepackaged meat products.

I wish to make it clear that any opinions I may express represent my personal conclusions and that no attempt has been made to have my thinking confirmed by the membership of the National Independent Meat Packers Association or the Tobin Packing Company, with whom I am associated. I make this statement knowing that our subject can be very highly controversial. 
FIFTH SESSION-MORNING OF THURSDAY, MAY 24, 1956

(W. K. Tripple, Vice President, Presiding)

\section{REPORT OF THE COMMITTEE ON EDUCATION, PRESENTED BY} H. E. CRAWFORD, CHAIRMAN

The program adopted by this committee includes projects that were instituted or recommended by the Conference for continued consideration and conclusion. Considering as a whole the projects with which your committee has been concerned during the past year, we feel that a great deal of good has been done toward the accomplishment of better relations with the general public and members of industry in the field of weights and measures. Officials nationwide have cooperated by using the various avenues available to them, such as radio, television, newspapers, and periodicals, to create added public interest.

The motion picture "A True Standard" has not received the general use by weights and measures officials that it warrants. As you know, this film, in color and with sound, was produced by the National Bureau of Standards. It is, in the opinion of the committee, the best medium available with which to explain why the official knows his test weights are correct. It assures the general public of the accuracy that is maintained in all weighing devices in order to protect their interests in buying or selling. This film may be shown by television stations and used to great advantage before public gatherings.

An unusual amount of time has been expended in correspondence with officials in various cities and States to promote the film's added use. It has been cited that its showing before high school classes of science and mathematics students has been worthwhile in the jurisdictions where this was practiced. It has been acknowledged as equally informative to more advanced science classes in colleges where a few showings have been reported. In one city the film has reportedly been shown to a total of over 6,000 high school and college students, and an official in a western State has recently secured the film for similar showings to the pupils in his jurisdiction.

There seems to be an unusual convenience offered for school showings because most of the schools in larger communities are provided with film projectors and students are well trained as operators. We have yet to receive a report of a film being damaged by student operators. For the busy official, these school showings have a decided advantage in the saving of time because it is only necessary that the film be delivered and later picked up after the close of the school session. One official occasionally appears during the showings and gives a short prepared talk on weights and measures in relation to the value of these services to the community. This is only one of the avenues through which this motion picture may be used successfully. We must all keep in mind that the high school students of today are the buyers and sellers of tomorrow, so this certainly may be assumed as constructive weights and measures educational promotion. 
The National Bureau of Standards has provided us with a report of the requests for this film, which is as follows:

Loans:

Short version:

To weights and measures officials $\ldots \ldots \ldots \ldots \ldots \ldots 19$

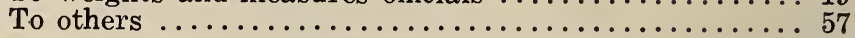

Total ..................

Long version:

To weights and measures officials $\ldots \ldots \ldots \ldots \ldots \ldots, 4$

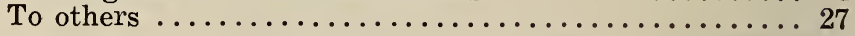

Sales :

Total ................

Short version:

To weights and measures departments .......... 12

To others $\ldots \ldots \ldots \ldots \ldots \ldots \ldots \ldots \ldots \ldots \ldots \ldots \ldots \ldots \ldots \ldots, 2$

Total .....................

Staff members of the National Bureau of Standards have shown the film to approximately fifty groups. The long version of the film has been shown before many audiences in at least twelve foreign countries. The Bureau has received many complimentary letters on "A True Standard." The short version has been used by several television stations for educational and general interest purposes. The film was accepted for showing at the "Golden Reel" Film Festival in New York City and at The Cleveland Film Festival during the past year.

In addition to the showing of this motion picture, several State and city officials have reported the showing of motion picture films of their own making. Your committee has received newspaper clippings which indicate that the officials have been wide awake and aware of the advantage of publicity tie-ins that can be unusually helpful. The favorable reception that all films have received surely has justified the time and expense involved in their production.

The National Bureau of Standards film is loaned without charge, except for the cost of transportation. Prints of the film may be purchased at a nominal cost. We recommend that every weights and measures department in the nation seriously consider securing a copy of "A True Standard." We were pleased to learn that the Bureau had completed another film which was shown to the Conference during the Wednesday morning session. The committee strongly recommends that the National Bureau of Standards continue developing informative and educational motion picture films and that early consideration be given to the production of a popular presentation of the story of weights and measures.

The committee is gratified by the cooperation and assistance rendered by the National Association of Scale Manufacturers throughout the year. The two outstanding examples of such cooperation are the composition, printing, and distribution of scale error charts and the inclusion in publicity releases of the story and the value of weights and measures administration.

The scale error charts were designed as a joint project of this committee and the Association of Scale Manufacturers. They give a graphic picture of large monetary effects of repeated scale errors, no matter how small. The charts have been made available to 
weights and measures officials in practically unlimited supply and have been widely used by them. We are informed that over 20,000 copies of the chart have been requested by and sent to the officials. An additional 40,000 copies have been distributed through industrial and business outlets. Several journals have printed articles about the charts and their application and, through their distribution channels, have carried the message widely.

The publicity program of the National Scale Manufacturers Association has resulted in at least 23 major articles in trade publications during the year. In addition, at least 34 short items have been carried by such publications. These articles are designed to emphasize the importance of reliable weighing instruments. They also are so written as to spell out the value of weights and measures supervision. Thus, a wide cross section of American business and industry has been exposed to information on our work.

Through its public relations program, the National Association of Scale Manufacturers has convincingly demonstrated the solid support that its members are ready and willing to provide to weights and measures officials, whose principal objective, more accurate weighing, is parallel with the objective of the scale manufacturers.

A continued project carried over from the previous year is the development of Civil Service job descriptions for weights and measures personnel. Subsequent to the 40th National Conference on Weights and Measures, approximately 100 representative officials were forwarded a questionnaire requesting information concerning their Civil Service status and requesting copies of job descriptions for personnel within their departments. The response was prompt and generous, and the information and material received have been thoroughly studied and considered in compilation of "model" job descriptions.

In accordance with recommended practice, we have applied the "Series" plan in developing these descriptions. There is an Introduction applicable to the series and to each job within it. The Introduction covers general principles and requirements, and serves to allow more concise specific descriptions.

We wish to point out that in only a relatively few jurisdictions will the entire series be applicable. It is believed, however, that the Introduction and such individual position descriptions as are appropriate will be useful in almost any jurisdiction.

The grades indicated are relative only, and must of course be fitted into existing grades of a particular jurisdiction. It is appropriate to call your attention to the report of the Committee on Education at the 39th National Conference on Weights and Measures (1954), which suggested salary schedules that were then considered generally adequate. We believe, however, that it is wise to caution the official that definite efforts must be made in each instance to fix the salary schedules of weights and measures personnel sufficiently high to attract the very best candidates. Needless to say, the salary schedules suggested in 1954 may not be in line today.

We acknowledge the services of the Office of Weights and Measures of the National Bureau of Standards in compiling these job descriptions. After composition in that Office, the descriptions were submitted to the Personnel Division of the Bureau for comment 
and suggestion. The assistance of the Bureau's professional personnel staff is gratefully acknowledged.

The model job descriptions are attached as a part of this report.

The final project receiving your committee's study and attention was the urging of weights and measures officials to formulate monthly and annual reports in narrative form. It seems to have been a general practice for many of those in charge of departments of weights and measures to compile annual reports in statistical form only. These most generally were uninteresting and consequently were seldom read by their superiors or by the general public. Such disinterest must be easily understood, for, unless the story of what the department of weights and measures is doing to insure fairness in commercial transactions is told, it would be unreasonable to expect a set of cold itemized figures to impress any citizen who has never had the opportunity of learning what such work really accomplishes.

In reply to our many inquiries, all officials agreed that a report combining narrative and statistical presentations is advisable, and advocated that more space be given in each report to a description of the services afforded by and the protection resulting from constructive weights and measures enforcement. It has been brought to our attention that recently one official has been writing weekly reports that deal almost entirely with the work being done within his State. In these reports he tells of significant faulty weighing and measuring devices discovered and the losses that occur through the errors found to exist. These reports are written in such an interesting manner that the authorities to whom they are sent cannot fail to read them in their entirety. Surely such reports tend to build good will and encourage support of a weights and measures organization.

It is worth noting that several officials in States, counties, and cities are now composing annual reports which are designed to illustrate the many functions of their work. These reports are composed in such a way that they prompt favorable newspaper comment following their release. Narrative reports, well written and arranged, can accomplish the very purpose for which they are intended in bringing to the attention of the general public the importance of the job. This may be contrasted with a straight statistical presentation that will develop little interest. If we wish our services to be recognized for what they are worth, we need to tell the story of weights and measures in a "down-to-earth" narrative form, so that any layman will appreciate their value.

The holding of training schools in all jurisdictions is becoming accepted as a "must" by many officials. Inspectors attending such schools acquire a more thorough knowledge of their laws, regulations, and recommended testing procedures. Training schools were held in several States during the past year. Handbook 44 was generally used as the textbook for these courses, and a representative of the Office of Weights and Measures, National Bureau of Standards, aided and assisted in the conducting of the classes. We recommend that this important phase of weights and measures education be continued and expanded.

We express our gratitude to the many officials who have responded to our letters and aided in furnishing the material neces- 
sary for our study. We also acknowledge the valued services afforded by W. S. Bussey, Secretary, National Conference on Weights and Measures, and by the members of the staff of the Office of Weights and Measures, National Bureau of Standards.

We also express our appreciation for the cooperation of the National Association of Scale Manufacturer's in designing and exploiting the use of the scale error charts, and in our point public relations program.

\section{NEIGHTS AND MEASURES SUPERVISION SERIES}

Introduction. This series includes all classes of positions the duties of which are to supervise or perform laboratory and/or field inspection, investigation, and general law enforcement work to insure compliance of commercial equipment, establishments, and individuals with the laws and regulations governing weighing and measuring practices and equipment.

Included in this series are positions of training, positions that involve the inspection of weighing and measuring practices and equipment to determine that accurate weights and measures of products and commodities are being represented and furnished by commercial dealers, positions supervising such employees, and positions of technical specialists in this field. These positions also include investigation of complaints wherein violations or suspected violations of weights and measures law or regulation have been reported.

Description of Duties. Positions allocable to this series characteristically involve performance of testing and inspectional work on all types of commercial weighing and measuring equipment.

Weighing equipment consists of equal-arm scales, pharmaceutical balances, computing scales, counter scales, counting scales, portable platform scales, warehouse scales, livestock scales, vehicle scales, and the like.

Measuring equipment consists of :

(a) Liquid.-Milk bottles, pharmaceutical graduates, lubricating-oil bottles, retail motor-fuel dispenser's, grease-measuring devices, liquid meters, and the like;

(b) Dry measures,

(c) Linear measures.-Yardsticks, tape measures, fabric-measuring devices, cordage-measuring devices, mileage-measuring devices, and the like.

Equipment used by personnel in this series in testing the accuracy of such weighing and measuring equipment includes standard weights, balances, standard capacity measures, standard length bars and tapes, standard thermometers, and the like.

To a great extent, the acceptability standards for commercial weighing and measuring devices are furnished in detail in the law and regulations.

Functions of personnel in these positions include (1) testing and inspecting commercial weights and measures and weighing and measuring devices for approval under the law, (2) making individual decisions on each device as to its conformance and taking official action accordingly, (3) instructing vendors in the provisions of the law and regulations, (4) detecting violations, (5) investigating alleged violations, and (6) arresting or otherwise bringing to justice violators of the weights and measures law. 
With the exception of beginning trainees, the work at all levels involves preparation of brief factual reports of findings and the completion of forms such as field inspection report forms and daily work reports.

Special investigations require originality of approach, each case involving an individual problem in detecting and obtaining evidence of violations.

Personnel in all levels of these positions must maintain working relations with owners, operators, and employees of commercial establishments, and, to some extent, with the general public. There is a continuing need on the part of the incumbents to inform others as to the provisions of weights and measures laws and regulations and to create interest and confidence in their work.

With the exception of beginning trainees, the work characteristically includes the making of decisions involving judgment in the application of weights and measures laws and regulations.

There are certain personal characteristics and qualifications that are desirable and important in varying degrees, according to the responsibilities of the job, for all positions in this series. These include mechanical aptitude, address, ability to meet and deal successfully with people in all walks of life, ability to think independently and analyze problems, initiative, adaptability to new situations, a judicial approach, a desire to learn, and the like.

\section{GRADE I}

\section{Inspector Trainee-Weights and Measures}

Definition. Under direction of the director (deputy superintendent) of weights and measures, and under close supervision of and usually accompanied by senior personnel of the Division of Weights and Measures, to be given in-service training in the technical aspects of inspecting and testing commercial weighing and measuring devices, in investigating complaints, and in making reports, and to conduct such inspections, tests, and investigations, according to prescribed procedures. To make recommendations as to decisions, based on the results of inspections, tests, and investigations, as to the acceptability of devices for commercial use under the law, and as to compliance with or violation of the law of commercial practices.

Minimum Qualifications. Education. Equivalent to successful completion of high school (twelfth grade). Experience. No previous experience in the field is required. Experience in mechanics, investigation, law enforcement, or business management is desirable.

Knowledges and Abilities. Ability in both spoken and written English. Basic knowledge of mathematics, algebra, leverage. Ability to work successfully with people of various economic levels.

Special Personal Characteristics. Good health, strength, and agility. Willingness to work irregular hours and to travel throughout the State. Excellent moral character. 


\section{Junior Inspector-Weights and Measures}

Definition. Under direction of the director (deputy superintendent) of weights and measures, and under supervision of a field supervisor of weights and measures (including definite procedural instructions, frequent checks as to mechanical performance, and quite rigid work-load outlines), to receive advanced in-service training in the more highly technical aspects of inspecting and testing commercial weighing and measuring devices and in investigating and taking indicated action on complaints, and to conduct routine inspections, tests, and investigations, according to prescribed procedures. To make decisions and take indicated actions, based on the results of inspections, tests, and investigations, as to acceptability of devices for commercial use under the law, and as to compliance with or violation of the law of a wide variety of commercial practices.

Minimum Qualifications. Education. Equivalent to a successful completion of high school (twelfth grade). Experience. At least one year of experience in weights and measures enforcement or similar law enforcement or technical investigation fields. Experience in mechanics and /or business management is desirable.

Knowledges and Abilities. Ability in both spoken and written English. Basic knowledge of mathematics, algebra, and leverage. Knowledge of major concepts of State weights and measures statutes and rules and regulations, and, in addition, knowledge of approved testing procedures for principal commercial weighing and measuring devices.

Special Personal Characteristics. Good health, strength, and agility. Willingness to work irregular hours and to travel throughout the State. Excellent moral character.

\section{GRADE III}

\section{Senior Inspector-Weights and Measures}

Definition. Under direction of the director (deputy superintendent) of weights and measures, and under limited supervision of a field supervisor-weights and measures (such as definite testing procedures, occasional checks as to mechanical performance, and work-load outlines), to undertake continuing self-education in the highly technical aspects of inspecting and testing commercial weighing and measuring devices and in detailed investigations of complaints, and to conduct routine and special inspections, tests, and investigations, according to prescribed procedures. To make decisions, based on the results of inspections, tests, and investigations, as to acceptability of devices for commercial use under the law, and as to compliance with or violation of the law of a wide variety of commercial practices. The incumbent will operate with wide latitude for independent decision and action.

Minimum Qualifications. Education. Equivalent to successful completion of high school (twelfth grade). Experience. At least three years of experience in weights and measures enforcement or 
similar law enforcement or technical investigation fields, with at least one of these three years specifically in the weights and measures field. Experience in mechanics and/or business management and academic accomplishment above that required are desirable and will be given consideration in the selection of candidates for this position.

Knowledges and Abilities. Good ability in both spoken and written English. Basic knowledge of mathematics, algebra, and leverage. Working knowledge of State weights and measures statutes and the rules and regulations, and, in addition, knowledge of approved testing procedures for all common commercial weighing and measuring devices. The incumbent should have knowledge of the basic principles of mechanical weighing and measuring equipment

Special Personal Characteristics. Good health, strength, and agility. Willingness to work irregular hours and to travel throughout the State. Excellent moral character.

\section{GRADE IV}

\section{Field Supervisor-Weights and Measures}

Definition. Under direction of the director (deputy superintendent) of weights and measures, yet with wide latitude for independent decision and action, to plan and supervise the working program of senior inspectors, junior inspectors, and inspector trainees. To plan and conduct in-service training of subordinate employees-such training to include the technical aspects of inspecting and testing commercial weighing and measuring devices, the investigating of complaints, and the making of reports. To review the activities of subordinate weights and measures field employees and to take such corrective action as is indicated by such review. To conduct inspections and tests on any or all commercial weighing and measuring devices and investigations on complaints, and, without normal reference to higher authority, to take action indicated by results of such inspections, tests, and investigations.

Minimum Qualifications. Education. The successful completion of high school (twelfth grade) and the successful completion of four years at a college or university or its equivalent. There may be substituted for each year of required college or university training one and one-half years of experience in weights and measures enforcement or similar law enforcement or technical investigation fields. Experience. At least five years of experience in weights and measures enforcement or similar law enforcement or technical investigation fields. (This experience or any part of it may be applied aslo to the educational requirements above.) Experience in manufacture or repair of commercial weighing or measuring devices, mechanics, and/or business management is desirable.

Knowledges and Abilities. Excellent ability in both spoken and written English. Basic knowledge of mathematics and algebra. Knowledge of leverage and the basic principles of mechanical weighing and measuring. Working knowledge of State weights and measures statutes and rules and regulations, and, in addition, knowledge sufficient to teach approved testing procedures for all common commercial weighing and measuring devices. Ability to 
speak effectively, either formally or informally, before small or large groups.

Special Personal Characteristics. Good health, strength, and agility. Willingness to work irregular hours and to travel throughout the State. Excellent moral character. Ability and willingness to impart ideas to others, to teach technical and administrative aspects of the weights and measures program, and to inspire others to their fullest capabilities.

\section{GRADE IV}

\section{Investigator-Weights and Measures}

Definition. Under direction of the director (deputy superintendent) of weights and measures, yet with wide latitude for independent decision and action, to plan and conduct special statistical and other studies and surveys in the weights and measures field. To administer a program of package-checking for compliance with law and regulations and to instruct inspector trainees, junior inspectors, and senior inspectors in this aspect of the program of the Division of Weights and Measures. To investigate complaints, received from staff members of the Division or from the general public, and to take such action as is indicated by the results of the investigation. Such complaints may pertain to mechanical devices or their use, or to activities or practices of vendors or vendees. To assist other personnel of the Division in the gathering of evidence for possible court action. To make clear and comprehensive reports on his activities.

Minimum Qualifications. Education. The successful completion of high school (twelfth grade) and the successful completion of four years at a college or university or its equivalent. There may be substituted for each year of required college or university training one and one-half years experience in weights and measures enforcement or similar law enforcement or technical investigation fields. A bachelor degree from a college or university with some studies of law included therein or supplemental thereto is desirable. Experience. At least five years experience in law enforcement or legal practice, of which at least one year must have been spent in weights and measures administration. (This experience or any part of it may be applied also to the educational requirements above.)

Knowledges and Abilities. Excellent ability in both spoken and written English. Knowledge of recommended methods of conducting investigations. Working knowledge of State weights and measures statutes and rules and regulations. Ability to manipulate reasonably precise measuring instruments. Ability to speak effectively, either formally or informally, before small or large groups.

Special Personal Characteristics. Good health, strength, and agility. Willingness to work irregular hours and to travel throughout the State. Excellent moral character. Ability and willingness to impart ideas to others and to teach methods and procedures. Willingness to work alone and to approach and attack a problem until the proper solution is found, regardless of the time, travel, or inconvenience involved. 


\section{Laboratory Technician-Weights and Measures}

Definition. Under direction of the director (deputy superintendent) of weights and measures, yet with wide latitude for independent decision and action, to conduct the laboratory procedures of the Division of Weights and Measures, including the testing and calibrating of office and field standards of mass, capacity, and length, and to make precision determinations of mass, volume, and length, as required. To advise on the procurement of such standards and the instruments used in such service. To test certain precise measuring equipment and make such measurement analyses as are required. To maintain the laboratory measuring instruments at maximum operating efficiency. To instruct field personnel of the Division of Weights and Measures on the broad aspects of the laboratory program. To conduct special investigations and tests on special commercial weighing and measuring equipment. To make clear, comprehensive reports on the various activities undertaken.

Minimum Qualifications. Education. The successful completion of high school (twelfth grade) and the successful completion of four years at a college or university or its equivalent. There may be substituted for each year of required college or university training one and one-half years of experience in weights and measures enforcement or similar law enforcement or technical investigation fields. A bachelor degree in either chemistry, physical chemistry, chemical engineering, mechanical engineering, or physics from a college or university is desirable. Experience. At least five years experience in weights and measures supervision, laboratory procedures, or similar work. (This experience or any part of it may be applied also to the educational requirements above.)

Knowledges and Abilities. Excellent ability in both spoken and written English. Ability to manipulate precise measuring instruments. Ability to speak effectively, either formally or informally, before small or large groups.

Special Personal Characteristics. Good health, strength, and agility. Excellent moral character. Ability and willingness to impart ideas to others, to teach technical matters, and to make observations and computations and thus derive results demanding both patience and precise techniques.

\section{GRADE V}

\section{Weighing Instrument Specialist-Weights and Measures}

Definition. Under policies established by the director (deputy superintendent) of weights and measures and with very wide latitude for independent decision and action, to serve as engineering advisor and weighing instrument specialist. To plan and, in many instances, conduct in-service training of weights and measures personnel. To plan testing procedures and instruct field personnel in their application. To prepare engineering designs of 
special testing equipment. To make detailed examinations of commercial weighing equipment for conformance with legal specifications, and to advise with manufacturers as to acceptance of such equipment for commercial use and as to required modifications-all involving engineering considerations. To confer and advise with users of weighing devices with respect to the engineering aspects of such devices and their installation. To conduct tests on special devices and execute comprehensive reports. To represent the Division of Weights and Measures publicly. To assist in the planning of inspection, testing, and enforcement programs. To operate highly specialized equipment for testing weighing devices.

Minimum Qualifications. Education. The successful completion of high school (twelfth grade) and the successful completion of four years at a college or university or its equivalent. There may be substituted for each year of required college or university training one and one-half years of experience in weights and measures enforcement or similar law enforcement or technical investigation fields. A bachelor degree in mechanical engineering from a university or college is desirable. Experience. At least six years experience in weights and measures or other law enforcement activity involving technical investigation. (This experience or any part of it may be applied also to the educational requirements above.)

Knowledges and Abilities. Excellent ability in both spoken and written English. Thorough working knowledge of State weights and measures statutes and rules and regulations. Knowledge of the basic principles of scale design and the application of leverage. Ability to manipulate difficult mechanisms. Ability to produce working drawings of relatively complicated machines. Ability to speak effectively, either formally or informally, before small or large groups.

Special Personal Characteristics. Good health, strength, and agility. Willingness to work irregular hours and to travel throughout the State. Excellent moral character. Ability and willingness to impart ideas to others and to teach methods and procedures. Willingness to work alone and to approach and attack a problem until the proper solution is found, regardless of the time, travel, or inconvenience involved.

\section{GRADE V}

\section{Measuring Instrument Specialist-Weights and Measures}

Definition. Under policies established by the director (deputy superintendent) of weights and measures and with very wide latitude for independent decision and action, to serve as engineering advisor and measuring instrument specialist. To plan and, in many instances, conduct in-service training of weights and measures personnel. To plan testing procedures and instruct field personnel in their application. To prepare engineering designs of special testing equipment. To make detailed examinations of commercial measuring equipment for conformance with legal specifications, and to advise with manufacturers as to acceptance of such equipment for commercial use and as to required modifications-all 
involving engineering considerations. To confer and advise with users of measuring devices with respect to the engineering aspects of such devices and their installation. To conduct tests on special devices and execute comprehensive reports. To represent the Division of Weights and Measures publicly. To assist in the planning of inspection, testing, and enforcement programs. To operate highly specialized equipment for testing measuring devices.

Minimum Qualifications. Education. The successful completion of high school (twelfth grade) and the successful completion of four years at a college or university or its equivalent. There may be substituted for each year of required college or university training one and one-half years of experience in weights and measures enforcement or similar law enforcement or technical investigation fields. A bachelor degree in mechanical engineering from a university or college is desirable. Experience. At least six years experience in weights and measures or other law enforcement activity involving technical investigation. (This experience or any part of it may be applied also to the educational requirements above.)

Knowledges and Abilities. Excellent ability in both spoken and written English. Thorough working knowledge of State weights and measures statutes and rules and regulations. Knowledge of the basic principles of liquid-measuring device designs. Ability to manipulate difficult mechanisms. Ability to produce working drawings of relatively complicated machines. Ability to speak effectively, either formally or informally, before small or large groups.

Special Personal Characteristics. Good health, strength, and agility. Willingness to work irregular hours and to travel throughout the State. Excellent moral character. Ability and willingness to impart ideas to others and to teach methods and procedures. Willingness to work alone and to approach and attack a problem until the proper solution is found, regardless of the time, travel, or inconvenience involved.

\section{GRADE V}

\section{Assistant Director-Weights and Measures}

Definition. Under policies established by the director (deputy superintendent) of weights and measures and with very wide latitude for independent action and decision, to manage the business affairs of the Division of Weights and Measures. To plan reporting systems, filing systems, and budget and accounting procedures. To exercise controls in routine personnel matters. To prepare written instructions as to method of operation and press, radio, and television information on activities. To assist the director (deputy-superintendent) in the planning of the affairs of the Division, and to serve as liaison between the Division and the other agencies of the government. To plan schools of instruction and programs of in-service training. To act in the absence of the director (deputy superintendent) as administrative head of the Division of Weights and Measures.

Minimum Qualifications. Education. The successful completion of high school (twelfth grade) and the sussessful completion of four years at a college or university or its equivalent. There may be substituted for each year of required college or university training one and one-half years of experience in weights and measures 
enforcement or similar law enforcement or technical investigation fields. A bachelor degree in business administration, with credits in accounting and personnel administration, from a university or college is desirable. Majors or minors in mechanical and/or electrical engineering also are desirable. Experience. At least six years experience in weights and measures administration or supervision. (This experience or any part of it may be applied also to the educational requirements above.)

Knowledges and Abilities. Excellent ability in both spoken and written English. Thorough working knowledge of State weights and measures statutes and rules and regulations. Ability to compose clear and concise business letters. Ability to appraise and manage personnel. Skill at personnel organization. Ability to keep accurate records and to prepare and justify operating budgets. Ability to speak effectively, either formally or informally, before small or large groups and on radio and television. Ability to design and supervise the production of informative displays.

Special Personal Characteristics. Good health, strength, and agility. Excellent moral character. Ability and willingness to impart ideas to others. Neat appearance.

\section{GRADE VII \\ Director-Weights and Measures}

Definition. Under only broad policies established by the to administer the weights and measures program of the State. In the field of weights and measures administration, to establish current programs and long-range plans; to develop and maintain an efficient well-organized and thoroughlytrained staff; to represent the State officially before small and large groups, both inside and outside the State; and to be the official spokesman of the State before national organizations.

Minimum Qualifications. Education. The successful completion of high school (twelfth grade) and the successful completion of four years at a college or university or its equivalent. There may be substituted for each year of required college or university training one and one-half years of experience in business or government administration, preferably in the weights and measures field. $E x$ perience. At least eight years of experience in business or government administration. (This experience or any part of it may be applied also to the educational requirements above.)

Knowledges and Abilities. Excellent ability in both spoken and written English. Ability to manage people. Ability to demonstrate and speak effectively, either formally or informally, before small or large groups and on radio and television. Ability to compose clear and concise business letters. Ability to develop an idea into a sound working plan, to look ahead, to visualize the requirements of the future, and to make positive yet flexible arrangements accordingly. Thorough working knowledge of State weights and measures statutes and rules and regulations. Natural ability to inspire subordinate personnel.

Special Personal Characteristics. Good health, strength, and agility. Neat personal appearance. Ability and willingness to direct personnel, to impart ideas to others, and to organize, plan, and direct a technical and administrative program.

(The report of the Committee on Education was adopted by the Conference.) 
By L. E. Stern, Deputy Attorney General, Department of Law and Public Safety, State of New Jersey

During the past several months I have conducted extensive research on the subject assigned to me. This study has convinced me that it is a subject about which the most learned minds might disagree even after long study and discussion.

The problem itself can be stated simply enough. Assuming a food package to have been shipped in interstate commerce, when can State weights and measures officials inspect it and proceed with prosecution in the event there is a violation of State Law?

The answer is not simple, because it depends in almost all cases upon determining the applicability of particular segments of six huge bodies of law. First, there are the Federal statutes; second, there are the administrative rules and regulations promulgated pursuant thereto; third, there are the decisions of the Federal courts, including Supreme, Circuit, and District; fourth, there are the State statutes; fifth, there are the State regulations; and sixth, there is the State case law as enunciated by the State courts at the various levels. To these six might well be added two more-the quasi-judicial determinations of the particular Federal and State agencies. It is true that, after examination of all of these, only certain of them may be found to be helpful to the particular problem. Nevertheless, they should all be checked.

The most important of these bodies of law, of course, is that body of decisions pronounced by the United States Supreme Court.

The decisions of the United States Supreme Court are the most important because the pronouncements of that court are the last word. Undoubtedly, the Congress, if it is dissatisfied with the result of a Supreme Court decision, may make new legislation, but that new legislation will also be subject to judicial review.

Some of you may be silently asking at this point-Well, what does the United States Supreme Court say as to when I can step in and act against food packages marked in violation of my State's law? The answer is that the Supreme Court has said a great many things in a great many cases. Yet, despite this, I think I may safely say that it has not yet ruled on your particular problem. The court, to be sure, has laid down at least three broad principles of law.

One of these is that the State government may pass reasonable weights and measures laws to protect the consumers of the State, and that such laws are a legitimate exercise of the "police power" of the State. The second principle, however, imposes limitations on the first. Regardless of the fact that a State law may have been enacted as a legitimate exercise of the State's police power, it may nevertheless be held invalid because it imposes a burden on interstate commerce. The third principle is a refinement of the second. That principle is that, if the State law imposes merely a casual or incidental burden on interstate commerce, it will not be struck down.

Two other limitations on how far a State may go in passing this kind of statute are found in the due process and equal protection provisions of the Fourteenth Amendment. An interesting case 
under the due process provision is the case of Jay Burns Baking Co. vs. Bryan, 264 U. S. 504, decided in 1924. That case concerned an act of the State of Nebraska requiring bread to be sold in $1 / 2$ pound, 1 pound, 11/2 pounds, or exact multiples of a pound, and prohibited the sale of loaves of bread at any other weights. The act allowed a tolerance of two ounces per pound over a 24-hour period. The Supreme Court held in effect that the tolerance could not be met unless the bakers wrapped their bread. The court said:

... The uncontradicted evidence shows that there is a strong demand by consumers for unwrapped bread ... It having been shown that during some periods in Nebraska bread made in a proper and usual way will vary in weight more than at the rate of 2 ounces to the pound during 24 hours after baking, the enforcement of the provision necessarily will have the effect of prohibiting the sale of unwrapped loaves when evaporation exceeds the tolerance.

The court concluded that the act "subjects bakers and sellers of bread to restrictions which are essentially unreasonable and arbitrary, and is therefore repugnant to the Fourteenth Amendment." You may be interested to know that not all the judges on the court felt this way. The dissenting opinion is written vigorously and includes an impressive array of statistics to show that the tolerance was reasonable. The dissenting opinion also relies heavily upon the case of Schmidinger vs. City of Chicago, which some of you may recall seeing on page 3 of your Weights and Measures Case Reference Book.

Nine years later, the Nebraska act again came before the Supreme Court (P. F. Peterson Baking Co. vs. Bryan, 290 U. S. 570). It had been changed to permit the Secretary of Agriculture to prescribe the tolerances. He had done so, prescribing 3 ounces over a 12-hour period. The court held that bakers could comply with this tolerance and upheld the statute. Both of the Nebraska cases are also in your case reference book.

There are other interesting cases under the due process provision of the Fourteenth Amendment and under the "equal protection" provision as well, but time does not permit discussion of them. I have included mention of these provisions to indicate to you that, even where there is no interstate commerce problem, the State statute may still be declared invalid as violative of fundamental constitutional rights.

Let us concentrate on the interstate commerce problem. We know that. though a State statute is enacted within a proper exercise of the State's police power, it may nevertheless be held invalid because it imposes a burden on interstate commerce. What constitutes a burden on interstate commerce? The fairly recent case of Dean Milk Co. vs. City of Madison, Wis., 340 U. S. 349 (1950) presents one example of such a burden. There the City of Madison passed an ordinance prohibiting the sale of milk that had not been processed and bottled within five miles of the city. The Supreme Court held this to be a burden on interstate commerce.

Another example is found in the case of Minnesota $v$. Barber, 136 U. S. 313 (1890). There the Minnesota statute prohibited the sale of any beef which had not been inspected by local inspectors within 24 hours of slaughter. The Supreme Court held the statute to be invalid, saying that the effect was to ban good meat from other States. 
In these two cases, the State statutes were held to impose a burden upon interstate commerce. Having these cases in mind, if you were the judge how would you have decided this case? A State law is passed fixing the capacity, form, and dimensions of containers for raspberries and strawberries, and prohibiting the use of any other type of container. An out-of-State basket manufacturer wants to sell to packers in the State his baskets, which have the same capacity but different form and dimensions than those prescribed by the State law. He brings a suit attacking the State law. Is the State law an undue burden on interstate commerce? The Supreme Court held that it was not and that the law was good. They said the law was not aimed at the basket manufacturer but at the in-State packer, and that the manufacturer could sell his baskets in the State. The fact remains, however, that no packers in the State would want to buy his baskets, since they were prohibited from using them. I am not criticizing the decision, but merely pointing out this fact.

The case Pacific States Box \& Basket Co. v. White may be found on page 7 of your case reference book. Another question raised in that case was whether the State law was in conflict with the Federal Standard Container Acts of 1916 and 1928. It was held that, since those Federal acts did not deal with the same subject matter as the State law, there was no conflict.

This brings us to the heart of our problem. We have seen that, even though no act of Congress has been passed on a particular subject, a State law may nevertheless be held to impose an undue burden on interstate commerce. Suppose that Congress has passed a law on the subject and the State also passes a law about it, what happens then?

A good starting point is the case of Savage v. Jones, 225 U. S. 501 , decided in 1912. An act of the State of Indiana required that packages of concentrated commercial animal feed be labeled with a detailed statement of ingredients.

A Minnesota manufacturer of such a product sold it in Indiana. The sales were F. O. B. Minneapolis, and were delivered to Indiana purchasers in original unbroken packages, the freight being paid by the Indiana purchasers. The Minnesota manufacturer brought a suit to enjoin the enforcement of the Indiana law. The United States Supreme Court held that the transaction involved interstate commerce. However, the court ruled that the Indiana act did not unduly burden interstate commerce. The Minnesota manufacturer argued that the State law conflicted with the 1906 Federal Food and Drug Act, which contained provisions prohibiting misbranding. The court pointed out that the Federal act did not include a requirement that the ingredients be stated on the label. The language of the Supreme Court opinion, delivered by Mr. Justice Hughes is significant:

If the purpose of the (Federal) act cannot otherwise be accomplished-if its operation within its chosen field else must be frustrated and its provisions be refused their natural effect-the State law must yield to the regulation of Congress within the sphere of its delegated power.

Mr. Justice Hughes went on to say:

But the intent to supersede the exercise by the State of its police power as to matters not covered by the Federal legislation is not to be inferred from 
the mere fact that Congress has seen fit to subscribe its regulations and to occupy a limited field. In other words, such intent is not to be implied unless the act of Congress, fairly interpreted, is in actual conflict with the law of the State."

The very next year, the Supreme Court decided the famous case of McDermott $v$. Wisconsin, 228 U. S. 115. A Wisconsin statute required that a certain syrup be labeled "glucose flavored with refiners' syrup." Under the Federal Food and Drugs Act of 1906, the syrup could be labeled "corn syrup with cane flavor." The product had been properly labeled under the Food and Drugs Act, but did not have on it the label required by the State of Wisconsin. A Wisconsin retailer sold the product and was convicted under the State law. The United States Supreme Court reversed this conviction, and held the Wisconsin statute invalid on the ground that it unduly interfered with the enforcement of the Federal law. The court held that, for a retailer to comply with the State law, he would have to remove the interstate label which met the Federal requirements and substitute a new one.

As to this, the court said:

To make the provisions of the act effectual, Congress has provided not only for the seizure of the goods while being actually transported in interstate commerce, but has also provided for such seizure after such transportation and while the goods remain "unloaded, unsold, or in original unbroken packages." The opportunity for inspection en route may be very inadequate. The real opportunity of government inspection may only arise when, as in the present case, the goods as packed have been removed from the outside box in which they were shipped ....

In 1916 the Supreme Court decided the case of Armour \& Co. $v$. North Dakota, 240 U. S. 510. In that case the North Dakota statute required lard not sold in bulk to be sold in containers holding 1,3 , or 5 pounds net weight, or multiples thereof, and to be so labeled. Armour \& Co., an out-of-State company, sold containers of their lard to North Dakota. The Armour containers held 2 pounds, 6 ounces net weight of lard and were so labeled. The Court held that the North Dakota act was not repugnant to the 1906 Food and Drugs Act. Interestingly, the Court pointed out that the North Dakota law applied to retail sales and not to the packages of importation, and that it did not burden interstate commerce. The court said :

The (Federal) act is directed against the adulteration and misbranding of food transported in interstate commerce. The State statute has no such purpose; it is directed to the manner of selling at retail, which is in no way repugnant to the Federal law ...., and the operation of that law is in no way displaced or interfered with.

Since the Supreme Court in this case says that the State law was not directed at interstate commerce but at retail sales within the State, why did not the court say the same thing in the McDermott case, where the defendant was charged with a retail sale of packaged syrup which violated State law. I think the answer is that in the syrup case the State law unduly burdened the enforcement of the Federal act because it would have required the removal of the Federal label, while in the North Dakota case there was no such interference with the operation of the Federal law. 
I think this reasoning explains, at least to some extent, the controversial decision of Cloverleaf Butter Co. v. Patterson, 315 U. S. 148, decided by the Supreme Court in 1942. In that case Alabama manufacturers processed packing-stock butter, making it into renovated butter. They sold the renovated butter in interstate commerce. A Federal statute gave the Secretary of Agriculture authority to inspect at the factories the packing-stock butter and the other materials used in the manufacture of the finished product, renovated butter. However, the Federal law did not authorize the Secretary to seize the packing-stock butter; he was only permitted to seize the finished product, renovated butter. Alabama passed a law authorizing the inspection and condemnation of the packingstock butter.

A bare majority of the court, five justices, held that the Alabama law was invalid. They said that Alabama could seize the packing-stock butter before it came to the manufacturer, and that it could regulate the sale of renovated butter within the State after it was made. But, they said, the State could not interfere during manufacture.

Four of the justices, including Chief Justice Stone who wrote the dissenting opinion, said there was no conflict of State and Federal law here. They said that, since the Federal government under its law could not seize the packing-stock butter during manufacture, the State should be permitted to do so. While I am inclined to agree with the reasoning expressed in the dissenting opinion, the basis of the majority opinion appears to be that, since the Federal government could inspect during manufacture and could seize the finished product, to permit the State to step in and seize during manufacture would interfere with the discretion of the Federal authorities and thus interfere with Federal enforcement.

As I said, this appears to me to be the key to the decisions-that is, that the basic question is whether the State law interferes unduly with the enforcement of the Federal statute. The same view is taken by Mr. Thomas W. Christopher, to whom I am indebted for his excellent article in the May 1955 issue of the Food Drug Cosmetic Law Journal.

A most interesting problem is raised by a group of cases under the Food, Drug and Cosmetic Acts. These cases do not directly involve the State's power to pass laws in this field. The cases to which I refer are those in which prosecutions were undertaken under the Food, Drug and Cosmetic Acts. Their interest to us lies in the fact that the courts construed the Federal power quite broadly in areas which were traditionally local or intrastate in nature.

Under the United States Constitution, the Federal government is given the power to regulate commerce among the several States ; it is also provided in the Constitution, however, that the "powers not delegated to the United States" are "reserved to the States." A traditional power of a State is its police power. While it is fairly clear that the State's police power cannot extend to interference with interstate commerce, the vital inquiry arises as to how far the commerce clause of the Constitution does extend. The 1948 decision of Sullivan v. United States involved these facts. A wholesale drug company in Atlanta, Georgia, purchased from an Illinois manufacturer a bottle containing one thousand sulfathiazole pills. The 
bottle was properly labeled under the Federal act. It was sold by the Atlanta, Georgia, wholesaler to a retail druggist in Columbus, Georgia. The druggist took twelve pills out of the bottle and placed them in a box which he marked "sulfathiazole." A criminal information was filed against him under the Food, Drug and Cosmetic Act. The prosecution was upheld by the Supreme Court.

Undoubtedly a decision like this indicates that the Federal power extends over activities which might logically be considered local or intrastate in nature. Does this mean that a State statute regulating such activities will be struck down as dealing with interstate commerce? I do not think so. First, we will recall that the State law must impose an undue burden on interstate commerce. Second, it is my guess that the Supreme Court's view of what constitutes interstate commerce is an elastic one depending upon the nature of the case. In my opinion, and it is really only a guess, I would think that the Supreme Court would treat the scope of interstate commerce more broadly in a case involving prosecution under Federal law than in a case where the validity of a State statute is being questioned.

Let me turn from a discussion of the law in this field, which I hope you have found interesting, to a very practical question some of you must be thinking about. When do you have the right to proceed under your State law?

It is obvious that it would be ridiculous for me to hazard an opinion as to whether a particular section of your State law would be declared invalid by the Supreme Court. Even after careful study of such a question, I could only make what we lawyers call an educated guess.

The practical answer to this question is quite clear, however. Your law is presumed to be valid until a court declares it to be invalid. Naturally therefore, you will enforce that law. Let me add that, if any of you have any doubts as to anything connected with that law, the legal counsel in your State are the proper persons to advise you in that regard.

I have discussed with you this morning some of the cases decided by the United States Supreme Court in which the limitations of permissible State action under particular circumstances have been examined by the court. Undoubtedly, many of you can probably think of some possible conflict between your State law and Federal law. I do not think that any serious practical problem is raised. If you enforce your laws, you have done your duty. It is not your duty to pass the laws, nor is it your duty to be the judge of them. Assuming that there is a twilight zone between the State and Federal jurisdictions, the only way we can make it a clear line is to let the courts give us the answers.

From my observations of the work of our New Jersey officials over the past year, and from what I have seen and heard this week, I have developed a tremendous admiration for your work. You are the most efficient official protectors of our citizens against chiselers and cheats. You are an invaluable aid to business and industry people, the vast majority of whom are completely honest and seek your advice as to the proper ways to approach their problems. The presence of such gentlemen here this week attests to that fine spirit of cooperation. This whole Conference, at which you have assem- 
bled from all parts of our country for the purpose of cooperative interchange of ideas, is a living example of the greatness of our democratic system. It is one of the many examples of the advantages inherent in our form of government which are not present in a totalitarian form.

\section{STATE-CITY WEIGHTS AND MEASURES COOPERATION IN WISCONSIN}

By C. L. JACKson, Chief, Division of Economic Practices, Department of Agriculture, State of Wisconsin

National Bureau of Standards Handbook 26, Weights and Measures Administration, states that the primary function of a weights and measures official is to "see to it that equity prevails in all commercial transactions involving determination of quantity. To this end are passed all laws on weights and measures; for this purpose are promulgated the weights and measures rules and regulations affecting the conduct of business and the specifications and tolerances governing the instrumentalities of weighing and measuring; and it is this principle which constitutes the keynote of the daily activity of the weights and measures official."

By the same token, the primary purpose of all programs of every city jurisdiction, every county jurisdiction, and every State jurisdiction is to achieve the equity in all quantity commercial transactions.

To accomplish this main purpose, there is required weights and measures uniformity-uniformity in laws, regulations, and ordinances; uniformity in interpretation and application of these legal requirements; uniformity in the interpretation and application of specifications and tolerances; uniformity in equipment test procedures, package weighing programs, legal enforcement techniques; and uniformity in telling the weights and measures story to the public. Uniformity and equity cannot be accomplished without cooperation in its truest sense, whether the problem be local, regional, State, or National in character.

So, cooperation is the keystone of all our efforts in the weights and measures activity in the State of Wisconsin. We recognize that, without this cooperation, we cannot accomplish the principal purpose of all our work, that of obtaining equity and uniformity.

Wisconsin is but little different from any other State as far as the problems of obtaining and maintaining equity and uniformity are concerned. With a population of about $31 / 2$ million, Wisconsin is quite equally balanced in agriculture, industry, the professions, and general business. Our weights and measures law enacted in 1911 provides for State supervision of weights and measure in the State Department of Agriculture. It provides that the State shall have direct supervision and shall conduct inspections in all areas outside of cities and villages in excess of 5,000 population. Currently there are 55 city departments of weights and measures. About 15 of these departments employ full time sealers. The State staff consists of nine area inspectors, two heavy-scale testing operators, a field supervisor, a weights and measure inspection supervisor, and a department division head.

Cooperation will work in direct proportion to the efforts put forth in its behalf. It requires more than merely the giving of lip service. We have to work at it to make it work for us. So in Wis- 
consin we are endeavoring to build cooperative activities and programs which will result in more uniformity and more equity.

We would like to point out some of the cooperative activities and programs which are being carried on jointly by city departments and the State office of weights and measures.

Cooperation through State Advisory Committee. About 2 years ago our State Department of Agriculture named a state-wide city department advisory committee. Its primary purpose has been to counsel with the State office on problems of state-wide concern and act as an exchange of technical and administrative information between State and city and among the city departments. This advisory committee has also as an objective improving the understanding of the problems of the various departments. One result has been that the sealers have become better acquainted. Periodic meetings are called either by the chairman of the committe or by the State office, which provides the secretary of the committee. Uniform testing procedures, including use of seals, changes in State laws and regulations, and state-wide testing and inspection programs, have been discussed by the committee. The committee represents the best in weights and measures leadership and thinking that we have in the State of Wisconsin. All state-wide policy statements to be issued by the State office and proposed regulations which may be considered are reviewed by members of the advisory committee before they are put into effect. This committee is serving a very useful purpose toward building more uniformity and progress in weights and measures administration.

Cooperation through Regional and State Conferences. Local, regional, and State conferences are important factors in building uniformity. The State is divided into territories for the purpose of city sealer sponsorship of regional meetings participated in by all city sealers in the territory and the State office. The meetings are ones of good fellowship, inspiration. and information. State-wide programs and progress are reviewed, and individual problems of sealers discussed. Places for the meetings and types of programs are developed by a local committee of city sealers. Groups get together on an average of about two times per year. The State office is encouraging an intensification of this type of meeting because it has been found that it is very effective in informing, training, and encouraging the work of the city sealer.

During the past several years two different types of state-wide training conferences have also been held. One was a two-dav school for sealers sponsored jointly bv the Department of Agriculture and the Wisconsin League of Municipalities. This school was especially well attended and found to be worthwhile. A similar training school on a more limited basis was held last July, attended bv all State sealers and the State city-sealers' advisory committee. No outside speakers were invited to attend, and the time was spent in demonstrations, panel discussions, and short informal discussions on various phases of the weights and measures work. This tvpe of meeting was found to be especially appropriate for training, and in reviewing state-wide programs and problems and developing plans for future activities.

Cooperation through Heavy-Scale Testing Program. Two new heavy-scale testing units put into operation and operating on a state-wide basis in both city and State territories have proven to 
be very helpful in building cooperation and uniformity throughout the State. Vehicle scales in city jurisdictions are tested by the State unit, working with the local sealer. In addition to greatly improving the type of test applied to scales in the cities, this program also has been helpful in giving local publicity to both the city and State program. The heavy-scale testing operators have had suggested news releases and mats available to turn over to the local editor. In many cases local editors have taken pictures, included the city sealer in the pictures, and published write-ups covering city and State weights and measures piograms. This program is one of the best examples of cooperation in action between city departments and the State office.

Cooperation through Newsletter and Publicity. For the past several years a monthly newsletter has been put out by the State office with the help and cooperation of both city and State sealers throughout the State. The newsletter is designed to be a "grass roots" publication carrying everyday experiences of weights and measures work in the field. Through the newsletter every effort is being made to emphasize the economic importance of weights and measures accuracy. It serves to keep all who are involved in the work abreast of state-wide problems and progress.

The State office encourages sealers to tell their story to local editors. Periodic weights and measures stories are put out by the State office to all weekly and daily papers in the State, and to television and radio stations. In addition, the State office has put on several TV shows in cooperation with the local sealer in the city where the station is located.

Cooperation through a State Handbook. In 1953 the Wisconsin legislature adopted by statute the specifications and tolerances of the National Conference on Weights and Measures as set forth in Handbook 44. With the issuance of H44 in loose-leaf form this past year, the State office obtained two types of loose-leaf leather notebooks and made them available to all city departments and to State sealers. Wisconsin Weights and Measures Handbook A is used for H-44. Wisconsin Weights and Measures Handbook B includes all appropriate State laws, State department rules and regulations, State department policies and directives, and further general and specific information of value to the sealer and inspector in his everyday work in the field.

Through these handbooks it is intended that every person working in weights and measures in the State will have a neat, attractive, complete, and up-to-date guide for intelligent and informed action.

Cooperation in Expansion of State Laboratory. Plans are being worked on at the present time to improve and expand our State weights and measures laboratory. With the addition of some more balances and other equipment in our laboratory and with the improvement of our laboratory techniques, it is planned that all city sealers, on a regular basis, will bring in all of their weights and other equipment for checking. Testing procedures will be discussed and work programs will be reviewed. This same method will be used for all State inspectors. However, before such a program can be developed to a point where it will be effective, it will be neces- 
sary that a new location be obtained on ground-floor level where vehicles can be driven into the building, and tests on both heavy and light equipment can be made. At the present time, our laboratory is quite well equipped with balances and standards for light testing, but it is located on the fifth floor of the capitol and thus is somewhat inaccessible.

Cooperation through State-wide Enforcement Surveys. It appears to us that we need to conduct more concerted, extensive, and specialized state-wide surveys. In the past several years, such enforcement drives have been carried out on potato-weighing equipment and potato packages and on canning factory scales. In each case the programs have been planned carefully and well in advance, and have been conducted on a state-wide basis with fine cooperation of all city and State sealers. This type of enforcement program has considerable merit in making the individuals affected recognize the importance of better weight control. In each case, at the conclusion of the survey, a state-wide release has been sent out to the State press. Special stories also were sent to trade publications of the industry affected. During the months of April and May, State and city sealers are conducting a survey of dairy-plant milkintake scales. With over 1500 milk intakes in our State, this involves a considerable amount of work. On the other hand, these scales weigh an average of 500 million dollars worth of product a year in Wisconsin.

We are also working to make our package reweighing program more effective on a State-wide basis. When this program has been studied and developed to the point where it is practical and effective, it is expected that this program too will be put into operation on a state-wide basis, with drives being made on specific commodities at various times throughout the year. In each case efforts will be made to give the project considerable publicity, and will be accompanied by a strong educational and enforcement follow-up.

Cooperation through State Information Clearing House. It is our objective to have the State office a focal point or clearing house for weights and measures investigations, projects, and programs. For example, presently, city sealers are encouraged to refer package labeling problems to the State office. These problems are then referred to our Food Inspection Section for enforcement and followup. The Food Section, on the other hand, refers all weight problems to the weights and measures office, where follow-up is conducted either by State or city sealers. City sealers refer technical and administrative problems to the State office, where efforts are made to help work out effective practical solutions. A free flow of information and a willingness to work together on mutual programs are vital to building uniformity and in making progress.

Cooperation with National Office. While we are on the subject of city-State cooperation, we would be remiss if we did not mention the splendid cooperation between the Office of Weights and Measures of the National Bureau of Standards and our State and city departments. This cooperation is just as vital to the success of our work as is cooperation on the city and State level. We have never had the Office of Weights and Measures fail us when we needed counsel and help. We have tried to reciprocate too to the best of our ability when called upon by the National office. 
Cooperation requires human engineering-doing real work together. We are trying in Wisconsin to work at cooperation so that it will work for us. It is paying off, we believe. These are a few examples of how we in Wisconsin are endeavoring to make progress and build uniformity through cooperative projects so that "equity prevails in all commercial transactions involving determination of quantity." We know that we are falling far short of our goal, but we have confidence that, through city-State and National cooperation, progress is being made.

\section{WHY WEIGHTS AND MEASURES TRAINING SCHOOLS?}

By T. C. HARRIS, JR., Supervisor, Weights and Measures Section, Division of Markets, Department of Agriculture, State of Virginia

As the official charged with the supervision of the weights and measures program in Virginia, I feel that I can speak without reservation on the necessity for having an annual weights and measures training school in every State.

The purpose of any State in having such a school is parallel, I think, to the purpose of holding an annual National Conference. Here at the National Conference, weights and measures officials have an opportunity to discuss problems of mutual interest. From the various committees of this Conference come proposed amendments or additions to the material previously adopted by the Conference. During open committee meetings prior to the Conference, all interested parties are given an opportunity to appear before these committees and offer their suggestions. From these earnest discussions come the proposed laws, regulations, and other recommendations of the committees to the Conference body for adoption.

After official adoption by the Conference, these recommendations become pilots to guide weights and measures officials in their enforcement program. In addition, codes adopted by the Conference are used by equipment manufacturers as their basic guide in the design and construction of commercial weighing and measuring devices.

In coniunction with the Conference, the National Bureau of Standards provides the necessary publication of the actions taken by the Conference which, in turn, are strongly recommended to the States for acceptance.

There is no question but that the National Conferences have made a great contribution to weights and measures administration throughout this country. The officers of these Conferences and the members of the various committees have worked long and diligently to discharge their responsibilities. To these men we are deenlv indebted. The fruits of the labor expended bv the Conferences have been manifested in the ever-popular Handbook 44 .

The Regional and State Conferences are of enual importance in promoting weights and measures services within their respective jurisdictions: however. we in Virginia weights and measures enforcement realize that these Conferences are just the beginning in the effort toward uniformity in the testing and inspectino of equipment and in the enforcement of the laws and regulations enacted or promulgated by the State. 
So that we can better understand and fulfill our responsibilities as enforcement officials, and so that we can digest collectively the provisions of Handbook 44, a 2-day Weights and Measures School is held in Richmond each year for State, City, and County inspectors. The first of such schools was held in 1949. This school was so successful that now it is considered a necessity in our training program.

I am sure that there is not a person here who would send an inspector into the field to discharge his duties without some kind of training. Yet, how many of us are guilty of sending a man into the field to enforce our laws with only a minimum of training, and many times without subsequent close field supervision? In my opinion, a minimum of training is insufficent and can have serious adverse effect on our program.

Too often we find ourselves blaming inadequate salaries, unqualified personnel, and lack of cooperation from our superiors as reasons for failures in our weights and measures program. True, these are very discouraging, but I feel that many, if not all, of these difficulties can be overcome.

The men who can help most to improve these conditions are the inspectors in the field--the men who actually enforce the laws and perform the physical tests on equipment. To do their jobs properly, these men must be thoroughly trained, preferably by qualified teachers who are leaders in the weights and measures field. In this connection the staff of the Office of Weights and Measures of the National Bureau of Standards has been most helpful.

For many years, in groups where weights and measures officials gather, I have heard it discussed that what was needed most in the weights and measures program was uniformity in inspections. At our school each year, a large part of our program is devoted to the study and correct interpretation of the specifications, tolerances, and regulations outlined in Handbook 44. This, we feel, is the shortest and quickest way to make uniformity become a reality. This has been done through a "Questions and Answers Session." At first the inspectors were required to submit the auestions to headquarters. These questions were in turn assigned to other inspectors for answering. Originally the questions, of a routine nature, frequently dealt with the problems encountered in the field. Later it became a challenge to each inspector to try to submit a question that would be difficult for another to answer. As the men became more interested in the questions and answers part of the school, more and more study of Handbook 44 was accomplished.

Eventually, however, the calibre of the questions began to diminish to the point that it became necessary for the supervisor to compile a list of questions which would renew interest in the studying of Handbook 44. As before, these questions were assigned to inspectors several weeks prior to the school.

Still later, a new plan was introduced whereby the supervisor and Mr. Jensen of the National Bureau of Standards jointly prepared a list of extremely difficult questions that made necessary an intensive study of the Handbook. These questions were mimeographed in the office and distributed to the inspectors approximately 1 month before the school. A notice accompanied the questions to the effect that no longer would the inspector be assigned a specific question, but that under a new procedure questions 
would be drawn from a hat and any inspector might be required to answer any of the questions.

This latter method of conducting the questions and answers session proved to be the most effective. The success of this particular method can be attributed to the fact that the men were compelled to study more intensively, thus broadening their knowledge of Handbook 44. The questions were "brain teasers," necessitating many hours of study. Without exception, the men came prepared to display their knowledge with pardonable pride.

While the questions and answers session is of great importance, it represents only a portion of our school. Since the beginning of our schools, the testing and inspecting procedures of practically all commercial weighing and measuring devices have been discussed and demonstrated. In this connection, an inspector conducts the physical test on a particular device in the presence of the other inspectors who subsequently offer constructive criticism. Here again, uniformity is achieved.

During recent years we have expanded our package checkweighing program considerably. The problems in this field are numerous. Here again, definite policies must be established and followed. The school affords an opportunity to review procedures and discuss new policies.

Through our belief in and support of an annual training school, we know that we are becoming better qualified to discharge the duties with which we are entrusted. Although we rely on the National Conference for guidance, the application of its accomplishments is left to the discretion of the individual States. In my opinion, this application can best be made through continuous training of inspectors. An annual school serves as an important means by which this training can be accomplished. Anyone who attends and participates in such a school will leave with a thorough knowledge of and a renewed interest in his weights and measures duties.

For these and numerous other reasons, I would strongly recommend that every State have an annual Training School.

\section{QUANTITY STATEMENTS ON ROLLS OF WALLPAPER}

By H. J. McDade, County Sealer of Weights and Measures, San Diego County, California

Wallpaper is being manufactured and sold in single, double, and triple rolls throughout the United States without any statement of quantity whatsoever. In some cases the roll will bear a statement of "Single," "Double," or "Triple" roll. This obviously is without meaning as to the actual quantity.

Section 19 of the Model State Law on Weights and Measures, adopted by the National Conference in 1951, reads in part, "that except as otherwise provided in this act, any commodity in package form shall bear on the outside of the package a definite, plain, and conspicuous declaration of (1) the net quantity of the contents in terms of weight, measure, or count, and (2) in the case of any package not sold on the premises where packed, the name and place of business of the manufacturer, packer, or distributor...." 
Generally speaking, the more expensive wallpapers are sold in rolls that are wrapped and therefore would come within the scope of Section 19. There is, however, a great deal of wallpaper sold in rolls that are not wrapped, and it is doubtful that Section 19 of the Model Law would here be applicable.

In the industry a roll of wallpaper is considered to contain 36 square feet, and the multiple rolls to contain multiples of this figure. There is no standard width for this product. It comes in 18, 201/2, $24,27,28$, and 36 -inch widths, and perhaps even in other widths, Without a standard width there can be no standard length, if each roll, regardless of width, is to contain 36 square feet.

This difference in width and lengths, without a statement of quantity on the package, causes considerable difficulty in the retailer's dealings with the consumer. There is oftentimes doubt in the customer's mind as to the integrity of the dealer. when he orders and pays for six rolls of wallpaper and apparently only two are delivered to him.

Some retailers would like to have regulations promulgated standardizing wallpaper to one width only. Others say that this cannot be done and make available to the consumer the variety of: patterns now in vogue in wallpaper design.

One thing that dealers, paper hangers, and consumers agree on, however, is that all rolls of wallpaper should bear an accurate statement of quantity.

When you consider that wallpaper sells for as much as $\$ 25.00$ and more per roll (in the case of a triple roll $\$ 75.00$ ), the consumer is entitled to know precisely the quantity he is getting. He should not have to rely entirely on the oral statement of the salesman from whom he is making the purchase, for information as to the quantity he is receiving.

It is not consistent with good weights and measures supervision that manufacturers of toilet tissue, selling for ten cents per roll, be required to state the size and number of sheets per roll, yet the manufacturers of wallpaper are allowed to furnish their products without any quantity statement whatever.

A statement of quantity on a roll of wallpaper should include such information as to whether it is a single, double, or triple roll, together with the width, length, and number of square feet contained therein.

(A motion by Mr. McDade to the effect that the matter of quantity statements on rolls of wallpaper be referred to the Committee on Laws and Regulations was adopted by the Conference.) 


\section{SIXTH SESSION-AFTERNOON OF THURSDAY, MAY 24, 1956}

(J. E. Mahoney, Vice President, Presiding)

REPOR'T OF THE COMMITTEE ON TRADING BY WEIGHT, PRESENTED BY G. L. JOHNSON, CHAIRMAN

During the past year your Committee on Trading by Weight has received support on the efficiency improvement it believed to be possible through trading in grains by hundredweight rather than by pounds per bushel. Your committee received such support from such organizations as American Farm Bureau Federation, The National Grange, The American Feed Manufacturers Association, The Central Retail Feed Association, The Eastern Federation of Feed Merchants, and numerous other State feed and grain trade organizations. Your committee also received support in its desire that the Agricultural Marketing Service of the U. S. Department of Agriculture conduct a study which would assess the problems, the advantages, and disadvantages involved in such a change in grain trading practice. Your committee has received support in its desire from such organizations as The National Grain and Feed Dealers Association, The National Grain Trade Council, The Soy Bean Growers Association, The National Soy Bean Processors Association, The Corn Industries Research Foundation, and The Midwest Feed Manufacturers Association, together with other State farm and agricultural trade associations.

In view of this support of the activities of your Committee on Trading by Weight as conducted over a number of years, your committee now feels that it is time to recommend, and it does recommend, that the National Conference on Weights and Measures endorse the principle of trading grains by hundredweight rather than the current practice of trading grains in pounds per bushel.

(The report of the Committee on Trading by Weight was adopted by the Conference.)

\section{TRADE PRACTICE IN THE MEAT PACKING INDUSTRY}

By L. D. SinclaIR, Chief, Packers and Stockyards Branch, Livestock Division; A.M.S., U. S. Department of Agriculture

It is my pleasure to appear before your 41st National Conference and speak briefly on the provisions of the Packers and Stockyards Act as it applies to weighing problems in the livestock marketing and meat packing fields. Authority under the Act stems from such general language as "It shall be unlawful for any stockyard owner ... to engage in or use any unfair, unjustly discriminatory or deceptive practice or device" in the conduct of his business and such stockyard operator must render reasonable stockyard services. The Act also requires that "It shall be the duty of every stockyard owner .... to use, observe and enforce just, reasonable and nondiscriminatory regulations and practices." Likewise, a commission man and a dealer and their employees must not engage in unfair practices, etc. The weighing of livestock is one of the most important services rendered at a stockyard. Accuracy and dependability are required to meet the requirements of the Act. 
A meat packer subject to the Act, and there are about 2000 that are, must not "engage in or use any unfair, unjustly discriminatory and deceptive practice or device in commerce" or engage in monopolistic practices or engage in a course of business for the purpose or with the effect of manipulating or controlling prices in commerce or of creating a monopoly in connection therewith. The Act gives the Secretary jurisdiction over all phases of the meat packer's business. This includes his buying operations on and off the livestock markets. Meat packers operate approximately 1,000 scales over which they buy livestock direct from livestock producers. These scales, in order to meet our requirements, should be tested and inspected semi-annually by a competent testing agency. The requirements of our Act relative to scale testing differ from State and local weights and measures laws in that the burden of having the scales tested is placed on the scale owner rather than making the Department of Agriculture responsible for conducting such tests. In order that scale owners may not be overburdened with scale testing requirements and in the interest of harmonious working relations, Mr. R. D. Thompson, our supervisor of scales and weighing, who formerly was with the State of Virginia and is known to most of you, has contacted many of you within the past year soliciting your assistance. He has been successful in procuring excellent cooperation generally-thanks to many State and local officials and scale company representatives. He has solicited your assistance in order that these scales have the proper testing and supervision to provide reasonable services at the various stockyards and at the buying stations owned by meat packers. We feel that with your assistance the job can be done without duplication of effort and a very valuable service can be rendered to livestock producers. We have found that the vast majority of stockyard operators and meat packers have welcomed a thorough testing and inspection of their scales because they too wish to receive accurate weights in connection with the operation of their business.

The making of false and fraudulent scale tickets or the making of false records in connection with the giving of false weights is made a felony under the Act, the penalty for which is imprisonment for a term of not more than 3 years and a fine of not more than $\$ 5.000$. We have prosecuted a good many men employed in the livestork marketing industry for making the false records resulting from fraudulent weights. Twenty some were prosecuted at one market at one time and all were found guilty in the Federal District Cnurt Mon who are morallv weak or who become greedv find it a temptation that is apparently too great to resist when they have the ability to obtain an advantage merely by pressing a false weight on a scale ticket. A cursory examination will not disclose these false weights. It takes close scrutinv and study by a person skilled in scales and weighing practices. Of course most weighers have a desire to weigh honestly and attempt to operate the scales so as to give accurate weights. This type of weigher creates no problem and needs onlv a reasonablv accurate scale to perform his duties in an acceptable manner. The dishonest weigher mav be auite skilled at his trade- the more skillfull he is the more clever he mav become at giving dishonest weights. Disclosure of false weighing and developing proof of this false weight is not always easy or simple, but it can be done if the person or persons making 
the study wish to spend the time and apply the patience that is necessary. The profits that can be realized from fraudulent weights is sizeable. In one market alone we proved by our study that this fraud exceeded one million dollars per year. In another it exceeded $\$ 250,000.00$. Also at a direct buying point one packer employee told me that a fraudulent scheme practiced at that point was worth over $\$ 250,000.00$ in a period of a few years to those engaged in the fraud. Some of this packer's employees took part in this scheme. It therefore is not a matter of idle talk, but requires constant attention by those who buy and sell livestock and by authorities in the Federal, State, and municipal governments who have jurisdiction over such matters.

Inasmuch as we have supervision over-all operations of meat packers coming within that definition in the Act, we have supervision of all practices surrounding the weights of items processed and sold by packers on a weight basis. Most meat products are sold in this manner. We will, of course, investigate matters complained of by any party who claims to be injured by false weights on an item by a meat packer and we may initiate an investigation on our own motion if false weights are suspected.

The distribution of meat products in the package form and in the frozen state has been on the increase in recent years, and this leads to the possibility for a greater number of errors in meat products. We have not had sufficient money or personnel to make extensive investigations in the field of weights in the sale and distribution of meat products. We have investigated the complaints that have come to us. However, these have not been very great in number or significance. The matter complained of most of the time is the shrink that takes place in the product between the time of packaging and the time of the retail sale and use by the customer. A reasonable shrink in a product is allowable, but any insufficiency in weight due to purposeful misweighing or any acts that would result in the furnishing of an underweight product would be unlawful and prohibited by the Act. Most products sold in package form must carry labels by the meat packer showing the weight and contents thereof, etc. The Meat Inspection Division of Agricultural Research Service of the Department enforces an act pertaining to labeling of these products. Any purposeful mislabeling of a product as to weight, contents, or otherwise by a meat packer would generally result in a violation of the Labeling Act as well as the provisions of the Packers and Stockyards Act. In instances of this kind we have worked with Dr. Scott of A. R. S. to coordinate our activities with Meat Inspection. We also find that in a great many instances the Food and Drug Act has application to a product. For instance, one of the largest soap manufacturers had experimented with a shortening product to which they had added carotene. This addition of carotene gave the particular product the appearance of butter, yet it was not intended to be used as a substitute therefor. Since this product contained animal fats, this company, before placing this product on the market, came to the Department to determine whether in our opinion the color and appearance of the product mav be objectionable from the standpoint of administration of the Packers and Stockyards Act and the Labeling Act. We came to the conclusion, as did Dr. Scott, that it did not appear that the product was objectionable from the standpoint of administra- 
tion of these acts so long as care was taken not to infer that the product had the qualities of butter or made reference to buttêr. The officials enforcing the Food and Drug Act passed on the product because it contained carotene as an additive. This product received the approval of all concerned and is now sold in most food stores. In the same manner the labeling of a product as to the weight content which contained a false statement would no doubt result in a violation of the Labeling Act as well as the Packers and Stockyards Act.

The State laws of many States bear on the matter of weights pertaining to the sale of such products as meat and meat food products. We have found most States quite ready and willing to assume their responsibility in connection with complaints surrounding alleged false weights. In the sale of livestock we have found that in a few States the State laws are not adequate to cover fraudulent weighing. We would certainly recommend that these States having inadequate laws pass and enforce laws prohibiting false and fraudulent weighing of livestock. It is our desire to work cooperatively with officials of State agencies responsible for the enforcement of laws pertaining to weights and measures. We feel that much can be accomplished through a cooperative working relationship. It is a field in which duplication of effort should be avoided. We feel that much has been accomplished along this line during the past few years, and we sincerely hope that much more may be accomplished in the future.

\section{DISCUSSION ON FOREgOING PAPER}

Mr. REESE: In Iowa the National Livestock Association has requested that we test the livestock scales to capacity, either with standard weights or through a "build up" test. I would like to have the opinion of the Department on this and also information as to what other States are doing.

Mr. SinclaIR: We feel that it is important to test scales up to the maximum loads that are being weighed. A "build up" test is satisfactory if properly and carefully done. Although all States are not testing the livestock scales completely in accord with our desires, many are. We are pleased that more and more States are working with us and assisting us in our effort toward accurate livestock weights.

Mr. R. D. THOMPSON: To elahorate. as many of you know, one reason that livestnck scales should be tested from zero to the maximum load weiohed is that they normally are used throughout that range. To contrast a vehicle scale mav never be used in the lower range. Now, as to the upper limit of a test, a livestock scale with a 9 bv 24-foot platform and 30,000-pound capacitv obviously could not hold 30.000 pounds of livestork. The test on this scale need go no higher than the top load that the platform can handle.

\section{PACKAGED FOOD STANDARDIZATION}

Bv T. E. Sullivan, Director, Food and Drug Division, State Board of Health, State of Indiana

It has been my privilege to attend many of the Indiana Conferences of Inspectors of Weights and Measures and to work closely with Rollin Meek and his group of inspectors. Through this association I have become more or less familiar with the problems 
encountered in administering weights and measures laws and regulations. As a result of this growing familiarity I cannot help but be aware of the similarity of many of the problems encountered by both groups and the need for better understanding and closer liaison between regulatory officials enforcing weights and measures laws and those enforcing food and drug laws. I believe this does exist in some jurisdictions but it should be encouraged in all jurisdictions-local, state, and federal. I believe it will result in better and more economical administration of both laws and more effective public protection.

Prepackaged foods is a good case in point. Such commodities present problems to both weights and measures inspectors and food and drug regulatory agencies. You are interested in seeing to it that the declared weight or measure is indicated accurately on the container-so are we. You are plagued with the possibility of deception in the way the container is made, formed, or filled-so are we. You are concerned with the thousands of odd sized containers of an almost infinite variety of foods as to how you can determine the accuracy of the net weight declaration quickly and economically-so are we.

I have long been intrigued with the advantages that would result to the manufacturers, to the wholesaler, to the retailers, and to the consumer if prepackaged foods could be required by law to be sold in so-called "standard sized" containers. From the manufacturer's standpoint the cost of containers would be reduced, the need for carrying a large assortment of various sized containers would be largely eliminated, and expensive production lines and filling and closing machines especially tailored to handle each size would be materially reduced. The wholesaler and the retailer would no longer find it necessary to carry a large inventory representing each size and could materially reduce the overhead cost of warehousing, bookkeeping, shipping, and delivering. And finally, the consumer would reap the benefit of these savings all along the line.

First let us explore the problem. On the retail market today the consumer is offered more than 4,000 prepackaged foods, ranging all the way from breakfast cereals to pickled rattle snake meat. Each food represents the production and sales efforts of from ten to more than one hundred competing manufacturers or repackagers, each attempting to get as much of the housewife's dollar as he can. Each brand of these foods will be displayed in packages ranging from single servings through containers for use by families of four, five, or more, to the larger so-called "economy" sizes. Each attempts to take advantage of the already established buying habits of the consumer or to influence the housewife to change her buying practices. Millions of dollars are spent each year by food manufacturers in market research and in efforts to redesign packages so as to make them more enticing to the consumer and thereby obtain a competitive advantage.

In discussing the possibilities of food package standardization with some of the top men in industry-men representing national distributors of meats, cereals, canned goods and confectionery items-and a number of others, I find they all favor simplification of the packaging problem but no company would be willing to eliminate a single package size unless it could be shown that (1) no competitive disadvantages would result; $(2)$ that there would 
be a material saving; and, (3) that it would be in the public interest to do so.

Each objected strongly to the idea of mandatory standardization that would result from Federal, State, or local legislation. Each believes that such legislation would be unrealistic and would result in the need for revamping equipment, containers, labels and advertising material so extensively as to materially increase costs to the consumer. Many expressed the opinion that the consumer is adequately protected by existing legislation and that the need is for better enforcement. All agreed that there are some abuses but felt they were minimal. They felt, too, that the consumer should take more interest by reading and studying labels on packaged foods, by comparing prices, and by reporting to proper authorities instances where he is victimized or misled.

Tn discussing this problem with retailers, I find again that most of them favor reducing the number of sizes of packaged food items they are required to carry. In fact, many of them exercise some measure of control by refusing to stock sizes that do not sell readily. Again, however, the retailer is forced to carry the food varieties, brands, and sizes demanded by the consumer and these demands vary with the neighborhood, the city (or rural community), and the State of location.

What about the consumer when she goes to a supermarket and is faced with an almost infinite variety of foods from which to choose, each packaged in from 6 to 10 sizes? How does she choose her purchases? Is she bewildered and confused? Does she buy primarily by size, by brand, by variety, by price, or a combination of these factors? Does she read the label? Does she know how much she is getting for her money? Does she wish there were less sizes to choose from? Should the weight be in even ounces or pounds or fractions of a gallon so she could figure the comparative price?

I attempted to secure some of the answers by talking with consumer groups, Parent-Teacher Associations, women's civic associations, and similar organizations. The inquiries were somewhat limited and the number of groups contacted was also limited. The information obtained does not begin to compare with the elaborate market studies on the subject that have been made by research analysts. However, I did get some common answers to these questions.

Curiously enough, it appears the housewife does not feel confused when confronted with a large selection of food items. In fact, she seems to revel in being able to pick and choose. She does compare prices between brands and does not always compare net-content declarations. She seems rather to select the quality that fits her pocketbook and would rather buy a 71/4-ounce package of a brand she likes than an 8-ounce package of another brand at the same price. As a result of radio, television, or newspaper advertising. she will experiment with different brands of familiar foods or with new foods and will continue to use them or discontinue buying them, depending on whether or not she and her family like them. She seems to prefer containers that will provide a given number of servings without having to store leftovers. Even when ample storage or refrigeration space is available in the home. she prefer's to open new containers whenever possible. 
In the case of staple cereals such as flour, rice, breakfast foods, etc., she is concerned lest they become "buggy" or otherwise deteriorated and prefers to buy package sizes that will be consumed in a limited time rather than larger packages at a lower unit price. In the case of prepared products such as corn flakes, crackers, and similar items, she prefers to pay a higher unit price for small packages or unit servings so as to provide more variety for hêr family without the danger of staling.

Many housewives still fear that canned foods stored in the refrigerator in opened cans will develop off flavors and may even cause illness. We know that this is a very rare occurrence, but the housewife prefers to have the entire contents of a can consumed at one sitting whenever possible and buys with this idea in mind.

Finally, the modern housewife likes to have things done for her. She prefers to buy foods as nearly as possible ready to serve and in the unit sizes most convenient for her family.

Other peculiarities in the housewife's buying habits were turned up. She will travel long distances to buy at a store advertising bargain prices for some item she wants but will not hesitate to pay a premium price for some other item in the same store. She will buy fresh fruits and vegetables at one store and not at another (though both are served by the same wholesaler) because the produce is more attractively displayed, or the vegetables are trimmed better, or the celery is crisper or the attendant gives her better service. The fact she pays a premium seems to be of secondary importance. She wants service and quality first.

Nevertheless, women with whom I have discussed this subject agreed that they would favor standard sizes for food packages if it did not interfere with quality, variety, or convenience in their purchases.

In addition to discussing this subject with industry representatives and consumer groups in the course of preparing this paper, I also reviewed some of the literature, including past proceedings of this Conference. During the Congressional hearings that led to the enactment of the first Federal Food and Drug law in 1906 and the present Food, Drug and Cosmetic Act of 1938, mention is made several times of the need for informing the consumer of what he is being offered with respect to the quantity of food in the package but nothing touching on standardizing or making uniform the size or contents of food packages. The 1938 Act attempts, however, to protect the consumer from fraud or misrepresentation by providing in Section 403 (e) (2) that a prepackaged food is misbranded unless the label includes "an accurate statement of the quantity of the contents in terms of weight, measure or numerical count"; in 403 (f) requiring this information to be placed on the label with such conspicuousness and in such terms as to render it likely to be read and understood by the ordinary individual under customary conditions of purchase and use.

Regulations adopted under this part of the Act seek to further safeguard the interests of the buyer by requiring (Sec. 1.8(e) (1) of 21 C.F.R.) that the statement of the quantity of contents reveal the "quantity of food in the package exclusive of wrappers and other material packed with such food" and (2) requiring the statement to be expressed in the terms of weight, measure or numerical count or a combination of numerical count and weight or measure 
"which are generally used by consumers to express such quantity of such food and which give accurate information as to the quantity thereof."

Subsection (f) (1) requires the use of the avoirdupois pound and ounce to express weight; the United States gallon of 231 cubic inches and quart, pint and ounce subdivisions to express liquid measure. It even provides that liquid measure express the volume at $68^{\circ} \mathrm{F}$. except in the case of frozen foods consumed as such. It further requires the use of the U.S. bushel of 2150.42 cubic inches for dry measure declarations and peck, dry quart, and dry pint subdivisions. It also requires the use of the United States standard barrel and its subdivisions of one-third, one-half, and three-quarters barrel.

Subsection $(\mathrm{g})$ requires that "statements shall contain only such fractions as are generally used in expressing the quantity of the food. A common fraction shall be reduced to its lowest terms; a decimal fraction shall not be carried out more than two places."

Subsection (h) seeks to protect the consumer by simplifying the net contents declaration and preventing the use of terms which, though technically accurate, would tend to confuse or mislead the consumer. It provides that the statement "shall express the number of the largest units contained in the package (for example, the statement on the label of a package which contains one quart of food shall be ' 1 quart' and not ' 2 pints' or ' 32 fluid ounces')" unless consumer usage requires otherwise. It also provides that where a quantity consists of a whole number and a fraction there may be substituted for the fraction its equivalent in smaller units (for example $13 / 4$ quarts may be expressed as 1 quart $11 / 2$ pints or 1 quart 1 pint and 8 fluid ounces; 11/4 pounds may be expressed as 1 pound 4 ounces). It prohibits the use of a statement using a unit declaration which equals or exceeds the number of smaller units in the next larger unit specified (for example, instead of 1 quart 16 fluid ounces the statement must read one and one-half quarts or one quart one pint; instead of " 24 ounces" the statement must be expressed as " $11 / 2$ pounds" or " 1 pound 8 ounces").

The consumer, therefore, is offered some measure of protection by the foregoing provisions of the Food, Drug, and Cosmetic Act. There is nothing in these provisions, however, which restricts the size or variety of packages and it is incumbent upon the buyer to "read the label" if he wishes to know how much he is getting.

The records of your own organization indicate that Food Package Standardization has been a subject of discussion for many years. An excellent paper on the subject was presented by A. W. Schwartz of New Jersey during the 13th Conference in 1920-that was 36 years ago; another on the need for standardizing canned food packages was delivered during the 27 th Conference by George Warner of Wisconsin and still another excellent presentation on the subject was made by Mr. Pisciotta of New York during the 28th Conference. During the 29th Conference held here in Washington in 1939, a committee headed by $\mathrm{Mr}$. Pisciotta presented an exhaustive report on the subject and a number of recommendations including one that Federal legislation be introduced to deal with the problem. This report was followed by a presentation of consumer and industry views and resulted in a heated discussion which 
lasted all day. I heartily recommend a study of the proceedings to all present.

During the 30th Conference the Committee on Standardization reported the results of the previous year's work and included in its report proposed legislation dealing with standard capacities for containers of dry foods, oils, syrups, honey and molasses, fruits, vegetables, and their juices.

During the 31st Conference held in 1941, a proposed bill "to prohibit the movement in interstate commerce of packages of food not of standardized units of weight or measure" was submitted by your Committee on Legislation. Its form and terminology were very similar to the Food, Drug and Cosmetic Act. It appears from the proceedings of the 32nd Conference that a great deal of opposition developed when the proposed legislation was introduced into Congress as H.R. 6784 and as a result the bill failed to make any headway.

Mr. Meek, in his report to the 33d Conference held in 1947 on the activities of the Committee on Legislation, summarized the difficulties associated with food package standardization when he reported the objections voiced by those who attended the hearing in Indianapolis held in connection with a redraft of H.R. 6784.

I have not attempted to include in this paper any of the detailed research or the many examples supporting the need for food package standardization which were included in the previous conference proceedings to which I have referred. They are in the record and are available to anyone who is interested. The committees that have worked on this problem are to be congratulated for having done an outstanding job. There can be no doubt the problem continues to exist only in more exaggerated form.

The question is, what to do? It is readily apparent that the over-all problem is so complex that a single federal law cannot be drafted to solve it satisfactorily. A series of federal laws, each dealing with a particular facet of the problem would be most difficult to draft because of the overlapping that occurs in the various types of packages and the types of food products they contain. Then, too, the opposition would be more concentrated as enactment is sought for each bill.

Legislation at the State level would not be practical as it would be most difficult to secure the enactment of uniform bills. Without complete uniformity of laws and interpretations, the result would probably be a series of trade barriers and endless court cases testing the constitutionality of each State law.

It is doubtbul if it will be possible to secure unanimous voluntary agreement among the various industries which would result in a satisfactory solution. Even if an agreement were reached with leaders in industry, there are enough fringe elements who would not comply to nullify the agreement to a great extent. Furthermore, it is probable any voluntary agreement would include only such items and sizes where a clear-cut advantage would result to the industries involved but would not cover many items where controversy exists.

It seems to me that the problem existing in this field is similar in most respects to the one which led to the inclusion of Section 401 in the Federal Food, Drug and Cosmetic Act. This section provides, in part, that "Whenever in the judgment of the Secretary (of 
Health, Education, and Welfare) such action will promote honesty and fair dealing in the interest of the consumer, he shall promulgate regulations fixing and establishing for any food or class of food, under its common or usual name, where practicable, a reasonable definition and standard of identity, a reasonable standard of quality and/or reasonable standards of fill of container."

Under this section the Secretary may begin action for a standard on his own initiative or on petition of any interested person. A procedure to be followed by the Secretary is outlined, including a provision for hearings at which any interested person may present his views, appropriate court review which may be instituted by anyone adversely affected by the adoption of a standard, and repeal or amendment of an existing standard.

Under authority of this section, individual standards have been promulgated for many foods and classes of foods. Each has been promulgated after it was found to be in the consumer's interest to do so. The standards embrace the very problem we are facing here - foods which vary in their composition to such an extent that the consumer is confused or misled, even though each of the foods complies with the misbranding or adulteration provisions of the law.

I am wondering, therefore, if a solution to the problem of food package standardization might not lie in appropriate Federal legislation which would authorize the National Bureau of Standards (or some other Federal agency if the Bureau is unwilling or unable to accept the responsibility) to promulgate standards of size and capacity of containers for any food or class of food whenever it found that it would promote honesty and fair dealing in the interest of the consumer to do so. Provisions could be included to safeguard the interests of persons affected by the standards and to amend, modify, or repeal a standard.

In this way, the problem could be tackled in areas where the greatest need of a solution is found to exist, without disturbing the status quo in other areas. Standards could be kept fiexible and amended or revised as needed. Similar standards could be adopted by States for foods in intrastate commerce.

\section{DISCUSSION ON FOREgOING PAPER}

Mr. HAGGART: Is there any standard relationship between liquids and solids in canned foods, as for example canned beef stews?

Mr. Sullivan : No, there is not. As a member of the Food Standards Committee of the Food and Drug Administration, I can report that relationship is a topic for consideration and is on the agenda of our next meeting.

Mr. Francis: Speaking only from the standpoint of consumers' interest, what is reasonable allowable shrinkage on prepackaged meats?

Mr. SUllivan : As far as I know, no arbitrary figures have been established. It is a question of reasonableness. I would say that what is reasonable is what may be expected. 
Mr. J. P. MCBRIDE: We recently received a complaint on a canned cooked ham that was labeled $11 / 2$ pounds net weight. We found the can to contain one pound of ham and one-half pound of liquids and semiliquids. Is there a standard relationship between solid and liquid on this product?

Mr. Sullivan: There is no standard. In a case of this kind we would examine the product, the processing procedure, and the like. If an unreasonable amount of liquid is introduced, we would say the processor had violated the Act.

\section{REPORT OF THE COMMITTEE ON NOMINATIONS, PRESCRIBED BY F. M. GREENE, CHAIRMAN, AND ELECTION OF OFFICERS}

The Nominating Committee submits the following report, including nominations for office in the National Conference to serve during the ensuing year, or until such time as their successors are elected. Careful consideration was given by those in attendance to several factors in its selection of nominees for office. Among these were established custom, geographical distribution, attendance records, previous recognition, and participation in the work and affairs of the Conference. As a result of their deliberations, 23 nominees have been selected from 22 States. They are as follows: For President: A. V. Astin, Director, National Bureau of Standards.

For Vice Presidents: M. A. NELSON, of Michigan; J. E. MAHONEY, of Maryland; A. J. MAYER, of Louisiana; J. C. GoLL, of North Dakota; C. J. WILLS, $J_{R}$, of Portland, Maine; R. K. SLough, of Akron, Ohio.

For Secretary: W. S. BUSSEY, National Bureau of Standards.

For Treasurer: G. F. AUSTIN, JR., of Detroit, Michigan.

For Chaplain: Rev. R. W. SEARLES, of Medina County, Ohio.

For Sergeant at Arms: FranK DELANEY, of Connecticut.

For members of the Executive Committee: A. H. DITTRICH, of New Hampshire; J. T. KENNEDY, of the District of Columbia; NALLS BERRYMAN, of Florida; J. F. TRUE, of Kansas; C. H. STENDER, of South Carolina; E. L. Randall, of Nevada; Norman Kirschbaum, of Wisconsin; G. A. Pullman, of Genesee County, New York; I. M. LEvY, of Chicago, Illinois; J. J. PowERS, of Philadelphia County, Pennsylvania; TOM WEBB, of Nashville, Tennessee; J. E. BowEN, of Newton, Massachusetts; E. F. MORAN, of Providence, Rhode Island; F. G. YARBRough, of Dallas, Texas; S. H. Christie, JR., of New Jersey.

(Signed)

F. M. GReENE, Chairman,

J. T. KENNEDY,

E. R. FISHER,

ERLING HANSEN,

ROBERT WILLIAMS,

I. M. LEVY,

J. P. LEONARD,

Committee on Nominations.

(The report of the Committee on Nominations was adopted and the officers were elected unanimously.) 


\section{REPORT OF THE COMMITTEE ON LAWS AND REGULATIONS, PRESENTED BY G. H. LEITHAUSER, CHAIRMAN, AND DISCUSSION THEREON}

Your Committee on Laws and Regulations submits its final report to the 41st National Conference on Weights and Measures. It should again be stated that uniform laws, uniform interpretations, and uniform inspection procedures are both desirable and essential for sound and efficient weights and measures enforcement. These can only be accomplished through the cooperation of industry, the public, weights and measures officials, and other enforcement agents. The cooperation of industry in our mutual endeavors has been good. The public gradually is being educated, especially through the efforts of National, regional, and State. weights and measures associations, as to the importance that weights and measures work plays in the daily economics of every person. The tentative report of your Committee on Laws and Regulations has been discussed during open meetings of the committee held at The Willard Hotel, Washington Room, Washington, D. C., on Monday, May 21.

The following items are presented for consideration:

1. Charcoal Briquets for Use in Outdoor Fire Places, Barbecues, etc.

Shall be sold by avoirdupois net weight.

In paragraph (e) (3), page 3 of the Model Regulations, it states that "Unless an unqualified statement of numerical count gives accurate information as to the quantity of commodity in the package, it shall be supplemented by such statement of weight, measure, or size of the individual units of the commodity as will give such information." Since there is no established size for individual briquets, it would appear that an unqualified statement of count would not comply to this paragraph.

(Item 1 was adopted by the Conference.)

\section{Floor Sweeping Compounds.}

Shall be sold by avoirdupois net weight.

Item 1, paragraph (e) (3) of the Model Regulations seems to apply to floor sweeping compounds.

(Item 2 was adopted by the Conference.)

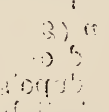

3. Extraordinary Terms Used in the Sale of Various Commodities.

It is recommended that the Conference go on record as condemning the use of such terms as big, giant, king size, huge, large, or other misleading terms when mentioning standard dry, liquid, weight, or measure quantities. 
Such terms, no doubt, are subtle in their intent for what psychological effect they may have. Designations of this kind are misleading, as the words big, giant, king size, huge, large, etc., suggest something above average. Obviously you cannot legally use in trade a larger than within tolerance, correct size, weight, or measure, or weighing or measuring device.

(Item 3 was adopted by the Conference.)

\section{Model Law Amendment.}

A proposal to change a sentence that was added to Section 7 of Form 2 of the Model Law by action of the 40th National Conference on Weights and measures. This proposed change would delete any reference to the National Conference on Weights and Measures. Your committee proposes that the sentence in question be amended to read as follows:

The specifications, tolerances, and regulations for commercial weighing and measuring devices, together with amendments thereto, as recommended by the National Bureau of Standards and published in the National Bureau of Standards Handbook 44 and supplements thereto, or in any publication revising or superseding Handbook 44, shall be specifications, tolerances, and regulations for commercial weighing and measuring devices of the State of - except insofar as specifically modified, amended or rejected by a regulation issued by the State- (insert title of enforcing officer).

It appears that reference to the National Conference on Weights and Measures is not necessary to strengthen the text. Moreover, when this reference was included in a recent Ohio bill, the mention of the National Conference proved to be a psychological handicap believed to be largely responsible for the failure of the bill to receive the approval of the Ohio State Legislature.

(Item 4 was adopted by the Conference.)

5. Oysters.

Oysters shall be classed in two groups:

Group (1). Raw or Fresh Oysters.-Raw or fresh oysters in tins, glass, or other containers, shall be sold by avoirdupois net weight or liquid measure, and the package shall not contain more than 10 percent liquid at $45^{\circ} \mathrm{F}$. Any tests made to determine the quantity of contents in a package shall consist of enough packages to total at least 1 gallon.

Group (2). Canned Oysters that are Heat Treated and Hermetically Sealed. - Canned oysters that are heat treated and hermetically sealed shall be sold by avoirdupois net weight and the drained weight of the oysters in each container shall be not less than 59 perecnt of the declared net weight of the contents of the package.

The oyster industry recommends the following method be used, in the field, to determine the free liquid contents of raw or shucked oysters. 
Open the container and, without pressure against the oysters in the container, drain for a period of 1 minute into a glass graduate, and from this procedure determine the amount of liquid so drained from the container.

Since raw oysters are subject to changes in the $p \mathrm{H}$ value, due either to improper refrigeration or age, the use of a $p \mathrm{H}$ comparator will determine any such changes. If the $p \mathrm{H}$ of the oysters reaches a $p \mathrm{H}$ of 5.8 or less, the free liquid content should not be determined.

(Item 5 was adopted by the Conference.)

6. Fertilizer for Lawns.

Your committee recommends that this item be held over. The assignment of the petroleum industry for this Conference includes lawn fertilizers. In view of this, your committee feels it should await the outcome of this presentation by the members of the API before making any recommendations.

(Item 6 was adopted by the Conference.)

\section{Inert Liquid Fertilizer.}

This is a holdover item from the 40th National Conference.

Inert liquid fertilizers shall be sold by volume based on the United States standard gallon of 231 cubic inches at $60^{\circ} \mathrm{F}$, its multiples and binary submultiples, or by avoirdupois weight.

It developed from discussions that a stipulation for temperature should be incorporated in the recommendation, because pressure was a determining factor.

(Item 7 was adopted by the Conference.)

\section{Rope and Cordage Products.}

Rope and cordage products should be sold by net weight or linear measure. Your committee feels that paying for rope on a price per pound basis gross weight and allowing up to 3 percent tare is contrary to all weights and measures principles and State and local laws which call for sale of all commodities on a net weight basis.

As early as 1941 the National Conference on Weights and Measures recommended sale of twine and cordage by net weight. This committee recommends that the Secretary to the National Conference on Weights and Measures again contact the proper Federal officials with the view of having Federal specifications on rope and cordage be on a net weight or lineal foot basis.

(Item 8 was adopted by the Conference.)

\section{Packing House Products.}

The committee recommends that, due to the controversial nature of this subject, this item be held over for 1 year. In the meantime, a committee should be appointed by the Secretary of the National 
Conference on Weights and Measures, representing the meat packers and members of the Laws and Regulations Committee, to meet as often as is required during the coming year to study this problem and try to come up with a solution satisfactory to all concerned.

(Item 9 was adopted by the Conference.)

\section{Fruits and Vegetables in Paper Cartons.}

Fruits and vegetables packed in paper cartons for the purpose of sale shall be construed to be in package form, and the net quantity of the contents shall be plainly and conspicuously marked on the outside of the package in terms of weight, measure, or numerical count.

The term for the purpose of sale is used so that carryall bags, tote bags, or other containers that are merely used as a means for transportation of the commodity only, are eliminated from marking requirements.

(After considerable discussion from the floor, it was moved that Item 10 be re-referred to the committee for further study. This motion was adopted by the Conference.)

\section{Seeds Gross for Net at Wholesale Level.}

Your committee has previously dealt with this subject.

We reiterate that the sale of seeds, at the wholesale level, shall be by avoirdupois net weight.

Sale of seeds by gross weight is a violation of most State laws, and it is up to the enforcement agents of the various jurisdictions where this law is being violated to enforce the law.

(Item 11 was adopted by the Conference.)

\section{Paint, Color Base Tinting Systems.}

As a result of a motion of the 40th National Conference, the method of labeling paints in the color base tinting system was referred to the committee for further study.

Because of the demand of consumers for a multiplicity of colors, shades, and tints of paints for household decorating, there has evolved in the industry a system under which a base vehicle (the principal liquid component) and many colorants (tubes or jars of minor liquid sizes) compose the stock of a paint merchant. The customer selects a color from a chart and indicates the total volume required. The desired color is made up by adding a stated amount of one or more colorants, according to predetermined instructions, and mixing.

This matter was brought to the attention of the Conference because most of the paint manufacturers have retained the standard size paint container (1 gallon, 1 quart, 1 pint, etc.), but have placed in these containers less than the standard volumes of liquid vehicle. Quantity statements have ranged from misleading-such 
as "Contents 1 gallon liquid. This container is short filled to allow for the addition of colorants." - to factual yet uninformativesuch as "31/32 gallon," "3 qts., 1 pt., 13 fl. ounces," and the like.

The chairman designated as a subcommittee for this purpose Mr. George H. Leithauser, Chairman, Mr. Nalls Berryman, and Mr. Miles A. Nelson.

As consultants to the subcommittee, the chairman selected the following representatives of the industry:

Mr. R. S. Bennett, President, Bennett's

Mr. W. L. Foy, Technical Director, The Foy Paint Company, Inc.

Mr. E. S. Torrence, Assistant to President, Painting \& Decorating Contractors of America
Mr. S. U. Greenberg, General Manager, Paint \& Varnish Factories, Sears, Roebuck \& Co.

Mr. Lloyd A. Owens, American Marietta Co.

Mr. I. E. Douglas, Executive Vice President, Retail Paint \& Wallpaper Distributors of America, Inc.

The subcommittee met in Washington during August 1955, and, after considerable discussion of the problem, was divided into three-man task forces to study and make recommendations on the advisability of adopting specific solutions: (1) The present system, under which a manufacturer decides on his own labeling policies without regard to uniformity; (2) a system that would provide standard volumes of vehicles or bases, such as 1 gallon, 1 quart, 1 pint, etc., and would require larger than standard size containers ; (3) the use of standard size containers, 1 gallon, 1 quart, 1 pint, etc., with these being filled uniformly but with less than the nominal quantity.

The reports of these three task forces were submitted to the chairman. The significance of the reports was in their similarity as to recommendation. It is on this basis that the Committee on Laws and Regulations developed its recommendation.

Since the quantity of colorant to be added to the base varies according to color to be produced and the individual formulas of the several manufacturers, and since most container manufacturers, filling lines, formulas, and retail shelves are set up for the standard containers, the committee concludes that hardships would be incurred if larger than standard containers were to be required.

A uniform fill of less than nominal volume cannot be recommended because of the wide variance among the volumes of colorant required for the different shades and among the different paint manufacturers.

The committee recommends that the solution to this problem be sought in informative and uniform labeling as to quantity of contents, and thus submits for the consideration of the Conference the following:

The base or vehicle for paints in the color base tinting systems shall be packaged in containers of nominal standard sizes, for example, 1 gallon, 1 quart liquid, 1 pint liquid, and the like. The containers shall be labeled according to the Model State Regulation for Package Marking Requirements, adopted by the 38th National Conference on Weights and Measures. The colorants for paints in these systems may be packaged in appropriate containers, and these containers also shall be labeled according to the provisions of the Model Regulation. 
If less than the nominal quantity of base or vehicle is packaged in a standard size container, the label of that container should bear, in addition to the information required under the Model Regulation, a simple and clear statement as to why the contents are less than the nominal amount. Special attention should be given to the prominence of this statement.

(Item 12 was adopted by the Conference.)

\section{Crimping Ribbon.}

Crimping ribbon shall be measured after crimping.

It was called to your committee's attention that there was some variance in measuring this type of ribbon. Some concerns were measuring before crimping and some measuring after crimping. Your committee feels that the practical way to measure this type of ribbon was after crimping, because the customer is purchasing the commodity in this finished state and certainly should get yardage as marked in said finished state.

(Item 13 was adopted by the Conference.)

\section{House Joint Resolution 496.}

The National Conference Committee on Laws and Regulations opposes House Joint Resolution 496 as now written.

(Item 14 was adopted by the Conference.)

\section{Peat Moss.}

Peat moss, Michigan peat, and other commodities of similar characteristics, when packaged in cellophane bags or similar containers, shall be marked as to avoirdupois net weight.

Your committee feels that, when this commodity is packaged in cellophane bags or bags of a similar nature, a cubical content declaration is not a clear and accurate indication of the net contents of the package.

(Item 15 was adopted by the Conference.)

(The report of the Committee on Laws and Regulations, as amended, was adopted by the Conference.)

\section{BREAKFAST MEETING OF THE INCOMING EXECUTIVE COMMITTEE OF THE CONFERENCE, FRIDAY, MAY 25, 1956}

On Friday morning, May 25, the newly elected Executive Committee and the chairmen of the standing committees met to discuss and reach decisions regarding the $42 d$ Conference. Present at the meeting were 9 of the 11 officers, 11 of the 15 Executive Committee members, the chairmen of the three standing committees, and the 
2 weights and measures representatives on the Advisory Committee. The meeting was presided over by the Conference President, Dr. A. V. Astin, and Vice President J. E. Mahoney. The following decisions were reached regarding the $42 \mathrm{~d}$ National Conference on Weights and Measures, 1957:

1. Place: Sheraton-Park Hotel, Washington, D.C. (The committee expressed its preference, in order, for (1) Sheraton-Park, (2) Shoreham, (3) any other hotel deemed satisfactory by the Secretary. The Secretary was directed to select the hotel.)

2. Date: June 3-7, 1957. (The committee recommended as its first choice the week of June 10. Because of previous commitments, no hotel in Washington that would be acceptable for the Conference is available during that week or the week following. Moreover, the same situation exists with respect to the entire month of May. Therefore, the Secretary has scheduled the 1957 Conference as indicated-June 3-7.)

A motion was adopted by the committee to the effect that all sessions of the 1957 Conference are to be held at the headquarters hotel. There will be scheduled an informal open house with tours of the laboratories of the National Bureau of Standards for those who wish to participate.

3. Duration: Open committee meetings on Monday, opening session Tuesday morning, Tuesday afternoon free of any scheduled meeting, the remainder of the week scheduled according to the needs of the program.

4. Program: Program topics to be selected and speakers to be designated by the Secretary. All Conference delegates are urgently requested to send in program suggestions for 1957 NOW.

5. Distribution of papers: The committee voted to continue for another year the system of distribution of Conference papers through a check-list arrangement.

6. Social Activities: Similar to previous years, except the Conference party is to be held on Tuesday night. To be arranged by the Secretary.

7. Ladies' entertainment: To be arranged by the Secretary after Consultation with a Ladies' Committee.

8. A motion was passed by the committee directing the President to appoint a committee of nine, representing weights and measures officials, manufacturers, users of devices, and the National Bureau of Standards, to study the advisability of formulating and establishing rules of operations and procedures for the Conference. The committee study also is to include the advisability of spelling out the relationship of the Conference with the National Bureau of Standards. This committee is to report its recommendations to the $42 \mathrm{~d}$ National Conference.

9. Motions were passed expressing appreciation for the interest and participation of Dr. Astin in the affairs of the Conference, and commending Mr. Bussey and Mr. Jensen on their handling of the Conference arrangements.

10. The Conference Chaplain, Rev. R. W. Searles, noted that, although he was directed by the previous Executive Committee to send appropriate cards for the Conference to members during sickness or at death, he has not been receiving information in time to carry out the wishes of the committee. All delegates to the National Conference are urged to inform the Chaplain of sicknesses and deaths at the following address: County Board of Education Building, Medina, Ohio.

11. The committee received two letters from the Ladies' Committee, one expressing appreciation to the Conference for its hospitality, especially for the luncheon and fashion show arranged for them, the other one expressing appreciation to the Maryland Weights and Measures Association for the corsages, one of which was provided for each of the ladies. The latter letter was turned over to the officers of the Maryland Association. 
(W. A. Kerlin, Vice President, Presiding)

\section{NATIONAL BUREAU OF STANDARDS RAILWAY TRACK SCALE ACTIVITIES}

\section{By H. L. BADGER, National Bureau of Standards}

(Presented by C. H. OAKLEY, National Bureau of Standards)

The responsibility of the Federal Government to establish standards of weights and measures and to make these standards available in a practical sense to the commerce and industry of the Nation is a basic assignment of the National Bureau of Standards. Conference members are familiar with the system whereby State standards of mass having weight values ranging, for example, from a small fraction of an ounce up to 50 pounds in the avoirdupois system, are submitted to the Bureau for certification. State standards, whether metric, avoirdupois, apothecary, or troy, are calibrated with great care in terms of the Standard of the United States, and these weights, when validated by proper certification of the National Bureau of Standards, become the legal State standards. Thus it is assured that the standard of mass for all States is identical. Commercial weighing devices, calibrated with test weights derived from these identical State standards, should be in agreement throughout the entire country, and commercial transactions within and between the States will therefore be effected on a uniform weight basis.

The system described above is an excellent one. Experience has proved, however, that it is not entirely adequate, that for extremely practical reasons it must be extended by the dissemination of mass standards greatly larger than the usual standards deposited in the laboratories of the several States, and that, in order to assure the same degree of uniformity, the National Bureau of Standards should carry on this work. This the Bureau has been doing since the second decade of the present century.

As a result of investigation begun about 1910, a lack of uniformity of weight indication between scales was disclosed; moreover, the differences were of intolerable magnitude. In 1913 Congress provided funds for the construction and equipment of a specially designed railway scale testing car. Through this equipment, with its load of several 10,000-pound weights, a system providing for the extension of weight controls into the largecapacity field was realized. This system provides for the designation as "master track scales" certain specially designed scales which, by virtue of refinements of design, exceptionally careful installation, and meticulous maintenance, have proved capable of sustaining highly accurate performance over a relatively long period of time. A scale so designated by the Bureau becomes a secondary reference for deriving standards of mass. On these scales, many of the scale test cars operated by railroad companies are standardized periodically by direct weighing methods. These scale test cars, which may be considered as tertiary standards, are then transported to and used for evaluating the performance of railroad- and industry-owned commercial-type railway track scales. All of these master track scales (nineteen in number, one of which, located at Clearing, Illinois, is owned by the National Bureau of 
Standards) are calibrated annually by the Bureau with test weights derived by a buildup process originating with the standard kilogram. Each master scale is therefore adjusted to a common standard. It follows that each test car standardized on one of these master scales will have been indirectly compared with the standard kilogram, the same basic standard from which your office standards were derived.

There are many scale test cars that do not have access to master track scales. In some cases it is just a matter of remote geographical location; in other instances, it is simply because the car does not meet certain requirements of the Interstate Commerce Commission and therefore may not be transferred from its own line to the line serving the master scale.

Insofar as feasible, without disrupting the schedule of master scale tests, arrangements are made for standardizing scale test cars of this group by substitution weighing effected on a commercial-type railroad scale selected for this purpose.

An interesting coincidence occurred recently in respect to field calibration of scale test cars. Car No. 1750 of the Clinchfield Railroad was calibrated by our No. 1 equipment on January 24, 1949. The test number was 9121-1 (the final digit identifies the equipment that made the test). On March 1 of this year-more than seven years later-the No. 2 equipment, usually assigned work west of the Mississippi, standardized the same scale test car, Clinchfield No. 1750, and-believe it or not-the test number was 9121-2.

Scale test cars used by railroads and by some of the larger industries (steel companies, for example) are of various sizes, ranging in general from about 30,000 pounds to 80,000 pounds. In order to calibrate, properly, master scales which are used over such a wide range, a multi-step test must be conducted. The Bureau provides a test load that can be varied by multiples of 10,000 pounds. Actually, each master scale is calibrated at loads of $30,000,40,000,50,000,60,000,70,000$, and 80,000 pounds.

Unlike the railroad-owned scale test cars, which move on their own wheels, the standard test weights of the Bureau, after standardization at Clearing, are transported in a specially built and specially equipped box car and are thus protected from wear that would impair their weight values.

In addition to the calibration of master track scales and the field standardization of scale test cars, the Bureau equipment is used for testing commercial-type railway scales. For this reason, the routing of our cars between master scales is varied each year, so that, insofar as practicable, a different group of commercial scales will be tested each year.

Although most railway scales are used primarily for the determination of freight charges, frequently the weight of the shipment, determined on such scales, is used as a basis for the sale of the commodity. Definitely, the performance of these scales is a matter of interest to State weights and measures regulatory agencies. The Bureau, fully cognizant of this fact, transmits a copy of the report of each test to the proper State official. Moreover, before beginning our operations in any State, the chief of the department of weights and measures is made acquainted with our plans in order that he may assign a member of his department as an official witness to the 
tests. This program offers an opportunity for State weights and measures officials to familiarize themselves with Bureau methods and procedures for testing scales of large capacity, thus broadening their experience.

So much for the background of this Bureau activity.

The speaker, operating the No. 1 unit of the Bureau, recently completed a calibration and inspection trip through the western section of the country. The No. 2 equipment, Mr. Leonard E. Lambrecht in charge, is rapidly approaching the conclusion of a similar tour of the eastern section.

As a result of special tests for a National Defense agency that required utilization of all the weights of both railway units for a period of approximately 90 days, the itineraries of these cars, originally scheduled to begin during June 1955, were not inaugurated until August 1955. Between that time and May 1 of this year, 17 master scales were calibrated. The current itinerary of the No. 2 equipment, to be completed early in June, provides for the test of the other two master scales.

All of the master scales already tested were found to be accurate within the maintenance tolerances; thirteen were found to be accurate within the adjustment tolerances; the other four were adjusted by the Bureau inspectors and were recalibrated. Considering that adjustment tolerances for master track scales range from 3.7 pounds at 30,000-pound load to 6.0 pounds at 80,000 -pound load and that the maintenance tolerances are just twice the adjustment tolerances, it becomes apparent that these scales are, in fact, very precise mechanisms despite their large capacity. It is important to note that the performance of these scales reported above is typical of the performance of the group for the past quarter century; it is interesting to note that one particular scale has never been readjusted since its installation.

Obviously, the calibration of a master scale is not a proper test for a 10,000-pound weight, but the performance of the group, and the last-mentioned scale particularly, clearly points out that the Bureau, throughout the years, has not deviated from the basic standard.

Both cars were quite busy during the period covered by this report. In addition to the master scale calibrations referred to above, a few scale test cars and a group of weights from a Stateowned vehicle scale testing unit were standardized in the field, and 355 commercial-type railway scales were tested and inspected. The tolerances applied during these tests are those developed through the joint efforts of the American Railroad Association (presently the Association of American Railroads), the National Scale Men's Association, the Scale and Balance Manufacturers Association, the Interstate Commerce Commission, and the National Bureau of Standards. These tolerances are presented in detail in section T.2.3.4. of the second edition of NBS Handbook 44 .

The results of tests made on commercial-type railway track scales may be summarized as follows: Two hundred and fifteen railroad-owned scales were tested; of these, one hundred and eighty-eight were found to be accurate and 27 inaccurate. The average percentage error of the accurate scales of this group was 0.09 ; the corresponding figure for the inaccurate scales was 0.37 . 
One hundred and ten industry-owned scales, not used for grain weighing, were tested. Ninety-three of these were found to be accurate and seventeen inaccurate, the average percentage errors being 0.08 and 0.35 , for accurate and inaccurate scales, respectively. The number of grain-weighing scales tested was 29. Applying the special grain-scale tolerance of 0.10 percent, we found that 19 scales with an average percentage error of 0.07 were accurate and that 10 scales with an average percentage error of 0.21 were inaccurate. For the entire group, the average percentage error of 300 accurate scales was 0.08 and the average error for 54 inaccurate scales was 0.34 percent. The average error for all scales tested was 0.12 percent, a figure well within the basic maintenance tolerance of 0.20 percent.

As a final summing up, we found that, for the entire group of 354 scales tested, 84.8 percent were accurate and only 15.2 percent were inaccurate. One scale, having an inordinately large error of 3.08 percent, was not included in the computation of results reported above.

\section{THE CURRENT SITUATION IN HIGHWAY AXLE-LOAD WEIGHING}

\section{By C. L. RICHARD, Consultant, Truck-Trailer Manufacturers Association, Los Angeles, California}

I have been granted this opportunity to discuss briefly a troublesome situation which prevails in one area of weights and measures administration and which merits attention and action by this body. Mv remarks are intended to explain reasons for the unsatisfactory situation and to recommend means for practical solution of its problems.

To prevent highway damage caused by excessive loading of motor vehicles, individual States have enacted laws limiting wheel and axle loads. These regulations, conceived in the public interest for highway preservation and safety, are essential and commendable in their basic objectives. Responsible segments of the motortransport industry and of highway-engineer groups agree upon need for regulation. However, because there is a general lack of understanding, uniformity. and realistic policy in formulating, internreting, or applying the regulations, there exists an acute need for informing both the industry and the regulating agencies regarding some plain facts which are known to you but unknown or unappreciated in many such industry or regulation areas. These facts relate to the important detail of axle-load concept and axleload determination.

One commonlv misunderstood aspect of regulation enforcement concerns the facilities and procedures for correct determination of axle lnads. As long ago as 1926 . at the 19th National Conference on Weiohts and Measures, the National Bureau of Standards presented a report which explained the accuracy limitations of portable wheel-load weighers. described correct methods for their use, and recommended liberal tolerances which were subsequently adonted by that Conference. Despite those circumstances. and although improved tvpe axle-load scales have become generally available. the motor-transport industry has been plagued with many instances of overload allegations based upon grossly incorrect use of 
wheel-load weighers by highway police untrained in their use and unfamiliar with their limitations. That phase of the situation was well illustrated in a report read to the 38th National Conference in 1953 that related the results of a study conducted by the Indiana Motor Truck Association in cooperation with State highway and police officials. The data demonstrated that, for the tandem-axle truck and trailer studies, incorrect use of the wheel-load weighers introduced differences of from 1,500 to 2,100 pounds in individual axle loads and differences of from 3,000 to 4,000 pounds in loads on tandem axle units.

The second factor responsible for confusion and controversy regarding application of axle-load regulations is a common failure of both the industry elements and the regulating agencies to consider the variability characteristic of vehicle axle loads. A National Bureau of Standards report to the 28th National Conference in 1938 demonstrated that summation of individual axle loads did not produce correct gross load weights because axle loads did not remain constant. Although later Conferences wisely took action to limit or prohibit the commercial weighing of vehicles by that method, the fundamental principle of axle-load variability is not generally recognized or considered by agencies of regulation; nor indeed are they commonly understood in the industry.

Again in 1954, at the 39th Conference, the National Bureau of Standards, reporting on its investigation of axle-load weighing, presented data showing that individual axle loads may change by as much as 3,000 pounds when a tandem-axle vehicle moves over a relatively smooth and level highway. Lacking and understanding of the established facts, some enforcement officials are disposed to accept the momentary weight of one axle load as evidence of purposeful and permanent overloading. Conversely, some truck operators make the false assumption that careful initial loading within limits will assure compliance with the strict letter of regulation.

As an incidental indication of the confused situation, it can be cited that some courts, informed of the factors mentioned, have dismissed overload allegations based upon weighing of axle loads and others have ruled the evidence to be unreliable and inconclusive.

The manner and degree in which axle loading of a typical motor vehicle changes during transit is illustrated graphically in figure 32 , which is based upon data collected by the National Bureau of Standards and some other impartial and responsible agencies. The essential fact illustrated is that the reaction of axle loads varies constantly and cannot be assumed or expected to remain the same.

Since the facts reviewed here are known to the Conference but are not generally known to the industry or to highway control agencies, improvement of conditions can be effected by education in the latter areas. That program is now under way through the medium of a publication being prepared under sponsorship of the industry for distribution to all groups and individuals concerned. The publication, financed by the industry. will present and illustrate all pertinent data and history collected by the National Bureau of Standards, the Conferences, the Bureau of Public Roads, and other recognized authorities. Preparation and editing is being directed by a former weighing engineer of the National Bureau of Standards fully conversant with the subjert. The object is to provide information which will encourage the industry to utilize 
improved vehicle types and better loading control and will aid enforcement officials in fair and efficient execution of their duties. It is my recommendation to this Conference that, through the appropriate committees, you support this commendable effort to improve a bad situation.

To supplement the education phase of the needed improvement program, there is necessary further research and study of all facets of the subject of highway loading imposed by different types of motor vehicles under typical conditions. Three past Conferences, aware of that need, have formally adopted resolutions requesting such research and study by the National Bureau of Standards. It is regrettable that those efforts failed of realization, because funds for that project were not available to the Bureau.

Two organized groups in the motor-transport industry lately have evidenced strong interest in the situation discussed. They are the American Trucking Association, whose members are naturally desirous of transporting maximum practical pay loads without suffering delays or penalties for alleged overloading, and the Truck-Trailer Manufacturers Association, whose members are endeavoring to reduce the inherent variables in articulated axle assemblies. Two other elements who have collateral interest in the subject are the Federal Bureau of Public Roads and the associated State Highway Officials, whose responsibility is highway safety and preservation. I have good reason to believe that each of these four groups could be encouraged to support financially and otherwise a concerted movement to provide funds for further investigations by the National Bureau of Standards in this important field.

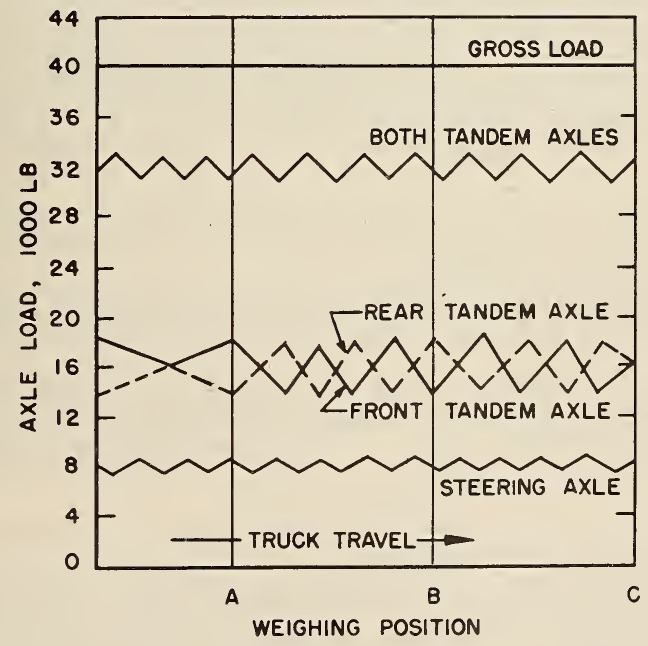

FIGURE 32. Typical axle-load variations for moving tandem-axie trucks.

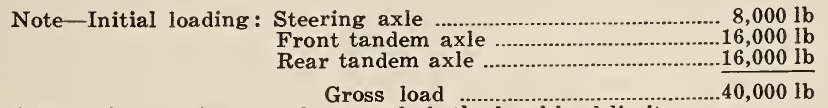

Assumption-16,000 pounds per axle is the legal load limit.

Then-if truck is weighed at position $A$, the front tandem axle is indicated as being overweight.

if truck is weighed at position B, the rear tandem axle is indicated as being overweight.

if truck is weighed at position $\mathrm{C}$, neither tandem axle is indicated as being overweight. 
It is also very probable that the Congress, when informed of the need for the research and studies by the Bureau, could be prevailed upon to allocate appropriate funds. In that connection I may remind you that recent legislation has appropriated several billion dollars of Federal funds for a long-range highway planning and construction program, and that study of the basic highway loading control problems should form a part of that program.

\section{DISCUSSION OF FOREgOING PAPER}

Mr. HANSEN: What is considered the most reliable method of measuring axle loads?

MR. RICHARD: Whatever method is used, it must be remembered that it will give only the momentary axle load. The preferred method is the built-in axle-load scale. Next is the portable wheelload weigher, one under each wheel; in the case of tandem axles, both axles should be weighed at the same time, using four weighers.

Mr. Christie: Can you report on the current thinking of highway officials and courts relative to tolerances on axle overloads?

MR. RICHARD: I purposely avoided that question because it is somewhat controversial. I would suggest that in the interpretation of axle-load regulations, consideration must be given to one of the principal factors I mentioned-load variability. Account should be taken of the distribution of load on the axles, and in fixing the allowable margin of overload consideration should be given to equalized loading on the axles.

Mr. SANDERS: You emphasized the need for further study by the National Bureau of Standards to develop the facts in connection with motor-truck and axle-load weighing. Such projects require money. I believe that the Bureau has the necessary facilities and is willing to do the work but needs monev to finance the proiect. Have you any suggestions regarding aid in this respect through contributions from industry or transfer of funds by Federal agencies?

MR. RICHARD: I cannot speak for the various segments of the industry or for the Congress.

Mr. J. G. Williams, JR.: What steps have been taken to assure equal axle loading before trucks go onto the highways?

MR. RICHARD: Many owners of truck fleets have installed scales at their loading docks. But let me reemphasize that control of the initial load distribution does not assure that the load distribution will be maintained in transit.

MR. CAMPBELL: Are truck and trailer manufacturers doing anything to improve axle stability?

MR. RICHARD: Studies are being made. One improvement being used is a pneumatic element as a substitute for springs.

Mr. HULSE (Truck Trailer Manufacturers' Association): Our Association does not have the money to conduct an investigation or to make a contribution to the National Bureau of Standards. I would suggest that there is a Highway Research Board, authorized by Congress and financed from the appropriations for highwavs. It would be appropriate, it seems to me, for this Board to explore variability in axle loads, tolerances, and the whole subject of truck weighing. 
Mr. HoffmaN (American Trucking Associations, Inc.) : I am not in a position to commit my principals, but I can say that they are greatly interested and have already instructed our engineering department to investigate this subject. Preliminary tests were made last year to study the variables mentioned by Mr. Richard. I can certainly report the proposals made here to our executive committee and get their reaction.

MR. RUSSELL : I think it will be of interest to the Conference that a new specification for 4-section motor-truck scales has been adopted by the American Railway Engineering Association, and that copies will be available for purchase about the first of next August from the Association office located at 59 East Van Buren Street, Chicago 5, Ill.

\section{REPORT OF THE COMMITTEE ON SPECIFICATIONS AND \\ TOLERANCES, PRESENTED BY R. E. MEEK, CHAIRMAN, AND DISCUSSION THEREON}

The tentative report of your Committee was given wide distribution some weeks ago. In response to the invitation therein contained to submit comments on the proposals made, some such comments were received; all of these have received the careful consideration of the Committee in executive session, held on May 20. On May 21 open hearings were held by the Committee to receive all further advance comments on its proposals, and all such further comments have been considered in subsequent executive session.

The Committee expresses its appreciation of the cooperation of officials and representatives of eauipment manufacturers and industry in presenting their viewpoints for the assistance of the Committee. Numerous suggestions have been concurred in; in those cases where suggestions have been modified or rejected, the Committee feels that there exist compelling reasons for its action.

In some cases amendments are now recommended to proposals made in the tentative report. Some proposals are now formally presented for the first time. What follows is the full recommendation of the Committee for changes in and additions to the codes of specifications, tolerances, and regulations for commercial weighing and measuring devices as previously adopted by the Conference.

[Secretary's Note: As each individual recommendation was presented, it was moved and seconded that it be adopted. Such motions prevailed in all cases except where otherwise noted.]

\section{GENERAL CODE}

Paragraph $G$-A.2. It appears that it is contradictory to provide, in this paragraph, that provisions of the General Code may be suspended, etc., by the terms of the General Code. To correct this inconsistency, it is recommended that this paragraph be amended by deleting the words "of the General Code or" which occur in line 5 of the printed paragraph, so that the paragraph will read as follows :

G-A.2. General CODE.-The requirements and provisions of the General Code apply to all classes of weighing and measuring equipment for which separate codes have been established, except insofar as they are specifically suspended, modified, or limited by the terms of some specific code. 
Paragraph G-A.3. To clarify the meaning of this paragraph in cases of conflict between the requirements of the General Code and specific codes, it is recommended that this paragraph be amended by deleting the words "of the General Code or" which occur in lines 5 and 6 of the printed paragraph, so that the paragraph will read as follows:

G-A.3. SpeCIFIC CoDES.-The requirements and provisions of a specific code for a particular class of weighing or measuring equipment apply to all equipment falling clearly within such class, except insofar as they are specifically suspended, modified, or limited by the terms of the specific code itself.

With the great increase in the use of recording elements in commercial weighing and measuring devices the committee is of the opinion that all appropriate requirements for indicating elements must be made effective also, and specifically, with respect to recorded representations. Accordingly, the committee recommends the addition of a new paragraph, to be inserted following paragraph G-S.5.4., and to read as follows :

G-S.5.5. Requirements For ReCording Elements ANd ReCoRded RepresenTATIONS.- Insofar as they are clearly appropriate, the requirements and provisions of the General Code and of specific codes for indicating elements shall be applicable also to recording elements and recorded representations.

Paragraph $G-N .1$. In order to broaden and clarify the provisions of the "Conflict with laws and regulations" paragraph of the General Code, the Committee recommends that paragraph G-N.1. be amended to read as follows:

G-N.1. CoNflict with LAwS AND REgulations.-If any particular provisions of these specifications, tolerances, and regulations are found to conflict with existing State laws, or with existing regulations or local ordinances relating to health, safety, or fire prevention, the enforcement of such provisions shall be suspended until conflicting requirements can be harmonized; and such suspension shall not affect the validity of enforcement of the remaining provisions of these specifications, tolerances, and regulations.

\section{SCALE CODE}

Paragraph A.1. Confusion having persisted as to the applicability of code requirements to "load-cell" scales, it is now recommended that a new first sentence be added to paragraph A.1. of the code, so that the paragraph will read as follows:

A.1. General.-This code applies to all types of weighing devices, including, but not limited to, those utilizing, as components, singly or in combination, levers, pendulums, springs, and load cells of electronic, hydraulic, pneumatic, or other design. The code comprises general requirements that are generally applicable to all classes of weighing devices, and specific requirements for certain individual classes of such devices. Such specific requirements supersede general scale requirements in all cases of conflict. (See also G-A.1., G-A.2., G-A.3., G-A.4., and G-A.5.)

Requirements for Livestock Scales.-The committee has been negotiating during the year with the Packers and Stockyards Branch, Livestock Division, Agricultural Marketing Service, of the U. S. Department of Agriculture, toward the harmonizing of requirements for livestock scales. Currently the difference between 
the provisions of Handbook 44 and those of the U. S. Department of Agriculture, although quite minor in nature, are such as to make the possible adoption of Handbook 44 requirements by the Division, appear inappropriate from their viewpoint. Only slight amendments to the Scale Code are required to bring about the desired correlation of requirements, and a meeting of minds has been achieved. Before presenting the Committee's recommendations for changes to effect this correlation, I wish to yield the floor to Mr. R. D. Thompson, Supervisor of Scales and Weighing, Livestock Division, U. S. Department of Agriculture, to make a statement in this relation:

Mr. THOMPSON : As many of you are aware, the Packers and Stockyards Branch, Livestock Division, Agricultural Marketing Service of the U. S. Department of Agriculture, officially issues requirements covering the performance and testing of livestock scales subject to its supervision as stipulated in the Packers and Stockyards Act. It is my pleasure to announce to you this morning that effective about July 1, 1956, we propose to adopt and include in such official requirements those portions of the General Code and the Scale Code of National Bureau of Standards Handbook 44-2d Edition-1955, as are applicable to livestock scales.

This action is being taken only after long and serious study and discussion among the personnel of the Branch. It is our belief that uniformity of requirements among the several States and their political subdivisions and those agencies of the Federal Government that have enforcement authority should be the constant aim. With such uniformity as our goal, the Packers and Stockyards Branch will adopt the provisions of the Codes of this Conference by citation and with cumulative provision. We believe that the cooperation and assistance that we are now receiving from the States, counties, and cities will be even greater and will be more conveniently rendered when our requirements are the same as yours.

It should be noted that we are making only one minor exception to the codes that you have adopted-that exception being with respect to minimum tolerance values for nonautomatic indicating scales. We shall be pleased to furnish copies of our new requirements and testing instructions as soon as they are available.

Mr. R. E. MEEK : Resuming presentation of the report, the Committee recommends, to accomplish the purpose previously stated, that, in the code for scales, paragraphs D.53. and P.1.2.1. be amended to read as shown below, and that two new paragraphs, to be designated P.1.2.4. and P.1.2.5., respectively, be added to the code, these to read as shown below:

D.53. SR For A SCALE With A Balance IndiCATOR.-The change in load required to cause (a) a relative change of 0.04 inch in the positions of rest of two indicators that move in opposite directions, (b) a change in the position of rest of an indicator such that there is a clear interval between adjacent edges of the indicator and a single zero graduation equal to 0.04 inch on a small-capacity scale, 0.12 inch on a large-capacity scale other than a vehicle, wheel-load, axle-load, livestock, animal, coal-mine, hand-operated grain hopper, or railway track scale, 0.25 inch on a vehicle, wheel-load, axle-load, coal-mine, hand-operated grain hopper, or railway track scale, and 0.375 inch on a livestock or animal scale, or (c) a change in the position of rest of an indicator equal to one division on a graduated scale if this distance is greater than that specified in (b). 
P.1.2.1. GENERAL.-The maximum maintenance SR., except as prescribed in P.1.2.2., P.1.2.3., P.1.2.4., and P.1.2.5., shall be the value of two of the minimum graduated intervals on the weighbeam, or 40 pounds, whichever is less. The maximum acceptance SR shall be one-half the maximum maintenance SR.

P.1.2.4. FOR LIVESTOCK AND ANIMAL SCALES NOT EQUiPPED WITH BALANCE INDICATORS.- The maximum maintenance SR shall be the value of two of the minimum graduated intervals on the weighbeam. The maximum acceptance SR shall be one-half the maximum maintenance SR.

P.1.2.5. For Livestock aNd ANIMAL Scales Equipped With Balance INDICATORS.- The maximum maintenance and acceptance SR shall be the value of one of the minimum graduated intervals on the weighbeam.

Paragraph $R .4 .1$. In order to correct the side title to make it appropriate to the text, it is recommended that the side title be amended to read as follows:

\section{R.4.1. ON RETAIL Food Scales.-}

\section{LIQUID-MEASURING DEVICE CODE}

Paragraph A.1.-To indicate clearly that requirements for meters installed on vehicle tanks are to be found, not in the code for liquid-measuring devices, but in the code for vehicle tanks, it is recommended that paragraph A.1. of the liquid-measuring device code be amended to read as follows:

A.1. This code applies to devices for the measurement and delivery of liquids, including liquid fuels and lubricants, but does not apply to meters mounted on vehicle tanks (for which see Code for Vehicle Tanks), to water meters, to devices used for dispensing liquefied petroleum gases or other liquids that do not remain in a liquid state at atmospheric pressures and temperatures, or to devices used solely for dispensing a product in connection with operations in which the amount of product dispensed does not affect customer charges.

Paragraph S.3.6. As a result of recent developments in the manufacture of retail gasoline dispensers. it is recommended that this paragraph be expanded to read as follows:

S.3.6. UNIT-PRICE INDICATION.-In a device of the computing type or the coin-operated type, automatic means shall be provided for displaying on each face of the device the unit price at which the device is set to compute or to deliver at any time the device is in operation. If a device is so designed as to dispense more than one grade, brand, blend, or mixture of product, automatic means also shall be provided for displaying on each face of the device the identity of the grade, brand, blend, or mixture being dispensed. (See G-R.5. for method of operation.)

Paragraph S.10.2.-The necessity and desirability of retaining the renuirements for the "sight glass" or "visigage" on retail liquid fuel devices was discussed during the 40th National Conference, and the matter was referred to this Committee for further study. The Committee has continued a study of the problem throughout the vear.

As a part of the Committee study, a survey was conducted to determine, on a nationwide basis, consumer reaction to the "sight glass" or "visigage" question. Approximately 30 State and local jurisdictions were reauested to participate. Arrangements were made with the operator of at least one well-located and reasonably 
busy retail gasoline station to paint over the gage glasses of each gasoline dispenser. Explicit instructions were given to each operator and employee that they note any questions or comments made by customers during the specified period of one month.

Of the thousands of customers who visited the more than 35 cooperating stations during the thirty days that the survey was in process, an average of less than three persons per station made any comment. Of these, almost all inquired only as to the reason for covering the "glass bowl." Virtually no adverse consumer reaction or sincere customer interest was noted. Several stations reported that no customer commented.

It should be noted that, with the adoption by the Conference in 1935 of the last clause of paragraph S.10.2., which reads, "However, ... a check valve may be installed in the discharge line of any device equipped with an effective air eliminator or equivalent means," the effectiveness of a "visigage" to indicate the actual condition of fill of the measuring system was greatly reduced, if not destroyed. A check valve installed between the outlet side of the meter and the inlet side of the "visigage" will maintain liquid in the gage and at the same time permit other measured liquid in the system to leak back, with no indication of such loss of measured liquid showing in the "visigage."

Having determined that the "visigage" provides little or no service to the weights and measures official and practically no protection to the consumer, and that the customer pays little or no attention to its existence, the Committee recommends that paragraph S.10.2. of the Code for Liquid-Measuring Devices be deleted, and that paragraph S.10.3. be renumbered to become S.10.2.

(It was moved and seconded that the recommendation of the Committee be adopted.)

Mr. Christie: I suggest that the Committee consider requiring installation of a check on the inlet side of the meter.

Mr. J. T. KENNEDY: Visigages were put on gasoline dispensers for a purpose. They were recommended by the industry. Although I have talked to the Committee and to a number of industry representatives, I have not been convinced that the visigage does not render a service to weights and measures officials I am under orders from a superior officer of mine that no gasoline dispensing device be permitted in the District of Columbia without a visigage, and the District of Columbia will vote against the deletion of paragraph S.10.2.

Mr. R. E. MEEK: At last year's Conference both sides of this question were presented, and the matter was then referred to the Committee for its recommendation. The Committee has considered this question carefully. I have already reported the indifference of the public toward visigages. We feel also that the visigage has little value to the weights and measures official. We are mindful of the reduced sizes of some visigages, of the fact that some are now located in inconspicuous positions, and of the effect on visigages of the check valves now commonly utilized on dispensing units. Our conclusion is that the visigage, as we know it, serves no useful purpose, and I ask your support for the Committee recommendation. 
(A rising vote was called for and taken, and the motion to adopt the Committee recommendation for deletion of paragraph S.10.2. was lost.)

Mr. R. E. MEEK : I shall continue with the report of the Committee.

\section{VEHICLE TANK CODE}

Paragraph S.21.1.1.-It has been brought to the attention of the Committee that the sentence construction of this paragraph is such as might cause misinterpretation of meaning. With no intended change in meaning, the Committee recommends that the paragraph be rephrased to read as follows:

S.21.1.1. Terms of INDICATion.-Meters shall indicate in terms of gallons. The value of the smallest unit of indicated delivery on a meter used for retail deliveries of liquid fuel for domestic use shall not exceed 1 pint, and on other meters shall not exceed 1 gallon. Fractional parts of the gallon shall be indicated in terms of either decimal or binary subdivisions.

New paragraph R.3.- It has been pointed out that in paragraph S.21.1.4. it is required that the indicating elements of meters mounted on vehicle tanks be readily returnable to a definite zero indication; thus there should be a regulation requiring such return to zero prior to each delivery. Accordingly, the Committee recommends that a new regulation be added to the code, to be numbered R.3., and to read as follows:

R.3. REturn of IndicAting Element to Zero.-On any meter used in making deliveries to individual consumers, the primary indicating elements shall be returned to zero before each such delivery.

\section{LIQUIFIED PETROLEUM GAS LIQUID-MEASURING DEVICES}

The Committee and the Conference are indebted to the Liquefied Petroleum Gas Association, the American Petroleum Institute, the manufacturers of liquefied petroleum gas liquid meters, numerous weights and measures officials, and others, for assistance and cooperation throughout the year. As a result of their efforts and those of staff members of the National Bureau of Standards, it is now possible for the Committee to present a tentative code for liquefied petroleum gas liquid-measuring devices. The committee proposes that this code be adopted by the 41st National Conference as a tentative code and that comprehensive study of its provisions be made during the ensuing year.

Detailed description of equipment suitable for testing liquefied petroleum gas liquid-measuring devices and explanation of testing procedures are now being prepared in the Office of Weights and Measures of the National Bureau of Standards. These will be distributed at the earliest possible date.

Three provisions of this tentative code for liquefied petroleum gas liquid-measuring devices seem worthy of some discussion and explanation in this report. The first of these relates to the requirement of paragraph N.2.1. to the effect that liquefied petroleum gas liquid-measuring devices be tested by means of volumetric provers. It should be noted that this requirement deals only with official testing by weights and measures officers, and does not preclude the 
use of other provers for purposes of the maintenance and servicing of commercial devices.

The conclusion of the Committee on the advisability of including this requirement in the code was reached after an evaluation of all of the information available to the Committee regarding provers for this purpose, and with the benefit of the advice of representatives of the liquefied petroleum gas industry and equipment manufacturers. Moreover, this requirement is believed to be in harmony with the present consensus of weights and measures officials, including those who have had experience with provers of the gravimetric type.

The second provision to be explained is the proposed tolerance structure. The tolerance provisions obviously are more lenient than those for other liquid-measuring devices and are unequal as to "overregistration" and "underregistration." The Committee is convinced that the recommended tolerances are the best and most equitable obtainable with current commercial devices and current testing procedures. The committee feels incumbent upon itself the responsibility to recommend tolerances that are realistic and at the same time that will require adequate performance from the best available commercial devices. A very thorough study, including consultation with representatives of all involved industries, has brought forth the development of the tolerances included in the tentative code.

The tolerance structure being proposed seems indicated by the device itself. Because of the "dryness" and other characteristics of the product being measured, the tendency of the device is to err toward "underregistration" (overdelivery). With the greater portion of the maintenance tolerance on the "underregistration" side, it is believed that the legal useful life of the device within tolerance will be lengthened.

On the other hand, it has been demonstrated conclusively that these devices can, without difficulty, be adjusted to within 2 cubic inches per indicated gallon of zero error. Thus, when adjustment becomes necessary, they can be brought within that error.

Attention of weights and measures officials and of persons repairing or servicing liquefied petroleum gas liquid-measuring devices is dir ected to General Regulation G-R.4., page 39, Handbook 44, which includes the words "Whenever equipment is adjusted, the adjustments shall be so made as to bring performance errors as close as practicable to zero value." It is the recommendation of the Committee that a liquefied petroleum gas liquid-measuring device be adjusted whenever it is found by test that the error of the device, on normal test, exceeds the acceptance tolerance of plus or minus 2 cubic inches per indicated gallon.

The third requirement that should be discussed is the recommended regulation covering vapor return lines (R.5.). Historically, until refinements of dispensing and receiving equipment were developed, it was thought by all in the industry that liquefied petroleum gas could not be pumped into a closed vessel, to a reasonable level of fill, without a vapor return line to relieve the pressure caused by the rise in level of the liquid. Consequently, for many years, every liquefied petroleum gas customer's receiving container was equipped with provisions for returning vapor to the supplier's tank. 
Recent engineering developments have resulted in a process that seems to be such as to make possible transfer of the fluid to a receiving container without the connection of the vapor return line. Since this process is, as yet, under study, the Committee is recommending a regulation (R.5.) that will provide the following:

1. Vapor return lines may not be used during delivery of liquid to those receiving containers that are so constructed that no vapor return line is necessary.

2. Effective July 1, 1957, no vapor return line may be used during delivery to receiving containers installed after that date.

3. Effective July 1, 1959, no vapor return line may be used during delivery to ANY receiving containers.

Moreover, the Committee is recommending that, whenever practicable, installers of liquefied petroleum gas receiving containers start immediately installing receiving containers that do not require vapor return lines for filling and that are without connections for vapor return lines, and that by July 1, 1959, such connections be removed from all receiving containers.

The Committee now recommends for Conference consideration and action the following Tentative Code for Liquefied Petroleum Gas Liquid-Measuring Devices:

\section{TENTATIVE CODE FOR \\ LIQUEFIED PETROLEUM GAS LIQUID-MEASURING DEVICES}

General Code References.-Liquefied petroleum gas liquid-measuring devices shall conform to all of the applicable requirements of the General Code, particularly G-S.1., G-S.2., G-S.3., G-S.4., G-S.5.1.1., G-S.5.1.2., G-S.5.1.3., G-S.5.2., G-S.5.3.1., G-S.5.3.2., G-S.5.3.3., G-S.6., G-T.5., and G-T.6. See also general regulations G-R.2., G-R.3., G-R.4., and G-R.5.

\section{A. APPLICATION.}

A.-This code applies to liquefied petroleum gas liquid-measuring devices, as defined. Insofar as they are clearly appropriate, the requirements and provisions of this code may be applied to devices used for dispensing other liquids that do not remain in a liquid state at atmospheric pressures and temperatures.

\section{DEFINITIONS.}

D.1. Liquefied Petroleum Gas Liquid-Measuring Device.-A system including a mechanism or machine of the meter type designed to measure and deliver liquefied petroleum gas in the liquid state by definite volume, whether installed in a permanent location or mounted on a vehicle. Means may or may not be provided to indicate automatically for one of a series of unit prices, the total money value of the liquid measured.

D.2. Liquefied Petroleum Gas.-A petroleum product composed predominantly of any of the following hydrocarbons, or mixtures thereof: propane, propylene, butanes (normal butane or isobutane), and butylenes.

D.3. RetaIl DevicE.-A device used for single deliveries of liquefied petroleum gas for domestic use and, in addition, any motor-fuel device (see D.4.).

D.4. Motor-Fuel Device.-A stationary device used for retail deliveries of liquefied petroleum gas as motor fuel to the fuel tanks of individual highway vehicles.

D.5. Wholesale Device.-Any device other than a retail device. 


\section{SPECIFICATIONS APPLICABLE TO \\ BOTH RETAIL AND WHOLESALE DEVICES}

S.1. UNITS.-A liquefied petroleum gas liquid-measuring device shall indicate its deliveries in terms of gallons or binary or decimal submultiples of the gallon.

\section{S.2. DESIGN.}

S.2.1. Sensitiveness.-A device shall be readily operable to deliver accurately each quantity that the device holds itself forth to deliver. If the most sensitive element of the indicating system utilizes an indicator and graduations, the relative movement of these parts corresponding to the smallest unit of indicated delivery shall be not less than 0.20 inch.

S.2.2. Diversion of Measured Liquid.-No means shall be provided by which any measured liquid can be diverted from the measuring chamber of the meter or the discharge line therefrom, except that a manually controlled outlet that may be opened for the purpose of emptying a portion of the system to allow for repair and maintenance operations shall be permitted; effective July 1, 1957, effective automatic means shall be provided to prevent the passage of liquid through any such outlet during normal operation of the device and to indicate clearly and unmistakably when the valve controls are so set as to permit passage of liquid through such outlet.

S.2.3. VAPOR ElIMINATION.-A device shall be equipped with effective means to prevent passage of vapor through the meter.

S.2.4. MAINTENANCE OF Liquid STATE.-A device shall be so designed and installed that the product being measured will remain in a liquid state during passage through the meter.

S.2.5. THERMOMETER WELL.-Means shall be provided for inserting, for test purposes, a mercury-in-glass thermometer either (a) in the liquid chamber of the meter or (b) in the meter iniet or discharge line and immediately adjacent to the meter.

S.3. Indicating Elements. (See also S.11. and S.20.)

S.3.1. READABILITY.-Quantity and money-value indications shall be readable from any reasonable customer position.

S.3.2. INDICATION OF DELIVERY.-A device shall be constructed to show automatically its initial zero condition and the amounts delivered up to the nominal capacity of the device.

S.3.3. DiAls AND SCALES.-Dials and graduated scales intended to remain stationary under normal operating conditions shall be permanently fixed in position.

S.3.4. AdVANCEMENT AND RETURN TO ZeRo.--Indicating elements shall be susceptible of advancement only by the mechanical operation of the device, they shall be readily returnable to a zero indication, and means shall be provided to prevent the return of these elements beyond their correct zero position. However, a device may be cleared by advancing the indicating elements to zero, but only if the movement, once started, cannot be interrupted, or if the indications are automatically obscured until the elements reach zero position.

S.3.5. Width of Graduations.-Graduations shall be not wider than 0.04 inch.

S.4. Provision For SEALING.-Provision shall be made for applying leadand-wire seals in such manner that no adjustable measuring or quantityindicating element and no adjustable element for controlling the delivery rate of a meter when such rate tends to affect the accuracy of deliveries, can be adjusted without mutilating the seal or seals.

S.5. MARKING.

S.5.1. LIMITATIONS OF USE.-If a device is intended to measure accurately only products having particular properties, its limitations shall be clearly and permanently stated on the device.

S.5.2. Discharge RATES.-A device shall be marked to show its design maximum and minimum discharge rates. However, on a retail device other than a motor-fuel device and on a wholesale device, such minimum discharge rate shall not exceed 20 percent of such maximum discharge rate. On a motor-fuel device such minimum discharge rate shall not exceed 5 gallons per minute. 
S.10. DESIGN.

S.10.1. Zero SeT-BACK INTERLOCK.-A motor-fuel device shall be so constructed that, after a particular delivery cycle has been completed by movement of the starting lever to its shut-off position, an effective automatic interiock will prevent a subsequent delivery being started until the indicating elements have been returned to their correct zero positions.

S.10.2. DeLIVERY HOSE.-The delivery hose of a retail device shall be of the wet-hose type with a shut-off valve at its outlet end.

S.11. Indicating Elements. (See also S.3.)

S.11.1. Minimum Delivery Indication.-The value of the smallest unit of indicated delivery on a retail device shall not exceed one pint.

S.11.2. VISIBILITY.-The bottom of the lowest indicating element of a motorfuel device shall be at least 36 inches above the normal level upon which the receiving vehicle or vessel stands. The indications of a motor-fuel device shall be readable from any position within a field of $120^{\circ}$, defined by two vertical planes each passing through the center of the face of the device at an angle of $30^{\circ}$.

S.11.3. Unit PRICE Indication.-In a motor-fuel device of the computing type, automatic means shall be provided for displaying on each face of the device the unit price at which the device is set to compute at any time.

S.12. Money-VAlue Computations.-Money-value computations on a motorfuel device shall be of the full-computing type in which the money value, at one or at each of a series of unit prices, shall be computed for every delivery within the range of measurement of the device. Value graduations shall be supplied and shall be accurately positioned. The value of each graduated interval shall be 1 cent. However, the requirement of this specification for money-value computation for every delivery within the range of measurement of the device shall apply only up to the greatest money value that can be indicated by the computing elements.

\section{ADDITIONAL SPECIFICATIONS APPLICABLE ONLY TO WHOLESALE DEVICES}

S.20. Indicating Elements. (See also S.3.)

S.20.1. Minimum Delivery InDiCATION.- The value of the smallest unit of indicated delivery on a wholesale device shall not exceed one gallon.

\section{N. NOTES.}

N.1. Testing Midium.-A liquefied petroleum gas liquid-measuring device shall be tested with liquid having the same general physical characteristics as the liquid to be commercially measured.

N.2. Testing Procedures.

N.2.1.-Liquefied petroleum gas liquid-measuring devices shall be tested by means of volumetric provers of nominal capacities of 50 gallons or more. Testing drafts should be equal to at least the amount delivered by the device in one minute at its maximum discharge rate.

N.2.2. NORMAL TESTS.-The "normal" test of a meter or meter-type device shall be made at the maximum discharge rate developed under the conditions of installation.

N.2.3. SPECIAL TeSTS.- "Special" tests, to develop the operating characteristics of meters and meter-type devices, shall be made as circumstances require. A motor-fuel device shall be so tested at a minimum discharge rate of (a) 5 gallons per minute or (b) the minimum discharge rate marked on the device, whichever is less. A wholesale device shall be so tested at a minimum discharge rate of (a) 15 gallons per minute for a device with a rated maximum discharge rate less than 50 gallons per minute, (b) 20 percent of the marked maximum discharge rate for a device with a rated maximum discharge of 50 gallons per minute or more, or (c) the minimum discharge rate marked on the device, whichever is less.

N.2.4. Temperature Correction.-Corrections shall be made for any changes in volume resulting from the differences in liquid temperatures between time of passage through the meter and time of volumetric determination in the test measure. 


\section{P. PERFORMANCE REQUIREMENTS EXCEPT TOLERANCES.}

P.1. Operating Conditions.-The deliveries of a device shall be accurate (a) irrespective of whether operation is continuous or intermittent and (b) irrespective of the speed of operation, subject, however, to the provisions of T.1.

\section{T. TOLERANCES.}

T.1. ON "NORMAL" AND ON "SPECIAL" TESTS.-Maintenance and acceptance tolerances for retail and for wholesale liquefied petroleum gis liquid-measuring devices shall be as follows:

(a) On "normal" tests the maintenance tolerance shall be 6 cubic inches per indicated gallon on underregistration and 3 cubic inches per indicated gallon on overregistration.

(b) On "normal" tests the acceptance tolerance shall be 2 cubic inches per indicated gallon on underregistration and on overregistration.

(c) On "special" tests the maintenance and acceptance tolerances shall be 6 cubic inches ner indicated gallon on underregistration and 3 cubic inches per indicated gallon on overregestration.

(The error of a liquefied petroleum gas liquid-measuring device-to which the tolerance is anplied-is the difference botween the indication of the device and the amount of liquid actually delivered by the device.)

\section{R. REGULATIONS.}

\section{R.1. INSTALLATION.}

R 1.1. Dischapge Rate.-A liquefied petroleum gas liquid-measuring device shall be so installed that the actual maximum discharge rate will not exceed the rated maximum discharge rate: if necessarv. means for flow regulation shall be incorporated in the inctallation, in which case this shall be fully effective and automatic in operation.

R.2. Lencth of DicCharge Hose.-The length of the discharge hose on a motor-fuel device shall not exceed 15 feet. measured from the outside of the housing of the device to the inlet end of the discharge nozzle, unless it can be demonstrated that a longer hose is essential to permit deliveries to be made to receiving vehicles or vessels. Unnecessarilv remnte location of a device shall not be accepted as justification for an abnormally long hose.

R.3. Condition of Fill of Discharge Hose-The discharge hose shall be completely filled with liquid before the "zero" condition is established prior to the start of a commercial delivery, whether this condition is established by resetting the primary indicating elements to zero indication or by recording the indications of the primary indicating elements. (See also R.4.)

R.4. REtURN OF INDiCATiNg Element tn Zern.-On anv device on which the primary indicating elements are suscentible of being returned to a zero indication, such primary indicating elements shall be returned to zero before each delivery.

R.5. VAPOR RETURN LINE.-During any metered delivery of liquefied petroleum gas from a supplier's tank to a customer's receiving container, there shall be no vapor return line from the customer's container to the supplier's tank.

(a) In the case of any customer's container to which normal deliveries can be made without the use of such vapor return line.

(b) In the case of any customer's container installed after July 1, 1957.

(c) Effective July 1, 1959, in the case of any customer's container.

(NOTE: It is recommended that all new customers' receiving containers be installed without connections for vapor return lines and that by July 1, 1959, all connections for vapor return lines on customers' receiving containers be removed.)

(It was moved and seconded that the recommendation of the Committee be adopted.) 
Mr. BAUCOM: Mr. Chairman, as a substitute for the motion before the Conference, I move that action on the Tentative Code dealing with liquefied petroleum gas liquid-measuring devices be deferred until the next annual National Conference on Weights and Measures; and that in the meantime the Specifications and Tolerances Committee be authorized and instructed to study the natural characteristics of liquefied petroleum gas, conduct tests, collect data, make observations, and transmit to the weights and measures officials of this Conference, and to other interested parties who may request them, such data pursuant to the development of a liquefied petroleum gas code as would be reasonable, practical, and acceptable.

Mr. BerRyMAN : I second that motion.

Mr. BAUCOM : Mr. Chairman and gentlemen of the Conference, I want it clearly understood in the outset that I do not minimize the praise which the Specifications and Tolerances Committee has justly earned, nor do I question in the least the sincerity of purpose and intent of this Committee in their deliberation and development of this Tentative Code. Nevertheless and notwithstanding, I am just as sincere in bringing to your attention certain fundamental facts which you should take into consideration before you express an opinion by your vote on this Tentative Code.

In the interest of saving time, I will not relate or discuss the background of my substitute motion, which covers eight years of practical experience in the handling, storing, measuring, and distribution of LP Gas using both gravimetric and volumetric provers. To those of you who have never had any experience in the handling or measuring of this commodity, I suggest that you have a conference with dulv authorized personnel of the LP Gas Association, the API, the NFPA, and weights and measures officials who have and who enforce LP Gas rules and regulations.

My reasons for offering this substitute motion are as follows:

1. The definitions and provisions are both confusing and inappropriate.

2. It is not susceptible to practical applications.

3. The tolerances are discriminatory and do not differentiate between the mechanical and operational.

4. It compels condemnation equivalent to confiscation of personal property which was bought and put into use under a legal status.

Now Mr. Chairman and fellow weights and measures officials, in order that you may be apprised of the thinking of industry on this subject, and with permission from the Chair, I wish to yield the floor to Mr. Ken Birkin, who represents the American Petroleum Institute, for any statement or comment he may care to make.

Mr. BIRKIN : I am chairman of the Weights and Measures Committee, American Petroleum Institute. I have been asked by George R. Benz, Chairman of API-LPG Committee, to read into the record of this 41st National Conference his letter of May 2, 1956, directed to Mr. W. S. Bussey. 
Mr. W. S. Bussey, Secretary

Committee on Specifications and Tolerances

National Conference on Weights and Measures

U. S. Department of Commerce

National Bureau of Standards

Washington 25, D. C.

\section{Dear Mr. Bussey:}

This will acknowledge receipt of the report (green) of the Committee on Specifications and Tolerances entitled, "Tentative Report of the Committee on Specifications and Tolerances (Received 4/9/56) Liquefied Petroleum Gas."

Although our acknowledgment has not been specifically requested, we believe that you will be interested in the following comments on the committee's report and draft of the "Tentative Code for Liquefied Petroleum Gas," prior to the meeting of the committee this month in Washington.

We are very happy that the tentative draft incorporates many of the suggestions made in our letter to you, reference Be-332-56, and as presented in the March 19 meeting in Washington when industry representatives met with the $\mathrm{S} \& \mathrm{~T}$ Committee, and do appreciate the efforts of the $\mathrm{S} \& \mathrm{~T}$ Committee to develop a practical code.

The proposed tentative code as drafted (green copy) still contains several items on which we desire to comment further for the purpose of clarification and for the purpose of having a code which is economically feasible and workable for industry and the consuming public. Our comments are as follows:

S.2.2. The last sentence of this paragraph states "... automatic means shall be provided to prevent the passage of liquid through any such outlet during normal operation of the device." What is meant by "automatic means"? We believe this wording should be clarified.

S.2.4. We would suggest that this be revised to read "A device shall be so designed and/or installed that the product being measured will remain in a liquid state during passage through the meter." This is important, in our opinion, since the device, i.e., back pressure regulator, which does the job of maintaining the product in a liquid state may or may not be built into the meter.

T.1. We are unable to see any justification for uneven tolerances; i.e., 6 cubic inches per gallon on underregistration and 3 cubic inches per gallon on overregistration. In our opinion tolerances should be equal on the plus as well as on the minus side and feel that some mutually satisfactory maintenance tolerance such as 5.0 cubic inches per gallon minimum be accepted. We should not overlook the fact that this tolerance is necessary as much for the prover operator and procedure as for the measuring system itself. We see no reason for changing the basic philosophy of equal, plus or minus tolerances in the case of this particular product.

R.5. In our letter Be-332-56 to you we pointed out the problem inherent in the use of a vapor return line. This was also thoroughly discussed in the March 19 meeting in Washington. We again desire to bring to your attention the fact that this is a problem which industry recognizes as a mutual one. However, to eliminate practically "overnight" the use of vapor return lines, as proposed in the tentative code, would in our opinion be a practical impossibility. For one thing, it would work a severe hardship on many hundreds of thousands of consumers who own their own storage systems, as well as the thousands of distributors who service them. We believe that a more realistic and practical approach to the problem would be developed, taking into account not only weights and measures and distributor interests, but also consumer interests.

Very truly yours,

/s/ Geo. R. Benz

Geo. R. Benz, Chairman API-LPG Committee

948 Adams Building, Bartlesville, Okla. 
For the record, I would further make it known that in LP Gas circles George Benz is recognized and accepted as a man outstanding in his knowledge and experience in handling and measuring LP Gas. It was through his courtesy and cooperation that last summer extensive and exhaustive tests on LP Gas metering system provers were conducted at Bartlesville, Oklahoma. The results of these tests were correlated and analyzed. A copy of the final report was placed in the hands of the S \& T Committee as early as last December.

Gentlemen, I urge that you give consideration to the unbiased recommendation of both sealers and industry that your actions be tempered with experience rather than theory. It is our earnest suggestion that action be deferred for at least another year, during which real down-to-earth experience may be acquired.

Mr. BAUCOM: Next I desire to yield the floor to Mr. A. C. Kreutzer, who represents the Liquefied Petroleum Gas Association, for any statement or comment he may care to make.

MR. KREUTZER: I am Arthur C. Kreutzer, Vice President and General Counsel for the Liquefied Petroleum Gas Association, and am speaking for over 2000 of our members who are affected by the proposed code and the liquefied petroleum gas industry generally.

Let me first express our appreciation for the privilege of the floor and also to the S \& T Committee and this Conference for the time and consideration they have given to the LP Gas industry. On our part we have tried to cooperate to the utmost. The work on meter provers and their testing has been a substantial contribution by this industry, representing nearly a quarter of a million dollars in time and material.

In our letter of April 26th we submitted several suggestions relative to the tentative code and we are sincerely distressed that our recommendations have not been followed. Clarifying language was recommended in several instances and was not utilized. We do not wish to take up your time with these minor changes except to point out that there is an element of confusion for industry in some of the language used, and this also enters into the complete picture.

However there are certain major principles involved. First, we wish to again emphasize that this industry has never recommended a particular type of prover. The Final Report of the S \& T Committee still contains this implication in stating that the conclusion of the Committee on this point was reached "with the benefit of advice of representatives of the liquefied petroleum gas industry."

Secondly, the provisions on tolerances do not conform to industry's recommendations. Nor do they represent a realistic interpretation of the Bartlesville tests, which test results we furnished to the S \& T Committee. Again there is a substantial deviation from the principles followed in other codes in the differing plus and minus tolerances.

Our final major objection relates to R.5. Industry cannot agree with the provisions prohibiting the use of an equalization or vapor return line. Safety is jeopardized. The purpose of this line is to equalize pressures between the container being filled and the container from which the product is being drawn. This is necessary in many instances to permit filling without causing a release of vapor to the air. If this line is eliminated, under many conditions the vapor will be vented into the atmosphere, presenting a combustible 
mixture that can be touched off by any nearby source of ignition. This is a most unsafe practice, a violation of the national safety standards of National Fire Protection Association Pamphlet No. 58 , and a violation of the State law or regulation in the 44 States that use this safety standard, as well as in numerous municipalities. The pertinent provision of this pamphlet reads: "Gas or liquid shall not be vented to the atmosphere to assist in transferring contents of one container to another."

Section G-N.1. of H44 does not solve this safety problem. To refresh your recollection, this section states that, where there is a conflict with existing safety laws or regulations, the enforcement of the provisions shall be suspended until the conflicting requirements can be harmonized. We can appreciate the value of this in caring for hidden or unknown conflicts at the time of code adoption. But here the conflict is present and obvious. The proposed code will create the conflict. We submit that it cannot be harmonized. There is no present proven and safe method that will permit the elimination of the equalization line. Experience with spray filling is entirely insufficient. Is it logical to adopt a "Tentative Code" and deliberately create a conflict when, through the provisions of H44, the provision is required to be held in abeyance? Would it not be advisable to prevent the creation of a conflict?

The economic effect of proposed retroactivity is confiscatory. The tentative code provides for retroactivity of its prohibition of the equalization line. The elimination of the equalization line will require new fittings on all existing tanks. In the case of underground tanks it will require that they be dug up. The cost for this alteration will vary from $\$ 75.00$ to $\$ 125.00$ per tank, depending on type of tank, location, etc. It is to be specifically noted that in the case of end fitted tanks, of which there are a substantial number in the industry, these tanks are not adaptable to present methods that purport to eliminate the equalization line (spray filling). The practical economic effect of retroactivity should be realized. There is involved a cost of $\$ 300,000,000$, based on the number of tanks in use multiplied by a medium cost of alteration of $\$ 100.00$. The cost must be borne by the customer. A substantial number of these tanks are owned by the customer. Even where the tanks are not owned by the customer, the dealer is not financially able to meet the cost of alteration. Accordingly, the customer is going to come out on the short end of the deal, even though equalization lines may be eliminated.

The Committee has stressed that the definition of the word "tentative" will solve the problem. This provision will not solve the problem for the reasons:

1. It will not be noted by legislators picking up the code.

2. It is not appropriate under the circumstances in this case. Refer to H44 on Classifications of Specifications. There you will find that retroactivity is not intended to be confiscatory.

The Committee report states that, as a technical code, it is presented for "Observation and Study." Yet this code is retroactive in effect and recommends "That all new customers' receiving containers be installed without connections for vapor return lines." An analysis of paragraph R.5. indicates that the language of the Tentative Code is inappropriate, does not apply, and its so called "tentativeness" will not solve the immediate problem for the 
reason that it (a) recognizes the necessity for use of a vapor return line, (b) says that regardless of necessity you cannot use the vapor return line, and (c) makes this dictatorial mandate retroactive.

Tentativeness and retroactivity are not compatible. If the provisions of R.5. are placed in effect, it can truly be said that "the operation was successful but the patient died." The purpose of the specifications promulgated in $\mathrm{H} 44$ is being overlooked. As stated in this handbook, the purpose is the prevention of fraud and not accuracy for accuracy's sake alone. We submit that this principle is being overlooked in the "Tentative Code."

It is our recommendation that the so-called tentative provisions of the Tentative Code be set aside until such time as a sound basis is prepared.

Mr. BAUCOM: I now desire to yield the floor to Mr. Paul Renfrew, who represents the Meter Manufacturers Association, for any statement or comment he may care to make.

Mr. RENFREw: My name is Paul Renfrew and I speak as chairman of the Meter Manufacturers' Weights and Measures Technical Committee. We appreciate the opportunity to express, for the record, our thinking on the proposed Tentative Code for LPG Measuring Devices.

First we would like you to know that we consider it an excellent job of spade work. It represents a good start, and we sincerely compliment the Committee on having made a good start. We do, however, doubt the advisability of adopting it at this time, and do not believe that anything will be lost by deferring action for a vear. Those weights and measures jurisdictions that now have facilities and trained personnel have already adopted codes and have them in operation.

On the other hand, there might be considerable gain by deferring adoption. In LPG we are handling a liquid with some extremely sensitive physical characteristics. Also the performance of a liquid-measuring device is very frequently influenced materially by atmospheric and installation conditions. There is therefore more human element involved in the testing of LPG meter systems than in any other petroleum product of equal consumption. Does it not seem essential that those who are considering such activity and responsibility have available to them the most authoritative and complete information possible?

Another year's study and research under the direction of weights and measures with industry cooperating should go a long way toward developing such data. Also the Conference would then be in a position to develop a code supported bv data created under the supervision of weights and measures officials. Such a code should receive unanimous approval.

We solicit your favorable consideration and want to assure vou of our continued good wishes and complete cooperation, whatever your decision.

Mr. BAUCOM: This, Mr. Chairman. concludes my reason for offering a substitute motion. I do not feel that it is necessary to say more than this-that not a single iurisdiction actually engaged in this field of activity has sufficient experience and data upon which to write a concrete and finite code at this time. The different jurisdictions are represented here and can speak for themselves. If I 
misrepresent them, they can stand up and say so.

MR. R. E. MEEK : I would remind the Conference that specifications and tolerances for liquefied petroleum gas liquid-measuring devices have been receiving our attention for some three or four years. The Committee has worked closely with the industry and the agencies represented by the men who have spoken this morning. They did make experiments and run tests, and they gave us an extensive compilation of their results. The Committee had understood that industry had agreed to furnish the Committee with definite recommendations and the necessary evaluation to serve as a basis for a tentative code. Since such was not forthcoming in sufficient detail, and to meet the urgent desires of weights and measures officials, the Committee proceeded to formulate a tentative code. This code is now presented for your consideration.

For your further information, it may be said that the first draft of this tentative code was circulated for comment well in advance of this meeting. Last March we held a meeting at the National Bureau of Standards, at which the Liquefied Petroleum Gas Association was represented by Mr. John MacIntosh of the Suburban Rulane Gas Company, the petroleum industry was represented by Mr. Paul Tucker of the Phillips Petroleum Company, and the meter manufacturers were represented by $\mathrm{Mr}$. Emmett Wehmann of Neptune Meter Company. A limited number of changes were suggested by these gentlemen, and I believe that most of these suggestions were accepted by the Committee. On two points, however, unanimous agreement was not reached. One of these was the tolerance structure, but I think the tolerances now proposed are substantially in agreement with the expressed desires of the gentlemen who appeared before us. The second point on which full agreement was not reached related to vapor return lines. The Committee was told that it appeared that such lines would not be necessary in view of recent developments in filling methods that gave promise of satisfactory performance without vapor return.

What is now proposed is a tentative code, which we believe constitutes a good basis for further study and experimentation. We intend to continue to advise with these organizations, and eventually a code "will be proposed for final adoption; but it may take several years to reach that stage.

Some of the criticisms included in the statements read here today have already been met. Regardless of the other points raised, I do not believe that it is consistent to defer action, as has been requested. I do believe that we are iustified in urging adoption by the Conference at this time of the Tentative Code as proposed by the Committee.

I feel that I should comment briefly on one other point. Mr. Baucom has said that he submitted some 18 proposed amendments to the code recommended bv the Committee. That is true, but they were given to us either late in the forenoon or early in the afternoon of last Mondav. the day on which the Committee must draft its final report if this was to be mimeographed and readv for distribution bv Tuesday morning. We saw merit in some of his suggestions, but simply did not have the time for as much study as would have been required to give them proper consideration and to studv their effect on the numerous provisions in the code. Had the Committee received these suggestions soon after our tentative 
report was distributed, they could have received the attention which I now assure Mr. Baucom will be given to them during the coming year.

Mr. HowARD : In developing a code for LPG devices, it is essential that we have some place to start from. The Tentative Code offers a starting point for the work that is ahead of us in perfecting a final code.

(A rising vote was called for and taken, and the substitute motion to defer action on the Tentative Code for Liquefied Petroleum Gas Liquid-Measuring Devices was lost.)

Mr. C. M. FULLER: Some 15 years ago, with the aid of the most competent engineers in the LPG industry, a gravimetric prover and testing method were developed, and we have been using them ever since with entire satisfaction and with no question as to their accuracy. Comparative tests with gravimetric and volumetric provers show both to be accurate. I think that it would be a serious mistake, as well as being absolutely unfair, to require that only the volumetric method be used, thus barring use of the other method that has been giving accurate and satisfactory results for many years.

I move that the pending motion to adopt the Tentative Code be amended to provide for deletion of that portion of the specification that requires liquefied petroleum gas liquid-measuring devices to be tested only by means of volumetric provers.

(The motion was seconded by Mr. Baucom.)

Mr. BRENTON: We have found that comparable results can be obtained with both gravimetric and volumetric provers. Mr. Fuller has done a commendable job with the gravimetric type of prover. In California we make no distinction between the two types as to their suitability for testing purposes.

(The question was taken, and the motion was agreed to.)

(The question was then taken on the adoption of the Tentative Code for Liquefied Petroleum Gas Liquid-Measuring Devices as amended, and this action was agreed to.)

Mr. R. E. MEEK : I shall resume presentation of the Committee's report.

\section{FARM MILK TANK CODE}

During the year, in the laboratories of the National Bureau of Standards, there was conducted another extensive study of the indicating elements of farm milk tanks. Resulting from that investigation was conclusive evidence that the accuracy of gage rod readings is adversely affected whenever the rod is so cold that moisture will condense on it from the surrounding air. Such condensation will result regardless of the thoroughness with which a rod is cleaned prior to its insertion into the milk for the purpose of making a quantity determination. Apparently the only satisfactory method of averting such inaccuracies is offered by the storage of the rod at room temperature. The Committee recommends, therefore, that there be added a new Regulation, to be numbered R.2. and to read as follows: 
R.2. STORAGE OF GAGE ROD.-Between periods of actual use for measuring, a gage rod shall be stored at room temperature and shall not be placed inside a farm milk tank.

\section{COMMITTEE INTERPRETATIONS}

Tolerances Applicable to Animal Scales.-According to T.2.3.1., page 66, Handbook 44, the basic maintenance tolerances for animal scales, on underregistration and on overregistration, are as shown in Table 9. The basic acceptance tolerances for these scales are one-half the basic maintenance tolerances. (Minimum tolerance values are given in T.2.2.).

As is indicated through a comparison between T.2.3.1. and T.2.3.2., the basic tolerances for animal scales are smaller than those for livestock scales. Such is not without precedent (basic tolerances for large-capacity scales, such as warehouse scales and grain hopper scales are less than those for vehicle scales, livestock scales, railway track scales, etc.). The Committee suggests that this difference in tolerances is appropriate, not only because livestock normally is weighed in much smaller drafts on animal scales than on livestock scales, but also because capacities of livestock scales normally are much greater than those for animal scales. A livestock scale must have a capacity of 6,000 pounds or more (see D.22.) ; whereas the capacities of animal scales normally would be less than 6,000 pounds.

The Committee deems it appropriate to include in this report the definite recommendation to owners and prospective buyers of livestock scales that they make every effort to include in their installation at least one animal scale. Information from the Packers and Stockyards Branch of the U. S. Department of Agriculture is that the average draft of livestock weighed on scales in posted yards is less than four head. It does not seem to be within the intended meaning of G-R.3. SUITABILITY OF EQUIPMENT, to weigh commercially single animals on livestock scales with capacities from 6,000 to 80,000 pounds.

Scale Code Paragraph R.19.- Several inquiries have been received by the Committee as to whether scale regulation R.19., page 73. Handbook 44, to be effective July 1, 1957, will prohibit the multiple-draft weighing of highway vehicles by law enforcement officers for the purpose of enforcing highway axle-load and grossload requirements. The Committee invites attention to the word "commercially" in line 3 of the regulation, which word was included to exempt specifically from the regulation such weighing. The Committee suggests that a precise definition of commercial equipment, for the purpose of determining whether or not a specific device is being used commercially, will be found in the General Code, paragraph G-A.1.

Another question that has been asked relative to scale regulation R.19. is, "Can a coupled highway-vehicle combination be uncoupled and each individual unit (or vehicle) separately weighed commercially ?" The answer to this question is "Yes." The individual units of the "coupled combination" can be uncoupled and weighed separately. The "gross," "tare," and "net" weights of the units can then be used to calculate the total net weight for commercial purposes.

Gallonage Charts for Farm Milk Tanks.-Because of continued 
apparent misunderstanding or misinterpretation of specification paragraph S.4. GALLONAGE CHART of the Farm Milk Tank Code, the Committee wishes to express its opinion again with respect to the matter of gallonage charts and poundage charts. The code specifies that "A gallonage chart shall show gallonage values only ..."

Since a weights and measures official is charged by the law with the certification of commercial devices, and further, in certain instances, with the verification, under oath, of such certifications, and since both the gaging and testing of farm milk tanks are accomplished volumetrically, the official chart must give values in terms of gallons only.

Nothing in the code prohibits, under agreement of both parties, the construction and commercial use of a supplemental chart in terms of pounds, based on some arbitrary conversion factor of pounds-per-gallon. Such poundage charts will not be certified or otherwise authenticated by the weights and measures official, nor will a chart that gives values in terms of pounds as well as gallons, under the provisions of the code.

The Term "In Level" as Used in Code for Farm Milk Tanks.The Committee presents herewith its understanding of the meaning of this term, and this is proposed for approval by the Conference as an interpretation, but not for incorporation in the code. Should misunderstanding persist, the Committee will, at some later time, propose language to be added to the code.

The term "in level" as used in paragraphs S.1.1., S.6., and R.1. of the code for farm milk tanks is to be interpreted as follows: A tank is "in level" when the level-indicating means (required by paragraph S.5. of the code) gives a "level" indication, that is, when the tank is in a position such that the level-indicating means with which it is equipped shows by its indication that the tank is level. This condition is fixed by the tank manufacturer when the levelindicating means is affixed to the tank or, in the alternative case provided for in paragraph S.5. of the code, when the top edge or edges of the tank are brought into a plane as the "accurate reference for level determinations." The "level" indication of the level-indicating means is the criterion for the proper positioning of a tank during a factory gaging operation, for the proper positioning of a tank when this is installed for use, and for the maintenance of a tank, after installation, in the proper position for use. Thus it is seen that it is the function of the level-indicating means to make possible the reproduction and maintenance of the designed operating position of a tank.

\section{GENERAL RECOMMENDATIONS OF THE COMMITTEE}

Center-Reading Design for Farm Milk Tanks.-Both experimental studies and commercial use have produced mounting evidence that one of the principal causes of inaccurate readings on farm milk tanks is out-of-level condition. Obviously, such inaccuracies are reduced to the minimum when the reading element of a tank is located at, or as near as practicable to, the vertical axis with respect to the tank walls. Accordingly, the Committee wishes again to urge that all manufacturers of such tanks make every effort to modify their designs so as to cause as nearly as possible center reading. 
Development of New Weighing or Measuring Devices or Modification of Existing Devices.-In many instances in the past, manufacturers have modified models or developed new models of commercial devices and included in such developments components that do not conform to Conference-adopted requirements. It seems to the Committee that the logical step toward harmonizing code requirements with engineering advancements would be for the manufacturer to confer with the Conference Committee on Specifications and Tolerances during the planning stage and before the device in question is put in production. Frequently this has not been done. In some cases the manufacturer has called upon a relatively small number of State and local officials and suggested either that, within their individual jurisdictions, they accept the equipment modification that is contrary to adopted specifications, or that they amend their individual requirements so as to make such acceptance legal.

This is contrary to the principle on which the National Conference was conceived and has progressed through the years-a principle of uniformity among all the State and local governments with respect to legal requirements and enforcement procedures.

The Committee suggests that manufacturers who find necessary or advisable the reconsideration of general or specific provisions of the Conference specifications, tolerances, and regulations, proceed through the established channels and submit their recommendations to the Committee. Such procedure will eliminate a tendency toward nonuniformity and also will avoid the need for Conference action to amend the codes in order to provide for engineering developments already in production- "legislation" to legalize a violation, as it were.

Codes and Specifications Written by Other Groups, with Specific or Implied Relation to the Weights and Measures Field.-Conflicts continue between codes adopted by the Conference and recommendations by other groups and organizations. The crux of this situation seems to be that these other developers of codes and specifications neither have a working knowledge of weights and measures enforcement problems, nor confer with weights and measures personnel prior to or during the preparation of their material.

In many cases recommendations are made that overlap into the weights and measures field. In certain areas of special consideration, for example, safety, codes are written that contain stipulations found later to be contrary to provisions necessary for correct quantity determinations. When these conflicts are discovered, additional consideration to harmonize conflicting requirements becomes necessary.

The Committee recommends strongly that all persons engaged in the preparation, development, or promulgation of codes relating to devices or practices, where commercial quantity determination may in any way be involved, take two definite steps.

1. Consult with the appropriate committee of the National Conference on Weights and Measures prior to the preparation of the codes, and

2 . Submit the appropriate sections of such codes to the Conference for study and comment.

This action would assure harmony between the requirements of the group developing the code and the codes of the National Conference on Weights and Measures. 
(It was moved and seconded that the recommendations of the Committee, as presented in its tentative and final reports as amended, be adopted. The question was taken and the motion was agreed to.)

\section{TRIBUTE TO STANLEY Q. BENNETT}

MR. J. G. Rogers: I desire to pay tribute to an industry representative who is about to retire. Many of us feel that he should not leave his work without some public recognition of the fine principles he has exemplified through the years. I speak of Stanley Q. Bennett of the Toledo Scale Co., who has attended the National Conference for many years. I have always thought that Stan epitomizes the finer concepts of the brotherhood of man. He is a man's man. In his unassuming way he has done much to promote the congeniality of our meetings. Teddy Roosevelt once said to a college group, "Don't flinch; don't foul; hit hard." Stan did that.

I think there will be an echo of my sentiments in the heart of each of you who knows Stanley Bennett. I appreciate the privilege of saying these few words about him.

\section{REPORT OF THE COMMITTEE ON RESOLUTIONS, PRESENTED}

\section{BY C. M. FULLER, CHAIRMAN}

\section{APPRECIATION TO HONORABLE SINCLAIR WEEKS, SECRETARY OF COMMERCE}

Whereas, this 41st National Conference on Weights and Measures has been honored by the presence on the program of the Honorable Sinclair Weeks, Secretary of Commerce; and

Whereas, the members of the Conference were most interested in the gracious message brought to them by Mr. Weeks; Therefore be it

Resolved, That the 41st National Conference hereby records its deep appreciation and gratitede to the Secretary of Commerce for his contribution to the Conference program.

\section{APPRECIATION TO DR. ASTIN AND THE STAFF OF THE} NATIONAL BUREAU OF STANDARDS

Whereas, the success of the 41st National Conference on Weights and Measures has been due in large part to the sympathetic leadership of Dr. A. V. Astin, Director of the National Bureau of Standards, to the wholehearted cooperation of the staff of the Bureau, and especially to the thoughtful planning and diligent efforts of Mr. W. S. Bussey, Chief of the Office of Weights and Measures, Mr. M. W. Jensen, Assistant Chief, and other members of the staff of that Office; Therefore, be it

Resolved, That this 41st National Conference on Weights and Measures records its sincere appreciation to Dr. Astin and his staff.

\section{APPRECIATION TO CONTRIBUTORS TO PROGRAM}

Whereas, the National Conference on Weights and Measures is dependent for its success upon the contributions to the program made by the speakers, those who demonstrate devices, and its committees; Therefore, be it

Resolved, That this 41st National Conference on Weights and Measures hereby records its appreciation to all such contributors to its program.

\section{APPRECIATION TO COOPERATING OFFICIALS}

Whereas, it is recognized that attendance at the meetings of the National Conference on Weights and Measures by weights and measures officers and other persons directly concerned with weights and measures administration in the States, counties, and cities, is made possible in large degree by the interest and cooperatior of the governing officials of those jurisdictions; Therefore be it

Resolved, That this 41st National Conference on Weights and Measures records its gratitude for such interest and cooperation by these governing 
officials and for this evidence of their support of constructive weights and measures supervision throughout the United States.

\section{APPRECIATION TO MANAGEMENT OF HEADQUARTERS HOTEL}

Whereas, the management of the Willard Hotel, through its facilities and the courtesies of its staff, has assisted materially in the conduct of this 41st to the management of said hotel.

National Conference on Weights and Measures; Therefore, be it

Resolved, That this, the 41st National Conference does express its thanks

\section{APPRECIATION TO SCALE JOURNAL}

Whereas, the National Conference on Weights and Measures recognizes the continuing services of the Scale Journal in reporting upon the activities of weights and measures officials and the proceedings of their formal meetings; Therefore, be it

Resolved, That this 41st National Conference on Weights and Measures records its appreciation for such services.

\section{APPRECIATION TO BUSINESSS AND INDUSTRY}

Whereas, the representatives of business and industry, by their support of the National Conference contribute to its accomplishments; Therefore, be it

Resolved, That the National Conference recognizes the increasing spirit of cooperation that has been demonstrated by business and industry toward those charged with official supervision.

\section{THE NATIONAL BUREAU OF STANDARDS MOTION PICTURE PROGRAM}

Whereas, the 41st National Conference on Weights and Measures has viewed with much interest the second weights and measures film, "Testing Mass Standards by Substitution," produced by the National Bureau of Standards; and

Whereas, the Conference recognizes the utility of such a film in furthering the objectives of weights and measures officials throughout the United States; Therefore be it

Resolved, That the 41st National Conference on Weights and Measures records its endorsement and commendation of the weights and measures motion picture program of the National Bureau of Standards; and be it further

Resolved, That the Conference urges the continuation and expansion of this program to the end that additional audio-visual aids may be supplied for the training of weights and measures officials and for the education along weights and measures lines of the general public.

\section{EDUCATION ON HIGHWAY WEIGHING}

Whereas, this Conference has been reminded of need for information and education of groups concerned with control of highway loading by motor vehicles, and

Whereas, the Conference is advised of a project, initiated by the motor vehicle transportation industry, to inform segments of the industry and highway load regulation officials regarding correct weighing methods and correct weighing equipment as recommended or approved by past Conferences and by the National Bureau of Standards; Therefore be it

Resolved that this 41st National Conference on Weights and Measures approve and commend the educational objectives of the project outlined to the Conference and being in the form of a compilation of technical scale and weighing information based upon reports of the National Bureau of Standards and recommendations of past Conferences.

Charles MorRis Fuller, Chairman

(Signed)
L. DERIENZO,
A. H. DITTRICH,
J. J. LEONARD,
J. J. POWERS,
C. H. STENDER,

Committee on Resolutions.

(The report of the Resolutions Committee was adopted by the Conference.) 


\section{REPORT OF THE TREASURER}

Balance on hand May 1, 1955

MAY 1,1956 $\$ 1,372.88$

RECEIPTS:

May 20-

Registration fees-1955 Conference, 390 at $\$ 5.00 \quad \$ 1,950.00$

Interest accrued

Total $\quad \frac{1,963.99}{3,336.87}$

DISBURSEMENTS :

May 16-20, 1955-

Expenses of 40 th National Conference

$1,110.03$

January 10, 1956-

Official Conference desk seal and die ___ $\quad 51.00$

March 19, 1956-

Honor Award Certificates and Seals

286.03
Balance on hand May 1, 1956
(Signed) George F. Austin, JR.,
Treasurer.

(The report of the Treasurer was adopted by the Conference.)

(The Forty-first National Conference on Weights and Measures adjourned sine die at 12:40 p.m.) 


\section{PERSONS ATTENDING THE CONFERENCE Delegates-State, City, and County Officials}

\section{CALIFORNIA}

State

County:

Alameda.

Kern

Los Angeles.

San Diego
JAMES E. Brenton, Chief, Bureau of Weights and Measures, Department of Agriculture, 1220 "N" Street, Sacramento.

William A. KerLiN, County Sealer of Weights and Measures, 333 Fifth Street, Oakland.

A. D. Rose, County Sealer of Weights and Measures, 1116 E. California Avenue, Bakersfield.

CHARLES MORRIS FUller, County Sealer of Weights and Measures, 3200 N. Main Street, Los Angeles.

Herbert J. MCDADE, County Sealer of Weights and Measures, 1480 F Street, San Diego.

\section{COLORADO}

State

HARRY N. DuFf, Supervisor, Weights and Measures Section, Division of Markets, Department of Agriculture, 3130 Zuni Street, Denver.

HARVEY H. HoustoN, Director, Oil Inspection Department, 1024 Speer Boulevard, Denver.

\section{CONNECTICUT}

State

Attilio R. Frasinelli, Commissioner, Food and Drug Commission, State Office Building, Hartford.

FranK M. Greene, Chief, Division of Weights and Measures.

Frank J. Delaney, State Inspector.

County:

Fairfield

William E. Sheehy, JR., County Sealer of Weights and Measures, County Court Building, Bridgeport.

Alvin Coger, Assistant County Sealer.

ERNEST WILSON, Assistant County Sealer.

Hartford

Fred E. MCKInNEY, County Sealer of Weights and Measures, County Building, 95 Washington Street, Hartford.

JoSePh J. FANELLI, Assistant County Sealer.

Tolland

William F. MASINDA, County Sealer of Weights and Measures, West Willington.

City:

Bridgeport

MaX Frankel, City Sealer of Weights and Measures, 925 Main Street.

Hartford

Nathan KaLECHMAN, City Sealer of Weights and Measures, 550 Main Street.

Middletown

Peter Grassi, City Sealer of Weights and Measures, P. O. Box 223.

New Britain

ARMAND J. Albanese, City Sealer of Weights and Measures, Municipal Building.

DELAWARE

State

RALPH W. WiNE, Director, Bureau of Markets, State Board of Agriculture, Dover. 


\section{DISTRICT OF COLUMBIA}

Weights, Measures, and Markets, Department of Licenses and Inspection, Room 131 District Building, Fourteenth and $\mathrm{E}$

District Streets, N.W., Washington, D. C.

J. Thomas KenNedy, Chief.

J. M. BOUCHER, Supervisor.

R. A. MONTGOMERY, Supervisor.

HOWARD BALACEK, Inspector and Investigator.

J. T. BENNICK, Inspector and Investigator.

W. R. CORNELIUS, Inspector and Investigator.

L. F. GNOTTA, Inspector and Investigator.

F. C. HARBOUR, Inspector and Investigator.

H. P. HUTCHINSON, Inspector and Investigator.

W. H. JENNINGS, Inspector and Investigator.

G. P. Kosmos, Inspector and Investigator.

T. B. MidDLETON, Inspector and Investigator.

I. L. WAGNER, JR., Inspector and Investigator.

F. M. WARNER, Inspector and Investigator.

W. W. WELLS, Inspector and Investigator.

\section{FLORIDA}

State

City:

Jacksonville

Miami

NALLS BerRymaN, Director, Weights and Measures Division, Department of Agriculture, Nathan Mayo Building, Tallahassee.

HowaRD E. CRAWFORD, Inspector of Weights and Measures, 431 West Eighth Street.

HARVEY E. HowARD, Supervisor of Weights and Measures, Coconut Grove Station, P. O. Box 708.

\section{ILLINOIS}

City: Chicago

IRVINE M. LEVY, City Sealer of Weights and Measures, Room 608 City Hall.

\section{INDIANA}

State

T. E. Sullivan, Director, Food and Drug Division, State Board of Health, 1330 West Michigan Street, Indianapolis.

ROLLIN E. MeEK, Director, Division of Weights and Measures, State Board of Health.

County:

Grant

Huntington

St. Joseph

Vigo

REUBEN C. PARKS, Inspector of Weights and Measures, Court House, Marion.

ROBERT DALE ENDSLEY, Inspector of Weights and Measures, Room 105 Court House, Huntington. STEPHEN C. GRZESKowiak, County Inspector of Weights and Measures, Room 14 Court House, South Bend.

ROBERT J. SiLCOCK, County Inspector of Weights and Measures, Room 5 Court House, Terre Haute.

City:

Gary

South Bend

Terre Haute

Cleo C. Morgan, Sealer of Weights and Measures, Room 204 City Hall.

BeRT S. CICHOWICZ, City Inspector of Weights and Measures, City Hall.

JOHN T. HARPER, Inspector of Weights and Measures, Room 205 City Hall.

IOWA

State

JAMES W. REeSE, Supervisor, Weights and Measures Division, Department of Agriculture, State Capitol, Des Moines. 
State

City: Topeka

State

State

AloIS J. MAYER, Director, Division of Weights and Measures, Department of Agriculture and Immigration, P. O. Box 4292 Capitol Station, Baton Rouge.

\section{MAINE}

State

City: Portland

JAMES A. Boyle, Deputy State Sealer of Weights and Measures, Department of Agriculture, State House, Augusta.

CharLes J. WILLS, JR., Sealer of Weights and Measures, 389 Congress Street.

\section{MARYLAND}

State

Paul E. Nystrom, Director of Extension Service, Department of Agriculture, University of Maryland, College Park.

JOHN E. MAHONEY, Superintendent of Weights and Measures, State Department of Markets, Board of Agriculture.

Norman H. TrayLOR, Assistant Dairy Inspector.

County:

Baltimore

Frank J. VitTeK, Chief Inspector of Weights and Measures, 25 Susquehanna Avenue, Towson.

GEORGE J. KueIN, Assistant Inspector, 3 Glade Avenue, Baltimore.

Montgomery

E. W. BuckuIN, Director, Department of Inspection and Licenses, County Office Building, Rockville.

LYNWOOD B. MORTON, Weights and Measures Inspector, Department of Inspection and Licenses.

City: Baltimore

GeORGe H. LeIThaUser, Chief Inspector, Division of Weights and Measures, Department of Public Works, 1106 Municipal Building.

EDWIN EDWARD JAFFA, Inspector.

\section{MASSACHUSETTS}

State

JoHN P. MCBRIDE, Director of Standards and Necessaries of Life, Department of Labor and Industries, 194 State House, Boston.

LAWRENCE A. HARNEY, State Inspector, $292 \mathrm{Mt}$. Pleasant Street, New Bedford.

City :

Boston

JoHN F. MCCARTHY, Sealer of Weights and Measures, Room 105 City Hall Annex.

Brookline and Measures, Town Hall. 
Cambridge

Malden

Newton

Salem sio.

City :

Dearborn

Detroit

Lansing

Pontiac

Port Huron

MICHIGAN

Clyde O. CotTom, Supervising Inspector of Weights and Measures, State Department of Agriculture, Lewis Cass Building, Lansing.

LEO J. BAUER, State Inspector.

LEE K. RICE, State Inspector, P. O. Box 43, St. Johns.

Rex J. Tutrle, State Inspector, 321 East Street, South, Morenci.

MARgARET TREANOR, Secretary, Bureau of Foods and Standards, State Department of Agriculture, Lewis Cass Building, Lansing.

Petér W. Vermullen, Superintendent, Department of Licenses, Weights and Measures, City Hall.

George F. Austin, JR., Deputy Sealer, Bureau of Weights and Measures, 740 Elmwood Avenue.

William B. Heaship, Supervising Inspector.*

J. T. DANIELL, Inspector.

C. D. MARSDEN, Inspector.

JAMES F. BAKER, City Sealer of Weights and Measures, 25 Gerald Avenue.

WALTER M. SAXTON, City Sealer of Weights and Measures, 333 N. Cedar Street.

G. F. TAYLOR, Chief Assistant Prosecuting Attorney.

WALTER A. BAERWOLF, City Sealer of Weights and Measures, Police Department.

A. C. Westphal, City Sealer of Weights and Measures, 1111 Pine Street.

\section{MINNESOTA}

State

ERLING HANSEN, Supervisor, Department of Weights and Measures, Railroad and Warehouse Commission, One Flour Exchange, Minneapolis.

GEORGE A. FAZENDin, State Inspector.

City: Minneapolis

FranK WolinsKI, Alderman, City Council, 3002 Colfax Avenue, No.

Russell S. ACKerman, Superintendent, Department of Licenses, Weights and Measures, Room 3 City Hall.

JohN G. Gustafson, Inspector.

\section{MISSOURI}

State

Rollo E. Singleton, Director, Weights and Measures Division, Department of Agriculture, Jefferson City.

H. C. ADAmson, State Inspector, 313 West Sixth Street, Fulton.

N. J. WAGNER, State Inspector, Canton.

City: St. Louis and Measures, Room 12 City Hall.

*Registered in absentia. 
State

State

State

City :

Keene

Manchester

Nashua

State

County:

Atlantic

Bergen

Burlington

Camden

Cumberland

Essex

Monmouth
Delbert Walrath, Chief Sealer, Division of Weights and Measures, Department of Agriculture, Capitol Building, Helena.

\section{NEVADA}

E. L. RANDALL, State Sealer, Department of Weights and Measures, Public Service Division, University of Nevada, P. O. Box 719, Reno.

Carlton W. Strond, Deputy Sealer, P. O. Box 812, Reno.

\section{NEW HAMPSHIRE}

Clement A. Lyon, Director, Bureau of Weights and Measures, Division of Markets and Standards, Department of Agriculture, State Office Building, Concord.

Alfred H. DitTrich, Chief Inspector.

Ronald M. Seaver, City Sealer of Weights and Measures, 72 Pine Avenue.

F. A. Genest, City Sealer of Weights and Measures.

JoSePh E. Deschamps, City Sealer of Weights and Measures, City Hall.

\section{NEW JERSEY}

L. E. Stern, Deputy Attorney General, Department of Law and Public Safety, Trenton.

Samuel H. Christie, JR., Assistant State Superintendent in Charge, Division of Weights and Measures, Department of Law and Public Safety, 187 W. Hanover Street, Trenton.

ArChie T. Smith, Assistant Superintendent.

JAMES E. Myers, County Superintendent of Weights and Measures, Box 1741, Hammonton. Michael J. Santimauro, County Superintendent of Weights and Measures, 66 Zabriskie Street, Hackensack.

ERNEST EDWIN DAwson, Assistant Superintendent.

PaUL F. NunN, County Superintendent of Weights and Measures, 236 Hooker Street, Riverside.

David F. Hummel, Assistant County Superintendent, First Avenue and Magnolia Road, Pemberton.

AlberT C. BeCKer, County Superintendent of Weights and Measures, City Hall, Camden.

AlFred LIRIo, County Superintendent of Weights and Measures, P. O. Box 369, Vineland.

WiNfield K. Thompson, Assistant County Superintendent, Court House, Bridgeton.

William H. SchNeIDEWIND, County Superintendent of Weights and Measures, Hall of Records, Newark.

JoHN A. J. Bovie, Assistant Superintendent of Weights and Measures, 82 W. Wall Street, Neptune City.

William I. Thompson, Assistant Superintendent, Lake and Grassmere Avenue, Wanamassa.

William G. Dox, County Inspector, 12 Campview Place, Keansburg. 
Morris

Passaic

Union

City :

Bayonne

Englewood

Fair Lawn

Hoboken

Linden

Passaic

Paterson

Union City

State

County:

Genesee

Monroe

Nassau

Niagara

Ontario

Oswego

Westchester City:

Binghamton

Ithaca

Lackawanna

Long Beach.

New Rochelle

Rochester.
DEL G. NeLsoN, County Superintendent of Weights and Measures, Court House, Morristown.

WILLIAM MrLLeR, County Superintendent of Weights and Measures, Administration Building, Paterson.

JAMES M. DiETZ, Ccunty Superintendent of Weights and Measures, Court House, Elizabeth.

JoSEPH G. VAYDA, Municipal Superintendent of Weights and Measures, Municipal Building, 26th Street and Avenue C.

LeONARD DeRienzo, Municipal Superintendent of Weights and Measures, City Hall.

ALPHONSE J. BEGYN, Superintendent of Weights and Measures, Borough Hall.

Anthony A. Grossi, Municipal Sealer of Weights and Measures, City Hall.

LAWRENCE T. Reagan, Municipal Superintendent of Weights and Measures, City Hall.

Paul DeVries, Municipal Superintendent of Weights and Measures, Municipal Building.

JosePH SHAw, Assistant Municipal Superintendent.

JosePH P. LeONARD, Municipal Superintendent of Weights and Measures, 115 Van Houten Street.

William J. KeHoe, Assistant Superintendent.

ALFRED O. OsLund, Municipal Superintendent of Weights and Measures, City Hall.

\section{NEW YORK}

JoHn J. LEONARD, Director, Bureau of Weights and Measures, Department of Agriculture and Markets, State Office Building, Albany.

Glens A. Pullman, County Sealer of Weights and Measures, 19 Buffalo Street, Bergen.

Earle D. Hubble, County Sealer of Weights and Measures, 1400 South Avenue, Rochester.

RoBert Williams, County Sealer of Weights and Measures, Old County Court House Annex, Mineola.

AUgust W. WeIDNeR, JR., Assistant County Sealer.

HENRY C. Hulshoff, County Sealer of Weights and Measures, 17 High Street, Lockport.

RaLPH F. Benham, County Sealer of Weights and Measures, Court House, Canandaigua.

Leland M. Flower, County Sealer of Weights and Measures, Lycoming.

Thomas C. ScotT, County Sealer of Weights and Measures, County Office Building, White Plains.

HARRY A. Lason, City Sealer of Weights and Measures, 60 Robinson Street.

E. PAUL NEDRow, City Sealer of Weights and Measures, 318 Columbia Street.

JoHN J. SERES, City Sealer of Weights and Measures, 84 Rosary Avenue.

MrS. Veronica R. Roche, Sealer of Weights and Measures, 562 East Market Street.

EVERETT J. ROBERTS, City Sealer of Weights and Measures, City Hall.

ANTHONY C. SAMENFINK, City Sealer of Weights and Measures, Rochester Food Terminal, Administration Building. 
Schenectady

Yonkers.

State

City: Charlotte

State

County:

Cuyahoga

Marion

Medina

Ottawa

City:

Akron

Cincinnati

Lorain

State

T. C. BECK, Assistant Director, Marketing Division, State Board of Agriculture, 122 Capitol Building, Oklahoma City.

OREGON

State

Walter B. Steele, Deputy State Sealer of Weights and Measures, State Department of Agriculture, Agriculture Building, Salem. 
State

County:

Bucks

Centre.

Dauphin

Philadelphia

City :

Altoona

Erie

Monessen

York

Commonwealth

State

City :

Providence

Woonsocket

State

CARL H. Stender, Assistant to Commissioner, Department of Agriculture, Wade Hampton Office Building, P. O. Box 1080, Columbia.

RALPH MAGOFFIN, Director, Bureau of Inspection. SOUTH DAKOTA

State

R. A. Powell, Chief Scale Inspector, Public Utilities Commission, Pierre.

DoN C. Hanna, Heavy Scale Inspector.

RUSSEll F. Shoemaker, State Inspector.

TENNESSEE

City :

Memphis

Nashville

V. D. Rogers, City Inspector of Weights and Measures, 590 Washington Avenue.

ToM WEBB, Sealer of Weights and Measures, 300 Demonbreun Street.

*Registered in absentia. 
State

City:

Dallas

Forth Worth

Houston

City: Salt Lake City

Edwin C. Westwood, City Sealer of Weights and Measures, 118 East First Street.

VERMONT

State

Arden L. LAPlant, Supervisor, Division of Weights and Measures, Department of Agriculture, Agriculture Building, Montpelier.

VIRGINIA

State

City:

Danville

Norfolk

Petersburg

Richmond

Roanoke

Joseph H. Meek, Director, Division of Markets, Department of Agriculture, 1200 East Main Street, Richmond.

Thomas C. HARRIS, JR., Supervisor, Weights and Measures Section, Division of Markets.

G. T. CoPENHAVER, State Inspector, Rural Retreat.

RICHARD D. MARKS, State Inspector, 2303 Price Avenue, Charlottesville.

Clarence E. Whitman, Field Supervisor, Scale Maintenance, Department of Highways, Richmond.

Clyde H. Wrenn, Sealer of Weights and Measures, City Market Building.

WEBSTER K. TRIPPLE, Chief, Bureau of Weights and Measures, c/o Department of Public Safety, City Hall.

C. R. BRANCH, City Sealer of Weights and Measures, City Hall.

Earl H. GWaltney, Assistant City Sealer.

J. G. Williams, JR., Chief Inspector of Weights and Measures, Department of Public Safety, The Mosque Building, Laurel and Main Streets.

A. B. Moody, JR., Inspector of Weights and Measures.

JAMES M. HUDGINS, Inspector of Weights and Measures, Division of Markets, City Market Building.

\section{WASHINGTON}

State

JoSEPH E. MCCAUleY, Supervisor, Regulatory Division, State Department of Agriculture, Old Capitol Building, Olympia.

City: Seattle
DoN M. TURNBuLL, Supervisor, Licenses and Standards, Office of the Comptroller, 100 County-City Building. 
State

County: Harrison

City :

Green Bay

Janesville

Kenosha

Milwaukee

Racine

Sheboygan

West Allis

State

Elvin R. Leeman, Director, Division of Weights, Measures and Petroleum Products, Wyoming Department of Agriculture, 308 Capitol Building, Cheyenne.

CharLes SatTler, Commissioner, Bureau of Weights and Measures, Department of Labor, 643 State Office Building, 1800 East Washington Street, Charleston.

MRS. BEATRICE LANHAM, County Sealer of Weights and Measures, Harrison County Court, Clarksburg.

WISCONSIN

Claire L. JACKson, Chief, Division of Economic Practices, Department of Agriculture, State Capitol, Madison.

NoRMAN KIRSCHBAUM, Supervisor, Weights and Measures Inspection, Division of Economic Practices.

Norris P. Tilleman, City Sealer of Weights and Measures, 310 East Mason Street.

ERvin W. SCHELLENBERGER, Sealer of Weights and Measures, City Hall.

FELIX C. MAYER, City Sealer of Weights and Measures, City Hall.

LouIs E. W ITT, City Sealer of Weights and Measures, 1331 North Fifth Street.*

ROBERT ZIERTEN, City Sealer of Weights and Measures, City Hall.

J. A. PEIKERT, Sealer of Weights and Measures, City Hall.

Jerome Persak, Assistant City Sealer of Weights and Measures, City Hall.

WYOMING

*Registered in absentia. 


\section{Delegates, Guests, and Conference Staff \\ National Bureau of Standards}

Director's Office:

A. V. Astin, Director.

L. J. BRIGGS, Director Emeritus.

WILMER Souder, Consultant to the Director.

A. T. McPherson, Associate Director for Testing.

R. S. Walleigh, Assistant Director for Administration.

Henry Birnbaum, Assistant to the Director.

MrS. F. T. ACHENBACH, Office of Associate Director for Chemistry.

W. S. Bussey, Chief, Office of Weights and Measures.

M. W. Jensen, Assistant Chief, Office of Weights and Measures.

R. W. SMITH, Consultant, Office of Weights and Measures (Honorary Life Member).

H. F. Wollin, Engineer, Office of Weights and Measures.

MrS. R. E. TAYLOR, Administrative Aide, Office of Weights and Measures.

MrS. F. C. BELL, Administrative Aide, Office of Weights and Measures.

W. R. TILley, Chief, Office of Technical Information.

JACK HARDESTY, Office of Technical Information.

Miss B. S. GilliaM, Office of Technical Information.

Chemistry Division:

J. H. Eiseman, Gas Chemistry Section.

V. E. Bower, Physical Chemist, Physical Chemistry Section.

Electricity and Electronics Division:

MrS. K. M. SchWARZ, Publications Writer, Engineering and Electronics Section.

Mechanics Division:

H. S. Bean, Chief, Capacity, Density, and Fluid Meters Section.

C. T. ColletT, Assistant Chief, Capacity, Density, and Fluid Meters Section.

J. C. Hughes, Capacity, Density, and Fluid Meters Section.

B. C. KeYSAR, Capacity, Density, and Fluid Meters Section.

A. T. Hattenburg, Capacity, Density, and Fluid Meters Section.

W. H. Gallagher, Physical Science Aide, Capacity, Density, and Fluid Meters Section.

MARY Squires, Capacity, Density, and Fluid Meters Section.

B. L. WILson, Chief, Engineering Mechanics Section.

D. R. TAte, Physicist, Engineering Mechanics Section.

L. B. MACURDy, Chief, Mass Unit, Mass and Scale Section.

H. E. Almer, Physicist, Mass Unit, Mass and Scale Section.

Miss E. M. Clinton, Physicist, Mass Unit, Mass and Scale Section.

H. H. Russell, Chief, Scale Unit, Mass and Scale Section.

H. L. BADGER, Physicist, Scale Unit, Mass and Scale Section.

C. H. OAKLEY, Weights and Measures Co-ordinator, Scale Unit, Mass and Scale Section.

Optics and Metrology Division:

L. V. JudSoN, Chief, Length Section.

J. S. BeERs, Physicist, Length Section.

Peter Hidnert, Physicist, Length Section.

B. L. PAGE, Physicist, Length Section.

R. W. Crouch, JR., Photometry and Colorimetry Section.

Organic and Fibrous Materials Division:

T. W. LASHoF, Paper Section.

\section{Guests Representing United States Government}

U. S. Department of Agriculture:

L. D. Sinclatr, Chief, Packers and Stockyards Branch, Livestock Division, Agricultural Marketing Service.

R. D. THOMPSoN, Supervisor of Scales and Weighing, Packers and Stockyards Branch, Livestock Division, Agricultural Marketing Service.

R. F. GuILFOY, Engineer, Transportation and Facilities Branch, Market Research Division, Agricultural Marketing Service.

B. W. WhITLOCK, Director, Grain Division, Agricultural Marketing Service.

T. J. McGure, Chief, Grain Market News Branch, Grain Division, Agricultural Marketing Service. 
J. R. ScotT, Chief, Trade Label Section, Meat Inspection Branch, Agricultural Research Service.

C. R. ADAIR, Agronomist, Field Crops Research Branch, Agricultural Research Service, Beltsville, Maryland.

U. S. Department of Commerce:

SinCLAIR WeEks, Secretary of Commerce.

C. D. Francis, Commodity Analyst, Business and Defense Services Administration.

U. S. Department of Defense:

W. R. CATER, Chief, Precision Equipment Laboratory, Tinker Air Force Base, Oklahoma City, Oklahoma.

U. S. Department of Health, Education, and Welfare:

J. C. Pearson, Director, Division of Federal-State Relations, Food and Drug Administration.

S. C. Rowe, Chemist, Food Division, Food and Drug Administration.

K. L. MilsteAD, Director, Division of Regulatory Management, Food and Drug Administration.

U. S. Department of the Treasury:

H. A. SERR, Assistant Director, Alcohol and Tobacco Tax Division, Internal Revenue Service.

N. T. Morsell, Chief, Tobacco Branch, Alcohol and Tobacco Tax Division, Internal Revenue Service.

E. W. Teagarden, Engineering Specialist, Bureau of Customs.

\section{Guests Representing Manufacturers of Weighing and Measuring Devices}

All-Weather Springs: JoHN W. Rockefeller, JR., Owner, 56 Main Street, Millburn, N. J.

American Meter Company:

James H. Judge, Assistant to President, Philmont and Bustleton Avenues, Philadelphia, $\mathrm{Pa}$.

WALlACE T. WhIte, Sales Engineer, Box 175, Wynnewood, Pa.

American Scale and Vise Company: C. V. MARKs, Chief Engineer, 2745 Southwest Boulevard, Kansas City, Mo.

Bloomer Brothers Company: RAYNoR M. Holmes, Research Engineer, Newark, N. Y.

Bowser, Inc.:

A. E. SPITZBerg, Vice President in Charge of Engineering, Fort Wayne, Ind.

E. J. Reinhart, Service Manager.

Brodie, Ralph N., Company, Inc.;

C. J. MCCAFFrey, Vice President, 550 S. Columbus Avenue, Mt. Vernon, N. Y.

DoN W. KINGSLEY, Eastern Manager.

PaUl Renfrew, Chairman, Weights and Measures Technical Committee, Alvarado and West 137th Avenue, San Leandro, Calif.

Chatillon, John, \& Sons: George C. Reiley, Vice President, Sales, 85 Cliff Street, New York, N. Y.

Continental Can Company, Inc.: William H. Wallace, Manager, Product Development and Standards, 349 Oraton Street, Newark, N. J.

Controls Cells Division of Balls Brothers Company: W. R. Swanson, Chief Development Engineer, 790 Walnut, Boulder, Colo.

Cox \& Stevens Electronic Scales, Division of Revere Corporation of America:

Walter K. DAvies, General Sales Manager, 630 Fifth Avenue, New York, N. Y.

Charles W. Silver, Wallingford, Conn.

JoSEPH N. ToDD, Consultant, 1417 Longfellow Street, Washington, D. C. Detecto Scales, Inc.:

SAMUEL M. JACoBS, President, 540 Park Avenue, Brooklyn, N. Y.

MACK RAPP, Vice President.

MrS. Carrie G. Woodland, Representative, Woodland's Temple Grove, P. O. Box 267, Fellsmere, Fla.

Dixie Cup Company:

Clement G. McBride, Assistant to President, Easton, $\mathrm{Pa}$.

JosePH G. Rogers, Special Assistant, Market Research Department.

Erie Meter Systems, Inc.: PAUl R. FishbuRN, Chief Engineer, Box 559, Erie, $\mathrm{Pa}$. 
Exact Weight Scale Company:

W. A. Scheurer, Vice President, 944 W. Fifth Avenue, Columbus, Ohio.

James F. Sullivan, Chief Engineer.

OLIVER H. WATSON, Manager, Chicago Division, 608 S. Dearborn Street, Chicago, Ill.

Fairbanks, Morse and Company:

C. G. GeHringer, Manager, Scale Division, 600 S. Michigan Avenue, Chicago, Ill.

RICHARD WASNIAK, Sales Engineer.

EUGENE F. Dumesnil, Manager, 659 E. 25th Street, Baltimore, Md.

Jerome C. KeNNEY, Field Engineer.

WALTER J. RUZEK, Field Engineer.

Fuller, H. J., Company: Harold J. Fuller, President, 1371 W. Third Avenue, Columbus, Ohio.

Gilbert \& Barker Manufacturing Company: William KeaY, Manager, Sales Service, West Springfield, Mass.

Girton Manufacturing Company: DarL Evans, Refrigeration Engineer, Millville, $\mathrm{Pa}$.

Gordon Cartons, Inc.: Charles B. Debuskey, Sales Manager, 1629 Warner St., Baltimore, Md.

Granberg Corporation:

R. C. ANDERson, Vice President, Sales, 1308 Sixty-seventh Street, Oakland, Calif.

Wilson M. Milligan, Eastern Division Sales Manager, 489 Fifth Avenue,

New York, N. Y.

Gurley, W. \& L. E.: Franklin G. Williams, Washington Representative, 5514 Nevada Avenue, N. W., Washington, D. C.

Hobart Manufacturing Company:

D. A. Meeker, President, Penn Avenue at Simpson Street, Troy, Ohio.

Murray W. Craig, Weights and Measures Representative.

RALPH E. STARKEY.

Kenneth C. Allen, Director, Special Research Division, 519 Dennison Avenue, Dayton, Ohio.

EDWIN E. Boshinski, Research Engineel.

ROBERT B. MEEKER.

E. A. Reussenzehn, Chief Scale Engineer, 448 Huffman Avenue, Dayton, Ohio.

Hodgson, A. E., 7044 Garrett Road, Upper Darby, Pa.

Howe Scale Company:

Richard F. Straw, Vice President, 2941 Scale Avenue, Rutland, Vt.

George D. Wilkinson, National Service Manager.

GeRALD J. Devine, Branch Manager, 36-12 47th Avenue, Long Island City, N. Y.

ROBERT A. PARHAM, Branch Manager, 1300 Curtain Avenue, Baltimore, Md.

Hunter, S. S., Inc.: William M. Shanhouse, General Manager, Syosset, N. Y.

Lily-Tulip Cup Corporation:

KeIth B. Mount, Assistant to Vice President, 122 E. 42d Street, New York, N. Y.

ROBERT R. PERO, Manager of Quality Control.

Loadometer Corporation:

EDwin E. Poweld, Sales Manager, 1503 W. 41st Street, Baltimore, Md.

Paul C. Botzler, Assistant Sales Manager.

Marvel Rack Manufacturing Company, Inc.: Charles W. McCarthy, President, 24 N. First Street, Minneapolis, Minn.*

McIntyre, John J., Sons: F. L. McInTYRe, Owner, 514 Knorr Street, Philadelphia, Pa.

Mojonnier Brothers Company: JosePH W. Nisonger, Sales Representative, 8711. Twenty-third Avenue, Adelphi, Md.

Neptune Meter Company: Emmetт F. Wehmann, Chief Development Engineer, 22-42 Jackson Avenue, Long Island City, N. Y.

Nicol Scales Company: William F. Nicol, President, 1315 S. Akard Street, Dallas, Tex.

Owens-Illinois Glass Company: J. D. LAIRD, Chief Specification and Service Engineer, Toledo, Ohio.

*Registered in absentia. 
Palmer Torsion Balance Company: David PALmer, President, 1186 Broadway, New York, N. Y.

Penn Scale Manufacturing Company, Inc.: SyDNEY BLACK, President, $150 \mathrm{~W}$. Berks Street, Philadelphia, Pa.

Richardson Scale Company: H. Bandstra, Service Manager, Clifton, N. J.

Rockwell Manufacturing Company:

PaUl A. MaNKIN, General Manager, Pittsburgh Equitable Meter Division, 400 N. Lexington Avenue, Pittsburgh, Pa.

GeORge E. BATCHeLDER, Project Engineer.

Albert J. Komich, Assistant Products Manager.

EDWARD R. EYLER, Sales Engineer, 12 Mayflower Court, Baltimore, Md. Sauter, August, of New York, Inc.:

Gerhart F. Czemba, 230 Park Avenue, New York, N. Y.

LOUIS F. GUY.

Saybolt, E. W., \& Company:

R. L. SchAEFER, Assistant Manager, 529 Avalon Boulevard, Wilmington, Calif.

PaUl A. Hargrove, Special Representative, 1480 Iola Street, Aurora, Col. Sealright Company, Inc.:

R. SANFoRd WeEks, Assistant to Vice President, Sales, Fulton, N. Y.

C. E. Foster, Chief Chemist.

Seraphin Test Measure Company: T. A. SeraPhIN, General Manager, 1314 N. Seventh Street, Philadelphia, Pa.

Shanner Equipment Company: JACK W. PolivkA, Sales Manager, 8923 Ogden Avenue, Brookfield, Ill.

Siemens, New York, Inc.: Alfred Kuebler, 350 Fifth Avenue, New York, N. Y.

Smith, A. O., Corporation:

ERWIN G. DUERINGER, Director of Engineering, 5715 Smithway Street, Los Angeles, Calif.

W. T. Schultze, District Sales Manager, 250 Park Avenue, New York, N. Y.

Spinks Scale Company: J. M. SPINks, President, 584 Manford Road, S.W., Atlanta, Ga.

Stimpson Computing Scale Company: JoHn J. WAAGe, President, 829 Logan Street, Louisville, Ky.

Streeter-Amet Company:

Verne C. KenNeDY, SR., President, 4101 N. Ravenswood Avenue, Chicago, Ill.

Robert T. Isham, Vice President.

Texoil Equipment Company, Inc.: JoHN L. Smiтh, Manager, Liquefied Petroleum Gas Department, 1816 Cockrell, Dallas, Tex.

Thatcher Glass Manufacturing Company: JAMES ARrandale, Quality Control Consultant, 623 W. Water Street, Elmira, N. Y.

Tokheim Oil Tank and Pump Company: WrLliam Louthan, Manager of Field Service, Fort Wayne, Ind.

Toledo Scale Company:

RoBert E. BELL, Manager, Research Engineering Department, 5225 Telegraph Road, Toledo, Ohio.

D. J. Boudinot, General Sales Manager.

Stanley Q. BenNeTt, National Manager of Weights and Measures and Sanitary Standards.

H. WARREN HEM, Senior Engineer.

ROBERT V. MILLER, Field Engineer.

Eugene C. KeLLeR, Manager, Government Division, 3329 Eighth Street, N. E., Washington, D. C.

JoHn J. McLeLlaN, District Manager.

Torsion Balance Company: Bernard Kearney, President, Clifton, N. J.

Triner Scale and Manufacturing Company: William J. RAY, General Sales Manager, 2714 W. 21st Street, Chicago, Ill.

U. S. Slicing Machine Company: MatT RIBbLe, Special Representative; Standard Computing Scale Division, 333 Larson Street, LaPorte, Ind.

Veeder-Root, Inc. :

DAvid J. Post, JR., Vice President, 70 Sargeant Street, Hartford, Conn.

A. E. McKeEver, Sales Manager, Master Meter Duplicator Division.

J. J. BRANnICK, Sales Manager, Special Products Division, 44 Cherryfield Drive, West Hartford, Conn. 
Washington Scale and Equipment Company, Inc.: AARON Yochelson, Partner, 1107 New Jersey Avenue, N. W., Washington, D. C.

Wayne Pump Company:

C. F. Bateman, Vice President, Salisbury, Md.

FreEDOM H. AINSWORTH, Chief Engineer.

TOM F. BREen, Service Manager.

WARREN J. DUBSKY, Project Engineer.

W. W. Gavin, Engineer.

Weatherhead Company: JoHn . D. Selim, Development Coordinator, 300 E. 131st Street, Cleveland, Ohio.

Wilson Refrigeration, Inc.: JoHN E. WILson, Director of Sales, Glenwood Avenue, Smyrna, Del.

Wood, John, Company:

L. G. Close, Manager, Mid-Atlantic States, Bennett Pump Division, 2127 N. Charles Street, Baltimore, Md.

W. M. Hoxie, Service Manager, Bennett Pump Division, Broadway and Lethen Streets, Muskegon, Mich.

Wright Machinery Company: J. T. PATRICK, Senior Engineer, P. O. Box 2211, Calvin and Holloway Streets, Durham, N. C.

\section{Guests Representing Associations, Business and Industry, and Railroads}

American Farm Bureau Federation: HuGH F. HALL, Legislative Assistant, 425 Thirteenth Street, N. W., Washington, D. C.

American Marietta Company: LLOYD A. OwEN, Technical Director, Trade Sales Division, 901 N. Greenwood Avenue, Kankakee, Ill.

American Meat Institute:

Chester Adams, 59 E. Van Buren Street, Chicago, Ill.

ARTHUR BroAdWin, 727 National Press Building, Washington, D. C.

American Railway Engineering Association: CHARLES L. RICHARD, Chairman, Scale Committee, 8951 S. Wilton Place, Los Angeles, Calif.

American Seed Trade Association:

William Heckendorn, Executive Secretary, 30 N. LaSalle Street, Chicago, Ill.

DeLOS L. JAmes, Representative, Hibbs Building, 725 Fifteenth Street, N. W., Washington, D. C.

American Society of Mechanical Engineers: GLen H. Stimson, c/o Greenfield Tap and Die, Greenfield, Mass.

American Standards Association: J. W. McNaIR, Assistant Technical Director, 70 E. Forty-fifth Street, New York, N. Y.

American Trucking Associations, Inc.: Charles P. Hoffman, JR., Automotive Engineer, 1424 Sixteenth Street, N. W., Washington, D. C.

Avery Adhesive Label Corporation: CARRou J. LEe, Field Sales Manager, 1616 S. California, Monrovia, Calif.

Cooperative Mills, Inc.: SAMUEL J. BEYhan, Executive Vice President, 2101 E. Fort Avenue, Baltimore, Md.

Corn Industries Research Foundation, Inc.: Floyd J. Hosking, Executive Vice President, 1001 Connecticut Avenue, N. W., Room 919, Washington, D. C.

Cryovac Company. R. H. Tucker, Assistant General Sales Manager, Cambridge, Mass.*

Dairy Industries Supply Association, Inc.: JoHN L. BARNHART, Technical Director, 1145 Nineteenth Street, N. W., Washington, D. C.

Esso Standard Oil Company:

LOGAN L. KENNEDY, Superintendent, Construction and Maintenance, 500 N. Broad Street, Elizabeth, N. J.

J. H. McClintock, Coordinator, Oil Conservation, 15 W. Fifty-first Street, New York, N. Y.

Food Field Reporter, Food Topics: Donald Michael Rauh, Washington Correspondent, 1232 National Press Building, Washington, D. C.

Franklin, Benjamin, Paint and Varnish Company: Harold L. PARKer, Vice President, 4820 Langdon Street, Philadelphia, Pa.

Gasoline Pump Manufacturers Association:

G. TheoN Wright, Managing Director, 420 Lexington Avenue, New York, N. Y.

G. Denny Moore, Consultant, 621 Bay Esplanade, Clearwater Beach, Fla.

\footnotetext{
*Registered in absentia.
} 
General Foods Corporation: EDward P. LEE, Technical Assistant to Director of Manufacturing and Engineering Department, 250 North Street, White Plains, N. Y.

General Mills, Inc.: O. A. OudAL, Products Control Manager, Grocery Products Division, 400 Second Avenue, South, Minneapolis, Minn.

Glass Container Manufacturers Institute, Inc.: C. E. WAGNER, Development Engineer, 99 Park Avenue, New York, N. Y.

Grain and Feed Dealers National Association: Alvin E. OLIver, Executive Manager, 725 Fifteenth Street, N. W., Washington, D. C.

Gulf Oil Corporation:

W. K. MCCoY, General Superintendent, Plant Operations and Equipment, Gulf Building, Pittsburgh, Pa.

E. C. Dickey, Superintendent, Marketing Equipment, Gulf Building, Box 6145 , Station $\mathrm{H}$, Atlanta, Ga.

J. O. HABICHT, Supervisor, Marketing Equipment, 1515 Locust Street, Philadelphia, $\mathrm{Pa}$.

Hewitt-Robins, Inc.: Charles W. HaInes, Manager, Petroleum Industry Sales, 666 Glenbrook Road, Stamford, Conn.

Inland Steel Company: R. J. LAVERY, Supervisor of Scales, 3210 Watling Street, East Chicago, Ind.

International Association of Ice Cream Manufacturers: Donald H. WiLliams, Dairy Technologist, 1105 Barr Building, Washington, D. C.

International Milling Company: JoHN T. LyNCH, General Sales Manager, 800 McKnight Building, Minneapolis, Minn.

Liquefied Petroleum Gas Association: Arthur C. Kreutzer, Vice President and Counsel, 11 S. LaSalle Street, Chicago, Ill.

Liquid Tight Paper Container Association: ARTHur W. Howe, JR., Assistant to Executive Secretary, 1532 Philadelphia National Bank Building, Philadelphia, $\mathrm{Pa}$.

Marvadel Ice Cream Company, Inc.: JoHN C. Krusen, Manager, 4001 Seven Mile Lane, Baltimore, Md.

Meat Trade Institute: JoSEPH CoHN, Counsel, 420 Lexington Avenue, New York, N. Y.

Miller, Byron, \& Associates: ByroN D. Miller, Consultant, 5018 Allan Road, Washington, D. C.

Millers' National Federation:

Herman FAKLeR, Vice President, 847 National Press Building, Washington, D. C.

Fred H. Mewhinney, Administrative Assistant to Vice President.

Mock Seed Company: Fred C. Mock, 1218 Smallman Street, Pittsburgh, Pa.

National Association of Dairy Equipment Manufacturers: JoHN MARSHALL, 1012 Fourteenth Street, N. W., Washington, D. C.

National Association of Food Chains: George Travis, Vice President for Merchandising, 726 Jackson Place, Washington, D. C.'

National Association of Scale Manufacturers: ARTHUR SANDERs, Executive Secretary, 1 Thomas Circle, Washington, D. C.

National Canners Association: HowARD L. STIER, Director, Division of Statistics, 1133 Twentieth Street, N. W., Washington, D. C.

National Farmers Union: STANLEY W. VoGT, Legislative Representative, Room 700 Bond Building, $1404 \mathrm{New}$ York Avenue, Washington, D. C.

National Independent Meat Packers Association: ARTHUR L. WINN, JR., (Laroe, Winn \& Moerman), General Counsel, Investment Building, Washington, D. C.

National Paint, Varnish and Lacquer Association, Inc.:

Daniel L. Boland, General Counsel, 1500 Rhode Island Avenue, N. W., Washington, D. C.

Raymond P. DeMember, Assistant Counsel.

LAURENCE KIEFER.

Oyster Institute of North America:

David H. Wallace, Director, 6 Mayo Avenue, Bay Ridge, Annapolis, Md.

Frank M. Mrles, Chairman, Weights and Measures Committee, Box 178, Norfolk, Va.

Painting and Decorating Contractors: E. S. TorRence, Assistant to President, 540 N. Michigan Avenue, Chicago, Ill. 
Paper Cup and Container Institute, Inc.:

DALE H. ECKERMAN, Executive Director, 250 Park Avenue, Room 1020, New York, N. Y.

ROBERT W. Foster, Assistant Executive Director.

Pennsylvania Railroad: George F. Yeager, Assistant Foreman, Scales, Test Department, Altoona, Pa.

Phillips Petroleum Company: PAUL W. Tucker, Technical Representative, Bartlesville, Oklahoma.

Pillsbury Mills, Inc.: CharLes E. Joyce, General Claim Manager, 608 Second Avenue South, Pillsbury Building, Minneapolis, Minn.

Produce Packaging Association: RoBert A. COOPER, Executive Secretary, 500 Fifth Avenue, New York, N. Y.

Reading Railroad Company: R. C. ThraN, Scale Inspector, Locomotive Shop, Reading, $\mathrm{Pa}$.

Republic Steel Corporation: HowaRD L. ZUPP, Corporation Weighing Supervisor, Oberlin Road, S. W., Massillon, Ohio.

Rotron Control Corporation: B. A. KNAUTH, Consultant, Woodstock, N. Y.

Safeway Stores, Inc.:

Serh T. ShaW, Vice President, 401 Southern Building, Washington, D. C.

B. E. DoBeLL, Manager, Legal Department, Fourth and Jackson Streets, Oakland, Calif.

HARMON L. ELDER, Public Relations Manager, 1845 Fourth Street, N. E., Washington, D. C.

William C. HoRne, Produce Consultant.

Saybolt, J. W., Business Counsellor on Weights and Measures Laws, 9209 Carlyle Avenue, Surfside, Miami Beach, Fla.

Scale Journal :

MARK W. PICKelL, Editor, 176 West Adams Street, Chicago, Ill.

Miss LoRA Svaniga, Secretary to Mr. Pickell.

Shell Oil Company:

MAURICE L. BARRETT, JR., Senior Engineer, 50 W. Fiftieth Street, New York, N. Y.

William T. Brown, Manager, Mechanical Division, Marketing Engineering.

Fred Larson, Project Engineer.

JOSEPH V. HAZEN, Division Engineer, 37-06-82d Street, Jackson Heights, Long Island, N. Y.

Sinclair Refining Company: Kenneth W. BiRKIn, Manager, Automotive Department, 600 Fifth Avenue, New York, N. Y.

Skelly Oil Company: Robert R. Wellington, Assistant Engineer, 605 W. Forty-seventh Street, Kansas City, Mo.

Socony Mobil Oil Company: L. E. REED, Manager, Motor Vehicles, 26 Broadway, New York, N. Y.

Suburban Propane Gas Corporation: William D. Cook, Assistant to President, P. O. Box 206, Whippany, N. J.

Suburban Rulane Gas Company: JoHn MacIntosh, Chief Engineer, P. O. Box 29, Charlotte, N. C.

Sun Oil Company: A. H. MARSH, Manager, Equipment and Material Research, 1600 Walnut Street, Philadelphia, Pa.

Texas Company: R. H. Tolson, Assistant Manager, Sales Department, Construction and Equipment Division, 135 E. 42d Street, New York, N. Y.

Thread Institute:

DAVID SNYDER, Executive Director, 11 W. 42d Street, New York, N. Y.

JAMES B. DUFFY, Member, Legislation Committee (Gardiner Hall Jr. Thread Company, 48 W. 38th Street, New York, N. Y.)

A. U. Fox, Member, Legislation Committee (American Thread Company, 260 W. Broadway, New York, N. Y.)

WrLliam E. KIDD, Member, Legislation Committee (Coats and Clark, Inc., 430 Park Avenue, New York, N.Y.)

Truck Trailer Manufacturers Association: JoHN B. HuLse, Managing Director, 710 Albee Building, Washington, D. C.

Union Bag Company: Charles Bauer, Patent Counsel, 233 Broadway, New York, N. Y. 
Vermiculite Institute: LESLE A. BARRON, Manager of Technical Service, 208 S. LaSalle Street, Chicago, Ill.

Visking Corporation:

ELIIOT BALESTIER, JR., Assistant to President, 201 Main Street, Hackensack, N. J.

WILLIAM M. SAWERS, Assistant Manager, Division of Special Services, 1025 Connecticut Avenue, N. W., Washington, D. C.

Western States Meat Packers Association, Inc.: L. BLAINE LILJENQUIST, Washington Representative, 917 Fifteenth Street, N. W., Washington, D. C.

Western Weighing and Inspection Bureau: E. M. CURL, Supervisor of Weights, 460 Union Station, Chicago, Ill.

\section{Other Guests}

Alexander, Arthur H., R. D. 2, Hanover, Pa.

BAKER, C. A., 231/2 Ogden Street, Binghamton, N. Y.

GAST, Fred W., No. 10 Cheverly Circle, Cheverly, Md.

GORDON, Leland, J., Weights and Measures Research Center, Denison University, Granville, Ohio.

SmITH, EDWIN C., SR., 145 Nassau Road, Huntington, Long Island, N. Y.

MANALO, NAPOLEON F., Chemist, Division of Test and Standards, Institute of Science and Technology, Manila, Philippines.

U. S. GOVERNMENT PRINTING OFFICE: 1957 - 398762 



